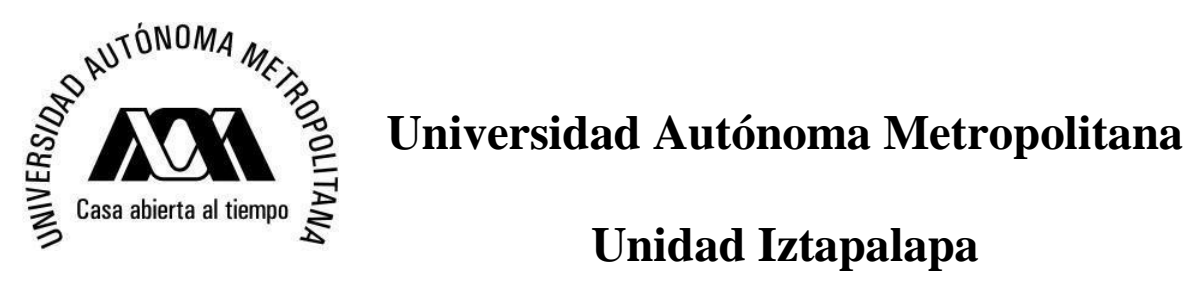

Posgrado en Humanidades

\title{
La textualidad académica de estudiantes de origen indígena en estudios de posgrado: el proceso de elaboración de tesis
}

Tesis que presenta

Verónica Martínez Santiago

Para optar por el grado de Doctora en Humanidades (línea de Lingüística)

Director de tesis: Dr. Héctor Muñoz Cruz

México, D.F., octubre 2017 

CONTENIDO

Pág.

Introducción 3

Capítulo I. La textualidad académica en el nivel superior: una perspectiva crítica de literacidad académica ....................................................................................... 10

1.1 La naturaleza de la comunicación escrita no escolar........................................... 10

1.1.1 Algunas características de la comunicación oral y escrita ..................................11

1.1.2 La comunicación escrita en situaciones cotidianas... ......................................... 13

1.2 La textualidad académica en el nivel superior: una forma de comunicación escrita en contextos escolares.................................................................................. 17

1.2.1 Paradigmas de la escritura académica en el nivel superior................................19

1.2.2 El lenguaje académico en el nivel superior .................................................26

1.2.3 Procesos de formación académica en el nivel superior: una transición en el lenguaje académico...

Capítulo II. El análisis cualitativo de contenido: una técnica metodológica para el análisis de la textualidad académica... ...............................................................552

2.1 El análisis de contenido en la investigación cualitativa... ...........................................53

2.2 El proceso metodológico de análisis cualitativo de contenido.................................... 55

2.2.1 Caracterización del estudio: los sujetos y obtención del dato empírico ........................56

2.2.2 Una etapa de preanálisis: construcción del corpus de datos .......................................57

2.2.3 Las explicaciones como unidad análisis ............................................................ 58

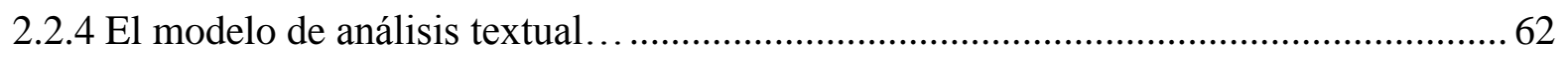

Capítulo III. La textualidad académica del proceso de elaboración de una tesis de grado: un análisis longitudinal.......................................................................................69

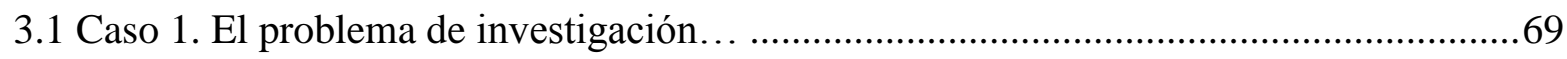

3.1.1 Fase 1: Un problema práctico desde la experiencia del investigador.................... 70

3.1.2 Fase 2: Un problema práctico respaldado en fuentes bibliográficas ...................... 75

3.1.3 Fase3: Un problema de investigación: la comprensión de un fenómeno................80 


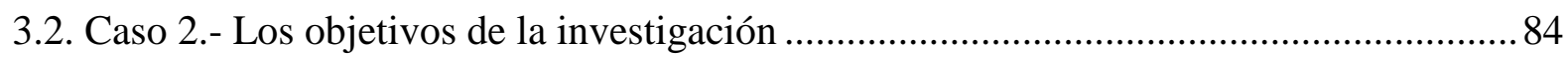

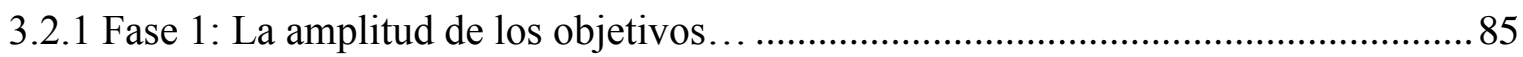

3.2.2 Fase 2: La estructura y el alcance de la investigación......................................... 92

3.2.3 Fase 3: Orientación contextual y concreción en los objetivos................................99

3.3. Caso 3. Los conceptos técnicos en la investigación................................................ 105

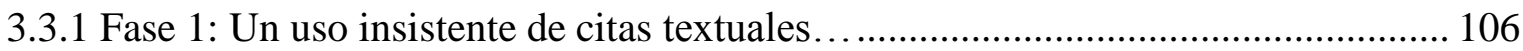

3.3.2 Fase 2: Un intento de explicaciones más propias.......................................... 123

3.3.3 Fase 3: Citas parafraseadas y elaboraciones propias del investigador... ...............146

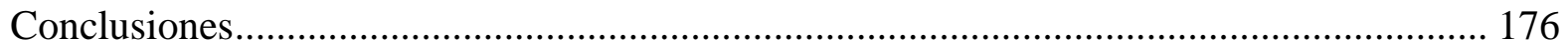

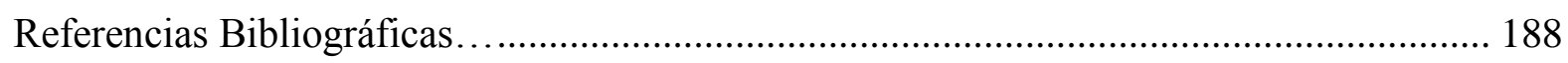

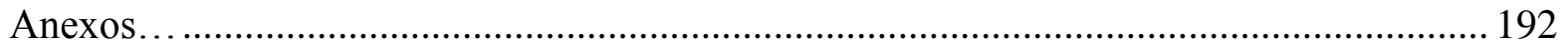




\section{INTRODUCCIÓN}

La escritura académica es un tema amplio y complejo en el nivel superior, ya que, en este contexto, la escritura se convierte en una práctica cotidiana que requiere de conocimientos y habilidades que influyen y en muchos casos determinan el logro académico de los estudiantes. Sin embargo, la escritura no es una tarea fácil, sino un proceso complejo de análisis, reflexión y desarrollo de habilidades de escritura que requieren bases teóricas y prácticas, especialmente en la elaboración de un proyecto de investigación como producto recepcional de titulación. Además, en el ámbito universitario existe el supuesto de que todo estudiante tiene ya las habilidades de redacción que exige la cultura académica. No obstante, es bien sabido que muchos estudiantes enfrentan día a día diversas dificultades cuando intentan construir un texto académico, sobre todo el desarrollo de una tesis.

Estas dificultades son de varios tipos, desde cuestiones ortográficas y de puntuación, hasta habilidades que implican el comunicar lo que uno quiere expresar en el texto, es decir, el saber qué decir y cómo decirlo. Así, es evidente que el escribir textos académicos no sólo implica conocer las cuestiones formales del texto, sino también, que independientemente del tipo de texto, el fin último es comunicarnos, lo cual muestra la complejidad que caracteriza la elaboración de textos académicos. En el caso de una tesis, esta noción se enfatiza porque se considera una contribución personal y original que recae en una sola persona, en el estudiante, cuya idea respecto a lo que es una tesis difiere de lo que significa para una institución académica, es más, es posible que un alumno no tenga conocimiento de qué es una tesis. Entonces, hay una distancia muy grande entre lo que saben y escriben los estudiantes en su cotidianidad fuera de la escuela, y lo que requieren conocer y escribir en el contexto académico. Esto es, la manera en que nos comunicamos de forma escrita fuera de la escuela es de naturaleza distinta a la manera en que nos comunicamos dentro de un escenario escolar. 
Por ello, armonizar lo que sabemos de la escritura cotidiana en espacios informales y aquellos espacios más formales y académicos, implica no solo habilidades cognitivas del alumno, sino también procesos formativos disciplinarios y pedagógicos como parte fundamental y de acceso a la cultura académica. Sin embargo, no siempre se crean estos espacios formativos y de acompañamiento para los estudiantes, lo cual repercute en las dificultades que van enfrentando los estudiantes universitarios, debido al desconocimiento de cómo funciona la cultura académica que regula entre otros aspectos, las prácticas textuales en el nivel superior, particularmente cuando se trata de una tesis de grado que es uno de los textos académicos más complejos para los estudiantes que muchos no logran concluir.

Esta problemática es muy común en los contextos académicos universitarios pero que desafortunadamente no se ha problematizado, por el contrario, se cree que el estudiante es el único responsable de su 'buena' o 'mala' escritura. En el contexto mexicano, particularmente el oaxaqueño, la atención a las prácticas textuales de la escritura académica es mínima o casi ausente, ya que hemos naturalizado la noción de que es deber exclusivo de los estudiantes escribir correcta y apropiadamente textos académicos, idea que se enfatiza aún más en el nivel de posgrado, el cual se convierte en un escenario complejo donde los estudiantes deben cubrir con los requerimientos que caracterizan dicho entorno.

Los intentos que se han hecho para tratar de atender esta problemática se queda únicamente en la construcción de cursos remediales que intentan resolver este problema, usualmente vigilando las deficiencias en la redacción de los estudiantes. Estas clases remediales, como las llama Lea y Street (1998), se diseñan para "reparar" los problemas de redacción que tiene un estudiante, refiriéndose únicamente a los errores que tocan la superficialidad del texto y no profundizan en el contenido del mismo, es decir, en los aspectos formales como la ortografía, la puntuación, aspectos gramaticales, entre otros. Sin embargo, se deja de lado el componente comunicativo esencial en cualquier texto académico.

Por ello, esta investigación es un intento por problematizar y cuestionar estas ideas implícitas respecto a la escritura académica en el nivel superior, mediante discusiones conceptuales que orientan la comprensión de este fenómeno. Una de estas orientaciones tiene que ver con la perspectiva en la cual nos posicionamos para entender, revisar y evaluar las prácticas textuales de los estudiantes; ya sea desde una mirada superficial del texto, como un 
La textualidad académica de estudiantes de origen indígena en estudios de posgrado: el proceso de elaboración de tesis

proceso de aculturación o desde una apreciación de la textualidad como practica social (Lea \& Street, 1998, Brice Heath 1983, Brice Heath \& Street, 2008). Estas miradas también implican el dominio de habilidades cognitivas (Cummins, 2002), y el paso por procesos formativos de socialización disciplinaria y de profesionalización (Muñoz, 2013), como parte fundamental para tener acceso a la cultura académica.

Por ello, considerando que este tema es un campo emergente de estudio, cabe precisar que el propósito de esta investigación no es determinar si los productos escritos de los estudiantes están bien escritos o no, sino estudiarlos y analizarlos para poder hacer una interpretación de ellos. Específicamente, es un intento por conocer y comprender la textualidad académica de estudiantes de posgrado, concepto que refiere particularmente al proceso de textualización que involucra no sólo los aspectos formales del texto, sino también cuestiones cognitivas, contextuales, culturales, e institucionales. Es así como me inclino por desarrollar una investigación que no sólo se quede en un nivel descriptivo de la superficie del texto, o de lo que los estudiantes deberían saber, sino en un estudio que revise la manera en que los estudiantes van elaborando su proyecto de investigación, y a la vez que cuestione las prácticas textuales que exige la cultura académica.

Desde esta apreciación, esta investigación tiene como propósito principal hacer una exploración del proceso de textualización que siguen los estudiantes del Programa de Maestría en Sociolingüística de la Educación Básica y Bilingüe, de la UPN, 201, en la elaboración de una tesis desde una perspectiva crítica de escritura académica, con el fin de proveer una mirada diagnóstica de dicho proceso, y así contar con elementos que me permitan apreciar que la forma en que estos estudiantes escriben implica no sólo el dominio de aspectos léxicogramaticales y/o la forma de estructurar un texto, sino también exige el desarrollo de aspectos cognitivos, formativos, así como institucionales, y/o socioculturales.

De este propósito general, se derivan las siguientes proposiciones que guían el rumbo de esta investigación.

- La escritura académica es un proceso comunicativo que involucra habilidades de redacción necesarios para la lógica de la presentación de un texto académico, habilidades cognitivas que un estudiante necesita desarrollar para mostrar la lógica de 
contenido del texto que construye, pero también implica el conocimiento de las normas académicas e institucionales insertas en una cultura académica.

- Las habilidades en la textualidad académica que presentan estudiantes de posgrado en el desarrollo de su tesis de grado están vinculadas con distintos procesos formativos que determinan el éxito o en la no culminación de una tesis de grado como documento recepcional de titulación.

- Las habilidades textuales que los estudiantes manifiestan en sus manuscritos evidencia la distancia que existe entre las exigencias de la cultura académica y lo que los alumnos saben y conocen de los textos académicos, particularmente, de las implicaciones que involucra la elaboración de una tesis.

Esta investigación es un estudio exploratorio que muestra un panorama general de la textualidad académica de estudiantes de posgrado, es decir, es una muestra que ejemplifica lo que ocurre respecto al fenómeno de estudio a partir de una construcción metodológica, la cual parte de las explicaciones como unidad de análisis desde la perspectiva de Maturana (1989) y del análisis de contenido cualitativo.

Dicha construcción metodológica implica el análisis cualitativo de los materiales para mirar no sólo el contenido manifiesto en los textos, sino también el contenido latente de los mismos (Mayring, 2000). Un elemento fundamental para este análisis cualitativo es identificar la unidad de análisis, que para este estudio son las explicaciones, las cuales implican un conocimiento, en ocasiones un conocimiento nuevo de quién explica. Por ello, recurro a los aportes de Maturana (1989) para plantear la naturaleza de las explicaciones, quien afirma que toda explicación involucra una pregunta, donde la respuesta a dicha pregunta es precisamente la explicación. Pero esta explicación a su vez implica lo que él llama una "conducta adecuada", es decir, una conducta que el interrogador acepta como satisfactoria.

Desde esta perspectiva, las explicaciones se convierten en la unidad de análisis de este estudio, ya que me interesa conocer cuál es la lógica de la explicación que manifiestan los textos revisados respecto al planteamiento de una problemática, pregunta que genera la explicación e implica una conducta adecuada. En esta lógica, y para efectos de esta investigación, las explicaciones se convierten en una oportunidad para conocer el 
La textualidad académica de estudiantes de origen indígena en estudios de posgrado: el proceso de elaboración de tesis

conocimiento que los sujetos investigados manifiestan sobre la problemática que plantean para el desarrollo de su investigación.

En esta construcción metodológica, otro elemento primordial ha sido la construcción de un modelo de análisis que se acercara lo más posible a la revisión y análisis del corpus de datos construido. Por ello, me apoyo fundamentalmente en los aportes de Street (2009) y Labov (2013), cuya metodología en cada estudio permite mirar los textos de una manera más integral, ya que los criterios a los que recurren comparten rasgos que interpretan no sólo las características manifiestas en los textos, sino, sobre todo, aspectos que subyacen en el "fondo" de dichos textos, es decir, sus rasgos "ocultos". De esta manera, esta construcción metodológica contribuye a un mejor entendimiento de la forma en cómo escriben los sujetos investigados, y particularmente a la lógica de explicación que ellos evidencian en sus manuscritos.

Esta investigación toma como base la producción escrita de estudiantes del Programa de Maestría en Sociolinguiística de la Educación Básica y Bilingüe, de la Universidad Pedagógica Nacional, Unidad 201, Oaxaca, México, programa que atiende a una diversidad de maestrantes cuyo producto final de titulación es el desarrollo de una tesis para la obtención del grado. De un grupo de estudiantes, se eligieron nueve de ellos para recuperar varios manuscritos para conformar el corpus de datos. Estos estudiantes, ahora egresados de dicho programa de posgrado, son profesores de educación básica, en su mayoría del nivel de primaria general e indígena, aunque también se encuentran profesores de preescolar y secundaria. Se caracterizan por ser de origen indígena, donde varios de ellos hablan una lengua indígena, entre las que se identifica el zapoteco de la sierra sur, el zapoteco de la sierra norte, el zapoteco de valles centrales, y el mixe; otros son monolingües en español. Cabe aclarar que la condición de origen indígena de los sujetos investigados no tiene un papel determinante en esta investigación, ya que desde un inicio no fue contemplada como una variable en el modelo teórico. Además, el enfoque de textualidad académica en esta investigación considera otros aspectos más allá de la condición étnica de los sujetos investigados. No obstante, es una característica importante del perfil sociocultural de dichos alumnos, sobre todo por el contexto oaxaqueño con una amplia diversidad cultural y 
lingüística, donde es un poco arriesgado definir quién es o no de origen indígena, lo cual es importante tenerlo como un referente contextual para el desarrollo de este estudio.

Una de las características propias de esta investigación es el desarrollo de un estudio longitudinal, esto es, mirar varios momentos a lo largo de proceso de construcción de una tesis. Para esto, fue necesario recuperar los manuscritos en al menos tres fases, una inicial, una intermedia y otra final, con el propósito de mirar las características propias de cada etapa y los posibles cambios que se manifestaran en cada una ${ }^{1}$. En la fase inicial se recuperaron los anteproyectos de investigación que los sujetos investigados presentaron cuando aún eran aspirantes al programa de posgrado, materiales que fueron el punto de partida para el análisis longitudinal. Después se recuperaron los protocolos de investigación que los sujetos, siendo ya estudiantes de posgrado, construyeron a un año de su proceso de inmersión a dicho programa. Finalmente, para la fase tres se solicitaron los borradores finales que presentaron al culminar sus estudios de posgrado. La diversidad de materiales que se obtuvo fue bastante rica porque permitió tener un abanico de posibilidades para seleccionar los documentos más significativos para el análisis textual.

De esta manera, este documento se organiza en tres capítulos que son necesarios para dar cuenta del proceso de la investigación y para comprender el objeto de estudio. El primer capítulo corresponde a la mirada conceptual que orienta teóricamente la investigación, el cual inicia con una discusión que explica la naturaleza de comunicación escrita no escolar. También, se desarrolla una discusión respecto a algunos paradigmas desde los aportes de Lea y Street (1998) que complejizan la escritura académica en el nivel superior, los cuales implican el desarrollo y dominio de distintas habilidades textuales y cognitivas (Cummins, 2002), dependiendo tanto del tipo del texto como del contexto donde se produce. Asimismo, se explican dos procesos formativos, de socialización disciplinaria y de profesionalización necesarios para tener acceso a la cultura académica en el contexto universitario (Muñoz, 2013). Estas discusiones teóricas me permiten no solo complejizar el objeto de estudio, sino también orientar el rumbo de la investigación.

\footnotetext{
${ }^{1}$ Para esto, fue necesario recuperar distintos borradores a lo largo del proceso de construcción de la tesis que se estaba desarrollando, para lo cual contacté a los nueve estudiantes inmersos en el programa de maestría referido para pedirles su apoyo en proveerme de copias de sus avances en torno a la investigación que cada uno estaba desarrollando, para lo cual no hubo ninguna objeción.
} 
La textualidad académica de estudiantes de origen indígena en estudios de posgrado: el proceso de elaboración de tesis

El capítulo dos corresponde a discusiones teórico metodológicas que orientan el análisis posterior. En este apartado, se expone una construcción metodológica que toma como unidad de análisis las explicaciones para el desarrollo del proceso de elicitación. Estas explicaciones giran en torno al planteamiento de un problema de investigación como parte del proyecto de tesis. El punto es conocer cómo los sujetos investigados desarrollan sus explicaciones para comunicar su comprensión y/o conocimiento del tema que trata o un conocimiento nuevo, lo cual significa que en este estudio las explicaciones construidas por los autores de los textos revisados son un elemento fundamental para conocer la racionalidad de explicar que se manifiesta en los textos analizados. Por ello, recurro a los aportes de Maturana (1989) y al análisis cualitativo de contenido, el cual permite mirar tanto el contenido expreso de los textos, así como el contenido oculto de los mismos. Esta construcción metodológica contribuye a indagar cuál es la lógica y sentido de formular una explicación científica.

En el capítulo tres, se desarrolla el análisis de los datos en cada uno de los casos que son: el problema de investigación, los objetivos de la investigación y los conceptos técnicos que los sujetos investigados explican en los materiales recabados. Entre los hallazgos, se identifica que la problemática que se plantea es un problema práctico que parte directamente de la experiencia del investigador, pero que llega a convertirse en un problema de investigación. Algo similar sucede con los objetivos, que en un inicio son dispersos pero que se van concretando conforme transcurre la investigación. Los conceptos técnicos también muestran cambios, la explicación de éstos parte del uso insistente de citas textuales que silencian la voz del estudiante investigador, hasta llegar a explicaciones conceptuales que combinan tanto la voz de los autores de la tesis como la de los autores citados.

Finalmente, está el apartado de las conclusiones, donde se pretende llegar a reflexiones más abstractas que muestren los aportes de esta investigación. Una de las conclusiones a las que se llega es que los cambios manifestados en el análisis evidencian el proceso formativo de socialización disciplinaria por el que pasaron los estudiantes investigados. 


\section{Capítulo I.}

\section{La textualidad académica en el nivel superior: una perspectiva crítica de literacidad académica}

El propósito de este capítulo es explicar la complejidad que involucra la textualidad académica en el nivel superior, como una forma de comunicación escrita, donde se encuentra la tesis como uno de los textos académicos más complejos y exigentes en el ámbito universitario. Para esto, es necesario tomar en cuenta los paradigmas que subyacen y permean tanto en la vida institucional como académica, y que orientan las distintas actividades relacionadas con la cultura escrita. Particularmente, con un lenguaje académico escrito que se va moldeando a partir de procesos formativos que los estudiantes van experimentando en su formación académica en el nivel superior. Para esto, inicio esta discusión, explicando algunos aspectos propios de la comunicación cotidiana no escolar que difiere en varios sentidos de la comunicación en ámbitos académicos.

\subsection{La naturaleza de la comunicación escrita no escolar}

Primeramente, es necesario mencionar que la comunicación es un hecho social porque es la forma en que interactuamos todos los seres humanos. Desde su etimología, comunicación, palabra derivada del latín communicare, significa "compartir algo, poner en común”, así la comunicación es un fenómeno inherente a la convivencia humana. Para poder comunicarnos el elemento esencial es el lenguaje, el cual es característica propia del ser humano; es la capacidad que tenemos para expresar nuestros pensamientos y emociones, a través de él materializamos nuestras ideas. Pero también, más allá de ser una facultad humana el lenguaje es uno de los medios principales por el que interactuamos con los otros, lo cual nos posibilita compartir con los demás aquello que pensamos o deseamos, nos permite intercambiar informaciones y establecer vínculos que crean y recrean la vida en sociedad a 
La textualidad académica de estudiantes de origen indígena en estudios de posgrado: el proceso de elaboración de tesis

través de sus distintas manifestaciones, es el elemento fundamental que utilizamos los seres humanos para comunicarnos. Así, el lenguaje es un hecho social, un instrumento de interacción y comunicación que nos mantiene interrelacionados los unos a los otros (Cassany, Luna \& Sanz, 2007).

\subsubsection{Algunas características de la comunicación oral y escrita}

Como es bien sabido, existen dos formas de comunicación muy comunes, una es a través del lenguaje oral y la otra es por medio del lenguaje escrito. A grandes rasgos, el lenguaje oral lo adquirimos en el seno familiar mediante un proceso natural de interacción con las personas que nos rodean, sólo es necesario estar expuestos a la comunidad lingüística del lenguaje en uso y gradualmente iremos adquiriendo la complejidad que implica la leng

ua de nuestro entorno. Este proceso como ya lo mencioné, se adquiere de forma natural e inconsciente, es decir, "[1]a adquisición y desarrollo del lenguaje oral no necesitan de una instrucción especializada, basta con que el niño forme parte de una comunidad que comparte una lengua para que él la desarrolle a través de estímulos psicológicos y sociales" (Rosas Ramírez, 2013, p. 50). Es así como todos los seres humanos adquirimos nuestra lengua materna y, a veces sin darnos cuenta, nos empezamos a comunicar con las primeras palabras hasta que logramos hacerlo con mayor fluidez.

Típicamente, la comunicación oral es espontánea, transitoria, fugaz, y ocurre mientras los interlocutores mantienen una conversación, la interpretación de los mensajes que cada uno emite depende directamente del contexto inmediato y de la situación comunicativa de la cual son parte. Es decir, la oralidad cumple una función comunicativa inmediata donde las personas hacen uso de habilidades conversacionales básicas (Cummins, 2002), las cuales refieren al uso del lenguaje oral en situaciones cotidianas que generalmente son conversaciones cara a cara, con contenidos conocidos y con estructura de oraciones simples, donde las personas están bastante familiarizadas con el tema y el contexto donde se producen ${ }^{2}$, es una capacidad básica

\footnotetext{
${ }^{2}$ Este tipo dominio conversacional tiene que ver con el cuadrante A, del esquema de Cummins (2002, p. 85) que explico más adelante, el cual requiere de un conocimiento básico del idioma además de contar con un soporte contextual muy claro como el tono de voz, los gestos. Un ejemplo de este cuadrante pueden ser las conversaciones cotidianas entre familiares y amigos.
} 
de comunicación interpersonal que poseemos todas las personas para poder comunicarnos oralmente con los otros.

Por otro lado, la comunicación basada en la escritura es otra forma de estar en contacto con los otros. Esta necesidad de comunicación nos exige como seres humanos insertarnos desde niños a los procesos de aprendizaje del lenguaje escrito, que usualmente sucede en contextos escolares. Es un aprendizaje formal donde los aprendices empiezan a conocer su lengua mediante un proceso metalingüístico y cognitivo que los lleva a estar más conscientes de las implicaciones de su lengua en distintos niveles como el fonético, sintáctico y semántico. La intención es lograr que aprendan a leer y escribir, aplicando diversas metodologías pedagógicas, es decir, en el nivel de escolaridad básico el objetivo es que los alumnos fortalezcan su competencia lingüística oral y escrita.

Esta forma de comunicación se caracteriza por ser permanente y duradera porque permite diferir, en tiempo y espacio, la información que contiene un texto escrito. En este caso, la interacción entre escritor y lector es diferente porque el escritor tiene la necesidad de explicitar a lo largo del texto lo que desea comunicar, además de describir y/o explicar aquellos elementos propios del contexto situacional. La comunicación escrita la utilizamos en múltiples ocasiones para pedir y dar información, para expresar lo que sentimos o pensamos y para registrar datos que consideramos importantes, el objetivo es usar la escritura para resolver o enfrentar situaciones cotidianas que requieren de la escritura como una forma de comunicación. Por ello, se considera que la escritura es un acto social porque conlleva la necesidad e intención de comunicarse con los otros, creándose una especie de diálogo donde el proporcionar o solicitar información es fundamental (Argudín \& Luna, 2005). En otras palabras, escritura es un instrumento que estimula la comunicación a través de sus diversas funciones que ésta desempeña en la sociedad como informar, documentar, anunciar o dialogar sobre un tema.

De esta manera, el lenguaje escrito favorece la creación de múltiples actividades comunicativas, diferentes a aquellas que ocurren en el campo de la comunicación oral cotidiana, la escritura se convierte así en una necesidad con función comunicativa social. Por ello, las distintas prácticas escritas que llevamos a cabo como usurarios de la lengua suelen diversificarse atendiendo sobre todo al tipo de lector que se destinen (un familiar o un 
La textualidad académica de estudiantes de origen indígena en estudios de posgrado: el proceso de elaboración de tesis

desconocido, un público amplio, un colectivo o una persona...) y, en consecuencia, presentar un carácter más coloquial o más formal. No obstante, para lograr tal comunicación se requiere primero adquirir esta habilidad a través de un aprendizaje formal e institucionalizado, que desde muy pequeños vamos aprendiendo, empezamos con el aprendizaje del lenguaje escrito, desde las prácticas escritas más básicas como escribir notas personales o los mensajes típicos de las redes sociales, hasta escribir documentos formales o académicos.

Estas dos formas de comunicación son parte de la cotidianidad de nuestra vida en sociedad, no obstante, ambos tipos de comunicación ejercen funciones sociales diversas. Tanto el lenguaje oral como escrito tienen fines comunicativos, las diferencias entre ambos están en el uso, en las funciones sociales que cada una desempeña. Y es aquí donde deseo ampliar mi discusión y explicar que los usos y las funciones del lenguaje difieren según los ámbitos de comunicación. En términos generales abordo la comunicación escrita desde dos perspectivas. Una que tiene que ver con los usos del lenguaje en espacios familiares y cotidianos, pero también más informales, es decir, la comunicación en contextos no escolares. Y la otra perspectiva que se ubica en el ámbito netamente escolar y académico. Esta explicación me ayudará a clarificar que la comunicación cotidiana y la comunicación académica son de naturaleza diferente y que cada una exige procesos lingüísticos y cognitivos también distintos, considerando que ambas desempeñan funciones sociales diversas en contextos específicos.

\subsubsection{La comunicación escrita en situaciones cotidianas}

Parte fundamental de vivir en sociedad es estar en constante interacción y la principal forma de hacerlo es a través de los distintos usos del lenguaje, el cual es de naturaleza sociocultural, porque es en las interacciones sociales donde éste se produce y se reproduce según sus ámbitos de uso. En el caso del lenguaje escrito, éste desempeña múltiples funciones sociales y culturales que permiten la comunicación y el intercambio de informaciones entre los individuos, la escritura es uno de los medios más importantes que utilizamos para mantenernos en contacto con otras personas. Sin embargo, el uso de esta herramienta de comunicación depende en gran parte del propósito y el contexto para utilizarla, es así como hago una distinción entre la comunicación escrita utilizada en situaciones cotidianas y aquella propia de los ámbitos escolares y académicos. No pretendo hacer una dicotomía entre estas dos formas 
de comunicación, sino definir y explicar que las intenciones, usos y funciones del lenguaje escrito son diferentes en ambos tipos de contexto y por lo cual requiere de un tratamiento diferenciado al momento de utilizarlo, aprenderlo o enseñarlo ${ }^{3}$.

En el caso de la comunicación escrita en situaciones cotidianas, me enfoco a aquellos escenarios más cercanos y familiares en que nos movemos, los cuales pueden ser un tanto privados y públicos, pero también más informales. Me refiero a "espacios informales" porque considero que éstos se caracterizan por ser más flexibles, en el sentido de que la interacción entre los interlocutores suele ser más espontánea y abierta, generalmente utilizan un lenguaje informal y existe cierta confianza entre el escritor y el lector. Además, los autores del texto tienen mayor libertad de escribir lo que ellos desean, su función es comunicar lo que ellos requieren según sus necesidades. El énfasis de la escritura en estos ámbitos está en emitir un mensaje y lograr la comunicación, no en la forma en cómo se escribe el mensaje que es lo característico en los contextos escolares, es decir que las personas no ponen atención y muchas veces no están conscientes de los usos de los aspectos lingüísticos de la lengua, aquí la escritura es más voluntaria y natural, generalmente no hay presión de nadie respecto a cómo se lleva a cabo el proceso de escritura en estos contextos. Por ello, el contexto, la intención para escribir y la situación comunicativa son fundamentales para que una persona decida la manera en que utiliza la escritura ya sea de forma impresa o digital.

Los usos de la escritura en ámbitos cotidianos son múltiples, desde la casa como un espacio más privado, utilizamos la escritura habitualmente para dejar una nota a un familiar, llevar un diario personal, hacer una lista de productos para ir al supermercado, etc. Del mismo modo, en la calle como un espacio más público siempre estamos en contacto con la escritura, la usamos para anotar alguna información que vemos y consideramos importante, pero también vivimos la escritura, la vemos impresa y la leemos en diversos tipos de anuncios publicitarios y comerciales que promueven un producto o solicitan algún servicio, también

\footnotetext{
${ }^{3}$ Considero fundamental aclarar que la comunicación de forma escrita en ambos contextos depende en gran medida de las habilidades lingüísticas que cada persona tenga. Es decir, ambas formas de comunicación implican necesariamente tener ya un dominio básico del lenguaje escrito, sin esta competencia lingüística y comunicativa sería muy difícil que una persona fluya en los diversos contextos cotidianos propios de la escritura no escolar. Para poder adquirir estas habilidades comunicativas es necesario llevar una formación escolar, un aprendizaje formal de la escritura que ocurre generalmente en escenarios educativos. Una vez que adquirimos las habilidades básicas del lenguaje escrito, se puede decir que contamos con los elementos básicos para poder expresarnos y comunicarnos de forma escrita.
} 
La textualidad académica de estudiantes de origen indígena en estudios de posgrado: el proceso de elaboración de tesis

están los periódicos en cada esquina que anuncian las noticias del día o en algún producto que compramos, entre muchas otras formas en que la escritura se manifiesta en la cotidianidad de nuestras vidas.

Otra de las características de este tipo de escritura es que permite la comunicación a distancia, de estar en contacto con personas que se encuentran lejos de nosotros; anteriormente era muy común el uso de la carta, pero más recientemente, surge el uso del correo electrónico y con mayor auge los usos de las redes sociales (Twitter, What's up, Facebook) que están reconfigurado la comunicación básicamente digital. Estas nuevas formas de interacción han abierto muchas posibilidades de estar en contacto con mucha gente y en muchas partes al mismo tiempo, facilitan enormemente la comunicación porque es muy rápida, casi instantánea y gratuita; ya no sólo mantenemos contacto con familiares o amigos sino conocemos y mantenemos contacto con personas de distintos países (Tirira, 2013). Las formas en que se utilizan estas redes sociales son múltiples, dependiendo de los intereses de sus usuarios y las personas con las que se contactan. Esta forma de comunicación ha hecho que la escritura se reinvente en el uso cotidiano de las redes sociales y sea parte de una cultura digital que evoluciona aceleradamente, por ejemplo, existe un uso elevado de las abreviaturas para simplificar la forma del mensaje y el código escrito ya no es el único sistema que se ocupa en estos espacios, también se utilizan los "emoticones" (ídem) como apoyo para expresar ideas, pensamientos y sentimientos por la emergencia del momento. Éste es un claro ejemplo de que la escritura se construye y reconstruye constantemente en la interacción con los otros.

Como se puede ver, en la cotidianidad de nuestras vidas hacemos diversos usos de la escritura, la vivimos todos los días porque siempre encontramos alguna manifestación de ella en los múltiples espacios privados o públicos en que nos movemos. Estos ámbitos más informales crean las condiciones para que la escritura en estos escenarios sea más espontánea, abierta, flexible y voluntaria. La escritura en este tipo de comunicación no escolar cumple funciones en el campo de lo cotidiano, su objetivo principal es comunicar ideas, pensamientos, intencionalidades, deseos, etc., ya sea digitalmente a través de las redes sociales, correo electrónico, cartas, etc., o de forma impresa como un diario, notas personales o comerciales, apuntes cotidianos, entre otros, pero ambas modalidades de manera informal, menos rígida en cuanto a seguir al pie de la letra las reglas lingüísticas o gramaticales estrictas de la lengua. 
Esto sugiere que existe cierto grado de confianza en la interacción comunicativa entre los interlocutores, la relación que se establece entre ellos es informal, mucho más relajada porque no se cubren "protocolos" que generalmente exigen otros tipos de escritura más formales. El propósito es interactuar con los otros, en expresar las ideas de una manera más autónoma, también por el contexto mismo que así lo permite, no hay nadie que esté vigilante de cómo se escriben los mensajes, no hay una evaluación de lo que se escribe.

Entonces, el uso del lenguaje escrito en situaciones cotidianas se vuelve un fenómeno habitual por la frecuencia en que se practica, la gente escribe lo que le es familiar, en darse a entender con los elementos que se tienen al alcance porque domina el tema y eso hace que la comunicación fluya sin dificultad. Esta manera de usar la escritura es una de las destrezas comunicativas interpersonales básicas y se caracterizan por dos aspectos fundamentales: a) que la comunicación está vinculada más directamente al contexto, lo cual es mucho más común en el mundo cotidiano; y b) porque las herramientas lingüísticas requeridas para este tipo de comunicación escrita se han automatizado en mayor medida, lo cual hace que el alcance cognitivo sea poco exigente (Cummins, 2002).

Esto significa que una persona hace uso de la escritura espontánea porque conoce el contexto donde la utiliza, porque sabe que hay libertad en decidir la forma de expresarse y porque la frecuencia y recurrencia con que utiliza este tipo de escritura más coloquial y personal ha contribuido a que esta persona haya automatizado de cierta forma los aspectos lingüísticos de la lengua, así, el uso del lenguaje escrito en estos escenarios es autónoma, voluntaria y con mayor flexibilidad. De hecho, los mismos escenarios en que nos movemos todos los días, sean estos privados o públicos pero informales, crean las condiciones que permiten que la escritura sea de esta manera, no existe un ojo vigilante del cómo escribimos, no hay que rendirle cuentas a nadie de la forma en que escribimos. Sabemos de antemano a quién o quiénes nos dirigimos, que hay una relación de confianza con el interlocutor y, por ende, es posible utilizar un estilo más informal de escritura.

Por tanto, puedo afirmar que las diferentes manifestaciones de la comunicación escrita en situaciones cotidianas, que involucra la práctica del lenguaje escrito, es de naturaleza 
La textualidad académica de estudiantes de origen indígena en estudios de posgrado: el proceso de elaboración de tesis

vivencial $^{4}$ porque se aprende de manera informal mediante la recurrencia de su uso, se caracteriza por su autonomía y su alto grado de flexibilidad por el contexto mismo en que se ubican como son los espacios informales, sea éstos públicos o privados, que requieren un uso del lenguaje menos especializado y técnico. No obstante, "tales usos del idioma no son en modo alguno inferiores a los más convencionales del mismo, relacionados con la alfabetización. Simplemente, son menos relevantes con respecto a las reglas lingüísticas del juego, establecidas en los contextos educativos típicos"(Cummins, 2002, p. 71).

En suma, el énfasis de la comunicación oral y escrita en estos ámbitos informales está en emitir un mensaje y lograr la comunicación y no en cómo se habla, se pronuncia o se escribe. Por ello, la comunicación cotidiana, particularmente la escrita, no está condicionada a las reglas convencionales de una institución académica, como ocurre en los ámbitos académicos que se caracterizan por seguir y centrar su atención en las reglas, normas y convencionalidades lingüísticas que requieren la puesta en marcha de todo un conjunto de habilidades lingüísticas y contextuales para crear una unidad textual comunicativa.

\subsection{La textualidad académica en el nivel superior: una forma de comunicación escrita en contextos escolares}

La comunicación escrita escolar es netamente académica, diferente a la comunicación escrita cotidiana como se ha caracterizado en el apartado anterior porque involucra un entramado complejo de concepciones y prácticas sobre las formas de expresión escrita en este ámbito. La comunicación escrita escolar necesariamente implica los usos y prácticas del lenguaje académico escrito, el cual se caracteriza principalmente por el desarrollo de procesos metalingüísticos ${ }^{5}$ desde que iniciamos nuestra vida escolar como seres humanos. Esto nos

\footnotetext{
${ }^{4}$ Otra forma de caracterizar esta forma de comunicación escrita en lo cotidiano es la propuesta de Barton y Hamilton (1998) quienes acuñan el término de escritura vernácula para referirse a prácticas de lectura y escritura que tienen su origen en la vida cotidiana y que son consideradas "no oficiales" porque no están reguladas por reglas formales impuestas por instituciones sociales dominantes como la escuela. Estas prácticas vernáculas de escritura están inmersas dentro del paradigma de los Nuevos Estudios de Literaciad o Cultura Escrita, la cual busca describir y comprender, desde una perspectiva etnográfica, las prácticas comunicativas contextualizadas de grupos humanos concretos.

${ }^{5}$ Utilizo este término de manera general como "una expresión que denota el volver sobre un hecho lingüístico en cualquier nivel de conciencia" (Tolchinsky, 2000). Y aclaro que mi intención no es profundizar en este tema, sino solamente me apoyo en este término para diferenciar algunos aspectos propios de la escritura académica.
} 
exige adentrarnos a un nuevo mundo donde la adquisición de la competencia escrita se ve sometida a un aprendizaje formal, institucionalizado y preestablecido. De ahí que en los diversos centros educativos se nos entrene, prepare e instruya para ser personas alfabetizadas y lograr transitar por los distintos niveles educativos y alcanzar finalmente el conocimiento de la cultura escrita y poder desenvolverse en ella (Cabrera \& Pelayo, 2005). Pero además de las funciones simbólicas y cognitivas, están las funciones del lenguaje en el proceso escolar, es decir, las diversas formas en que utilizamos el lenguaje. Por ejemplo, hacer una reseña, un resumen, una carta, entre otros, cuyas funciones varían dependiendo del tipo de texto.

Así, desde pequeños cuando nos insertamos al sistema escolar, una de las cosas que empezamos a aprender es a leer y a escribir, es decir, a alfabetizarnos; y vamos transitando por los niveles académicos hasta llegar al universitario, aprendiendo paulatinamente aspectos cada vez más complejos de la lengua. Sin embargo, cada persona va adquiriendo un domino distinto del uso del lenguaje académico, particularmente, de la escritura académica. Y entonces, se supone que los estudiantes en nivel superior ya cuentan con las habilidades de redacción para escribir textos académicos. Pero, desafortunadamente es bien sabido que los estudiantes en este nivel educativo presentan fuertes dificultades en cuanto a los diversos usos del lenguaje académico en ámbito universitario, y que se enfrentan a retos de lectura y escritura académicas que no siempre logran superar.

Por ello, considero importante explicar que las formas de utilizar el lenguaje en los escenarios escolares difieren en gran medida con el tipo de lenguaje que utilizamos en la cotidianidad de nuestras vidas no escolares. En otras palabras, el desarrollo del lenguaje escolar es una especie de sociolecto $^{6}$, que implica una forma de comunicación particular ya sea oral o escrita, al cual no todos tienen acceso, porque se encuentra dentro de un ámbito bastante específico y no tan fácil de acceder, como lo es la cultura académica.

Por esta razón, abordo la complejidad que involucra la escritura académica enmarcada en una cultura escrita o literacidad académica, donde existen una multiplicidad de prácticas textuales y formas de comunicación tanto orales como escritas que conforman la vida

\footnotetext{
${ }^{6}$ Dialecto social que describe la variedad lingüística por un grupo social. Dentro de las variedades lingüísticas, los sociolectos corresponden a las variedades diastráticas (diferencias socioculturales de una comunidad lingüística) con una estrecha relación con las variedades diafásicas (diferencias entre los tipos de modalidad de expresión) (Coseriu, 1970, citado en Schlieben-Lange, 1997, p. 40).
} 
La textualidad académica de estudiantes de origen indígena en estudios de posgrado: el proceso de elaboración de tesis

académica, y donde subyacen paradigmas que complejizan aún más este concepto tan necesario de comprender. Pero antes, es necesario precisar que en este estudio me apoyo de


connotación más específica, y que se refiere a un "proceso complejo e integral en el manejo y desarrollo de habilidades en la toma de decisiones al plasmar las ideas por escrito y para la conformación de la unidad textual como medio comunicativo que involucra, además de la articulación y estructuración formal, el conjunto de funciones del lenguaje en la expresión escrita y de la información contextual, cultural, de construcción de conocimiento e identidad, manifestada en la intencionalidad comunicativa en los diversos géneros textuales (Hernández Rodríguez, 2013, p. 37).

En otras palabras, el concepto de textualidad académica se enfoca de manera particular al proceso de construcción de una unidad comunicativa textual que implica una mirada integral del texto que toma en cuenta no sólo los aspectos formales del texto, sino también aspectos cognitivos de construcción de conocimiento, contextuales, culturales, e identitarios que complejizan aún más el proceso de redacción. Este concepto es de gran utilidad para esta investigación, tanto en términos teóricos como metodológicos, para mirar lo que sucede en el ámbito universitario donde la textualidad académica es un campo poco explorado, y cuya comprensión sería parcial si no se tiene como referente la discusión sobre la cultura escrita o literacidad académica. Ante este escenario, un punto de partida es la visión que tenemos de la escritura académica, en la cual subyacen paradigmas respecto al lenguaje académico, particularmente el escrito.

\subsubsection{Paradigmas de la escritura académica en el nivel superior}

El lenguaje académico es parte inherente al contexto universitario, donde existe una gran diversidad de prácticas textuales que son necesarias para el buen desarrollo del contenido y las convenciones de las disciplinas. Tales prácticas requieren generalmente el despliegue de

\footnotetext{
${ }^{7}$ El concepto de textualidad se ha estudiado desde la perspectiva de la lingüística textual, cuyos planteamientos involucran los aspectos formales del texto, cuestiones cognitivas y didácticas, escenario en el cual la aportación de Hernández Rodríguez (2013) es de gran relevancia. En esta obra, él explica de forma más detallada los alcances de la perspectiva de la lingüística textual. No obstante, aclaro que en mi estudio me apoyo únicamente de este concepto para complejizar y enriquecer la discusión en torno al tema de la escritura académica, y para tener elementos metodológicos para mirar la textualidad de los sujetos investigados, pero que no parto necesariamente de la perspectiva de la lingüística textual.
} 
habilidades de escrituración que los estudiantes teóricamente deben poseer para poder desenvolverse académicamente. Es decir, los alumnos deben mostrar el dominio de su lenguaje académico alcanzado, mediante las evaluaciones que determine cada institución universitaria. En ocasiones suelen ser exámenes estandarizados que se centran en diversas dimensiones y funciones del lenguaje como los conocimientos que sobre la gramática se tienen, el vocabulario, el nivel de comprensión de lectura o la escrituración de textos complejos que exigen un alto grado de claridad, coherencia y precisión sobre lo que se desea argumentar (Cummins, 2002). Así, la evaluación del lenguaje académico en ámbitos universitarios varía según las necesidades y exigencias de la disciplina o programa de estudio. No obstante, en múltiples ocasiones no queda claro qué es lo que se le solicita al estudiante y qué es lo que se entiende por lenguaje académico, específicamente, el escrito. Por ello, vale la pena explicar sucintamente algunos de los paradigmas que subyacen en las prácticas textuales, de cómo la concepción de los fenómenos sufre una transformación y se da un tránsito mucho más técnico y complejo de lo que involucra el lenguaje académico enmarcado por una cultura escrita en el nivel superior.

\section{a) Dos modelos de la cultura escrita: autónomo e ideológico}

Lo anterior se relaciona con la concepción que se tiene de la "cultura escrita" de la cual Street (1984) propone dos perspectivas conceptuales, un "modelo autónomo" y un "modelo ideológico" ambos propuestos para comprender con más criticidad la cultura escrita. El "modelo autónomo" parte de la idea de que la cultura escrita en sí misma - autónomamente tendrá efectos sobre otras prácticas sociales y cognitivas. Esto significa que el hecho de incorporar la "cultura escrita" a los pobres, a los "analfabetos", en los pueblos, a los jóvenes, etc., resultará en la mejora de sus capacidades cognitivas y sus perspectivas económicas, con el fin de hacerlos mejores ciudadanos, independientemente de las condiciones sociales y económicas que explican su "analfabetismo". Este modelo autónomo de la cultura escrita disfraza los supuestos culturales e ideológicos que lo sustentan para después ser presentados como si fueran neutrales y universales y que esa cultura escrita como tal tendrá estos efectos benignos (Street, 2003) ${ }^{8}$.

\footnotetext{
${ }^{8}$ Traducción simple del texto original en inglés
} 
De esta manera, vemos que el "modelo autónomo" de la cultura escrita descansa sobre el supuesto que ésta funciona precisamente de forma autónoma, neutral e imparcial en las diversas actividades de la lectura y escritura, las cuales son independientes de la vida social de las personas, incluyendo su aprendizaje y enseñanza, es decir que dichas actividades son ajenas al contexto donde se producen. De hecho, todavía existe esta visión dominante de la cultura escrita, a la cual "muchos aún atribuyen... las mayores consecuencias políticas, económicas, sociales y morales y creen firmemente que leer y escribir conducirán a la movilidad social, promoverán la democracia y prepararán el camino para una vida moral y digna (Kalman, 2008).

Por su parte, el modelo ideológico desde la perspectiva de Street (2003), postula que la cultura escrita es una práctica social y no simplemente una habilidad técnica y neutral; lo cual quiere decir que siempre está inmersa en principios epistemológicos socialmente construidos. Se trata del conocimiento, es decir que las formas en que las personas se ocupan de la lectura y la escritura están arraigadas en concepciones de conocimiento, la identidad y el ser. Asimismo, está siempre inserta en las prácticas sociales, por ejemplo, las de un determinado mercado laboral o en un contexto educativo particular, y los efectos del aprendizaje de dicha cultura escrita dependerán entonces de esos contextos particulares. La cultura escrita, en este sentido, siempre es discutida, tanto sus significados como sus prácticas, de ahí que las versiones particulares de ella sean siempre "ideológicas", siempre arraigadas en una visión particular del mundo y en un deseo de que esa cultura escrita domine y margine a otros (Gee, 1991, Besnier \& Street, 1994, citados en Street, 2003, pp.77-78) ${ }^{9}$

Esta mirada "ideológica" de la cultura escrita que propone Street, provee posibilidades para advertir que tanto el conocimiento como las prácticas que ésta involucra van más allá de las habilidades cognitivas que una persona posee para desenvolverse en los distintos ámbitos de la cultura escrita. Es decir, la cultura escrita considera lo que la gente sabe o entiende respecto a la lectura y escritura, los significados que ellos le otorguen según el contexto en donde se producen tales prácticas. También, toma en cuenta las maneras en que las personas hacen uso de la lectura y escritura, de quiénes son los sujetos que leen o escriben y en dónde lo hacen. Entonces, tanto el conocimiento, el uso de la cultura escrita, así como su aprendizaje y

\footnotetext{
${ }^{9}$ Traducción simple del texto original en inglés
} 
la enseñanza no se pueden entender si no se toma en cuenta el contexto de donde emergen. Por ello, esta perspectiva de ideológica refiere a una práctica social situada de la cultura escrita (Kalman, 2008)

Ambos modelos son de gran utilidad para comprender de forma más crítica lo que ocurre en el ámbito académico, porque éstos son la plataforma en la cual Lea y Street (1998) identifican tres paradigmas que subyacen en las diversas actividades de la lectura y escritura académicas, y que explico a continuación.

\section{b) Tres paradigmas de la cultura escrita en el ámbito académico}

Desde los Nuevos Estudios de Literacidad (NLS por sus siglas en inglés) o Cultura Escrita, Lea y Street (1998) han identificado tres paradigmas desde donde se han enseñado, aprendido, revisado y evaluado las distintas prácticas de textualidad académica en el contexto universitario. Uno es el paradigma de habilidades de estudio (Study Skills), otro de socialización académica (Academic Socialisation), y otro de Literacidad Académica o Cultura Escrita (Academic Literacies). Concretamente, estas tres perspectivas se pueden resumir de la siguiente manera:

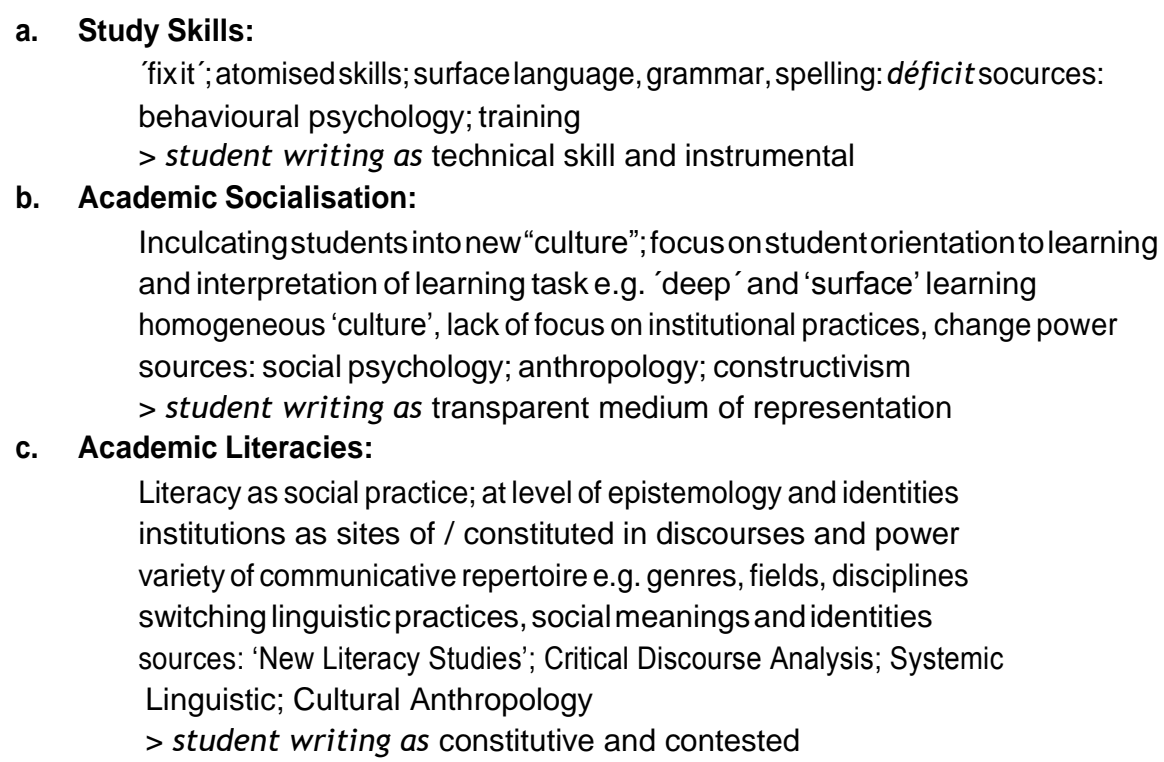

Figura 2.- Paradigmas de la Escritura del Estudiante en la Educación Superior (Street, 2010, p. 350) 
La textualidad académica de estudiantes de origen indígena en estudios de posgrado: el proceso de elaboración de tesis

La primera perspectiva refiere al paradigma de habilidades de estudio donde claramente la escritura y, en general, el lenguaje académico se mira como una habilidad individual y cognitiva, centrando la atención en las características superficiales de una lengua como son las cuestiones gramaticales, ortográficas, de puntuación e incluso la caligrafía. En este enfoque la escritura de los alumnos es vista como una habilidad técnica e instrumental que se queda en la superficie el texto y en la forma de la lengua (Lea \& Street, 1998), en mirar cómo se escribe tal texto, dejando al margen otros aspectos básicos de textualidad como la coherencia y el fin comunicativo del texto mismo, es decir, se queda en el nivel formal y estructural de la lengua. En este sentido, se supone que una vez aprendido las convenciones lingüísticas de un idioma, es posible transferir tal conocimiento a cualquier otro contexto sin ninguna dificultad ${ }^{10}$. No obstante, como profesores vemos con desánimo que no es así, que por el contrario la gran mayoría de los estudiantes universitarios presentan diversas dificultades de compresión lectora y de redacción, y que no basta con que un alumno escriba sin errores ortográficos, sino que logre expresar sus pensamientos de una manera clara y coherente.

Un segundo paradigma refiere a la socialización académica que considera que el estudiante debe seguir un proceso de inducción e inmersión a una nueva "cultura académica", la cual se asume como homogénea. Esto significa que la cultura académica es considerada como neutral y que conlleva ciertas regulaciones que rigen las prácticas académicas y discursivas propias del ámbito universitario. Lo anterior implica que "las prácticas de escritura son consideradas como estáticas y fijas a las cuales los estudiantes tienen que ajustarse" (Hermerschmidt, 1999, p. 10) ${ }^{11}$ porque se asume que una vez aprendidas las normas, convenciones y prácticas textuales que marca la disciplina misma, es posible aplicarlas a cualquier contex to y construir cualquier texto académico sin dificultad alguna.

Así, la socialización académica es un proceso de aculturación donde el estudiante aprende e interpreta las regulaciones y convenciones textuales que constituyen los distintos discursos disciplinarios, así como los géneros textuales propios de cada campo de

\footnotetext{
${ }^{10}$ Cuando los alumnos proyectan en sus textos dificultades de este tipo generalmente se suele diseñar actividades y programas remediales con el fin de "reparar" la escritura de los alumnos, asumiendo que con el sólo hecho de aprender y conocer los aspectos formales de una lengua será posible construir cualquier tipo de texto académico. Para ello, se han creado diversos programas de educación compensatoria o remedial que han buscado diseñar propuestas que ayuden al estudiante a "superar" sus problemas de redacción.
}

${ }^{11}$ Traducción simple del texto original en inglés 
conocimiento, incluyendo las prácticas de lectura, escritura y construcción de textos propios del ámbito universitario (Lea, 1999). Por tanto, todo aquel que desee lograr un buen desempeño y ser parte de una nueva cultura académica tendrá que aprender sus formas, sus normas y sus prácticas para tener acceso a esta cultura y cubrir las expectativas institucionales respecto a lo que significa leer y escribir en la universidad.

El paradigma de literacidad académica o cultura escrita ${ }^{12}$ es un tercer enfoque que asume y reconoce que existen múltiples literacidades que varían en tiempo y espacio y, además, cuestiona las relaciones de poder que conllevan dichas literacidades. Este paradigma concibe la literacidad o cultura escrita como una práctica social (Barton \& Hamilton, 2000; Gee, 2010; Brice Heath, 1983; Street, 1993, 2003; Lea \& Street 1998), donde nada está dado y por el contrario se pregunta cuáles han sido las prácticas académicas que han dominado el campo, y cuáles han sido marginadas. En esta perspectiva, el contexto juega un papel primordial porque considera que las prácticas de la cultura escrita como prácticas sociales siempre varían de un contexto a otro, de una cultura a otra, por eso las formas y los efectos de las distintas prácticas escritas dependen de las diversas condiciones en que surgen.

En este sentido, la literacidad académica se vincula con una visión más ideológica, social y cultural, destacando que las prácticas de lectura y escritura están indisolublemente ligadas a la cultura y estructuras de poder en la sociedad, a la vez que reconoce las variedades de prácticas culturales asociadas a los procesos de lectoescritura en diversos contextos. De esta manera, la literacidad entendida como una práctica social implica que tales prácticas no son unidades aisladas donde se puede observar la conducta de quienes escriben, ya que éstas involucran actitudes, valores, sentimientos y relaciones sociales y culturales (Street, 1993). Barton \& Hamilton, (2000) ${ }^{13}$ plantean que las prácticas de literacidad incluyen la noción que la gente tiene de la misma literacidad, el cómo se construyen esas prácticas así como los discursos que las rodean, y en cómo las personas hablan sobre ellas y le dan sentido. Así, la

\footnotetext{
${ }^{12}$ En este documento hago uso indistintamente de los términos "literacidad académica" y "cultura escrita" para referirme "academic literacy", es una de las traducciones propuesta por Kalman (2008).

${ }^{13}$ Barton \& Hamilton (1998) desarrollaron una investigación en Inglaterra llamada "Local literacies: Reading and writing in one community", desde la perspectiva de la literacidad académica. Su atención se centró en los usos cotidianos de la escritura en contextos locales. Su postura era mostrar lo que la gente de la comunidad de Lancaster hacía con escritura como forma de comunicación en distintos contextos de su vida cotidiana.
} 
La textualidad académica de estudiantes de origen indígena en estudios de posgrado: el proceso de elaboración de tesis

literacidad o cultura escrita adquieren otra tonalidad y significado tomando en cuenta principalmente el contexto donde se producen tales prácticas.

Estos tres paradigmas proporcionan una mirada mucho más amplia pero también más compleja de lo significados e implicaciones del lenguaje académico, sobre todo porque cada uno, se sustenta y apoya en distintas teorías y/o enfoques y disciplinas que moldean las formas de comprender el lenguaje académico en el nivel superior. Como se puede ver en la Figura 2, cada perspectiva tiene sus propias raíces y tradiciones. El paradigma de habilidades de estudio se sostiene en la psicología conductista cuya preocupación es la transmisión del conocimiento. La socialización académica se asocia con el constructivismo y el aprendizaje situado como marcos organizativos, así como con el campo de la antropología, análisis del discurso y la teoría de géneros (discursivos). Finalmente, el paradigma de literacidad académica como práctica social tiene sus bases en Los Nuevos Estudios de Literacidad, pero también influenciado por la lingüística crítica y social, por la teoría crítica y sociocultural que enfatiza una teoría del aprendizaje y que ubica en primer plano el poder, la identidad y la agencia en el rol del lenguaje en el proceso de aprendizaje (Lea \& Street, 2006).

Estas tres orientaciones teóricas intelectuales de la escritura académica han coexistido en el ámbito universitario. La visión de las habilidades de estudio es la que ha permeado más en los procesos de enseñanza-aprendizaje, revisión y evaluación de las prácticas de textualidad en este nivel educativo, en menor medida el enfoque de socialización académica o alfabetización académica como la nombra Carlino (2004, 2005), y el menos desarrollado es el de literacidad academica o cultura escrita puesto que también es uno de los menos desarrollados e investigados académica e institucionalmente.

Como es posible observar, cada una de estas perspectivas implica también usos, funciones y prácticas diferentes del lenguaje académico escrito. Por ejemplo, los usos y funciones del lenguaje académico en el marco del paradigma de habilidades estarían más orientados a exigir cuestiones de formalidad del texto, el escribir correctamente respetando las regulaciones lingüísticas y gramaticales, así como los signos de puntuación, es el aspecto formal y superficial del lenguaje. En el caso del paradigma de socialización, los usos y funciones del lenguaje estarían enfocados a la reproducción de textos académicos, es decir que el estudiante entienda cómo se debe escribir académicamente y haga un uso correcto de tales 
textos, mediante procesos de formación asimilacionistas, por ejemplo, que el alumno universitario sepa hacer una tesis, tanto en su forma como en su contenido, pero no se pone atención en aspectos como, qué entiende el alumno de lo que es una tesis.

En el último paradigma, se tomaría en cuenta la función social del lenguaje, qué es lo que los alumnos saben y conocen del lenguaje académico, cuál es su contexto, qué tan familiarizados están con el lenguaje académico escrito, esto les permitiría reflexionar y comprender sobre sus exigencias e implicaciones y les daría posibilidades de manejar más abiertamente su propio lenguaje, de ser más creativos y disminuir la gran brecha que existe entre lo que los alumnos saben y pueden hacer con el lenguaje y lo que las instituciones educativas esperan de ellos.

Entonces, desde la investigación en Nuevos Estudios de Literacidad (NLS, por sus siglas en inglés) cuestiona este punto de vista y sugiere que en la práctica la cultura escrita varía de un contexto a otro y de una cultura a otra y, por lo tanto, hace que los efectos de dicha cultura escrita sean diferentes precisamente porque sus condiciones son también diferentes. Contrario, al enfoque autónomo que simplemente está imponiendo concepciones occidentales de cultura escrita en otras culturas o, dentro de un país, las de una clase o grupo cultural sobre otros (Street, 2003).

No obstante, mirar los procesos de textualización de los estudiantes en el nivel universitario desde esta mirada de la cultura escrita como práctica social, es una posibilidad compleja debido a que estos alumnos se enfrentan a un lenguaje y cultura académicos con lo cual muchas veces no están familiarizados, tomando en cuenta que escribir académicamente es un proceso mucho más complejo de lo que aparentemente en la vida cotidiana significa. Escribir un texto académico requiere del conocimiento y dominio no solamente de las normas lingüísticas y formales de la lengua escrita y de sus recursos expresivos, sino también de sus prácticas y de las funciones vinculadas directamente a la producción y legitimación del conocimiento académico. Sin embargo, todo este conocimiento generalmente se obvia en los distintos escenarios académicos en los diversos niveles de escolaridad y, cuando se ha puesto atención en estos aspectos, el análisis y/o evaluación de un texto usualmente se ha quedado en la parte superficial del mismo, es decir en su carácter estructural.

\subsubsection{El lenguaje académico en el nivel superior}


La textualidad académica de estudiantes de origen indígena en estudios de posgrado: el proceso de elaboración de tesis

Lo anterior tiene que ver con que las distintas prácticas de la cultura escrita en el ámbito universitario forman parte de una "cultura académica" que determina las diversas formas en que se hace uso del lenguaje académico tanto en lo oral como en lo escrito, como se explica a continuación.

\section{a) La cultura académica: un escenario simbólico}

La cultura académica es un entramado de usos, funciones, prácticas y nociones de lo que es, exige e implica el lenguaje académico en el contexto universitario, el cual despliega toda una gama de prácticas textuales y comunicativas inmersas en este contexto. Es "un escenario (espacio de coordenadas, de referentes y de tensiones) para mirar los modos de leer y escribir que se originan desde prácticas pedagógicas y didácticas universitarias concretas" (Parra Mosquera, 2013, p.2). De esta forma, el lenguaje académico cobra un sentido específico según los referentes que propone el mismo contexto y que a su vez determinan formas concretas de leer y escribir en este ámbito. Por ejemplo, las lecturas especializadas y textos argumentativos como los ensayos o tesis son prácticas comunes que exige este contexto en el nivel superior.

Así, la cultura académica se caracteriza como un escenario con cierta "estabilidad" (Ídem), pues de alguna manera ya tiene preestablecida una gama de posibilidades textuales ${ }^{14}$ (resúmenes, ensayos, monografías, reportes, informes, tesis, etc.) que tanto profesores como estudiantes deben llevar a la práctica. La cultura académica universitaria, de igual forma, establece lo que es valorado, aceptado y lo que no, según las exigencias y necesidades del contexto y el momento específico en el que se soliciten. Por ello, la cultura académica también involucra las "prácticas... [que son] producto de las relaciones de trabajo, el poder, la producción y la reproducción [donde] se producen nuevos símbolos, saberes y sentidos” (p. 3). Es decir, que dichas prácticas no son neutrales ni homogéneas, por el contrario, existe una gran diversidad de prácticas de lectura y escritura que surgen y se moldean según los

\footnotetext{
${ }^{14}$ No obstante, estas posibilidades textuales (géneros discursivos) no son fijas, se adaptan al contexto y pueden ser modificadas según las exigencias de dicho contexto, según los actores involucrados y los fines comunicativos que se persigan. Es decir, la "estabilidad" mencionada es relativa porque los géneros discursivos también se van construyendo y reconstruyendo, y dicha estabilidad sólo se conserva en cierta media (Bazerman, 1988; Miller, 2005). En apartados posteriores desarrollaré esta discusión sobre los géneros discursivos en el nivel de educación superior.
} 
propósitos que se persigan, depende de quién o quienes las solicitan o las promueven, depende también de quiénes las ejecutan y de cómo se entiende lo que significa el lenguaje académico en el nivel superior.

Desde esta perspectiva, el lenguaje académico cobijado por el ámbito universitario se torna mucho más complejo, las prácticas de textualidad adquieren un matiz menos claro del qué y el cómo se da la comunicación académica. Entre un nivel educativo y otro el lenguaje académico tanto conversacional como textual se va complejizando y el estudiante se va enfrentando a nuevas formas de utilizar el lenguaje. De hecho, Cummins menciona que:

[en] la medida que el estudiante progresa de un nivel a otro, las tareas académicas que tiene que realizar y los contextos lingüísticos en los que debe desenvolverse van siendo más complejos con respecto a los registros utilizados en estos contextos. No sólo hay un vocabulario en constante aumento y una carga conceptual que envuelve las palabras que no suelen encontrarse en los contextos extraescolares cotidianos, sino que las características sintácticas (por ej., construcciones en voz pasiva, y no en activa) y convenciones discursivas (por ej., utilizar con eficacia recursos cohesivos en la escritura) también se hacen cada vez más distantes de los usos conversacionales del idioma en contextos no académicos". (Cummins, 2002, p. 84)

Específicamente en el nivel superior y más aún en el nivel de posgrado, donde coexisten tanto lo conversacional como la textualidad que incluye las lecturas académicas, se demanda un considerable dominio del idioma donde las exigencias cognitivas son mayores, el contexto inmediato es reducido o incluso nulo, y donde el estudiante debe manipular dichos requerimientos propios de este ámbito escolar para lograr el dominio académico del lenguaje. Es decir que en este escenario simbólico de la cultura académica es donde del lenguaje académico va tomando formas particulares tanto en lo oral como en lo escrito.

\section{b) El lenguaje académico: lo escrito y lo conversacional}

Como he referido, el lenguaje que se utiliza en los contextos escolares mantiene particularidades precisas que involucran tanto las habilidades y prácticas textuales académicas así como también las habilidades conversacionales que todos aquellos inmersos en dicho escenario tendrían que utilizar para poder enfrentarse y cumplir con las exigencias que demanda el lenguaje en el nivel superior. Esto significa que el dominio del lenguaje 
La textualidad académica de estudiantes de origen indígena en estudios de posgrado: el proceso de elaboración de tesis

académico en el contexto escolar no se limita a cuestiones de textualidad, a la producción de textos académicos sino que implica también el desarrollo de habilidades conversacionales (Cummins, 2002) sobre todo en el nivel superior donde los debates grupales, las presentaciones orales, las participaciones en conferencias, entre otros, son prácticas escolares que exigen en particular este nivel educativo.

Estas habilidades conversacionales académicas son distintas a las que utilizamos en situaciones cotidianas no escolares. Las capacidades conversacionales en el ámbito académico se vinculan directamente con el Dominio Cognitivo del Lenguaje Académico (DCLA) (Cummins, 2002). Esto quiere decir que las distintas prácticas de leer, escribir y conversar en espacios académicos como el universitario demandan formas específicas de interacción con los otros, donde una persona necesita hacer uso de su repertorio lingüístico concreto según el nivel de exigencia que requiera la situación comunicativa y contextual en la que se encuentre.

Lo anterior se aprecia claramente en el esquema (Figura 1) que propone Cummins (2002) para mostrar el alcance de las exigencias cognitivas y el apoyo contextual que involucran las distintas tareas y actividades lingüísticas de las cuales hacemos usos los seres humanos tanto en nuestra vida cotidiana ${ }^{15}$ así como en los diversos escenarios académicos en que fluimos durante nuestra escolaridad.

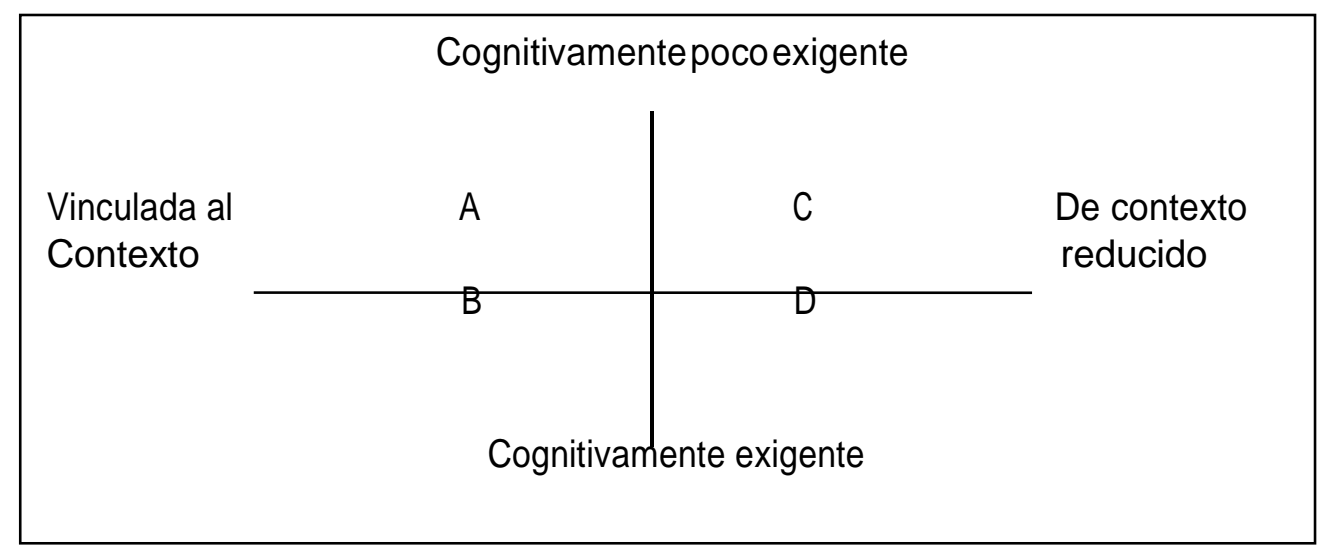

Figura 1.- Alcance del apoyo conceptual y grado de participación cognitiva en las tareas y actividades del lenguaje (Cummins, 2002, p. 85)

\footnotetext{
${ }^{15}$ Cummins (2002), hace su planteamiento sobre los usos del lenguaje en contextos escolares, sin, embargo, considero de manera personal que el esquema que él propone es de gran utilidad para comprender aquellos usos de lenguaje más coloquiales.
} 
Como se puede apreciar en la figura 1, se consideran varios parámetros que ayudan a ubicar las distintas actividades del lenguaje considerando principalmente el contexto y el nivel de cognición en cada cuadrante. Cummins (2002) explica que:

[1]as partes superiores del continuo vertical consisten en tareas y actividades comunicativas en las que las herramientas lingüísticas se han automatizado en gran medida y, por tanto, requieren poca intervención cognitiva para un rendimiento adecuado. En el extremo inferior del continuo, se sitúan tareas y actividades en las que las herramientas lingüísticas no se han automatizado y, por tanto, precisan de una activa intervención cognitiva (p. 85).

En este esquema cada uno de los cuadrantes representa formas distintas de utilizar el lenguaje. En el cuadrante A entrarían los usos del lenguaje en situaciones cotidianas muy familiares, de poco alcance cognitivo puesto que las habilidades tanto conversacionales como escritas se han automatizado por su uso recurrente en la vida diaria, es decir, la comunicación está sujeta al contexto inmediato donde surge tal situación comunicativa. El cuadrante $\mathrm{C}$ tiene características similares, pero de contexto reducido.

En los cuadrantes B y D se ubica el lenguaje académico cuya característica principal es el alto nivel cognitivo y el uso de habilidades lingüísticas con mayor abstracción que éste demanda. La diferencia sería que en el cuadrante B existe apoyo del contexto por ejemplo entrarían en este cuadrante las diversas habilidades conversacionales que exige el ámbito universitario como lo son los debates y presentaciones grupales, así como las participaciones en foros, congresos, seminarios u otros espacios públicos que demandan el dominio de un vocabulario más técnico y especializado, el dominio de formas de expresión como el convencimiento, las persuasión, el contrargumento, la exposición o la explicación, donde muchos de los temas propios de las distintas áreas de conocimiento son especializados, con explicaciones densas y con un léxico poco común.

En el cuadrante D las exigencias del lenguaje académico son también complejas, pero se le añade la característica de tener contexto reducido, es decir que las actividades académicas de este cuadrante están descontextualizadas y la interacción con el o los interlocutores no se da en un contexto inmediato como ocurre en el cuadrante B. El cuadrante 
La textualidad académica de estudiantes de origen indígena en estudios de posgrado: el proceso de elaboración de tesis

D por su parte abarca toda una diversidad de textos académicos como los resúmenes, los ensayos, las tesis, los reportes, las reseñas, artículos de investigación, entre muchos otros, lo cual implica el manejo de distintas formas de expresión escrita que van desde la descriptivas hasta las argumentativas y persuasivas, así como el uso de un vocabulario mucho más técnico y científico, de estructuras oracionales más complejas. En otras palabras, las actividades de este cuadrante requieren de un dominio de lenguaje académico cognitivamente más exigente y mucho más abstracto, que se aplica no sólo para la elaboración de los textos sino de las lecturas académicas que suelen ser más científicas.

En concreto, la esencia del dominio del lenguaje académico "es la capacidad de hacer explícitos unos significados complejos de forma oral o escrita, mediante el mismo lenguaje y no por medio de claves contextuales o paralingüísticas" (Cummins, 2002, p. 86). Es así como en los contextos escolares, en particular en el nivel superior, convergen tanto lo textual como lo conversacional y ambos exigen el dominio cognitivo del idioma que estará determinado por la situación comunicativa que se esté dando.

En este sentido, el contexto cobra especial relevancia porque es el que determina las formas en que se utiliza un idioma sea éste oral o escrito, así como el nivel de complejidad y las intenciones que se tengan al momento de participar en un acto comunicativo. Por ello, "el 'dominio de un idioma' no puede conceptuarse fuera de los contextos concretos de uso y sólo podemos hablar de diferentes niveles de habilidad o dominio (o grados de acceso) con referencia a contextos específicos" (Cummins, 2002, p. 71). Por tanto, es necesario diferenciar cuáles son esas formas del uso del lenguaje y cómo éstas se relacionan con el contexto inmediato o reducido según sea el caso, ya que éste es el que dicta las pautas de tipo de lenguaje a utilizar y el nivel de exigencia cognitiva que se requiere para dicho contexto.

Idealmente, una persona o en su caso un estudiante en el nivel superior y en específico en posgrado, tendría las posibilidades de poder transitar sin problema de un cuadrante a otro, manifestando en formas diversas su dominio del lenguaje tanto cotidiano como académico en contextos diversos. Sin embargo, lograr el dominio del lenguaje, sobre todo el académico, es un gran reto para cualquier estudiante en el nivel universitario porque no todas las personas poseen las mismas habilidades de comunicación, algunas pueden expresarse mejor oralmente y otras por escrito, otras tienen menos dificultades con unos textos que con otros y otras tienen 
mejor desarrolladas sus habilidades orales en algunos contextos que en otros. Con esto quiero decir que el grado de dominio de las destrezas lingüísticas y comunicativas no es inherente al ser humano, sino que depende en gran medida "al grado en que una persona tiene acceso y maestría suficiente para comprender y utilizar el tipo concreto del lenguaje empleado en contextos educativos, necesarios para cumplimentar las tareas académicas” (pp. 83-84).

Lo anterior significa que el grado de dominio lingüístico y académico de una persona estriba en las posibilidades y el nivel de acercamiento que dicha persona haya tenido con el lenguaje académico, y de cómo éste es funcional en el contexto de las tareas y actividades académicas comunes. Por tanto, lograr el dominio del lenguaje académico depende de múltiples factores vinculados con su formación académica, su acercamiento a los procesos de lectura y escritura, a cuestiones culturales, lingüísticas y sociales que influyen y en muchos casos determinan el éxito o fracaso de un estudiante en su desempeño académico. Por ello, al momento de enseñar, revisar o evaluar el lenguaje académico de un estudiante no se pueden obviar los factores mencionados porque de alguna manera éstos permean en la forma en que un estudiante se expresa tanto de manera oral como escrita.

No obstante, considero que en el terreno educativo superior existe un desequilibrio en el nivel de atención que se le otorga al desarrollo de lenguaje académico conversacional y escrito. Entre lo conversacional y lo académico, generalmente se práctica más lo conversacional, las clases son por lo regular a través de interacciones comunicativas orales, lo cual implica un soporte contextual inmediato, la interacción es cara a cara, tanto profesores como alumnos tienen las posibilidades de comunicarse en el momento, conocen el tema que se está abordando y ello les da la oportunidad de aclarar dudas e inquietudes y de manifestar sus opiniones y posturas. Así, todas las actividades desarrolladas en contextos inmediatos como el aula escolar contribuyen a que la comunicación fluya, y que paulatinamente los alumnos se vayan apropiando de los conocimientos de la disciplina, de las herramientas lingüísticas expresivas, como un lenguaje oral más técnico y afinado que con el paso del tiempo podrán fortalecer y llegar a utilizarlo.

Con la escritura académica también hay muchas posibilidades de ejercerla, pero su tratamiento es distinto, la intención de comunicar argumentos académicos implica que el autor del texto despliegue todo un conjunto de habilidades lingüistas y textuales para darse a 
La textualidad académica de estudiantes de origen indígena en estudios de posgrado: el proceso de elaboración de tesis

entender. Además, el contexto de la situación comunicativa no es inmediato, el escritor tiene la necesidad de explicitar a lo largo del texto lo que desea comunicar, y describir aquellos elementos con mayor abstracción que no son tan simples de expresar de forma escrita. Por ello, como he referido anteriormente, el lenguaje académico escrito es cognitivamente más exigente y mucho más abstracto, lo cual involucra procesos de lecturas académicas también con mayor abstracción. No obstante, puedo decir que en el nivel superior la atención al desarrollo de tales destrezas comunicativas es limitada, no hay suficientes apoyos pedagógicos ni didácticos que les permita a los estudiantes desarrollar sus habilidades textuales, sobre todo cuando se trata de un documento recepcional de titulación como lo es la tesis.

Lo anterior puede ser por distintas razones, una es porque en este nivel, licenciatura y posgrado, usualmente se asume que los alumnos ya han adquirido las habilidades lingüísticas y de redacción del lenguaje académico y que no tendrían problemas de poner en práctica. Otra es que la escritura académica en este nivel educativo es una actividad que por lo general se realiza en solitario, el alumno se enfrenta solo al proceso de construir un texto académico y en ese proceso de textualización se le presentan diversas dificultades tales como: a) escribir para sí mismo y no para sus lectores; b) transcribir el conocimiento recuperando lo que sabe sobre el tema sin reflexionar, desaprovechando la potencialidad epistémica de la escritura; c) revisar solo la superficialidad de texto y por último; d) posponer lo más posible el momento de empezar a redactar (Carlino, 2004). Esto sucede durante gran parte del proceso formativo superior del estudiante, en las muchas actividades académicas que desempeña donde el lenguaje académico escrito es el centro de atención.

\section{c) La tesis: una escritura científica}

Como se ha mencionado, escribir académicamente es un proceso complejo que exige el despliegue de distintas habilidades para poder construir un texto académico. Sin embargo, concretamente en el proceso de construcción, desarrollo e implementación de un proyecto de investigación, las dificultades en el lenguaje académico escrito se acentúan. En términos generales, ha habido pocas propuestas para guiar a los estudiantes en los procesos de textualización tanto en el contexto universitario como en los niveles previos. Por ejemplo, uno de los enfoques que está siendo desarrollado en la universidad es la perspectiva de 
alfabetización académica ${ }^{16}$ impulsada en América Latina por Paula Carlino. De hecho, esta autora asevera que hacer una tesis como parte de un posgrado, que implica el desarrollo de una producción escrita original, es una de las fases y experiencias más arduas del trabajo académico, y en la que se invierte mayor tiempo, ya que a diferencia de cursar una carrera de grado o realizar otro tipo de textos académicos, es una actividad en la cual no se perciben metas intermedias, que exige una gran autoorganización, por ello, una tesis no se puede comparar con otras formas de comunicación escrita antes intentada, sobre todo para quienes las inician sin experiencia en el campo de la investigación (Carlino, 2003). Además, continuando con el argumento de esta autora, una tesis no solo exige una serie de conocimientos disciplinares, metodológicos y discursivos, sino también demanda el desarrollo de estrategias metacognitivas y capacidades personales a fin de sostener un trabajo arduo que no muestra resultados por mucho tiempo. Desde esta mirada, el desarrollo de una tesis "es usualmente el camino para iniciarse en la cultura de la investigación, cuyas prácticas y valores centrales suelen aguardar a los recién llegados de forma implícita” (Carlino, 2003, p.7)

Así, el comienzo y desarrollo del proceso de elaboración de una tesis no es un trabajo sencillo ni accesible para cualquier alumno, por el contrario, este proceso es muy complejo porque implica que el estudiante ponga en práctica sus conocimientos previos respecto al lenguaje académico escrito, asumiendo que ya cuenta con un conocimiento avanzado de normas y requerimientos lingüísticos que exige el área de conocimiento en que se desenvuelve. Para esto hay que considerar que, en el desarrollo de un proceso de investigación, cada disciplina tiene sus propias formas de validación tanto en lo teórico como en lo empírico, pero también posee distintas maneras en que cada campo de conocimiento argumenta de forma escrita sus afirmaciones, resultados, etc. (Carlino, 2005).

No obstante, el desarrollo de un proyecto de investigación como una tesis no es una responsabilidad individual del estudiante, ya que este tipo de textos académicos están insertos en la cultura académica que establece tanto nociones de lo que es una tesis, como regulaciones

\footnotetext{
${ }^{16}$ Este enfoque tiene como objetivo introducir a comunidad estudiantil procedentes de diversas culturas a una nueva cultura académica y llegar a dominar las convenciones textuales que exige este contexto. Uno de los proyectos más conocidos que tiene como base esta perspectiva es "Writing Across the Curriculum" (WAC), el cual ha sido impulsado por David Russell teniendo sus raíces en el contexto anglosajón. Este enfoque sostiene que la escritura es una herramienta indispensable para aprender y por lo tanto debe utilizarse más allá de las clases exclusivamente de la enseñanza de lenguas, lo cual exige que la escritura no quede fuera de las temáticas abordadas en las disciplinas, sino que sea parte constructiva de ellas.
} 
La textualidad académica de estudiantes de origen indígena en estudios de posgrado: el proceso de elaboración de tesis

en la forma en que se desarrolla y se presenta como documento recepcional de titulación. Sin embargo, se le ha dado poca atención al tratamiento y las implicaciones que conlleva el desarrollo de un trabajo de investigación, puesto que aún se cree que tal habilidad es responsabilidad del alumno y se supone que ya debe dominar. En efecto, en las instituciones universitarias, en general, no existe una tradición en concreto de la enseñanza y acompañamiento en el proceso de construcción de un documento de titulación, como lo es la tesis (Castelló \& Iñesta, 2012), cuando es uno de los géneros discusivos más complejos que un estudiante en el nivel superior debe enfrentar para poder obtener el título de licenciatura o posgrado.

Esta idea tiene que ver con la escritura científica "no como un recurso, sino como un aspecto fundamental del aprendizaje de las actividades científicas (Rymer, 1988, citado en Tolchinsky, 2000, p. 40), la cual persigue no sólo justificar las aseveraciones teóricas (y empíricas), sino también justificar que tal investigación es una contribución al campo de conocimiento inserta dentro de una comunidad científica en particular (Carlino, 2005). De esta manera, la comunicación académica escrita de los resultados de un proyecto de investigación como una tesis demanda un lenguaje académico científico, técnico y especializado con una exigencia cognitiva muy alta (Cummins, 2002), que requeriría de un tratamiento también muy específico por parte de los programas institucionales en los niveles de pre y posgrado, considerando que dicha comunicación va dirigida a un público particular que domina el mismo tipo de lenguaje académico.

Así, llegar a dominar el lenguaje especializado que exige la construcción de una tesis implicaría desarrollar acciones pedagógicas que contribuyan al conocimiento que involucra este género discursivo en el nivel superior con el objeto de guiar a los estudiantes y llegar al término de su formación universitaria con un documento que es de suma importancia en este nivel educativo como muestra de sus aprendizajes disciplinarios, pero también de la afinación de su lenguaje académico escrito.

Hasta aquí, la tesis de ha explicado desde un "deber ser" de la universidad, es decir, corresponde a la noción de la cultura académica que refiere a los usos y costumbres institucionales. Sin embargo, la tesis también tiene implicaciones sociales, lo cual refiere a las nociones que la gente tiene de lo que es una tesis como un documento social, es decir, la tesis 
no solo es un documento recepcional de titulación dentro de una cultura académica, sino también es una práctica social que adquiere un significado particular desde los sujetos y el contexto en donde se construye. Ambas miradas de la tesis contrastan, porque generalmente lo institucional no toma en cuenta la función social de la tesis; no obstante, lo social influye en la manera en que se llevan a cabo las prácticas textuales en torno a su elaboración en el espacio institucional. Esto es, la forma en que los maestros o facilitadores y sus estudiantes interactúan es una práctica social que afecta la naturaleza de la cultura escrita que se está aprendiendo y las ideas que sobre ella tienen los participantes, especialmente los nuevos estudiantes y su posición en las relaciones de poder, por lo que no es válido sugerir que la cultura escrita pueda ser "dada" de manera neutral para después sólo experimentar sus efectos "sociales" (Street, 2003)

Entonces, la tesis como uno de géneros discursivos más complejos en el ámbito académico, inserta dentro de una cultura académica dominante, no solo exige una escritura más científica que involucra el desarrollo de habilidades cognitivas, sino también, implica repensar su papel como una práctica social que cuestione entre otros aspectos las relaciones de poder que se dan entre autor y el tutor de tesis, con el fin acercar lo más posible lo que exige la institución formadora y lo que sabe o conoce el alumno respecto a lo que es una tesis.

\section{d) El lenguaje académico en el proceso de escolarización}

Lograr el dominio del lenguaje académico, tanto en lo oral como en lo escrito implica pasar por un largo proceso de escolarización, ya que es en el ámbito educativo donde se aprende, se enseña y se exigen las múltiples prácticas y conocimientos respecto a la lectura, escritura, y dominio conversacional académico, específicamente en el nivel universitario. En este sentido, Cummins afirma que:

la educación desempeña un papel importante para impulsar nuestro desarrollo continuo del idioma según ciertas trayectorias cruciales para la categoría del empleo futuro y para las oportunidades que se abran. Este desarrollo del lenguaje incluye la adquisición del léxico de la lectoescritura, predominantemente grecolatino, los vocabularios especializados de determinadas áreas de contenido y la capacidad de interpretar y utilizar una sintaxis más compleja en las modalidades oral y escrita (Cummins, 2002, p. 71). 
Así, desarrollar el lenguaje académico no es sólo una responsabilidad del contexto universitario sino también de los niveles previos que de alguna manera aportan elementos esenciales en las habilidades lingüísticas y textuales que una persona debe dominar y poder desempeñarse en los diversos ámbitos académicos de su formación escolar. De este modo, se supone que la educación (regularmente formal) desde el nivel básico tendría que proveer todas las herramientas teóricas, metodológicas, pedagógicas y didácticas para alcanzar paulatinamente el dominio cognitivo del idioma académico, considerando también el nivel de acceso y práctica que tengamos de él, así la escuela se convertiría en un espacio que puede guiarnos como estudiantes para desarrollar las destrezas lingüísticas, textuales y conversacionales que involucra el dominio del lenguaje académico en los distintos niveles de escolaridad.

No obstante, los niveles educativos por los que atravesamos no siempre cubren estas expectativas. En el nivel de educación básica la enseñanza de la escritura se ha enfocado al aprendizaje del código alfabético, se ha enfatizado el uso correcto (gramatical) de la lengua y siguiendo las sugerencias de las guías de redacción que muestran el buen uso del lenguaje escrito y oral. De esta forma, en este nivel educativo "prevalece una evaluación maniquea, la cual califica el uso correcto e incorrecto de la lengua que se utiliza como medios para comunicar los aprendizajes esperados, puntualizando que para hablar o escribir bien se deben seguir las recomendaciones de los manuales de redacción, escritos por gramáticos, filólogos o escritores reconocidos por su buen uso del lenguaje” (Rosas Ramírez, 2013: 49).

En este contexto, se privilegia el lenguaje académico pero de una manera un tanto superficial pues se concentra en aspectos formales, gramaticales y fonológicos, sobre todo en los primeros grados, es decir que el alumno utilice correctamente las reglas gramaticales, tanto de forma oral como escrita, y las aplique adecuadamente en las actividades desarrolladas en el aula, pero descuida el uso comunicativo del lenguaje, del cómo el estudiante puede expresar con claridad sus ideas, pensamientos, argumentos, emociones, etc., mediante el lenguaje como instrumento de comunicación. Esta parte es la que no se ha desarrollado ampliamente en la educación básica, considerando que es un pilar fundamental en la formación y vida académica en una persona. 
En concreto, la educación básica enfatiza el uso del lenguaje escrito a través de actividades didácticas propuestas por el plan y programas, pero el lenguaje oral académico queda al margen de dichas actividades y sólo se recuperan las participaciones orales en los debates grupales, pero sin la guía del profesor para dirigirlos (Ídem). Con este tipo de instrucción los niños, tal vez en su mayoría, terminan este nivel educativo sabiendo leer y escribir, al menos y en cierta medida los textos que los planes de estudios sugieren, pero el lenguaje conversacional académico sigue quedando ausente.

El nivel medio superior por su parte, se caracteriza por el desarrollo de áreas de conocimientos específicos donde se supone que los estudiantes adquirirían las competencias necesarias para ingresar al nivel superior, entre las que destaca la lectura y escritura académicas. En este contexto, aumenta el nivel de complejidad en todos los campos, particularmente en el plano del lenguaje académico “[1]os programas de educación media superior se inclinan por el estudio breve de lenguas clásicas como el griego y el latín, que se comparan con la morfología del español, y pretenden impulsar el desarrollo de habilidades comunicativas académicas a través del estudio de la literatura mexicana y universal" (Rosas Ramírez, 2013, p.49). En este nivel educativo, la prioridad es impulsar los conocimientos literarios en el campo de español, sin embargo, no se percibe el desarrollo de habilidades de textualidad académica que los estudiantes utilizarían en el nivel superior. De hecho, se advierte una falta de atención y continuidad en el desarrollo de prácticas textuales entre un nivel educativo y otro, y en específico cuando los alumnos ingresan al nivel universitario, donde los usos y manifestaciones del lenguaje académico son más complejos.

En suma, en los diferentes escenarios educativos, particularmente en el nivel superior, coexisten tanto la comunicación conversacional como la comunicación textual, ambas conforman el lenguaje académico que se caracteriza por su elevada exigencia cognitiva y su estilo formal de comunicación. Sin embargo, comúnmente se le ha dado más peso al aspecto conversacional que al textual, principalmente cuando se trata del desarrollo de proyectos de investigación como la tesis, el cual es una de los procesos más importantes en el contexto universitario, pero también uno de los más complejos y difíciles de lograr precisamente por la atención limitada a este asunto. Aunque la formación académica respecto al lenguaje en los niveles previos juega un papel importante porque se supone que los alumnos ya han adquirido 
La textualidad académica de estudiantes de origen indígena en estudios de posgrado: el proceso de elaboración de tesis

y desarrollado sus habilidades comunicativas académicas de forma oral y escrita, su ingreso al nivel universitario se distingue por procesos formativos que no exigen los niveles anteriores.

Por ello, considero necesario explicar qué implica para el estudiante la transición entre su formación previa y su inserción al nivel superior, y en qué medida es posible lograr ese dominio académico del lenguaje, considerando que este contexto involucra prácticas de lectura, escritura y dominio conversacional más elaborados. Me refiero concretamente a los procesos de socialización disciplinaria y profesionalización que cada estudiante experimenta en el marco de una nueva cultura académica a la cual se incorpora y que determina las distintas formas de leer, escribir e interactuar en este nivel educativo.

\subsubsection{Procesos de formación académica en el nivel superior: una transición en el lenguaje académico}

Uno de los principales propósitos de las instituciones universitarias es la formación del capital humano en las diferentes áreas de conocimiento específicas para dar respuesta a las demandas sociales que se vinculan con aspectos laborales, económicos e incluso políticos. En el nivel universitario, considerado como un espacio institucional, se ponen en juego realidades y lógicas de distinto orden y se entrecruzan formaciones y procesos formativos por los que el estudiante transita como son los procesos de socialización disciplinaria y de profesionalización que están enmarcados y delimitados por la cultura académica que, como se ha explicado, define, regula y formaliza las prácticas del lenguaje académico. En otras palabras, es en el escenario simbólico de la cultura académica que los estudiantes experimentan una transición en su formación académica de los niveles previos anteriores y su inserción al contexto universitario, este cambio no sólo comprende un reposicionamiento intelectual, una nueva mirada respecto al campo de conocimiento, sino sobre todo implica una afinación en el lenguaje académico, sea oral o escrito. Esto es, los alumnos en distintos niveles van mostrando un dominio cada vez más avanzado del lenguaje académico a través de su paso por el proceso de socialización disciplinaria y de profesionalización, procesos formativos que son necesarios para que un alumno en el nivel superior sea parte de esa cultura académica que en muchos contextos universitarios se obvia.

\section{a) El proceso de socialización disciplinaria}


El proceso de socialización disciplinaria es una especie de transformación que el estudiante experimenta, es una transición intelectual y académica de su nivel formativo previo al nivel universitario. Esta transición implica una incorporación a un nuevo campo de conocimiento, a una nueva cultura académica, en donde el estudiante inicia un proceso de aprendizaje de conocimientos racionales y científicos que involucran las distintas disciplinas del saber y desde donde se pueden estudiar, explicar e interpretar diversos tipos de fenómenos que contribuyan al entendimiento de las realidades sociales. El centro de atención del proceso de socialización disciplinaria es el aprendizaje de conocimientos particulares y especializados que requieren tratamientos pedagógicos diferenciados de áreas con un alto nivel de especialización y de autonomía, ya que cada campo disciplinar decide las teorías y conocimientos que pretende desarrollar en el estudiante como parte de su formación académica y profesional.

En este sentido, el alumno aprende el contenido de una disciplina determinada pero también aprende las exigencias de estilo y las convenciones que la misma disciplina acuerda. Así, este proceso de socialización disciplinar refiere a todas "las actividades docentes, acciones de acceso a fuentes de estudio y realización de proyectos académicos y prácticas profesionales" (Muñoz, 2013, p. 5). Esto implica toda una gama de situaciones de aprendizaje que van guiando al estudiante en su proceso de inmersión a un nuevo campo de conocimiento mediante todas aquellas actividades pedagógicas y académicas que la institución educativa, el programa de estudios y los profesores organizan para construir un camino por donde los estudiantes transiten y los lleve finalmente al término de sus estudios de licenciatura o posgrado.

En este proceso de acompañamiento que cada institución o programa decide cómo desarrollar, está también la parte de cómo cada estudiante está viviendo dicho proceso. Es decir, se espera que en el transcurso de proceso de socialización disciplinaria el estudiante se vaya formando y especializando en el campo de conocimiento que haya elegido, y por tanto, también se espera que sus conocimientos se vayan enriqueciendo, al igual que sus destrezas conversacionales y cognitivas. Particularmente en el lenguaje académico, el alumno se va apropiando de las habilidades conversacionales de contexto reducido, empieza a hacer uso de un vocabulario mucho más especializado y abstracto de su disciplina; también va 
La textualidad académica de estudiantes de origen indígena en estudios de posgrado: el proceso de elaboración de tesis

desarrollando sus habilidades textuales mediante las distintas prácticas de lectura y escritura que demanda el contexto en el que se desarrollan.

Es necesario considerar también que el proceso de socialización disciplinar varía de contexto a contexto, las exigencias no son las mismas, por ejemplo, hacer un resumen o una lectura comentada exige habilidades distintas a aquellas cuando se realiza un texto argumentativo como lo es un ensayo o una tesis. Por ello, el nivel alcanzado en el dominio del lenguaje académico es distinto para cada alumno donde, con relativa frecuencia, no logran comprender fácilmente lo que se requiere en cada caso particular, es decir, están hasta cierto punto alejados de las demandas institucionales y académicas universitarias ${ }^{17}$. Posiblemente para muchos, hacer un ensayo o desarrollar un proyecto de investigación es algo totalmente novedoso por lo que su inmersión a dichos procesos exigiría mayor apoyo por parte de la institución y, en específico por el profesorado.

En esta línea, uno de los procesos formativos más importantes en que se ve reflejada dicha transición es el desarrollo de su proyecto de investigación como producto final de titulación. Para esto, la escuela o programa de pregrado o posgrado desarrolla toda una serie de acciones académicas que pueden ser las tutorías individuales o colectivas, foros, seminarios, entre otros, con la intención de guiar al alumno por ese camino que lo llevará a obtener el grado. Por su parte, el alumno elige una problemática o fenómeno a investigar, se plantea una pregunta de investigación, va aprendiendo a formular hipótesis, proposiciones, y/o axiomas que le dan orientación a su trabajo, se va nutriendo de nuevas discusiones teóricas, si es el caso, recurre a fuentes empíricas para demostrar cómo sucede tal fenómeno en un contexto específico. El paso por este proceso formativo de investigación contribuye a que el estudiante se vuelva especialista en el tema que haya elegido y por tanto vaya involucrándose cada vez más y con mayor profundidad en las implicaciones del desarrollo de tal proyecto de investigación.

\footnotetext{
${ }^{17}$ Tal distanciamiento se debe a diversos factores como por ejemplo "La masificación e interculturalización de la educación superior ha provocado un abismo entre ésta y las prácticas familiares y escolares. Para algunos estudiantes los usos formales del lenguaje y la escritura han pasado a ser totalmente extraños" (Tolchinsky, 2000, p. 39)
} 
De esta manera, el estudiante se convierte en un investigador que ha adquirido cierto dominio de las implicaciones intelectuales y académicas del desarrollo de un proyecto de investigación como puede ser la tesis. Lo anterior conlleva que el alumno haya experimentado un proceso de transición disciplinaria que puede evidenciarse en las diversas manifestaciones que haga, de forma oral o escrita, del lenguaje académico. Esto es, los estudiantes en el nivel superior requieren hacer uso de un repertorio lingüístico más amplio y más complejo según las distintas prácticas textuales que desarrolle y según las exigencias y convenciones académicas que la institución universitaria demande. En concreto, el proceso de socialización disciplinaria conlleva el dominio paulatino de un discurso científico y especializado respecto a determinadas áreas de conocimiento, donde se espera que los estudiantes vayan creciendo académicamente $\mathrm{y}$, en particular, afinando su propio lenguaje académico tanto oral como escrito, es decir, este proceso implica el logro del Dominio Cognitivo del Lenguaje Académico (Cummins, 2002).

Por tanto, el proceso de socialización disciplinaria en el nivel superior refiere a cómo los estudiantes van adoptando prácticas y discursos propios de este ámbito educativo, qué tanto van alcanzando el dominio del lenguaje académico, donde cada contexto cobra singularidad y donde el estudiantado debe cumplir con las exigencias retóricas de la vida académica y profesional. Pero también, es importante que el estudiante conozca y domine las demandas institucionales que cada contexto universitario establece para el buen funcionamiento de la vida académica, es decir, el proceso de socialización disciplinaria no ocurre en solitario, también se ve acompañado por un proceso de profesionalización.

\section{b) El proceso de profesionalización}

En términos generales, el proceso de profesionalización implica el desarrollo de habilidades en una persona para que adquiera las capacidades específicas necesarias dentro de la profesión que ha decidido estudiar. En este sentido, la profesionalización está estrechamente vinculada con cuestiones de instrucción, de enseñanza y aprendizaje, así como de formación del estudiantado, lo cual implica no sólo la capacitación en el nivel profesional en el que se instruya, sino también con los aprendizajes especializados que adquiera según las orientaciones que determine la misma universidad. El proceso de profesionalización incluye "toda una gama de prácticas institucionales de funcionamiento laboral que se orientan al 
La textualidad académica de estudiantes de origen indígena en estudios de posgrado: el proceso de elaboración de tesis

contacto, intercambio y organización de los miembros de un determinado sector profesional” (Muñoz, 2013, p. 5).

Esto significa que cada ámbito universitario define las distintas formas de organización en que se desarrolla todo el ejercicio de profesionalización de los actores involucrados en dicho contexto. Para esto, cada institución cuenta con un sistema de normas que regulan tanto la conducta del estudiante como las prácticas institucionales universitarias que realizan, que van desde la parte administrativa hasta la pedagógica, orientando y delimitando el rol que cumple la universidad como un espacio educativo que fomenta las acciones y conocimientos especializados.

El sistema normativo que diseña cada universidad contempla las relaciones laborales y académicas que determinan las acciones mismas de la universidad. Cada institución universitaria define sus propios modos de operar, su estructura organizativa y los vínculos que establece tanto al interior del espacio universitario, así como al exterior con otras instituciones. En el terreno curricular, cada universidad, según el nivel sea licenciatura o posgrado, determina los campos de conocimientos y el tratamiento de los mismos. Decide también las formas de titulación que pueden ser examen de conocimientos, tesinas, tesis, proyectos de intervención, entre otros, donde el grado de complejidad de cada modalidad de titulación aumentará según el nivel educativo en que se realice, sea éste pregrado o posgrado. Esto es fundamental para cualquier escenario académico de nivel superior porque el proceso de titulación es un trámite administrativo y una necesidad académica que el estudiante debe realizar para obtener el grado y cubrir también las demandas que no sólo el ámbito académico universitario exige sino también la sociedad.

Por tanto, el proceso de profesionalización por lo común atañe a las formas de organización que cada contexto universitario plantea con el fin de formar profesionales en áreas de conocimiento específicas. En concreto, la profesionalización estriba en todas aquellas prácticas institucionales que la universidad lleva a cabo para el buen funcionamiento de la vida institucional y académica universitaria.

Estos dos procesos formativos por los que el estudiante transita regulan y complejizan de cierta manera las prácticas del lenguaje académico en el nivel superior, siendo éstos el acceso a una nueva cultura académica que les provee de elementos lingüísticos y textuales que 
enriquecen la formación profesional de las personas, quienes a su vez diversifican las formas y usos del idioma en los distintos escenarios académicos.

Sin embargo, el lenguaje académico es un asunto complejo porque desde una perspectiva crítica de la cultura escrita, el lenguaje académico, particularmente el escrito, es un ente integrado que refleja no sólo las habilidades lingüísticas y cognitivas del estudiante, sino también cuestiones de identidad y relaciones de poder entre lo que exige la institución y la trayectoria académica y cultural que ha vivido el estudiante. Es decir que en el ámbito educativo superior el lenguaje académico es una práctica social académica, esto es, una combinación de los aspectos que plantea el paradigma de socialización académica y los propuestos por la perspectiva de literacidad académica o cultura escrita como explico en el siguiente apartado.

\section{c) El lenguaje académico en el nivel superior, una práctica social académica}

En el ámbito universitario, como se ha discutido, está inmerso dentro de una "cultura académica" que orienta y hasta cierto punto determina las diferentes nociones y prácticas del lenguaje académico que involucra tanto lo conversacional como lo escrito (Cummins, 2002). Pero también, en este contexto el lenguaje académico cobra singularidad porque se manifiestan factores de tipo social, cultural, institucional y/o político que permean e inciden en las formas de leer y escribir de los sujetos. Por ello, considero que en la esfera académica universitaria coexisten principalmente tanto el paradigma de socialización como el del literacidad académica, donde el lenguaje académico se manifiesta en distintas prácticas sociales, pero también escolares porque están insertas dentro de un contexto escolar con características concretas como sucede en el ámbito universitario. En este sentido, el lenguaje académico como práctica social académica involucraría considerar aspectos que conciernen tanto al enfoque de socialización académica como a la perspectiva de literacidad académica. Algunos de esos aspectos serían la cultura académica, los géneros discursivos, el contexto, así como los aspectos culturales, lingüísticos y sociales de los autores del texto, por mencionar algunos.

Ya se ha indicado que una de las particularidades del contexto universitario es que éste está inmerso dentro de una cultura académica que es considerada por la perspectiva de socialización académica. Esta cultura implica comprender que las diferentes comunidades 
La textualidad académica de estudiantes de origen indígena en estudios de posgrado: el proceso de elaboración de tesis

científicas o disciplinas contienen y desarrollan conocimientos y prácticas de lenguaje propios tales como los tipos de textos académicos que se leen, el lenguaje que ocupan, las corrientes teóricas que abordan, y los diversos textos que se construyen van en función de las necesidades de dichas disciplinas ${ }^{18}$. Esta idea supone que el estudiante deberá adquirir en dicho proceso las nociones y herramientas necesarias que le permitan no solo fortalecer sus habilidades discursivas sino sobre todo tener la capacidad de elaborar, producir y comprender textos académicos acordes con las exigencias de las comunidades científicas.

En otras palabras, el uso y dominio del lenguaje académico es inherente a la cultura académica, la cual se caracteriza por mantener cierta "estabilidad" pero también por su carácter "cambiante" (Parra Mosquera, 2013). Este autor explica que el carácter estable de la cultura académica se vincula con esa visión homogeneizadora respecto a las formas de utilizar el lenguaje en ámbitos escolares, según el campo de conocimiento en que se produzcan. Es decir que hay una parte de la cultura académica que simbólicamente va estructurando, organizando y hasta cierto punto determinando las prácticas textuales en el terreno universitario.

Un claro ejemplo de ello en el escenario universitario refiere a los géneros discursivos que en cierta forma mantienen cierta estabilidad debido al fenómeno de la recurrencia de situaciones en que se utilizan maneras específicas de comunicación académica (Bajtín, 1998). Esta idea de recurrencia de situaciones significa que el uso constante y frecuente de cierta forma de comunicación, sea ésta oral o escrita, va adquiriendo solidez mediante la práctica de uso hasta llegar a tener cierta estabilidad (Camps \& Castelló, 2013), al grado de alcanzar tal fuerza y lograr institucionalizarse como ocurre en el entorno académico, donde estudiantes y profesores utilizan formas concretas de comunicación. Por ejemplo, participan oralmente en espacios académicos como son los foros, los congresos, las conferencias, los seminarios, sesiones de clase, pero también participan de forma escrita cuando redactan textos académicos que van desde los resúmenes, hasta los ensayos o tesis.

\footnotetext{
${ }^{18}$ Esta idea se vincula estrechamente con el enfoque de Alfabetización Académica propuesta por Carlino (2005), el cual refiere a las nociones y estrategias discursivas necesarias que los estudiantes deben adquirir para poder ingresar a la nueva cultura académica universitaria mediante un proceso de inmersión donde vayan conociendo y familiarizándose con las distintas formas en que la universidad opera desde el ámbito académico.
} 
En ambos casos, las personas utilizan un lenguaje académico específico, ya sea de forma oral o escrita. Entonces, aunque existe una gran heterogeneidad de géneros discursivos académicos, las personas tendrán que elegir entre una u otra forma de comunicación académica tomando en cuenta el contexto discursivo dado, el tema a desarrollar, la situación concreta de comunicación discursiva, los participantes involucrados en dicha comunicación, entre otros. Es decir que "ante cualquier texto es necesario tener en cuenta algunos de estos criterios para tratar de identificar sus características dominantes, tanto en lo que se refiere al papel social del escrito como a su esquema organizativo básico o a las particularidades más estrictamente discursivo-lingüísticas que lo distinguen de otros textos" (Calsamiglia, 1997, p. 183). De esta manera, a través de la recurrencia de los géneros textuales, se alcanza la convencionalidad de los mismos.

En este sentido, el carácter estable de la cultura académica está ligado a la estabilidad relativa de las diversas formas de comunicación en el terreno académico, según el nivel de recurrencia de situaciones en que se hayan utilizado, donde los distintos usos del lenguaje académico están determinados por el tipo de género discursivo que exija el contexto. Por tanto, el dominio del lenguaje académico como práctica social académica implicaría el conocimiento de este fenómeno de estabilidad que es parte de la naturaleza de la cultura académica y que no puede quedar al margen porque es una necesidad para todos los involucrados en este contexto, especialmente para los estudiantes, es primordial conocer cómo y bajo qué parámetros fluye la comunicación académica en este nivel educativo. En otras palabras, no es posible ignorar las exigencias institucionales y formas de comunicación académicas que las universidades demandan, si se quiere avanzar exitosamente en la formación profesional de cualquier individuo.

Retomando a Parra Mosquera (2013), este autor afirma que la cultura académica no sólo tiene un carácter estable, sino también un carácter cambiante, donde las prácticas académicas y discursivas pueden ser modificadas, es decir que tal fuerza homogeneizadora no es absoluta, sino que en sus prácticas deja fisuras donde puede cuestionarse ese "carácter estable" de la cultura académica, creando posibilidades de transformarla. Esto significa que nada está dado, ni todo es absoluto, que la cultura académica se construye así misma a través de las prácticas académicas de los sujetos que la conforman, que a pesar de que existen formas 
La textualidad académica de estudiantes de origen indígena en estudios de posgrado: el proceso de elaboración de tesis

de comunicación relativamente estables, éstas también tienen posibilidades de cambiar o de crear nuevos estilos de comunicación académica.

Esto sucede también con los géneros discursivos porque, aunque pueden llegar a adquirir un alto nivel de estabilidad por su uso recurrente, la recurrencia en sí misma posibilita un cambio o una transformación del mismo género, ya que la recurrencia de una situación social es en sí misma un reconocimiento socialmente construido, es decir, que un género discursivo es una acción social que se construye y reconstruye socialmente (Miller, 2005). Por ello, no se debe considerar al género como un hecho social unitario, considerando que las definiciones formales, las características que se esperan, la fuerza institucional, el impacto y la comprensión del género varían a través de tiempo, del lugar y la situación (Bazerman, 1998). Así, los géneros discursivos considerados como acciones sociales no son estáticos, ni fijos, ni totalmente estables, por el contrario, a pesar de la recurrencia en su uso éstos pueden construirse y reconstruirse según el entorno, las circunstancias, las condiciones y los sujetos que los producen.

$\mathrm{Y}$ es aquí donde el contexto cobra especial relevancia como parte fundamental del carácter cambiante de la cultura académica y como parte esencial de la perspectiva de literacidad académica, entendida la literacidad como prácticas sociales del lenguaje que no son unidades aisladas, sino que en ellas se pueden observar la conducta de quienes escriben, la cual involucra actitudes, valores, sentimientos y relaciones sociales y culturales (Street, 1993). De ahí que esta visión de literacidad asuma que en la práctica la literacidad varía de un contexto a otro, de una cultura a otra, por eso las formas y los efectos de las distintas prácticas escritas dependen de las diversas condiciones en las que surgen. De esta manera, el contexto es relevante porque es el que determina el cómo se llevan a cabo las prácticas académicas.

Lea (1999) afirma que el enfoque de literacidad académica tiene que ver con las "relaciones sociales que rodean prácticas particulares de escritura y las instituciones en las que éstas tienen lugar.... [por ello] es necesario considerar el contexto social en el cual los eventos de literacidad están ocurriendo y darse cuenta de los significados que se producen para las personas que estén involucradas en cualquier proceso de lectura y escritura" ${ }^{19}$ (p. 106). Desde esta misma perspectiva, Barton \& Hamilton (2000) también plantean que diferentes prácticas

\footnotetext{
${ }^{19}$ Traducción simple del original en inglés.
} 
de literacidad son dinámicas y cambiantes así como lo son las vidas de las personas y de la sociedad de la cual son parte, además éstas están asociadas a diferentes dominios de la vida, esto es, que las diversas prácticas de cultura escrita son prácticas que las personas realizan según el ámbito en el que se encuentran tales como: la escuela, el hogar, el trabajo, entre otros que forman parte de su vida cotidiana. Así, las acciones y los significados que involucran las prácticas del lenguaje académico dependen directamente del contexto, considerando que "[e]1 lenguaje es contexto, es la arquitectura de la conducta social en sí misma, y por tanto, parte de la estructura social y de las relaciones sociales" (Blommaert \& Jie, 2010, p. 7).

Concretamente en el escenario académico universitario, las prácticas del lenguaje académico, tanto oral como escrito, son diversas y distintas, aunque se encuentren en un mismo ámbito o dominio. De esta manera, "no todos los textos que se escriben en la universidad comparten las mismas finalidades ni responden a las mismas situaciones académicas" (Camps y Castelló, 2013, p. 24). De hecho, “el desarrollo del lenguaje se caracteriza por una diferenciación creciente, según los contextos y tareas concretos. Diferentes contextos requieren accesos a registros lingüísticos específicos para su funcionamiento adecuado o satisfactorio" (Cummins, 2002, p. 71). Esto es porque cada disciplina, comunidad discursiva o comunidad de práctica (Johns, 1997) posee características particulares por lo que cada práctica del lenguaje solo tiene sentido en el ámbito donde surge.

De esta manera, es muy importante tomar en cuenta el contexto donde se produce una situación comunicativa para poder comprender el tipo de texto que se está construyendo. Esta idea implica que los contextos son cambiantes y dinámicos, sobre todo porque los contextos universitarios cada vez más se caracterizan por tener una mayor diversidad lingüística y cultural que de alguna manera permea los usos y las prácticas del lenguaje académico. Así, "[1]a realidad empírica de la comunicación intercultural muestra un gran aumento de su presencia en la educación superior contemporánea y, paulatinamente, comienza a ser concebida como un importante motor de cambio, aunque no planificado, en el plano pedagógico (Muñoz, 2013, p. 6). En este sentido, los espacios universitarios son cada vez más espacios multiculturales y multilingües donde se aloja un gran número de estudiantes con características sociales, culturales, lingüísticas, económicas y académicas diversas, lo cual 
La textualidad académica de estudiantes de origen indígena en estudios de posgrado: el proceso de elaboración de tesis

matiza el terreno universitario, pero también lo vuelve mucho más complejo, aspecto que una práctica social académica del lenguaje académico no debe obviar.

Otro aspecto fundamental que está relacionado con el planteamiento anterior y el uso del lenguaje académico como práctica social debe considerar es al estudiante como actor principal en los procesos de enseñanza y aprendizaje del lenguaje académico, así como las formas de revisión y evaluación del mismo. Tomar en cuenta al autor o lector de un texto implica considerar, desde la perspectiva de la literacidad académica, su identidad, su cultura, su trayectoria académica, las nociones y significados que el alumno tiene respecto a la litercidad académica como práctica social académica, el tipo de relación que establece con la universitaria, considerando que las instituciones son espacios de poder donde las prácticas académicas toman lugar. En otras palabras, el sujeto que aprende, desde la visión de la literacidad académica, desarrolla diversas acciones académicas, textuales y conversacionales que están incrustadas en principios epistemológicos construidos socialmente y tiene que ver con el conocimiento, con las formas en que la gente aborda la lectura y escritura y cómo éstas están enraizadas en formas particulares de concebir el conocimiento, la identidad y de comprender el mundo (Lea \& Street, 1998; Street 1993, 2003).

Específicamente, no es factible asumir que un estudiante tiene la responsabilidad total del desarrollo de su propio lenguaje académico, por el contrario, es necesario estar conscientes y hacer consciencia de que el alumno ingresa a una nueva cultura, pero también llega con una cultura propia, con un bagaje de conocimientos que puede contribuir a su acercamiento al ámbito académico, es importante, como profesores conocer a nuestros estudiantes, cuáles con sus fortalezas y qué habilidades podemos desarrollar con ellos. No es viable revisar o evaluar un texto o una participación de ellos sino sabemos quiénes son.

Los aspectos explicados anteriormente son sólo algunos de muchos otros factores que un enfoque de literacidad como práctica social académica debe considerar. Sin embargo, los ya mencionados dan posibilidades para enriquecer la mirada respecto a la gran diversidad de prácticas académicas del lenguaje en el contexto universitario. Por un lado, no se puede obviar la presencia de un sistema, de una estructura como lo es el carácter relativamente estable de la cultura académica que rige las distintas formas de aprender, abordar, enseñar, revisar y evaluar el lenguaje académico. Es necesario conocer que existen formas preestablecidas de utilizar el 
lenguaje, sobre todo su uso textual, por ejemplo, cuando se trata de hacer una tesis, se tiene una idea general de lo que es una tesis y lo que implica tanto académica como socialmente.

No obstante, es preciso reconsiderar que ese mismo sistema o estructura simbólica que rige hasta cierto grado las normas y prácticas académicas también tiene cierta flexibilidad porque las mismas prácticas académicas varían de un contexto a otro. Por ello, el contexto es fundamental para poder comprender el tipo de situación comunicativa que se esté dando, el tipo de texto que se esté solicitando, y comprender entonces el uso específico del lenguaje académico. De ahí que el rol del estudiante sea central en el desarrollo de la práctica académica porque él o ella no juega un papel pasivo en la construcción de textos o en sus manifestaciones académicas conversacionales. Por el contrario, el estudiante es el actor principal en las acciones académicas en el nivel superior, su rol es totalmente dinámico y, por tanto, es el estudiante el que otorga en gran parte posibilidades de transformar o modificar las distintas formas de leer, escribir y comunicarse académicamente, con el apoyo principalmente del profesorado y la institución universitaria.

Esto es posible tomando en cuenta que la cultura académica en el nivel superior posee también un carácter cambiante que da cabida para que todos los actores que participan en ella tengan posibilidades de construir nuevas formas y usos del lenguaje académico, de abonar y enriquecer a las que ya existen, siempre intentando dotar al estudiante de herramientas y experiencias textuales que sean relevantes tanto para su vida académica y profesional dentro de las aulas, así como para su vida futura fuera de los escenarios escolares.

Esta combinación de cierta estabilidad, pero también de flexibilidad proporciona una mirada mucho más compleja pero también más crítica de la cultura académica, la cual ya no se reduce a solo un proceso de aculturación por el que tiene que pasar el estudiante, sino que se resinifica a partir las acciones de los sujetos involucrados en ella, creando posibilidades de reestructurar, reorganizar e incluso modificar las practicas del lenguaje académico. Así, tanto la mirada desde el paradigma de socialización académica como el de literacidad académica enriquecen una visión que es necesaria para observar las prácticas textuales académicas y considerar al lenguaje académico como una práctica social académica. 


\section{Conclusiones específicas}

En suma, es importante mencionar que en las instituciones mismas permean ciertas nociones de lo que es e implica el lenguaje académico, particularmente, el lenguaje académico escrito. Dichas nociones descansan en alguno de los tres paradigmas que Lea y Street (1998) identifican que coexisten en el ámbito universitario, ya que la textualidad académica en nivel superior, licenciatura y posgrado, no puede obviar las reglas y convenciones linguiísticas de una lengua, porque éstas son necesarias para la cohesión y comprensión de dicho texto, ni tampoco las distintas convenciones del lenguaje académico, ya que son importantes aprenderlas y comprenderlas para hacer buen uso de ellas, tomando en cuenta que dichas prácticas están legitimadas por la cultura académica misma y en este escenario no es posible ignorarlas. Sin embargo, tampoco puede quedar de lado el sujeto que aprende, su contexto, ni las relaciones de poder que se manifiestan entre él o ella y el profesor y con la institución formadora, ya que tanto el sentido como el significado de las distintas prácticas de textualidad académica dependerán desde dónde se posicione el lector o evaluador del texto.

En este escenario complejo y de tensión se encuentra la tesis como uno de los textos más complejos inserto en una cultura académica que norma gran parte de las formas en que se concibe y se lleva a la práctica, donde el proceso de elaboración de una tesis implica necesariamente transitar por procesos formativos de socialización disciplinaria y de profesionalización para tener acceso a la cultura académica, así como el uso de un lenguaje académico mucho más técnico como una exigencia más de dicha cultura académica. Sin embargo, las discusiones teóricas abordadas, donde se considera el lenguaje académico como una práctica social académica, contribuyen a mirar y actuar de una manera más crítica y reflexiva los procesos de enseñanza y aprendizaje, revisión y evaluación de las diversas prácticas textuales que día a día enfrentan los estudiantes en el nivel superior. Esta mirada más crítica es la que orienta tanto la ruta metodológica a seguir, así como el análisis posterior para comprender las implicaciones de lenguaje académico en el proceso de elaboración de un proyecto de investigación como lo es la tesis, concretamente en el nivel de posgrado. 


\section{Capítulo II. \\ El análisis cualitativo de contenido: una técnica metodológica para el análisis de la textualidad académica}

A manera de preámbulo, es importante mencionar que analizar las producciones escritas en el ámbito académico en el nivel superior se ha convertido en todo un reto porque existen estudios que han priorizado sobre todo el análisis de aspectos léxicos y morfológicos en los procesos de textualización, algunos desde un enfoque cuantitativo. Por ejemplo, un estudio reciente es el de Hernández Álvarez (2013) centrado en una perspectiva cuantitativa, realiza un análisis sobre la escritura de estudiantes universitarios para evaluar los escritos a partir del número de faltas en las que se incurren, principalmente respecto a cuestiones ortográficas Otro estudio similar realizado es el de Hernández Ramírez (2015) cuya metodología combina tanto lo cuantitativo como lo cualitativo porque en esta investigación se analizan aspectos ortográficos pero también se abordan cuestiones como el diseño del texto y las fases de redacción.

En el ámbito académico superior también se manifiestan estas miradas que hasta cierto punto se han naturalizado, ya que cuando se evalúa un texto, generalmente se queda en un nivel de las características superficiales del texto que involucran aspectos ortográficos, morfológicos, de puntuación, e incluso de caligrafía. De hecho, en mi experiencia en el desarrollo de esta investigación me enfrenté a esta forma de mirar textos académicos, ya que inicialmente, mis intentos metodológicos también se quedaban en este nivel. Por ello, decidir la metodología más adecuada para el análisis textual que trascendiera esta perspectiva fue todo un reto, considerando que mi propósito en esta investigación no es calificar los performances textuales, sino tener una visión diagnóstica general del estado en que se encuentra esta práctica de la escritura académica en el proceso de construcción de una tesis de grado. Entonces, este proceso implicó tanto en mi investigación como en mí como investigadora, una transición de pasar de una mirada que se quedaba en la superficie del texto, a una forma más relacionada 
La textualidad académica de estudiantes de origen indígena en estudios de posgrado: el proceso de elaboración de tesis

con la lógica conceptual de cómo los sujetos investigados desarrollan sus explicaciones en torno a un conocimiento nuevo.

Por ello, en este proceso de investigación cualitativa, hago una construcción metodológica donde una primera posibilidad fue el análisis cualitativo de contenido, el cual me permite no solo mirar el contenido manifiesto de los textos, sino también el contenido latente de los mismos (Mayring 2000). Para esto, también fue necesario recurrir a los aportes de Maturana (1989) respecto a las explicaciones consideradas como una actividad lógica conceptual, que integra una unidad compuesta, esto es, sus componentes y las relaciones que la conforman. Por ello, las explicaciones son la unidad de análisis en este estudio y la base del proceso de elicitación.

Esta construcción metodológica me permitió conocer la lógica y sentido de formular una explicación, es decir, cómo estos estudiantes comunican un conocimiento, a veces nuevo, en sus manuscritos construidos. El punto era conocer y comprender con mayor profundidad la racionalidad de las explicaciones mediante los aportes del análisis cualitativo de contenido en la textualidad académica, lo cual en otros estudios se ha trabajado desde el nivel léxico. Así, el propósito de este capítulo es exponer y explicar esta construcción metodológica en la cual me apoyé para desarrollar el análisis de los materiales recabados.

\subsection{El análisis de contenido en la investigación cualitativa}

El análisis cualitativo de contenido, en sus inicios, fue concebido con una mirada cuantitativa que aún se sigue utilizando, sin embargo, esta metodología recupera varios elementos cualitativos como el contexto, las palabras de los sujetos investigados y sobre todo la mirada inductiva (Bogdan y Biklen, 2007), elemento clave en esta investigación. Desde esta perspectiva, el análisis cualitativo de contenido es bastante útil para el desarrollo del análisis textual ya que me permite analizar los productos escritos elegidos en su contenido manifiesto y latente, y no sólo quedarme en la superficie del texto como se ha indicado.

\section{a) El análisis cualitativo de contenido}


Antes que nada, vale la pena explicar que la metodología del análisis de contenido originalmente fue concebida desde una perspectiva cuantitativa, entre los primeros intentos por definir el análisis de contenido se encuentra Berelson quien sostiene que el análisis de contenido es "una técnica de investigación para la descripción objetiva, sistemática y cuantitativa del contenido manifiesto de la comunicación" (Berelson, 1952, citado en Andréu, 2000, p. 2), con lo cual queda evidente la visión cuantitativa que ha caracterizado al análisis de contenido.

No obstante, llega después una mirada más abierta de lo que es el análisis de contenido, cuando Bardin lo define como "el conjunto de técnicas de análisis de las comunicaciones tendentes a obtener indicadores (cuantitativos o no) por procedimiento sistemáticos y objetivos de descripción del contenido de los mensajes permitiendo la inferencia de conocimientos relativos a las condiciones de producción/recepción (contexto social) de estos mensajes" (Bardin 1996, citado en Andréu, 2000, p. 3). En esta definición se mantienen los rasgos de objetividad y sistematicidad pero se añaden otras posibilidades cuando el autor refiere a que los indicadores pueden ser cuantitativos o no. De esta posibilidad, aparece el enfoque cualitativo del análisis de contenido el cual "se define a sí mismo... como una aproximación empírica, de análisis metodológicamente controlado de textos al interior de sus contextos de comunicación, siguiendo reglas analíticas de contenido y modelos paso a paso, sin cuantificación de por medio" (Mayring 2000, citado en Cáceres, 2003, p. 56), donde el texto, el contexto y el carácter interpretativo cobran fuerza para el desarrollo del análisis cualitativo de contenido.

Esta mirada cualitativa del análisis de contenido es la que orienta esta investigación porque éste consiste en todo un conjunto de técnicas sistemáticas e interpretativas del sentido oculto de los textos (Andréu, 2000). Como se ha referido, algunos de los propósitos del análisis de contenido es denotar tanto el contenido manifiesto como el contenido latente de los datos analizados. Lo importante de mirar dicho contenido es encontrar aspectos comparativos que den cuenta de la lógica de la explicación académica, agrupando dichos aspectos de forma sucesiva hasta llegar a la conceptualización, o bien, integrar dichos datos en interpretaciones o abstracciones de mayor nivel que permitan establecer conexiones entre los temas de análisis y de éstos con la teoría previa (Cáceres, 2003). 
La textualidad académica de estudiantes de origen indígena en estudios de posgrado: el proceso de elaboración de tesis

Así, el análisis cualitativo de contenido es una estrategia metodológica que permite interpretar no sólo lo que se encuentra manifiesto en el texto analizado, sino, sobre todo, llegar a interpretar el contenido latente en el texto, tomando en cuenta el contexto donde se emite el mensaje. Para esto, se asume una mirada inductiva para el desarrollo de categorías, ya que “desde la perspectiva del análisis de contenido cualitativo es central el interés por el desarrollo de categorías tan cerca como sea posible del material a interpretar" (Andréu, 2000, p. 23).

De esta manera, el análisis cualitativo de contenido ha sido de gran utilidad para revisar los materiales recabados y para llegar a conocer la textualidad académica de los sujetos investigados, concretamente cómo organizan sus argumentos y estructuran sus explicaciones en torno al planteamiento de una problemática, partiendo principalmente de las explicaciones como unidad de análisis, la cual se explica más adelante, y que dio pie al desarrollo del proceso metodológico en esta investigación.

\subsection{El proceso metodológico de análisis cualitativo de contenido}

Como se mencionó anteriormente, el análisis cualitativo de contenido descansa sobre las características de la investigación cualitativa mencionadas previamente, pero manteniendo el rigor científico, de donde Cáceres (2003, respaldado en Mayring, 2000) propone un procedimiento que soporta, pero también enriquece esta técnica metodológica en la que me apoyo para el desarrollo del análisis posterior. El proceso de aplicación de esta técnica implicó el desarrollo de distintos momentos, considerando que la intención de este estudio es hacer un análisis longitudinal. No obstante, este proceso no se dio de forma secuencial, sino que fue un ir y venir entre una parte y otra, con el fin de pulir lo más posible el camino metodológico a seguir en la investigación.

Lo anterior significa que formalmente hay una secuencia lógica para presentar el proceso y los resultados de la investigación, la cual es la perspectiva institucional formadora, es decir, hay una progresión secuencial necesaria para cubrir los requerimientos institucionales. Sin embargo, en la práctica, dicha secuencia no se da como tal, sino, como lo mencioné, es un ir y venir constante entre la conceptualización básica, el proceso de elicitación y la interpretación, cuya integración apunta a la comprensión del objeto de estudio como eje medular de esta investigación. En otras palabras, la articulación de estos tres 
elementos crea una especie de amalgama que provoca un efecto acumulativo para conocer y comprender el objeto de estudio. Entonces, dichos elementos no se pueden mirar de forma aislada, sino como un todo integral que le dan sentido al fenómeno estudiado.

\subsubsection{Caracterización del estudio: los sujetos y obtención del dato empírico}

Esta investigación toma como base la producción escrita de estudiantes del Programa de Maestría en Sociolingüística de la Educación Básica y Bilingüe, de la Universidad Pedagógica Nacional, Unidad 201, Oaxaca, México, programa que atiende a una diversidad de maestrantes cuyo producto final de titulación es el desarrollo de una tesis para la obtención del grado. De un grupo de estudiantes se eligieron nueve de ellos para revisar sus manuscritos. Estos alumnos, ahora egresados de dicho programa de posgrado, son profesores de educación básica, en su mayoría del nivel de primaria general e indígena. Se caracterizan por ser de origen indígena, donde varios de ellos hablan una lengua indígena, entre las que se identifican está el zapoteco de la sierra sur, el zapoteco de la sierra norte, el zapoteco de valles centrales, y el mixe. Otros son hablantes monolingües en español.

Cabe precisar que el carácter de origen indígena no es determinante en esta investigación, más bien, es una característica del perfil sociocultural de dichos alumnos, es decir, que, por el contexto oaxaqueño con una gran diversidad cultural, es arriesgado definir, sin una apropiada investigación, quién tiene una ascendencia indígena, tomando en cuenta que la lengua no es el único elemento que define la identidad de una persona. Además, por las características de este estudio, desde la perspectiva de textualidad, la cuestión de etnicidad no es una variable determinante en el modelo teórico, ya que la pretensión inicial era presentar un desarrollo de las prácticas textuales en el nivel superior con docentes de educación básica y media superior del país, y no solo de Oaxaca, pero el rumbo que tomó la investigación, se decidió considerar solo el contexto oaxaqueño; por lo que el factor de etnicidad no ha sido central en el desarrollo de esta investigación. Entonces, considero que el perfil lingüístico de los sujetos investigados es importante mencionarlo como un rasgo interviniente $\mathrm{y}$ caracterizador inicial de los estudiantes y como un referente contextual para el desarrollo de este estudio únicamente. 
La textualidad académica de estudiantes de origen indígena en estudios de posgrado: el proceso de elaboración de tesis

Para poder realizar el estudio longitudinal era necesario recuperar los manuscritos en al menos tres fases, una inicial, intermedia y otra final, con el fin de mirar las características propias de cada etapa y lo posibles cambios que se manifestaran en cada una ${ }^{20}$. En la fase inicial se recuperaron los anteproyectos de investigación que los sujetos investigados presentaron cuando aún eran aspirantes al programa de posgrado, materiales que fueron el punto de partida para el análisis longitudinal. Después se recuperaron los protocolos de investigación que los sujetos, siendo ya estudiantes de posgrado, construyeron a un año de su proceso de inmersión a dicho programa. Finalmente, para la fase tres se solicitaron los borradores finales que presentaron al finalizar sus estudios de posgrado. La diversidad de materiales que se obtuvo fue bastante rica porque permitió tener un abanico de posibilidades para seleccionar los documentos más significativos para el análisis textual; no obstante, también demandó una revisión cuidadosa para construir el corpus de datos, el cual fue el siguiente paso.

\subsubsection{Una etapa de preanálisis: construcción del corpus de datos}

La etapa del preanálisis es un primer acercamiento a los materiales, es lo que Bardin denomina "un periodo de intuiciones. Pero que tiene como objetivo la operacionalización y la sistematización de las ideas de partida para poder llegar a un sistema preciso de desarrollo de las operaciones sucesivas, a un plan de análisis" (Bardin, 1996 citado en Porta \& Silva, 2003), donde un primer paso es precisamente la elección de los materiales, lo cual se fue dando por etapas, porque debido a la intención de desarrollar un estudio longitudinal fue necesario "estar" en el campo para darle seguimiento a los avances que iba presentando cada uno de los estudiantes seleccionados para el desarrollo de esta investigación. Entonces, los materiales no se obtuvieron de forma conjunta ni simultánea, sino que se fueron recuperando poco a poco durante el proceso de construcción de tesis que siguieron los estudiantes investigadores. Esto implicó revisar los textos de los estudiantes en varios momentos de forma metódica y sistemática de manera que los materiales quedaran lo mejor organizados posibles y así poder decidir con cuál de ellos trabajar partiendo en principio de mis "intuiciones".

\footnotetext{
${ }^{20}$ Para esto, fue necesario recuperar distintos borradores a lo largo del proceso de construcción de la tesis que se estaba desarrollando, para lo cual contacté a los nueve estudiantes inmersos en el programa de maestría referido para pedirles su apoyo en proveerme de copias de sus avances en torno a la investigación que cada uno estaba desarrollando, para lo cual no hubo ninguna objeción.
} 
Lo anterior derivó en el desarrollo de varios ensayos que me permitieran caracterizar de forma muy general los manuscritos para elegir aquellos que manifestaran rasgos coincidentes en el proceso de construcción de una tesis. Así, el objetivo de esta etapa era construir un corpus de datos general, mediante la revisión constante de los materiales, no obstante, era necesario delimitarlo aún más para orientar mejor el análisis. Por ello, a la par, fui buscando un elemento primordial que no sólo concretara aún más el corpus general, sino también definiera la dirección que tomaría el análisis cualitativo de contenido de los materiales seleccionados, me refiero a la unidad de análisis.

\subsubsection{Las explicaciones como unidad análisis}

Como ya lo he mencionado, las explicaciones que construyen los sujetos investigados para plantear una problemática en los productos escritos analizados, conforman la unidad de análisis en este estudio y la base principal en el proceso de elicitación, por lo que es preciso, en primer lugar, exponer de forma breve la naturaleza de las explicaciones desde la perspectiva de Maturana (1989).

\section{a) La naturaleza de las explicaciones}

Primeramente, este autor parte de la idea de que la explicación involucra una pregunta, donde la respuesta a dicha pregunta es precisamente la explicación. Pero esta explicación a su vez implica lo que él llama una "conducta adecuada", es decir, una conducta que el interrogador acepta como apropiada, la cual es una forma de evaluar el conocimiento, ya que, si la respuesta o explicación a la pregunta es satisfactoria, entonces se acepta como una conducta adecuada. De esta manera, según Maturana la conducta adecuada es una expresión del conocimiento. Esto es, considerando que la explicación implica una conducta adecuada y ésta es una expresión del cocimiento, significa entonces que a través de las explicaciones manifestamos nuestro conocimiento respecto a algo.

No obstante, esto no es nada simple, porque el gran reto es identificar "la conducta adecuada" y cómo surge ésta, lo cual la convierte en lo que Maturana define como una “explicación científica", que implica la propuesta de un mecanismo que genera el fenómeno que se desea explicar. Para esto, primero se observa el fenómeno que se desea explicar, que es 
La textualidad académica de estudiantes de origen indígena en estudios de posgrado: el proceso de elaboración de tesis

la pregunta, lo cual generaría una explicación científica puesto que se inserta dentro de un campo de conocimiento específico. Las explicaciones generadas tendrían que proponer un mecanismo del fenómeno estudiado, pero también otros que pueden observarse (Maturana, 1989, pp. 65-66).

Entonces, para poder desarrollar una explicación, y conocer cómo surge una "conducta adecuada" primero es necesario distinguir una unidad simple y una unidad compuesta que son constituyentes de la conducta adecuada $\mathrm{y}$, por ende, de la explicación científica. Maturana afirma que cada vez que distinguimos algo como un todo y no lo descomponemos en partes, lo distinguimos como una unidad simple, donde el funcionamiento de la distinción indica las propiedades que caracterizan la unidad simple. (pp. 67-68). Por otro lado, las unidades compuestas, es cuando la unidad simple se descompone en las partes que la integran.

Al respecto, Maturana menciona que cuando la unidad distinguida es simple, la tarea es simple. Se especifican las propiedades y eso es suficiente. Pero cuando la unidad distinguida es compuesta, hay un problema con sus componentes, con sus relaciones (68-69). Entonces, para superar este problema, él distingue dos características de las unidades compuestas: una tiene que ver con la organización y la otra con la estructura de las unidades compuestas.

La organización refiere a las relaciones entre los componentes que hacen que la unidad sea lo que uno afirma que es (p. 68). En otras palabras, la organización hace alusión a la correspondencia que hay entre las partes de conforman una unidad. Por ejemplo, los elementos que hacen que una explicación sea una explicación y no otra cosa, como un lema o una instrucción. Esta organización según Maturana es invariable porque si la organización cambia, entonces la unidad cambia también, y se convierte en otra cosa diferente, retomando el mismo ejemplo, si la organización de una explicación cambia, tal vez sería una instrucción y dejaría de ser explicación.

No obstante, Maturana afirma que lo que sí puede cambiar es la "estructura" de la unidad compuesta, la cual es la segunda característica que Maturana identifica, que refiere a los componentes y las relaciones que forman parte de una determinada unidad. Así, las unidades compuestas tienen la misma organización, pero una estructura distinta. De modo que la organización es invariable y es común a todos los miembros de una clase determinada de 
unidades compuestas, pero la estructura siempre es individual. Esto significa que la organización de una unidad hila las partes de dicha unidad mediante una estructura que es flexible y variable. Entonces, la organización se mantiene, pero la estructura cambia continuamente.

Esta perspectiva de Maturana complejiza la naturaleza de las explicaciones, concretamente, las científicas. Sin embargo, proporciona aportes importantes para el entendimiento de lo que es una explicación, así como sus implicaciones. De este modo, las explicaciones como unidades compuestas, se retoman como la unidad de análisis en esta investigación como se explica a continuación.

\section{b) La unidad de análisis: las explicaciones}

Considerando que las explicaciones implican una conducta adecuada y que ésta, a la vez, es una expresión del conocimiento (Maturana, 1989), entonces, las explicaciones se convierten en la unidad de análisis de este estudio, ya que me interesa conocer cuál es la lógica de la explicación que manifiestan los textos revisados respecto al planteamiento de una problemática, pregunta que genera la explicación e implica posiblemente una conducta adecuada. En esta lógica, y para efectos de esta investigación, las explicaciones se convierten en una oportunidad para conocer el conocimiento que los sujetos investigados manifiestan respecto a su conocimiento, tal vez nuevo, sobre la problemática que plantean para el desarrollo de su investigación.

Retomando los argumentos de Maturana, la conducta adecuada es, una explicación satisfactoria dentro del contexto en donde se produce, la cual se caracteriza por implicar no sola una unidad simple, sino sobre todo unidades compuestas que se identifican a través de dos características importantes, que es la organización y las estructura. Por ello, para esta investigación, el punto central era identificar las explicaciones como unidades compuestas, es decir, cómo está organizada y qué estructura manifiesta, considerando que éste último elemento es variable.

El reto, como dice Maturana es dar cuenta de cómo surge la "conducta adecuada" que constituye una explicación científica con el fin de caracterizar la lógica para explicar un conocimiento, en este caso respecto al planteamiento de un problema de investigación. De esta 
La textualidad académica de estudiantes de origen indígena en estudios de posgrado: el proceso de elaboración de tesis

manera, las explicaciones como unidades compuestas son la base del proceso de la elicitación en este estudio.

Desde esta perspectiva de las "explicaciones científicas" se revisaron los materiales recabados y se identificaron dichas explicaciones que los autores investigados hacían para plantear su problema de investigación, desde una visión ampliada de la problemática, es decir, que esta mirada implica el problema a investigar en sí mismo, los objetivos de la investigación, así como los conceptos técnicos en los que se apoyan los investigadores para explicar el fenómeno a investigar. Así las “explicaciones”, como una unidad de análisis, representan los segmentos del contenido del texto que pueden ser caracterizados e individualizados para posteriormente categorizarlos, relacionarlos y establecer inferencias a partir de ellos, es decir, es el alimento informativo para procesar la información (Cáceres, 2003).

Entre sus características encontradas en los manuscritos, es que las explicaciones muestran la forma en que los investigadores hacen mención respecto a un asunto con la intención de que dicho asunto se haga más perceptible, en este caso en relación a un problema de investigación. Otro rasgo de la "explicación" como unidad compuesta de análisis, es que, en términos generales, manifiesta un inicio, un desarrollo y un cierre, lo cual permite identificar cualidades específicas en esos tres momentos, aunque como se verá en el capítulo de análisis, se encuentran explicaciones que no mantienen totalmente esta estructura, puesto que ésta es cambiante. Finalmente, las explicaciones tienen la particularidad de ser variables, en extensión, ya que pueden conformar un sólo párrafo o un conjunto de ellos, dependiendo del asunto que se desea explicar. Es decir, las explicaciones como unidad de análisis conforman únicamente los extractos necesarios para desarrollar el análisis textual, sin embargo, estos fragmentos son suficientes para proveer un panorama general del proceso de textualización y construcción de una tesis en el nivel de posgrado.

Así, esta construcción metodológica que combina tanto la naturaleza de las explicaciones científicas de los estudiantes investigados, así como los aportes del análisis de contenido para llegar a identificar y conocer el contenido latente de los productos escritos analizados, han sido cruciales para conocer con mayor precisión la lógica de la explicación de los sujetos investigados. 
Una vez decidida la unidad de análisis se fue conformando un corpus de datos por cada uno de los elementos que comprende la visión ampliada de la problemática en sus tres fases, es decir, el problema a investigar, los propósitos de la investigación y los conceptos técnicos implicados, quedando un corpus más delimitado para el desarrollo del análisis textual, para lo cual fue necesario construir un modelo de análisis.

\subsubsection{El modelo de análisis textual}

Uno de los pasos fundamentales en el análisis cualitativo de contenido es el establecimiento de reglas de análisis, pero por su carácter cualitativo, estas reglas son flexibles y abiertas a modificaciones según la manera en que el material es procesado y las propias necesidades de la investigación (Cáceres, 2003). Por ello, en esta etapa, se decidió por la construcción del modelo de análisis que estableciera dichas reglas mediante criterios definidos que orientaran el rumbo del análisis con base en el corpus construido. Para esto se tomo como base la naturaleza de las explicaciones científicas propuesta por Maturana (1989), en la idea de encontrar elementos que me permitieran analizar dichas explicaciones para conocer el ciclo de la lógica conceptual que los estudiantes muestran en sus argumentaciones.

Este proceso nuevamente fue un ir y venir de revisión de posibilidades para elaborar una propuesta que mantuviera esta mirada de la explicación, pero también que no se quedara en la superficie del texto ${ }^{21}$. Después de varios intentos, finalmente, logré diseñar un modelo de análisis que recupera los aportes de Street (2009) y Labov (2013). En un estudio realizado con estudiantes de doctorado en una clase de literacidad académica, Street (2009) identifica algunas características 22 "ocultas" que subyacen en los capítulos de un libro editado, tales como: el marco comunicativo, las contribuciones o aportes del autor, la voz y postura, así como, señalizaciones y la estructura. Por su parte, Labov (2013) hace un estudio sobre el análisis de narrativas ${ }^{23}$, donde identifica elementos que evidencian su estructura, éstos son: abstract o resumen, orientación, complicación, evaluación, resolución y coda.

\footnotetext{
21. Esta fase tomó un tiempo considerable, ya que, incluso, diseñé un modelo de análisis que no tuvo éxito porque precisamente enfatizaba los aspectos léxico y morfológico de los datos.

${ }^{22}$ Estas características se basan totalmente en el estudio de Street (2009) que originalmente está en inglés. La traducción simple del mismo es mía.

${ }^{23}$ Aclaro que el texto de Labov (2013) es de otra naturaleza, mi estudio difiere en gran medida de lo que el desarrolla en su investigación. No obstante, recuperé algunos de sus aportes que me han ayudado para construir el
} 
La textualidad académica de estudiantes de origen indígena en estudios de posgrado: el proceso de elaboración de tesis

Estos estudios analizan textos muy diferentes, el primero estudia los capítulos de un libro editado y el segundo analiza la estructura narrativa. No obstante, ambos permiten mirar los textos de una manera más integral, es decir, estos estudios muestran una forma distinta del análisis textual porque los criterios a los que recurren comparten rasgos que interpretan no solo las características manifiestas en los textos, sino, sobre todo, aspectos que subyacen en el "fondo" de dichos textos, es decir, sus rasgos "ocultos". Esto evidencia la complejidad que involucra los textos académicos, pero al mismo tiempo, estos estudios aportan elementos muy significativos y bastantes útiles para el análisis textual desde una perspectiva integral del texto como unidad comunicativa, ya que proponen esquemas interpretativos para el análisis textual, de los cuales elegí los siguientes considerando las necesidades de la investigación. Principalmente, opté por aquellos elementos que se acercaran lo más posible analizar la lógica de la explicación, y los cuales adapté para analizar los materiales recabados en este estudio. Estos elementos son:

- Orientación, para esta investigación se identifican dos modalidades, una es contextual y la otra disciplinar. La primera contiene información respecto al tiempo, lugar, las personas, elementos que proveen información adicional sobre el asunto a explicar. La orientación disciplinar tiene que ver con el campo disciplinar al cual se afilian los autores. Algunas de cláusulas utilizadas en esta orientación incluyen usualmente verbos de estado como "ser", "estar" o "tener".

- Estructura, en general, se refiere a las características de organización del texto que se toman en cuenta para estructurarlo, en este caso refiere a la estructura de la explicación, donde una de las características es tematizar los apartados o subapartados que integren la explicación si fuera el caso, ya que, aunque existan ciertos elementos necesarios en un texto, también es posible que el autor lo organice de una forma más personal. Otra característica es que la estructura generalmente incluye una apertura donde se presenta el contenido del texto, un desarrollo que es una especie de plot donde se desarrollan los argumentos, y un cierre donde usualmente se plantean las conclusiones a las que se llega. No obstante, la estructura de la explicación puede variar e incluir elementos más precisos de la explicación.

modelo de análisis de mi investigación, pero que no es mi intención, bajo ninguna circunstancia analizar narrativas. 
- Voz, se refiere a "la capacidad del autor en hacerse entender como un sujeto situado" (Blommaert, citado en Street, 2009, p. 12) con el fin de establecer quién es él o ella en el texto. No es sólo una cuestión de presentar datos e información de una forma supuestamente objetiva, sino plasmar su propia voz en el texto.

- Señalización, tiene que ver con hacer referencia sobre un mismo argumento durante todo el documento, utilizando algunas veces los mismos términos, bajo el riesgo de caer en la repetición. Sin embargo, estas repeticiones léxicas y discursivas ofrecen al lector señalamientos que lo van guiando a través del texto con lo cual él o ella puede tejer las ideas y argumentos complejos a lo largo del texto.

- Evaluación es una apreciación global de la explicación mediante frases, un resumen breve o señalizaciones discursivas.

- Coda es el elemento que finaliza la explicación, se compone de una o dos cláusulas que le dan fin a la secuencia explicativa.

- Contribución o aportes del autor es donde se espera que el autor del texto añada sus aportes personales a lo que ya es conocido y no sólo trate de resumirlo. Es una contribución de la pieza de escritura, ya sea un conocimiento, a un nuevo campo o a futuras direcciones o investigaciones.

Estos elementos han sido de gran relevancia para el desarrollo metodológico. Sin embargo, enfatizo el elemento de "señalizaciones" puesto que se convierte en una estrategia a la que más recurren los autores de los textos revisados en sus argumentos. Las señalizaciones son un elemento que utiliza Street (2009) para analizar las características ocultas que subyacen en los capítulos de un texto editado. Estas "señalizaciones" son palabras, frases o expresiones que se repiten en diversos momentos de un texto o parte de él y que van orientando al lector hacia el propósito que desea llegar el autor de texto. Éstas pueden ser de repetición léxica cuando refieren a vocablos específicos, o de repetición discursiva cuando se refieren a frases, expresiones o argumentos que se repiten de forma literal, mediante sinónimos, o con un sentido similar.

Por ejemplo, cuando los autores de los textos analizados intentan plantear su problemática, recurren al vocablos o frases que mencionan en varios momentos de su explicación para mostrar la existencia de un problema que ellos identifican. Aunque, en 
La textualidad académica de estudiantes de origen indígena en estudios de posgrado: el proceso de elaboración de tesis

algunos casos se hace un uso excesivo de estos vocablos y expresiones, lo cual repercute en la forma en cómo los autores de los textos plantean sus argumentos. Así, las señalizaciones de repetición léxica o discursiva es una estrategia que no sólo guían al lector hacia la evidencia de un problema, sino, sobre todo, son de gran aporte para mí como investigadora para conocer las formas en que los sujetos investigados desarrollan su explicación.

Estas señalizaciones de repetición léxica y discursiva, al igual que lo otros elementos identificados, se traducen en el siguiente cuadro que manifiesta el modelo de análisis construido.

\begin{tabular}{|c|c|c|c|}
\hline \multicolumn{4}{|c|}{$\begin{array}{l}\text { Objeto de investigación: La tesis de grado, el proceso de elaboración de un proyecto de investigación en } \\
\text { tres fases (inicial, intermedia, final) }\end{array}$} \\
\hline \multicolumn{4}{|c|}{$\begin{array}{l}\text { Metodología: El análisis cualitativo de contenido y los aportes de Street (2009) y Labov (2013) para la } \\
\text { construcción de este modelo de análisis }\end{array}$} \\
\hline $\begin{array}{l}\text { Unidad de } \\
\text { análisis }\end{array}$ & Criterios & & Descripción \\
\hline \multirow{4}{*}{$\begin{array}{l}\text { Explicaciones } \\
\text { sobre el } \\
\text { problema de } \\
\text { investigación } \\
\text { (Una visión } \\
\text { ampliada de la } \\
\text { Problemática: el } \\
\text { problema, los } \\
\text { objetivos de la } \\
\text { investigación y } \\
\text { conceptos } \\
\text { técnicos) }\end{array}$} & \multirow[b]{2}{*}{ Orientación } & Contextual & $\begin{array}{l}\text { Son frases que orientan al lector sobre el espacio, tiempo o } \\
\text { lugar de donde parte la investigación. Y generalmente se } \\
\text { utilizan verbos de estado "ser, "estar", "tener". }\end{array}$ \\
\hline & & Disciplinar & $\begin{array}{l}\text { Son frases que el autor utiliza para mostrar a qué campo } \\
\text { disciplinar se afilia o del cual intenta partir para el desarrollo } \\
\text { de su investigación. }\end{array}$ \\
\hline & \multirow{2}{*}{ Estructura } & Apertura & $\begin{array}{l}\text { Es una especie de abstract que da inicio a la explicación e } \\
\text { informa de manera muy general lo que se pretende } \\
\text { desarrollar en la explicación. La apertura puede ser de forma } \\
\text { personal, impersonal e incluso más académica cuando se } \\
\text { recurre a algún pensamiento de un campo disciplinar. }\end{array}$ \\
\hline & & Desarrollo & $\begin{array}{l}\text { Es una especie de "plot" donde el autor se vale de distintas } \\
\text { estrategias para desarrollar sus argumentos en las } \\
\text { explicaciones a analizar. Las estrategias no están definidas a } \\
\text { priori al análisis pero algunas se pueden relacionar con } \\
\text { alguno o algunos de los ejes de análisis que se describen en } \\
\text { este modelo. }\end{array}$ \\
\hline
\end{tabular}




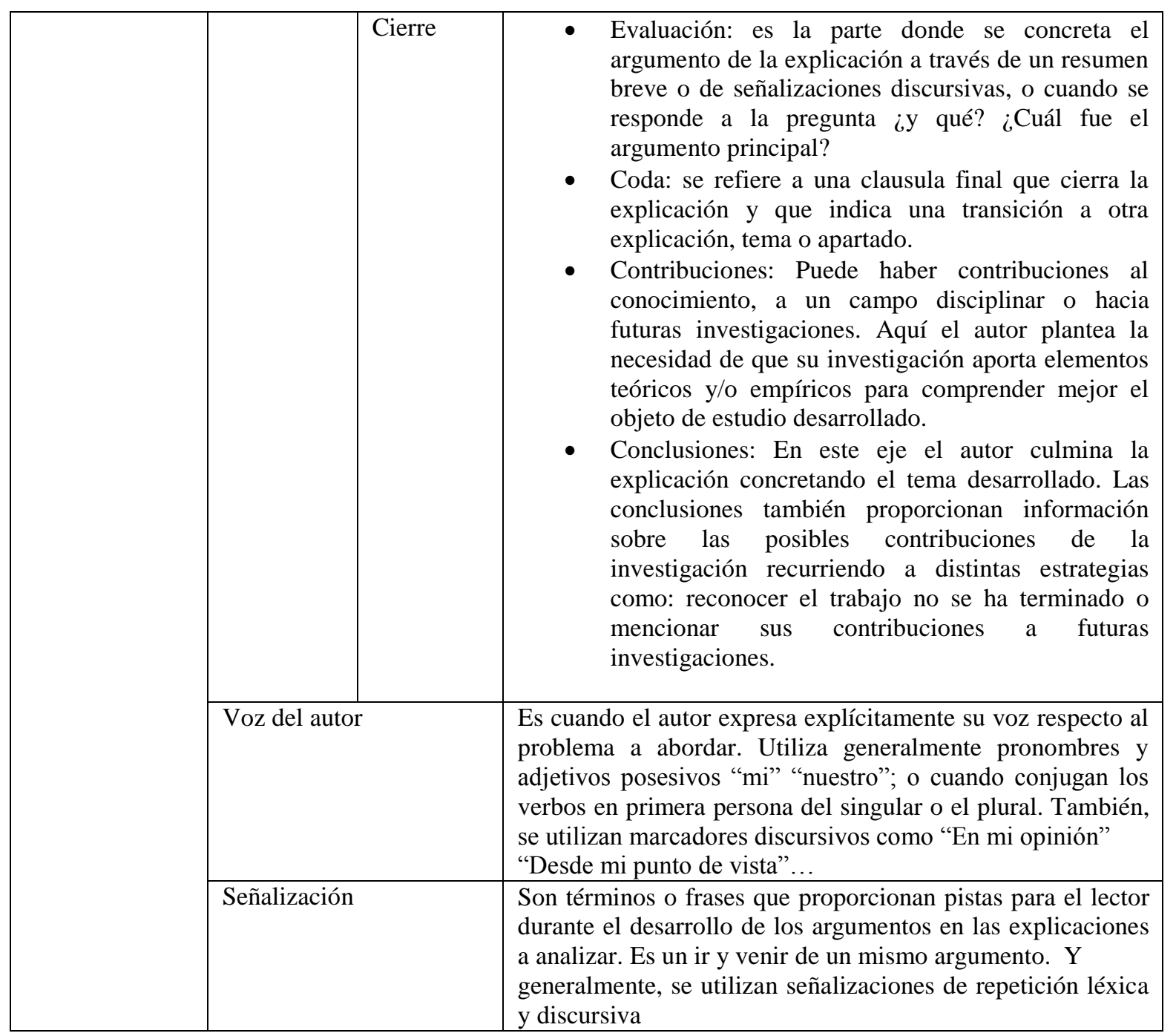

Como se puede observar, este modelo de análisis se construye a partir de los aportes de Street (2009) y Labov (2013), lo cuales adapté para desarrollar el análisis de corpus de datos construido. Este modelo análisis destaca elementos que permiten identificar componentes esenciales de la actividad conceptual que muestran las explicaciones construidas por los estudiantes investigados. En otras palabras, estos elementos son útiles para analizar las explicaciones como la unidad de análisis porque parten desde una perspectiva inductiva e interpretativa, características que comparten ambos estudios. Esta mirada me ayudó a acercarme lo más posible a analizar el corpus de datos construido y conocer la lógica de la explicación que muestran los estudiantes investigados para comunicar lo que saben o aprenden respecto al planteamiento de un problema de investigación. 
La textualidad académica de estudiantes de origen indígena en estudios de posgrado: el proceso de elaboración de tesis

Cabe aclarar que este modelo de análisis es un intento por llegar a explorar la textualidad académica de los estudiantes, por ello, este esquema interpretativo no es obligatorio para analizar cada uno de los casos, sino que se va ajustando a los datos, es decir, los datos nos hablan. Esto con el fin de hacer una revisión de la textualidad académica en estudiantes de posgrado para tener una visión diagnóstica del estado en que se encuentra esta práctica académica tan cotidiana y tan poco problematizada en el nivel superior.

Por tanto, para mirar de una forma más integral los productos escritos revisados, ambos estudios, al igual que los procesos seguidos anteriormente en la etapa de preanálisis y la definición de la unidad de análisis, me han sido de gran utilidad para esta investigación porque éstos son la guía para construir un modelo de análisis que me permita revisar y analizar los productos escritos de algunos estudiantes de posgrado, con el fin de conocer las habilidades textuales que despliegan en sus textos al momento de construir un texto académico, concretamente la elaboración de una tesis.

\section{Conclusiones específicas}

A manera de cierre, en el proceso metodológico se tomó la decisión de partir de las explicaciones que los estudiantes investigados elaboran para plantear su entendimiento o conocimiento respecto a una problemática de investigación, con el fin de conocer la racionalidad de explicar un conocimiento, es decir, cómo dichos estudiantes investigadores comunican lo que saben respecto a un tema. Por ello, las explicaciones son la unidad de análisis y la base del proceso de elicitación de esta investigación.

Otra estrategia metodológica fue recurrir al análisis cualitativo de contenido el cual fue necesario para mostrar no sólo el contenido manifiesto en los materiales revisados, sino, sobre todo, el contenido latente de los mismos. Entonces, partir de estudiar la lógica de la explicación apoyada en el análisis cualitativo de contenido, permitió hacer una exploración más de fondo del corpus recabado y construir un modelo de análisis que me acercara lo más posible a analizar aspectos significativos de la explicación que tienen que ver con cuestiones cognitivas, pero también con procesos de socialización disciplinaria. 
Con este recorrido metodológico, se logra articular los tres elementos indispensables de toda investigación que son: conceptualización, elicitación e interpretación, cuyo efecto acumulativo constituye la comprensión del objeto de estudio que es la textualización de los estudiantes de posgrado en el proceso de elaboración de una tesis. 


\section{Capítulo III.}

\section{La textualidad académica del proceso de elaboración de una tesis de grado: un análisis longitudinal}

Este capítulo expone el desarrollo de la fase de análisis e interpretación de los materiales recabados como elemento medular de esta investigación, en éste se presenta el estudio de tres casos o componentes que integran las explicaciones en torno a una problemática de investigación desde una visión ampliada. Esto es, el problema de investigación, los objetivos de la investigación, así como los conceptos técnicos necesario para plantear una problemática; el análisis de estos tres elementos contribuye a conocer la lógica de las explicaciones que desarrollan los estudiantes investigados, es decir, el punto es acercarnos lo más posible a la textualidad académica de los estudiantes de posgrado con el fin de tener una panorama general del estado en que se encuentra esta práctica académica tan cotidiana, pero muy poco problematizada en el ámbito universitario.

\subsection{Caso 1. El problema de investigación}

El caso que se presenta a continuación refiere a las distintas estrategias que los autores utilizan para plantear una problemática de investigación, donde van reflejando los cambios que se van presentando a lo largo de las tres fases analizadas en este estudio. Con ello se pretende tener un panorama general de cómo los autores de los productos escritos revisados en las tres etapas presentan su problemática, pero también su entendimiento de lo que es un problema de investigación.

Cabe aclarar que en el desarrollo de este análisis hago referencia a los "autores del texto" refiriéndome a los sujetos que construyen los manuscritos revisados. Primero, porque en un inicio ellos son aspirantes al programa de posgrado referido, por lo cual, en la fase inicial, aún no tiene la condición de estudiantes en dicho programa. También, me refiero a ellos como "estudiantes investigadores" porque independientemente de ser estudiantes o no, 
son ellos los que construyen sus textos y además inician su formación dentro del campo de la investigación. Por eso, en varios momentos recurro de forma indistinta a los términos autores, estudiantes, y/o investigadores para darles el crédito como sujetos que están en proceso de construcción de uno de los textos académicos más complejos en el ámbito universitarios, es decir, la tesis.

\subsubsection{Fase 1: Un problema práctico desde la experiencia del investigador}

En esta fase se exponen algunos ejes de análisis que muestran las estrategias a las que recurren los autores de los textos revisados para mostrar y ubicar una problemática que ellos identifican en su experiencia docente y que manifiestan en su anteproyecto de investigación como aspirantes al Programa de Maestría en Sociolingüística de la Educación Básica y Bilingüe en la UPN 201.

\section{a) Señalizaciones: para mostrar la existencia de un problema}

En este primer eje de análisis, una las estrategias recurrentes en todos los documentos escritos revisados en esta fase inicial es que los autores del texto se valen de señalizaciones discursivas que, en este caso, se caracterizan por el uso de vocablos o frases que señalan y enfatizan que efectivamente existe un problema, ya que el sentido de éstas es de una "necesidad", "carencia de algo" e incluso "deficiencia en algo", lo cual evidencia el problema que ellos identifican y que esperan desarrollar. Uno ejemplo de este tipo de señalizaciones es el siguiente:

\footnotetext{
La realidad que se vive como docente es extremadamente preocupante, porque no se cuenta con suficientes armas para proponer propuestas innovadoras que impacten en el medio social en donde se presta el servicio educativo...

En donde las comunidades cuentan con su propia cultura y lengua. Y por lo consiguiente $\underline{\text { no }}$ ha sido recuperada por los educadores originarios. Por no contar con una metodología adecuada al medio social en que se desarrolla la practica docente. (NHG-I1-F1)
}

En este primer ejemplo se puede observar cómo la autora del texto utiliza expresiones que evidencian que ella identifica un problema, cuando ella dice "realidad... preocupante" inicia explicando que existe una situación que debe atenderse. De ahí, utiliza otras expresiones como "no se cuenta con suficientes armas", "no ha sido recuperada" o "no contar con una metodología", son señalizaciones de repetición discursiva que se caracterizan por ser negativas porque inician con el vocablo "no". Esto muestra claramente la "carencia de algo", en este 
La textualidad académica de estudiantes de origen indígena en estudios de posgrado: el proceso de elaboración de tesis

caso, la autora da a entender que hace falta una "metodología adecuada", problemática que podría recuperar para desarrollar su investigación.

Otro ejemplo es el siguiente:

\begin{abstract}
La mayoría de los alumnos tienen una buena comprensión lectora, cuando se trata de cuentos, se les dificulta demasiado cuando se trata de un texto informativo o la resolución de un problema matemático, esto debido a que no comprenden algunas palabras o no entienden $l o$ que se les pregunta...

La redacción en la mayoría de los alumnos es deficiente en cuanto a la coherencia de sus ideas, además de la faltas de ortografía que son muy notables, esto aunado a la falta de estética en sus textos. (MAGV-I2-F1)
\end{abstract}

En este ejemplo se observan nuevamente señalizaciones discursivas con sentido negativo que proyectan la existencia de un problema identificado por el autor. Cuando él dice "se les dificulta demasiado", "no comprenden", "no entienden" o "la redacción... es deficiente" recurre a señalizaciones de repetición léxica y discursiva porque se repiten vocablos y también frases cuya función es mostrar que hay un problema, en este caso parecer ser con la redacción de los alumnos.

Un ejemplo más es esta forma de plantear un problema es:

\begin{abstract}
Ante esta situación no se ha logrado el desarrollo de un bilingüismo coordinado en los alumnos y persiste el predominio de una lengua sobre la otra, dentro del aula por la forma de trabajo de los docentes se usa más el español que el zapoteco, mientras que fuera del aula los alumnos emplean más la lengua indígena para comunicarse, provocando de tal manera algunos problemas de comunicación tanto en una lengua como en la otra, específicamente en la expresión oral y escrita de los alumnos, ya que existe una gran diferencia entre la estructura de la lengua zapoteca y el español, por lo que los alumnos muestran confusión en diferentes circunstancias y esto se debe a que los docentes no hemos sabido trabajar con alumnos en un contexto bilingüe e intercultural. (RRG-I6-F1)
\end{abstract}

En este ejemplo, una vez más se aprecian varias señalizaciones discursivas que guían a lector para conocer el problema que se plantea. Las frases resaltadas en negrita tales como "no se ha logrado", "problemas de comunicación" o "los alumnos muestran confusión" son ejemplos en negativo que le permite al autor evidenciar que hay un problema porque mantienen el mismo sentido, es decir que tales señalizaciones orientan al lector a la comprensión de una problemática.

Con estos ejemplos queda claro que una de las estrategias iniciales que utilizan los autores de los textos revisados tiene que ver con el uso de señalizaciones discursivas que se 
caracterizan por el uso de vocablos y/o frases generalmente en negativo para ubicar un problema, lo cual da un sentido de que "hace falta algo", "existe la necesidad de algo" o "hay deficiencia en algo". En otras palabras, esta estrategia se basa en que los autores consideran que utilizando dichas frases y mostrando la carencia, falta o necesidad de algo, les permite no solo ubicar el problema si no partir de él para desarrollar un posible proyecto de investigación. Además, en estos ejemplos se puede apreciar que las señalizaciones funcionan como pistas que se van dando mediante el uso de vocablos con un sentido similar como se nota claramente en el segundo ejemplo "se les dificulta, no comprenden, no entienden, es deficiente, faltas de...”. Estos términos, que en este caso pueden funcionar como sinónimos de una misma idea, se utilizan para mostrar y reiterar la existencia de un problema.

Ahora bien, las señalizaciones discursivas presentadas solo muestran el cómo los autores evidencian un problema que ellos identifican. Sin embargo, es necesario conocer cuál es el problema que ellos refieren, y para esto, se valen nuevamente de señalizaciones para ubicar su problemática y orientar al lector.

\section{b) Señalizaciones: para ubicar el problema identificado}

Los autores de los textos revisados nuevamente utilizan la estrategia del uso de señalizaciones de repetición discursiva pero en este caso es para guiar al lector sobre la problemática que ellos plantean en su anteproyecto. Es importante aclarar que el uso de este tipo de señalizaciones no sólo se ubica en el apartado del planteamiento, sino también en otros momentos del documento revisado, lo cual sugiere la necesidad por parte de los autores de dejar claro cuál es el problema que ellos desean presentar a lo largo de su documento. Continuando con los mismos autores de los ejemplos anteriores, en el primer caso, la autora ubica su problemática en los siguientes momentos:

Presentación

...las comunidades cuentan con su propia cultura y lengua. Y por lo consiguiente no ha sido recuperada por los educadores originarios. Por no contar con una metodología adecuada al medio social en que se desarrolla la practica docente. (NHG-I1-F1)

Planteamiento del problema

no contamos con una metodología para la enseñanza de la lecto-escritura mixe.

La preocupación ha sido muy grande, por lo que se considera que es momento de iniciar con este trabajo, proponer una metodología para la enseñanza de la lengua mixe en el aula. 
La textualidad académica de estudiantes de origen indígena en estudios de posgrado: el proceso de elaboración de tesis

(NHG-I1-F1)

Justificación

Además no puede aprender a leer y escribir en su propia lengua materna, por que el docente no cuenta con una metodología para la enseñanza de la lecto-escritura mixe.

Por lo que se considera que es de suma importancia contar con infinidades de materiales escritos en mixe, una metodología específica para la enseñanza de la lengua materna. (NHG-I1-F1)

Preguntas de investigación

8.-¿El docente cuenta con una metodología para la enseñanza de la lengua materna del niño y la niña de primer grado? (NHG-I1-F1)

Objetivos específicos

5.- proponer una metodología para la enseñanza de la lecto-escritura mixe. (NHG-I1-F1)

En este ejemplo se puede observar claramente la estrategia el uso de señalizaciones de repetición léxica y discursiva porque el autor no solo repite términos como "metodología" y "enseñanza" sino también recurre a argumentos con sentido similar; es decir, el uso de frases o expresiones que se mencionan en distintos momentos en el documento y que permiten ubicar cuál es el problema que la autora identifica y se desea abordar. En este caso, éste tiene que ver con "la falta de una metodología para la enseñanza de la lectoescritura en la lengua mixe", pero también la necesidad de contar con una, como se menciona por ejemplo en el planteamiento y en el objetivo específico la necesidad de "proponer una metodología para la enseñanza de la lecto-escritura mixe".

Otro ejemplo del uso de este tipo de señalizaciones de repetición léxica y discursiva en distintos momentos del documento revisado es el siguiente:

Introducción

... se intentará llevar a cabo una propuesta globalizadora la cual estará enfocada entre otras cosas, fundamentalmente hacia la lectura y producción de textos propios. (MAGV-I2-F1)

Planteamiento del problema

La mayoría de los alumnos tienen una buena comprensión lectora, cuando se trata de cuentos, se les dificulta demasiado cuando se trata de un texto informativo... (MAGV-I2-F1)

Objetivos

- $\quad$ Provocar en los alumnos apasionamiento por la lectura y la producción de textos por gusto, a su vez lectores y en un futuro autores.

- Apoyar a los alumnos a desarrollar su habilidad para producir textos a través de las técnicas Freinet.

- Partir de la lectura y producción de textos para abordar los contenidos curriculares, construyendo de forma conjunta una atmosfera y un ambiente más agradable e interesante para los alumnos. (MAGV-I2-F1) 
En este ejemplo también se nota claramente cómo el autor se apoya en la estrategia de señalización de repetición léxica cuando recurre varias veces a los términos "lectura" y "producción de textos", y de repetición discursiva cuando menciona algunos argumentos con sentido similar para orientar al lector en cuál es la problemática que él identifica, en este caso las señalizaciones orientan a que el problema tiene que ver con "la lectura y producción de textos" que se menciona en los distintos momentos a lo largo del documento. Es así como el uso de esta estrategia de señalización de repetición léxica y discursiva le permite al lector ubicar su problemática a lo largo de su documento.

Un ejemplo más de esta estrategia de señalización de repetición discursiva es el siguiente:

Presentación

A lo largo de la educación primaria no se logra el desarrollo de un bilingüismo coordinado en la mayoría de los alumnos...(RRG-I6-F1)

Justificación

... realizar un trabajo de investigación en el posgrado acerca del nivel de bilingüismo que logran desarrollar los alumnos

no se ha logrado el desarrollo de un bilingüismo coordinado en los alumnos dentro del aula por la forma de trabajo de los docentes se usa más el español que el zapoteco...(RRG-I6-F1)

Contextualización

... los docentes empleamos el español como lengua de instrucción, aun cuando los docentes somos hablantes de la lengua indígena

Esta situación de alguna manera ha limitado el desarrollo de nuestra lengua indígena, por esta misma razón no se ha logrado un bilingüismo coordinado en los alumnos. (RRG-I6-F1)

Propósitos

$>$ Sistematizar estrategias didácticas que faciliten el desarrollo de la lengua zapoteca y el español en un mismo nivel hasta lograr un bilingüismo coordinado en los alumnos de educación primaria. (RRG-I6-F1)

Este ejemplo tiene la característica de que el autor no incluye en su documento un apartado correspondiente al planteamiento del problema. Sin embargo, identifico a lo largo de su documento momentos en que el autor intenta explicar su problemática mediante el uso de señalizaciones de repetición léxica y discursiva cuando menciona en varias ocasiones los términos "bilingüismo coordinado", y reitera en distintas momentos que "no se ha logrado el desarrollo de un bilingüismo coordinado" y que "dentro del aula... se usa más el español que el zapoteco". El sentido de estas dos frases se retoma en uno de los propósitos que el autor plantea a través de "estrategias didácticas". Esto revela nuevamente el uso de señalizaciones 
La textualidad académica de estudiantes de origen indígena en estudios de posgrado: el proceso de elaboración de tesis

de repetición léxica y discursiva para guiar al lector para conocer el problema que identifica y que posiblemente desea abordar en el proyecto de investigación.

Estos tres ejemplos muestran visiblemente el uso de la estrategia de señalización léxica y discursiva para ubicar la problemática que cada autor plantea. Esta estrategia consiste en utilizar términos o argumentos con un sentido y significado similar que se repiten a veces literalmente para poder ubicar la problemática planteada. Estas señalizaciones se presentan básicamente en la presentación o introducción del documento, en el planteamiento del problema, en la justificación y en los objetivos y propósitos que se exponen. Esto indica que el problema mantiene una misma ruta ya que no sólo se menciona como una problemática, sino que se convierte como una posible pregunta de investigación o como un propósito. Entonces, esta estrategia es útil no solo para los autores que recurren a ella sino también para los lectores porque estas señalizaciones de repetición léxica y discursiva proporcionan pistas mediante el uso de los mismos argumentos a lo largo del escrito para ir indicando cuál es el problema que los autores intentan plantear en su anteproyecto de investigación. No obstante, es necesario mirar cómo los autores van modificando algunos aspectos en el planteamiento de su problemática, lo cual corresponde a la segunda fase de este estudio.

\subsubsection{Fase 2: Un problema práctico respaldado en fuentes teóricas}

En esta etapa el planteamiento de la problemática de caracteriza por dos aspectos fundamentales. Por un lado, aún se percibe que los autores de los protocolos de investigación revisados recurren a la estrategia de señalizaciones discursivas para mostrar la existencia de un problema, utilizando vocablos que revelan efectivamente que su existencia, similar a la fase anterior. Pero, por otro lado, en esta fase se nota claramente que la forma de plantear y/o ubicar un problema cambia de manera considerable. En este caso, los autores en todos los casos recurren a fuentes bibliográficas para ubicar y respaldar su problemática. Es decir que, en esta etapa, ya no solo se basan en su experiencia propia, sino que presentan la necesidad de incluir conceptualizaciones vinculadas al problema que intentan desarrollar. 


\title{
a) Señalizaciones para mostrar la existencia de un problema respaldados en fuentes bibliográficas
}

En este eje de análisis, se evidencia notablemente la presencia de fuentes bibliográficas que los autores de los trabajos revisados utilizan para apoyar el planteamiento del problema. Esto sucede en todos los casos cuando los autores citan textualmente o de forma indirecta el argumento de otros autores externos, lo cual les da elementos a los autores para sustentar su propio argumento. Sin embargo, también se nota el uso de vocablos que reflejan la "carencia" o "necesidad" de una situación que debe atenderse, ambas características se reflejan en el siguiente ejemplo:

\begin{abstract}
A pesar de las propuestas de la DGEI, varias investigaciones realizadas por los profesionales en este campo como Girón (2010), argumenta que la lengua materna solo ha servido como puente para la adquisición de la segunda lengua y que no existe la educación Intercultural Bilingüe en las escuelas primarias bilingües, sino más bien se da una educación castellanizante. (p.2)

... Creo pertinente, abordar este tema del uso de la lengua mixe, por lo que, durante décadas, la lengua originaria ha sido discriminada y desvalorizada. En la actualidad, se ha comprobado que la lengua materna ha sido utilizada como puente por algunos investigadores que han ido al campo educativo. (p. 3) (NHG-I1-F2)
\end{abstract}

En este caso, la autora recurre al argumento de otro autor "Girón (2010)" para plantear su problemática mediante una cita indirecta que le ayuda a sostener que "la lengua materna solo ha servido como puente para la adquisición de la segunda lengua" con lo cual la autora se apoya en esta cita para mostrar que existe un problema relacionado con la lengua materna en un contexto bilingüe. Este argumento lo refuerza más adelante en el desarrollo de su texto cuando recurre a señalizaciones de repetición discursiva que muestran el uso de vocablos que evidencian la existencia de un problema como en este caso cuando la autora afirma que "a) la lengua originaria ha sido discriminada y desvalorizada... la lengua materna ha sido utilizada como puente" manifestando que el problema tiene que ver con una lengua indígena que ha sufrido discriminación. De esta manera, en este ejemplo se aprecia claramente cómo la autora recurre a fuentes bibliográficas para plantear su argumento respecto a la existencia de un problema y lo reafirma cuando repite textualmente el argumento del autor mencionando que "la lengua materna ha sido utilizada como puente...". Con esto recupera el argumento del autor y lo refuerza en el suyo propio para plantear y respaldar su problemática apoyada en con el uso de vocablos que reflejan la situación complicada, en este caso de una lengua. De esta manera, se hace evidente dos de las estrategias a las que recurre la autora para exponer su problemática, una tiene que ver con recurrir al apoyo de autores externos mediante una cita 
La textualidad académica de estudiantes de origen indígena en estudios de posgrado: el proceso de elaboración de tesis

indirecta y, al mismo tiempo, emplear señalizaciones de repetición discursiva para respaldar su argumento.

En el siguiente caso, el autor recurre a las mismas estrategias que el caso anterior, la leve diferencia es que él inicia con un argumento personal y después lo respalda con una cita indirecta de un autor externo como se evidencia a continuación:

\begin{abstract}
Aunado a esto considero desde mi punto de vista y experiencia que el hecho de dejar que los alumnos lean y expresen libremente sus ideas es algo que en la escuela primaria en algunas ocasiones no se ha tomado en cuenta, de igual manera nos encontramos con algunos docentes a los cuales solo les preocupa terminar con lo impuesto por el plan y programas de estudios, a través de los libros de texto, sin importar los intereses de los alumnos o el desarrollo de sus habilidades para expresar sus idea. Contrario a esto también se pueden observar en las escuelas a docentes que parten de los intereses de los alumnos para abordar sus clases, esto de acuerdo a las ideas de Freire (2002), quien afirma que lo que debería de importar realmente en el aula seria partir de las necesidades de los alumnos y no de los deseos del educador... (MAGV-I2-F2)
\end{abstract}

En este ejemplo, el autor en un primer momento utiliza señalizaciones de repetición discursiva mediante vocablos que muestran una problemática cuando él afirma lo siguiente: “dejar que los alumnos lean y expresen libremente sus ideas es algo que en la escuela... no se ha tomado en cuenta" que a los docentes solo "les preocupa terminar con lo impuesto en el plan y programas de estudios... sin importar los intereses de los alumnos". Con estas afirmaciones, el autor advierte la existencia de un problema que se vincula en principio con la falta de atención en los intereses de los alumnos para expresarse libremente, argumento que se basa en su experiencia personal como lo indica al inicio del extracto citado. No obstante, este autor también recurre al apoyo de otro autor "Freire (2002)" a quien cita de forma indirecta y quien plantea literalmente que "lo que debería de importar realmente en el aula sería partir de las necesidades de los alumnos". Este argumento se ubica contiguamente a los argumentos anteriores y refleja una postura contraria, es decir que en la escuela el problema es que "los intereses de los alumnos no importan", pero en la cita se afirma que "sí deberían de importar"; esto refleja que el problema se vincula tanto en los comentarios personales como en la cita indirecta, ya que en ambas se menciona la problemática, aunque una cuestione a la otra.

Otro ejemplo similar es el siguiente, donde el autor del texto presenta una cita indirecta de otro autor para respaldar su propio argumento mediante la estrategia de repetición discursiva, como se aprecia a continuación. 
La diversidad étnica en las escuelas son culturas o alumnos invisibles como lo afirma Philips (1972) porque la escuela como institución no reconoce ni fomenta una educación multicultural que aspire a considerar la diversidad cultural e individual de los alumnos. Aún la escuela pertenezca al nivel de Educación Indígena, poco se ha hecho por atender las características culturales de los niños. La situación escolar es compleja ante este panorama de la diversidad. (FMM-I4-F2)

En este ejemplo se nota cómo el autor recurre al argumento de otro autor "Philips (1972)" para indicar su problemática que se vincula con que "La diversidad étnica en las escuelas son culturas o alumnos invisibles" con ello respalda una problemática que intenta plantear no sólo con el apoyo de otros autores sino también con argumentos que reflejan un sentido de "carencia" y/o "necesidad", por ejemplo cuando menciona que "la escuela... no reconoce ni fomenta una educación multicultural" o cuando dice que "poco se ha hecho por atender las características culturales de los niños", manifestando así la necesidad de atender esta problemática. De esta manera se aprecia claramente que tanto de la cita indirecta como en los argumentos personales del autor se enfatiza en los argumentos subrayados el problema de "la invisibilización cultural de alumnos en el nivel de educación indígena" mediante el uso de señalizaciones de repetición discursiva, donde el autor respalda su argumento mediante el uso de fuentes bibliográficas externas para evidenciar una problemática.

Un caso más en este eje de análisis se desarrolla a continuación:

\begin{abstract}
Sin embargo, es muy común escuchar en las reuniones de consejo técnico escolar a docentes de educación primaria, que laboran en contextos rurales o urbanos, hacer mención de dificultades que tienen sus alumnos para comprender textos a la hora de leer. Estas dificultades pueden ser de diferentes tipos, hay maestros que dicen que $\underline{s u s}$ alumnos a la hora de leer no tienen fluidez en su lectura, que deletrean silaba por silaba; en otros casos, hay niños que mantienen una fluidez constante en la lectura, pero les cuesta trabajo expresar algunas ideas sobre el texto leído. En algunos contextos rurales las dificultades pueden resultar mayores, ya que los niños suelen manejar palabras y significados diferentes los representados en los textos y libros que se leen en la escuela. Esta situación lleva a los docentes a proponer ciertas actividades que pueden enmendar los rezagos de la lectura, pero cuyos resultados no parecen ser alentadores, como menciona Ramírez Leyva (2010:10) en algunos estudios encuentran deficiencias en las habilidades de lectura y escritura aproximadamente en el $60 \%$ de jóvenes que cursan el tercer año de educación básica. (HGL-I8-F2)
\end{abstract}

En este ejemplo, el autor también utiliza la estrategia de señalizaciones de repetición discursiva para mostrar una problemática. En este caso sucede lo mismo que en los casos anteriores, el autor recurre al uso de vocablos con sentido negativo para plantear la existencia 
La textualidad académica de estudiantes de origen indígena en estudios de posgrado: el proceso de elaboración de tesis

de un problema y que éste tiene que ver con las dificultades que tienen los alumnos para leer con fluidez cuando este autor afirma “... dificultades que tienen sus alumnos para comprender textos... sus alumnos a la hora de leer no tienen fluidez en su lectura, que deletrean silaba por silaba... les cuesta trabajo expresar algunas ideas...". Con estas expresiones el autor muestra clara evidencia que la problemática es la dificultad en los alumnos para comprender textos y leer con fluidez.

Se nota que esta problemática se identifica a partir de la experiencia laboral del autor cuando al inicio de este extracto él menciona que en "las reuniones de consejo técnico escolar, los docentes... hacen mención de las dificultades que tienen los alumnos...", con lo cual queda claro que la problemática que se plantea surge de la experiencia laboral del autor, y que además refuerza con la cita indirecta de "Ramirez Leyva (2010:10" cuando afirma que "en algunos estudios encuentran deficiencias en las habilidades de lectura y escritura en el $60 \%$ de jóvenes... en educación básica". Esto significa que tanto en los argumentos personales del autor como en la cita que él plantea se muestra la problemática de la comprensión de textos, con lo cual ya no sólo son sus argumentos personales sino también éstos se ven apoyados por otros argumentos mediante citas indirectas de fuentes bibliográficas.

De esta manera, esta segunda fase de análisis y específicamente en este eje analítico, los autores citados utilizan nuevamente la estrategia de señalizaciones de repetición discursiva donde hacen uso de vocablos con un sentido de "carencia" o "necesidad" para atender un problema, lo cual es similar a la fase anterior. Es decir, en esta etapa los autores aún parten de un problema que han advertido en su experiencia personal y/o laboral y que de alguna manera desean atender. No obstante, es posible apreciar que el planteamiento de su problemática no se queda en este nivel empírico, sino que se nota un corrimiento hacia el uso de fuentes bibliográficas de otros autores externos que apoyan los argumentos del investigador para plantear su problemática de investigación. Así, se puede apreciar un avance entre la fase 1 y esta segunda fase en la manera en que los autores de los textos revisados plantean su problemática.

En la primera etapa, lo problemas identificados eran problemas prácticos basados en la experiencia personal y/o laboral de los autores. En esta segunda fase, la problemática se caracteriza por incluir fuentes bibliográficas de otros autores que ayudan a cada uno de los 
investigadores citados a plantear el problema que ya no se queda en el nivel práctico y empírico, por el contrario, el hecho de incluir a otros autores es un indicio de que se perfila un problema de investigación. Con esto se demuestra que dichos autores expresan su necesidad de recurrir a otras voces que apoyan el planteamiento de su problemática y a la vez éste adquiera mayor solidez. Así, la problemática desarrollada en esta fase ya no es un problema práctico sino se está convirtiendo en un problema de investigación donde el autor intenta primero comprender un problema, situación o fenómeno suscitado en el campo educativo, más que solucionarlo, como se presenta en la siguiente fase de este análisis.

\subsubsection{Fase 3: Un problema de investigación: la comprensión de un fenómeno}

Una de las características de esta etapa es que el planteamiento de la problemática se orienta hacia un problema de investigación, lo cual se refleja en la forma en que los investigadores enuncian la intención de su estudio, partiendo primeramente desde su experiencia, característica que se mantiene desde las fases anteriores, como se muestra en los siguientes ejes de análisis.

\section{a) Señalizaciones para mostrar la problemática, la experiencia del autor}

En este primer eje de análisis se percibe todavía que la problemática parte de la experiencia del autor y esto lo lleva a plantearse una problemática como se aprecia en los siguientes ejemplos:

a) ...en mi experiencia como docente frente a grupo me he percatado de que al inicio de cada ciclo escolar se manifiesta en las reuniones de consejo técnico escolar un rezago importante relacionados en con la lectura y escritura, ... HGL-I8-F3 (18DIC2014)

b) El interés sobre el tema nace primeramente como una problemática personal al darme cuenta de mi ineficiencia al intentar interactuar comunicativamente tanto en mi proceso formativo como en el ámbito laboral e incluso en algunos otros contextos sociales, esta misma problemática pude observarla en la mayoría de alumnos con los que he trabajado. (MAGV-I2-F3/16DIC2014)

c) Estas prácticas de hacer preguntas aún prevalecen en la actualidad en los centros escolares o más bien siguen siendo una de las formas de la enseñanza escolar, como docente frente a grupo se recurre al uso de las preguntas con diferentes intenciones. Tal vez, como alumno se considere solo como una evaluación del conocimiento para aprobar, pero como docente quizás tenga otras implicaciones desde la lógica del proceso de la enseñanza y el aprendizaje escolar. (FMM-I4-F3 /12NOV2014) 
En los tres ejemplos mencionados se nota claramente cómo cada uno de los autores recurre a su experiencia personal y laboral para ilustrar el problema que intentan investigar. Por ejemplo, en el primer caso, a) el autor expresa una problemática que parte de su "experiencia como docente" donde "se manifiesta en las reuniones de concejo técnico escolar un rezago importante relacionados con la lectura y escritura". Con esto el autor deja claro la problemática que desea abordar partiendo de su experiencia docente. En el caso b), el problema que se plantea parte también de la experiencia del autor, no obstante, éste lo plantea de forma distinta porque inicia su argumento aludiendo a un tema que parte de "una problemática personal" sobre su "ineficiencia al intentar interactuar comunicativamente" y que "esta problemática pudo observarla en la mayoría de alumnos con los que ha trabajado". En este caso, el autor primeramente alude a un tema que surgió de un problema identificado en su experiencia docente, situación que nos va indicando que para él ya no se trata de un problema práctico que requiere una solución, sino de un tema como un fenómeno que él desea investigar.

Finalmente, en el caso c), el autor plantea un tema de estudio que surge nuevamente de su experiencia como docente cuando menciona que "como docente frente a grupo se recurre al uso de las preguntas con diferentes intenciones". En este argumento él muestra que es docente frente a grupo, aunque lo hace de forma indirecta cuando afirma "como docente... se recurre al uso de preguntas" porque utiliza el verbo "recurrir" conjugado en forma impersonal "se recurre" el cual es una forma de plantear un estilo indirecto en su discurso. Así, este autor va definiendo cada vez más un tema de investigación porque cuando él menciona "pero como docente quizás tenga otras implicaciones desde la lógica del proceso de la enseñanza y el aprendizaje escolar" está sugiriendo algunas posibilidades que se presentan en su quehacer docente y que posiblemente merecen ser estudiadas.

De esta manera, se puede argumentar que en las tres fases los autores parten de su experiencia para plantear la problemática, sin embargo, en la fase tres es diferente porque ésta va orientada hacia un tema de investigación como se evidenció en los ejemplos anteriores donde los autores expresan, más allá de un problema que requiere solución, un fenómeno que desean investigar. Este planteamiento se refuerza con el siguiente eje de análisis donde los autores mencionan la intención de su investigación, pero ya no con el propósito de 
solucionarlo, como sucedió en la fase 1, sino declaran su necesidad de comprender un fenómeno suscitado en su experiencia docente.

\section{b) Señalizaciones, la intención del investigador}

En este eje de análisis, los casos presentados muestran la intención del investigador que está orientada hacia el estudio y la comprensión de un fenómeno que se quiere investigar. Vale la pena aclarar que los siguientes argumentos van de la mano con los extractos citados anteriormente, pero por cuestiones de organización se ubican en este eje de análisis, como se presenta a continuación:

a) Se torna realmente interesante investigar la influencia de este tipo de interacción comunicativa en el proceso de enseñanza-aprendizaje pues es un tema del que ya algunos autores han investigado pero que en la práctica educativa se sigue presentando recurrentemente. (MAGV-I2-F3 /16DIC2014)

En este primer caso, se puede apreciar claramente la intención del autor cuando refiere a que es "interesante investigar la influencia de este tipo de investigación comunicativa" porque parte de su interés personal. Además, él menciona que "es un tema que... algunos autores han investigado pero que... se sigue presentando...". Con esto, el autor revela que dicho tema ya no parte únicamente de su experiencia e interés personal, sino que es una problemática en otros espacios escolares, lo cual lo respalda para definir su problema de investigación.

En los siguientes dos casos, la intención de los autores persigue el mismo fin, desarrollar un estudio para comprender un fenómeno suscitado en su práctica docente:

b) Por ello, en esta etapa como docente investigador nace mi inquietud de saber lo que implican las preguntas del docente en el contexto de las tareas académicas para la enseñanza y aprendizaje en un aula de Educación Primaria indígena. (FMM-I4-F3 /12NOV2014)

c) ... considero necesario conocer las formas y los estilos de comunicación que se manifiestan en el aula de clases. Puesto que las aulas son espacios donde el lenguaje y la comunicación son una herramienta primordial para cumplir con los propósitos pedagógicos del proceso enseñanza - aprendizaje, en este caso para la enseñanza de la lengua escrita. (AGG-I5-F3/21NOV2014)

En estos dos ejemplos, ambos autores plantean su intención de investigar un tema. En el primer ejemplo, b) el autor expresa que "como docente investigador nace mi inquietud de saber lo que implican las preguntas del docente" con lo cual expresa su preocupación por "saber" lo que ocurre con una situación que se presenta en su actuar docente. Es decir, este autor clarifica su intención de comprender dicha situación, más allá de resolverla. En el caso 
La textualidad académica de estudiantes de origen indígena en estudios de posgrado: el proceso de elaboración de tesis

c), el autor también define la intención de su investigación mediante su argumento donde menciona lo siguiente "considero necesario conocer las formas y los estilos de comunicación que se manifiestan en el aula de clases..." donde él deja claro su intención de "conocer" un fenómeno suscitado en el ámbito pedagógico. Ambos autores utilizan verbos en infinitivo como "saber" y "conocer" que claramente revelan el deseo del investigador por entender lo que ocurre un fenómeno producido en su quehacer docente.

En los siguientes casos, la intención de los autores persigue un fin similar a los casos anteriores:

d) ... pero lo más importante es analizar, comprender y explicar que hay al fondo de estos actos lingüísticos al tratarse de un espacio tan particular como el aula, en donde se ponen en juego un conjunto de significados, contextos e intenciones que caracterizan las situaciones interactivas y comunicativas entre el profesor y los alumnos. (RRG-I6-F3 /12NOV2014)

e) Estas situaciones son las que ahora me permiten indagar sobre los procesos alfabetizadores que de dan día a día en las aulas, y de manera específica y particular, en las actividades de lectura. (HGL-I8-F3 /18DIC2014)

En ambos casos, los autores investigadores plantean la misma necesidad de conocer más acerca de un tema en el ámbito educativo. En el caso d), el autor literalmente expresa que "lo más importante es analizar, comprender y explicar que hay al fondo de estos actos lingüísticos", con lo cual revela su intención de "comprender" de una manera más minuciosa lo que ocurre con el fenómeno de los actos lingüísticos mediante un análisis que le ayude a explicar dicho fenómeno. En el último caso e) sucede algo similar cuando el autor expresa su propósito de "indagar sobre los procesos alfabetizadores" donde, de igual manera, mediante el uso del verbo en infinitivo "indagar" clarifica su intención de entender una situación de enseñanza como son los "procesos alfabetizadores", con lo cual va definiendo su intento por comprender una problemática suscitada en su experiencia docente. Así, en este eje de análisis, la intención de cada uno de los investigadores está orientada hacia la comprensión de fenómeno de estudio porque evidencian su interés por conocer, saber o indagar sobre una situación para dar cuenta de lo que sucede con tal fenómeno.

Es así como en esta fase final, los casos presentados revelan una problemática que parte en cierta manera de la experiencia vivida del investigador pero que trasciende al hecho de comprender un fenómeno con lo cual el problema inicial se convierte en un problema de investigación. En otras palabras, se muestra un corrimiento metodológico donde en un inicio, 
en la fase uno, el problema se quedaba en un nivel práctico el cual tiene su origen en el mundo (Booth et al, 2008), posiblemente en la experiencia del investigador y que éste puede resolverse "haciendo algo" para lograrlo. No obstante, "un problema de investigación se origina en la mente (del investigador), debido a un conocimiento incompleto o una comprensión errónea" (Ídem, p. 71) de un fenómeno.

\section{Conclusiones específicas}

De esta manera, se puede apreciar en este estudio longitudinal cómo se plantea el problema de investigación. En la primera fase, se evidencia que el problema refiere a un problema netamente práctico porque parte directamente de la experiencia personal y/o laboral del investigador y también porque, mediante señalizaciones de repetición léxica y discursiva, se muestra con claridad que la intención de los investigadores es darle solución a su problema identificado, con lo cual es más que evidente que el problema se encuentra en el nivel empírico. En la fase 2, se notan algunas modificaciones en el planteamiento del problema, se observa todavía que el problema surge de la experiencia del investigador, pero ahora los autores recurren al apoyo de otros autores mediante citas textuales o indirectas de fuentes bibliográficas que refuerzan sus argumentos para establecer una problemática y darle mayor solidez apoyado en los argumentos de autores externos, lo cual son indicios de que el problema práctico inicial se perfila hacia un problema de investigación que busca el entendimiento de un fenómeno identificado en un contexto específico. Finalmente, en la última fase, se aprecia que, aunque el problema parte de la experiencia del autor, éste trasciende a un nivel más de comprensión, es decir, los autores identifican una situación en su ámbito personal o laboral que intentan conocer y/o explicar, y ya no con la intención de darle una solución. Por tanto, en este estudio se evidencia no sólo la forma en cómo los autores van planteando su problemática sino también reflejan su comprensión en cuanto a lo que es e implica un problema de investigación que seguramente tiene que ver directamente con la formación que han recibido a lo largo del programa de maestría en el que estuvieron inmersos por dos años.

\subsection{Caso 2. Los objetivos de la investigación}

Uno de los aspectos totalmente implicados en las explicaciones de la problemática como 
La textualidad académica de estudiantes de origen indígena en estudios de posgrado: el proceso de elaboración de tesis

unidad de análisis son los objetivos que los autores de los textos revisados formulan para orientar su investigación. Así que, en este caso, se hace un desarrollo longitudinal en sus tres fases de cómo los autores de los productos escritos establecen sus objetivos y al mismo tiempo determinan el alcance de su investigación.

\subsubsection{Fase 1: La amplitud de los objetivos}

Los manuscritos revisados en esta etapa muestran claramente los objetivos que los autores pretenden desarrollar en su investigación. Estos objetivos se ubican en distintos apartados como la introducción, justificación y/o en un apartado exclusivo para este fin. Además, éstos se caracterizan por ser muy variados, es decir, cada autor propone entre cuatro y siete objetivos, algunos divididos en generales y específicos. La revisión realizada de cada uno de los documentos revela algunas características recurrentes de cómo los autores plantean sus propósitos, lo que nos permite mirar los fines que persigue en la fase inicial como anteproyecto de investigación.

\section{1) Señalizaciones para definir el alcance de los objetivos}

Una de las estrategias utilizadas por los autores para determinar el alcance de su investigación es el uso de señalizaciones de repetición discursiva que se ven reflejados en los propósitos que cada autor formula y que están directamente vinculados con el problema que ellos mismos plantean con el fin de orientar y definir el alcance de la investigación que desean desarrollar. Entre los primeros aspectos identificados en tales propósitos es que éstos se caracterizan por ser muy abarcativos y presentar cierta imprecisión, vaguedad y dispersión como se muestra en los siguientes ejemplos.

a) Fortalecer la identidad cultural y lingüística de los mixes, mediante un modelo de lectoescritura que respondan a sus necesidades y características concretas. (NHG-I1-F1)

b) Obtener conocimientos teóricos-metodológicos para realizar un análisis profundo de la lengua didzaa en general y la variante de san Baltazar Guelavila. (AGG-I5-F1)

c) Desarrollar un trabajo de investigación acerca del uso de la lengua indígena en los procesos de enseñanza y aprendizaje en la educación primaria en un contexto bilingüe e intercultural. (RRG-I6-F1)

d) Contribuir al mejoramiento del sistema educativo indígena, a partir de una propuesta curricular destinada a los pueblos originarios. (WEZ-I9-F1)

En cada uno de estos ejemplos, se puede apreciar que los objetivos planteados se 
orientan hacia algún estudio de una lengua indígena. En el caso a) el propósito que el autor persigue es abarcativo en el sentido de que a través de un modelo de lecto-escritura se asume que se fortalecerá la identidad cultural y linguiística. Es decir, que el objetivo se plantea a largo plazo, como una consecuencia, efecto o impacto que los resultados de la investigación tendrían tanto en la lengua como a la cultura mixe. No obstante, el propósito no se relaciona directamente con la investigación en sí misma, y es en la segunda parte cuando el autor menciona que se logrará "mediante un modelo de lectoescritura". Por tanto, parece que el objetivo tendría que estar enfocado a diseñar un modelo de lectoescritura. Algo similar sucede con el caso b) donde el autor pretende "obtener conocimientos teóricos metodológicos para realizar un análisis profundo de la lengua zapoteca", este objetivo parece contribuir más a la formación del autor que como un objetivo directo de su investigación; tal vez el objetivo de la investigación estaría enfocado más en la segunda parte cuando refiere a "realizar un análisis profundo" pero la expresión de "un análisis profundo" revela cierta imprecisión por parte del autor porque no aclara qué tipo de análisis refiere, cómo lo piensa hacer y qué entiende por "profundo", el cual es un vocablo poco preciso.

En el ejemplo c) sucede lo mismo que en los casos anteriores, el propósito del autor es muy amplio puesto que su intención es "Desarrollar un trabajo de investigación sobre el uso de la lengua indígena", pero no se aclara qué tipo de trabajo de investigación desea "desarrollar" aunque específica que tiene que ver con el "uso de la lengua indígena" tampoco queda claro qué se pretende hacer con el uso o a qué lengua indígena se refiere. De forma similar es el ejemplo d) donde el autor propone "Contribuir al mejoramiento del sistema educativo indígena" definiendo que el alcance de la investigación supone mejorar todo el sistema educativo indígena, lo cual también es un tanto ambicioso por ser tan abarcativo e impreciso, ya que la idea de contribuir al mejoramiento deja abierta muchas posibilidades del cómo contribuir y mejorar un sistema educativo, aunque de alguna manera lo menciona en la segunda parte de su objetivo cuando dice "a partir de una propuesta curricular", característica que comparten todos los ejemplos mencionados. Es decir que los objetivos señalan en la segunda parte de la oración una forma de responder a la primera parte, ya sea con un modelo de lectoescritura, un análisis profundo o una propuesta curricular, lo cual indica que posiblemente es en la segunda parte donde estaría enfocado el propósito principal de la investigación, aunque ésta también suele ser un tanto extensa y ambiciosa. 
La textualidad académica de estudiantes de origen indígena en estudios de posgrado: el proceso de elaboración de tesis

Así, estos ejemplos se caracterizan porque las señalizaciones de repetición discursiva, es decir los términos utilizados por los autores, comparten una misma intención que es que el propósito de los autores tengan un impacto más allá de la investigación, lo cual implica que éste sea a largo plazo una vez terminada la investigación, y tal vez pueda suceder así. Sin embargo, con esto, los autores corren el riesgo de perderse en el rumbo de su investigación, es decir, la ausencia de un objetivo más concreto y a corto plazo, repercutiría directamente en el curso y tiempo que tomará el estudio que cada uno de ellos presenta.

En los siguientes casos, tomando como base las señalizaciones de repetición discursiva, se aprecia que estos objetivos también se caracterizan por ser objetivos muy amplios, abiertos y poco precisos, como se muestra a continuación:

\footnotetext{
a) Definir el perfil lingüístico de egreso de los alumnos a la concluir la educación primaria. (FMM-I4-F1)

b) Analizar la relación interpersonal que existe en las aulas de Educación básica. (GMV-I7-F2)

c) Considerar la evaluación como un proceso constante en el aula. (GHV-I3-F1)

d) Formar niños productores de diferentes textos. (HGL-I8-F1)
}

En el caso a) y b) los objetivos son muy abarcativos porque el alcance de éstos implica el desarrollo de objetivos muy extensos para poder desarrollarlos. En el primer caso, "Definir el perfil sociolingüístico" es muy amplio e involucraría considerar varios elementos que estén inmersos en esta problemática, tal vez documentos oficiales, el conocimiento de otras lenguas, el curriculum, etc., sobretodo porque el campo de estudio que se plantea es muy amplio, como lo es todo un sistema de "educación primaria". De igual manera en el caso b) el objetivo es muy impreciso porque el autor pretende "Analizar la relación interpersonal" pero no aclara de quiénes, de los alumnos, de los maestros, o la relación entre ambos ambos. Ttambién, similar al caso anterior, se intenta englobar a todo el nivel de "Educación básica”. Así, estos ejemplos revelan objetivos muy abiertos que tal vez poco ayuden a orientar la investigación.

Los siguientes casos c) y d) comparten estas características de amplitud e imprecisión porque los objetivos planteados son extensos en el sentido de que los verbos utilizados reflejan vaguedad. Por ejemplo, en el caso c) "Considerar la evaluación como un proceso en el aula" refiere simplemente a tomar en cuenta la evaluación como un recurso en el aula, pero no se aclara el tipo de evaluación, en qué proceso, a quiénes va dirigido, etc. Lo mismo sucede en el ejemplo d) respecto a "Formar niños productores de diferentes textos" porque la idea de 
"formar" a una persona implica que puede ser a largo plazo, no se especifica los textos que se desean trabajar, y en qué nivel se pretende desarrollar.

De esta manera, estos ejemplos muestran, a través de señalizaciones de repetición discursiva, que los objetivos planteados se caracterizan por ser muy extensos y abiertos, lo cual crea imprecisión en lo que cada autor desea desarrollar en su investigación. No obstante, también es posible apreciar que los autores pretenden dar solución a su problemática, es decir, tienen la clara intención y el deseo que aportar algún tipo de beneficio ya sea para su lengua, su comunidad, para el contexto escolar e incluso para todo el sistema de primaria general y/o indígena como se mostró en los ejemplos anteriores. Esta forma de plantear los objetivos de la investigación involucra no sólo lo que cada autor desea lograr sino también con la forma en cómo lo plantea, en este caso, abordaré de manera general el tipo de verbos que los autores utilizan y cómo éstos influyen en el alcance que cada objetivo pueda tener.

\section{2) Señalizaciones para mostrar el tipo de verbos}

Los objetivos son una parte medular para guiar el rumbo de toda investigación, por ello es muy importante conocer cuáles y cómo son los objetivos que formulan los autores para su investigación. Uno de los aspectos identificados en los productos escritos revisados en la fase inicial, mediante señalizaciones de repetición discursiva, tiene que ver con el tipo de verbos que se utilizan, los cuales a veces son muy ambiciosos y/o abarcativos y que de alguna manera comprometen el alcance del proyecto de investigación y al mismo tiempo crean cierta imprecisión y vaguedad en lo que se pretende desarrollar.

\section{a) $\underline{\text { Verbos abstractos/subjetivos }}$}

Uno de los rasgos de los siguientes ejemplos evidencia el uso de verbos que dejan muy abierto el objetivo que se plantea, por ejemplo:

- Fortalecer la identidad cultural y lingüística de los mixes, mediante un modelo de lecto-escritura que respondan a sus necesidades y características concretas. (NHG-I1F1)

- valorar la lengua materna de los alumnos y alumnas. (NHG-I1-F1)

- Provocar en los alumnos apasionamiento por la lectura y la producción de textos por gusto, a su vez lectores y en un futuro autores. (MAGV-I2-F1)

- Liberar a los alumnos de la opresión, capaces de expresarse libremente sin miedo a 
La textualidad académica de estudiantes de origen indígena en estudios de posgrado: el proceso de elaboración de tesis

la equivocación o a la diferencia. (MAGV-I2-F1)

- Considerar diversos aspectos en la valoración del logro académico de mis alumnos (GHV-I3-F1)

Estos verbos transitivos comparten el rasgo de que tienen un nivel de subjetividad y abstracción complejo porque no se puede definir con precisión el alcance de éstos. Por ejemplo, cuando se dice "valorar la lengua materna" es difícil tener como propósito este fin porque no queda claro el cómo se piensa hacer y si es posible hacerlo. Lo mismo sucede con los otros verbos "fortalecer" "provocar", "liberar" y "considerar" lo cuales siguen esta misma línea de ser abstractos, ya que se quedan en un nivel de subjetividad del autor, es decir, no hay forma, por ejemplo, de determinar hasta dónde es posible "provocar en los alumnos apasionamiento". Es por ello, que este tipo de verbos suelen comprometer un proyecto de investigación porque crea cierta vaguedad en lo que se quiere desarrollar y cómo hacerlo.

\section{b) Verbos para solucionar un problema}

Otro tipo de objetivos que se aprecian en los productos escritos revisados tiene que ver con la idea de solucionar un problema, es decir, los propósitos están encaminados a dar atención o resolver una problemática, lo cual clarifica la idea de que los problemas identificados en esta etapa inicial aún no se consideran como problemas de investigación, sino más bien, son problemas que surgen de la experiencia misma del autor y cuyo fin es solucionarlo. Esto se refleja en los siguientes ejemplos:

- Lograr la elaboración de un documento que permita a los docentes y personas originarias interesadas en adquirir elementos para establecer el uso oral y escrito de la lengua en las comunidades y en las escuelas. (AGG-I5-F1)

- Construir vocabulario completo de las palabras en uso y desuso como legado escrito de mi lengua destinado hacia la misma población hablante de la lengua didzaa (zapoteca) de san Baltazar Guelavila. (AGG-I5-F1)

- Sistematizar estrategias didácticas que faciliten el desarrollo de la lengua zapoteca y el español en un mismo nivel hasta lograr un bilingüismo coordinado en los alumnos de educación primaria. (RRG-I6-F1)

Estos objetivos muestran que la intención de los autores va dirigida a conseguir un propósito que atienda las necesidades de un grupo cultural y lingüístico. En este caso, en los tres ejemplos citados las investigaciones se relacionan con las lenguas originarias, y se percibe que los autores intentan responder a los problemas que enfrentan dichas lenguas, por ejemplo, "Construir vocabulario" para su uso oral y escrito, "Sistematizar estrategias 
didácticas" y "Lograr un bilingüismo coordinado". Esto revela que el propósito que pretenden desarrollar los autores es contribuir, en este caso, al estudio de las lenguas indígenas, a profesores inmersos en este contexto, a la comunidad donde se habla la lengua y/o a un contexto escolar como se evidencia en los ejemplos citados. Esta característica de intentar atender las necesidades de un grupo de personas, una población o incluso de todo un nivel educativo como la "educación primaria", revela la amplitud de los objetivos y compromete el alcance de la investigación por la misma expansión que manifiestan tales objetivos.

Otros objetivos identificados incluyen verbos que se vinculan directamente con el desarrollo de habilidades en los alumnos como se muestra a continuación:

- Apoyar a los alumnos a desarrollar su habilidad para producir textos a través de las técnicas Freinet. (MAGV-I2-F1)

- Crear condiciones que faciliten la producción de diferentes textos en el aula. (HGL-I8-F1)

En estos ejemplos se aprecia que los objetivos van dirigidos al contexto escolar, específicamente al aula de clases. También se percibe la necesidad de que los alumnos desarrollen habilidades para la producción de textos, lo cual quiere decir implícitamente que el problema identificado por estos autores tiene que ver con la falta de "apoyo" y "condiciones" que permitan a los estudiantes producir textos, y por tanto, estos objetivos responderían de cierta forma a solucionar dicho problema. Así, estos ejemplos muestran nuevamente que los objetivos intentan responder y dar atención a la problemática identificada inicialmente mediante el uso de verbos como "apoyar" o "crear".

Otro grupo de objetivos comparten una característica muy similar y bastante explícita en los verbos que plantean, ya que éstos están dirigidos a desarrollar propuestas que atiendan directamente una problemática, como se muestra a continuación:

- $\quad$ proponer una metodología para la enseñanza de la lecto-escritura mixe (NHG-I1-F1)

- Hacer una propuesta metodologica que incluya las competencias a desarrollar en i, ii y iii ciclo de primaria, en lenguas originarias. (zapoteco del valle con variantes). (FMM-I4-F1)

- Analizar las propuestas de diversos autores para mantener una óptima relación interpersonal en el aula. (GMV-I7-F1)

- Diseñar una propuesta curricular para el medio indígena en el nivel de educación primaria, a partir de los elementos culturales, para propiciar la interculturalidad en las aulas. (WEZ-I9F1) 
En estos ejemplos, se puede notar que las señalizaciones de repetición discursiva revelan que todos los objetivos plantean el desarrollo de una propuesta, en los dos primeros casos, son propuestas metodológicas dirigidas a lenguas indígenas, los otros dos casos se relacionan con cuestiones interpersonales y con la cuestión curricular, pero todas intentan "proponer" alguna estrategia para darle solución a la problemática que identificaron inicialmente. Es así como el tipo de verbos a utilizar en los objetivos define también el tipo de investigación que se desea desarrollar, ya sea para diseñar estrategias, hacer documentos, desarrollar habilidades o realizar propuestas metodológicas o curriculares con el fin de dar atención a una problemática que está inmersa en un grupo escolar, escuela o en una comunidad. El punto es "solucionar" un problema que afecta directamente a los diversos sujetos inmersos en los contextos mencionados.

Es así como las señalizaciones para definir el alcance de los objetivos y para mostrar el tipo de verbos, nos ayuda a conocer cómo los autores de los anteproyectos revisados plantean sus objetivos de investigación. En el primer eje de análisis, se puede apreciar que, por los objetivos formulados, el alcance de la investigación es bastante extenso, por esto suelen ser muy abiertos y poco precisos, puesto que involucran un objeto de investigación amplio como "definir el perfil sociolingüístico de alumnos de educación primaria" o los otros casos mencionados, donde se abarca tanto un grupo amplio de sujetos como todo un nivel educativo. Esto hace que los anteproyectos presenten cierta imprecisión.

Por otro lado, las señalizaciones de repetición discursiva que muestran el tipo de verbos que los autores utilizan revelan que los verbos suelen presentar ciertos niveles de subjetividad y abstracción, es decir que son complejos para desarrollarlos en una investigación porque su misma naturaleza de que el significado puede quedar en la subjetividad de los autores y los lectores también, como por ejemplo "liberar", "provocar" o "considerar" que son difíciles de definir y por tanto, orientar el rumbo de una investigación. También, se identificaron verbos que literalmente mencionan el desarrollo de una "propuesta" que atienda, mejore o solucione un problema como sucede en los casos analizados anteriormente.

Con estos ejes de análisis desarrollados, es posible conocer la naturaleza del problema identificado como problemas prácticos (Booth et al, 2008), es decir que se basan en un interés muy personal y en la experiencia directa del autor que vive cotidianamente en su contexto 
laboral y/o comunitario como se mencionó en los ejes de análisis desarrollados anteriormente. Entonces, los problemas prácticos requieren de soluciones posiblemente prácticas como sucede cuando los autores plantean como objetivo darles solución a dichos problemas mediante el desarrollo de estrategias o propuesta metodológicas para atender las necesidades de cierto grupo cultural y/o lingüístico.

En suma, los objetivos planteados en los productos escritos revisados se caracterizan por su amplitud, imprecisión, pero también, por intentar dar solución a un problema práctico. No obstante, se pudo percibir en los objetivos que los autores intentan no solo solucionar un problema sino contribuir al contexto laboral donde se encuentran, como lo es el sistema educativo básico general e indígena, a su comunidad y al grupo de personas con las que trabajan como son los alumnos. Es por ello, que estos objetivos se plantearon de forma consciente en base al interés y experiencia de cada uno de los autores. Ahora el siguiente paso sería revisar hasta qué punto o en qué forma los sujetos investigados hacen modificaciones a este anteproyecto para construir un protocolo de investigación una vez terminado el primer año de formación en el programa de maestría en que están inmersos, lo cual se analiza en la fase dos de este estudio longitudinal.

\subsubsection{Fase 2: La estructura y el alcance de la investigación}

Esta fase se caracteriza por varios aspectos que revelan algunos cambios diferentes a la fase 1 en cuanto a la manera de plantear los objetivos que guían la investigación. Una de estas modificaciones es que todos los autores formulan un objetivo general y en promedio tres objetivos específicos. Esto difiere de la etapa anterior donde solo se mostraban objetivos, varios en forma de lista, pero sin tener un objetivo central, lo cual hacía que la dirección de la investigación fuera un tanto incierta. Ahora, en esta fase los objetivos tienen mayor precisión y contribuyen de alguna manera a clarificar cuál será la ruta que seguirá la investigación que propone cada investigador.

\section{1) Señalizaciones para mostrar la estructura de los objetivos generales planteados}


La textualidad académica de estudiantes de origen indígena en estudios de posgrado: el proceso de elaboración de tesis

Una de las características más notorias en los productos escritos revisados en cuanto al objetivo general de la investigación en cada caso, es que todos muestran un verbo principal que se ubica al inicio de la oración y que además el tipo de verbos que se utilizan manifiestan un cambio, distinto a los utilizados en la etapa anterior, como se muestra a continuación:

a) Explicar el uso de la lengua mixe, mediante la observación en un aula bilingüe de primer grado de primaria "José María Morelos y Pavón" para conocer sus funciones en la escolarización de los niños. (NHG-I1-F2)

b) Caracterizar las prácticas de escritura que se dan en el aula para marcar tendencias sobre las que cumplen el propósito de la producción de textos. (MAGV-I2-F2)

c) Identificar y describir las funciones de las preguntas que el docente utiliza como mediación en su discurso para mejorar la comunicación y el desarrollo cognitivo en un aula con diversidad étnica. (FMM-I4-F2)

d) Caracterizar la lectura en voz alta que se realizan en un aula de sexto grado de educación primaria, el cual permita apreciar los procesos, funciones y significados que se configuran en torno a esta práctica”. (HGL-I8-F2)

En estos ejemplos se puede notar claramente que la estructura de los objetivos generales inicia con un verbo en infinitivo, pero estos verbos persiguen un sentido más de conocer y comprender un fenómeno, más que solucionar un problema. Como se puede apreciar en los 4 casos todos presentan la intención del investigador mediante un verbo principal en infinitivo al principio de la oración seguidos de un sustantivo donde se manifiesta el fenómeno a investigar, lo cual respondería a lo "qué" cada investigador desea investigar. Por ejemplo, "Explicar el uso la lengua mixe...", "Caracterizar las prácticas de escritura...", "Identificar y describir las funciones de las preguntas..." o "Caracterizar la lectura en voz alta", estos ejemplos evidencian el "qué" de la investigación, lo cual va clarificando la intención del investigador. Así, estos verbos son parte de una estructura más definida que inicia con un verbo en infinitivo + sustantivo lo cual manifiesta el "qué" quiere lograr el investigador. Además, los verbos utilizados como caracterizar, explicar, describir o identificar en los cuatro casos permiten orientar la investigación y definir su alcance de una forma más limitada y posible para los investigadores. En otras palabras, estos verbos suelen ser más concretos y alcanzables a corto plazo, porque sugieren logros creíbles y aceptables que tienen que ver con el entendimiento de un fenómeno que se desea conocer, más que resolver.

Otra de las características de la estructura de estos objetivos es que también incluyen el para qué de la investigación, es decir, se intenta responder "para qué" realizar la investigación, lo cual se refleja en la segunda parte de la oración compuesta de la preposición "para” o una expresión con un sentido similar, seguida de un verbo en infinitivo que no es el 
principal de la oración, como se muestra en los ejemplos anteriores, “a) ... para conocer sus funciones...”, “b) ...para marcar tendencias...”, “c) ... para mejorar la comunicación...” o “d) ... el cual permita apreciar los procesos...”. Es así como cada uno de los objetivos citados muestra claramente cuál es la intención que cada investigador revela en su investigación, es decir que responde al "qué", así como el "para qué” de la misma, lo cual indica dos elementos importantes que guían la investigación y reducen la posibilidad de caer en la dispersión o perder el rumbo.

Otra particularidad en la estructura de los objetivos planteados por los sujetos investigados es que el objetivo no solo presenta el qué y el para qué, sino también el cómo llevar a cabo la investigación, como se exhibe en los siguientes casos:

a) Explicar el uso de la lengua mixe, mediante la observación en un aula bilingüe de primer grado de primaria "José María Morelos y Pavón” para conocer sus funciones en la escolarización de los niños. (NHG-I1-F2)

b) Identificar la funcionalidad de la evaluación en la enseñanza y aprendizaje en la educación primaria, mediante el análisis microetnográfico, la entrevista y observaciones de campo de la práctica docente para replantear el papel de dicha evaluación en la actualidad (GHV-I3-F2)

c) Identificar y analizar los procesos de interacciones comunicativas que se establecen entre los alumnos de un grupo de $1^{\circ}$ y $2^{\circ}$ grado de primaria indígena en un contexto multicultural a través de una investigación microetnográfica. (RRG-I6-F2)

d) Caracterizar los roles que sume el alumno en los procesos de interacción social que dan en el aula a través de la observación. (GMV-I7-F2)

Además de que el objetivo general contempla en su estructura el "qué" y "para que", en varios casos también se presenta el “cómo" se piensa desarrollar la investigación, lo cual refiere a proponer alguna ruta metodológica para llevar a cabo el estudio planteado. Para esto, los autores se valen del uso de preposiciones como "mediante" y "a través de" que indican el sendero que cada autor pretende seguir. En los cuatro casos se evidencia esta característica, “a) mediante la observación”, "b) mediante el análisis microetnográfico”, “c) a través de una investigación microetnográfica” o "d) a través de la observación”, con esto el objetivo general manifiesta mayor estabilidad puesto que proporciona otro elemento importante como lo es la vía metodológica que seguirá la investigación para orientar mejor el rumbo del estudio a desarrollar.

Es así como en este eje de análisis se demuestra que los objetivos generales planteados en esta fase mantienen una estructura que revela características compartidas. Una de estas características refiere a que todos los objetivos inician con un verbo principal + sustantivo 
La textualidad académica de estudiantes de origen indígena en estudios de posgrado: el proceso de elaboración de tesis

que se orienta más al conocimiento o comprensión de una problemática o fenómeno. En esta estructura los objetivos también incluyen el "qué" se pretende desarrollar, "para qué" hacerlo, y "cómo" se piensa desarrollar. Aclaro que estos tres aspectos no se presentan de forma simultánea en todos los casos, pero son aspectos recurrentes en varios de los casos mencionados, lo cual revela una estructura mucho más definida que guía con mayor certeza el rumbo de la investigación. Estos tres momentos manifestados en varios de los objetivos contribuyen a la delimitación de la problemática a investigar y orientan con mayor certidumbre al autor para llevar a cabo su investigación. Es así como el objetivo general planteado posee una estructura que le da más dirección y sentido a lo que cada autor desea desarrollar.

\section{2) Señalizaciones en los objetivos específicos planteados}

Los objetivos específicos se caracterizan por ser en promedio tres por cada autor, en su mayoría mantienen verbos en infinitivo similares a los objetivos generales mostrados, como se advierte en los siguientes ejemplos:

a) Describir el uso de la lengua mixe en el aula bilingüe. Caracterizar el uso de la lengua mixe en el aula bilingüe. Explicar las funciones que cumple la lengua mixe en el aula bilingüe. (NHG-I1-F3)

b) Identificar y definir las características de las diferentes prácticas de escritura en el aula. Comparar diferentes prácticas de escritura para marcar tendencias sobre ellas. Describir las estrategias que se dan para la producción de textos. (MAGV-I2-F2)

c) Detectar la intencionalidad de las actividades evaluativas cotidianas en la práctica de la enseñanza y aprendizaje.

Identificar qué instrumentos de evaluación son más empleados en la práctica educativa. Analizar las acciones implementadas por el docente luego de la revisión de sus actividades evaluativas. (GHV-I3-F3)

d) Describir las preguntas según su función en el discurso del docente en un aula con diversidad étnica.

Clasificar las preguntas como discurso de tipo proléptico y de contingente utilizadas por el docente en un aula con diversidad étnica.

Caracterizar las preguntas que promueven el desarrollo cognitivo en los alumnos. (FMMI4-F2)

e) Describir los tipos de interacciones comunicativas entre alumnos presentes dentro del aula. Caracterizar las interacciones comunicativas que establecen los alumnos en trabajos colectivos o colaborativos. (RRG-I6-F2)

Los verbos mostrados en los casos anteriores siguen la misma línea que los verbos utilizados en los objetivos generales, son verbos que buscan el entendimiento de un fenómeno 
o un caso en particular. Además, estos verbos funcionan como el verbo principal de la oración, es decir, la estructura general de los objetivos específicos es: verbo principal en infinitivo + sustantivo + complemento como por ejemplo en el caso "a) Describir $+\underline{\text { el uso de la lengua }}$ $\underline{\text { mixe }}+\underline{\text { en el aula bilingüe }}$ ” o en el caso “b) Describir $+\underline{\text { las estrategias }}+\underline{\text { que se dan para la }}$ producción de textos", o como en el caso “d) Describir + las preguntas según su función en


específicos son diferentes a los objetivos generales, sobre todo en su estructura, ya que los específicos no presentan el "para qué" y el "cómo" de la investigación. Así, se puede percibir que los autores manifiestan una diferenciación a grandes rasgos en cómo formular un objetivo general y uno específico, lo cual se evidencia en los ejemplos anteriores.

Sin embargo, se puede notar que los objetivos específicos presentan cierta imprecisión porque algunos son muy similares al objetivo general y otros incluso lo rebasan en el alcance, como se aprecia a continuación:

a) Objetivo General:

Explicar el uso de la lengua mixe, mediante la observación en un aula bilingüe de primer grado de primaria "José María Morelos y Pavón" para conocer sus funciones en la escolarización de los niños.

Objetivos Específicos:

- Describir el uso de la lengua mixe en el aula bilingüe.

- Caracterizar el uso de la lengua mixe en el aula bilingüe.

- Explicar las funciones que cumple la lengua mixe en el aula bilingüe. (NHG-I1-F3)

En este ejemplo, mediante el uso de señalizaciones de repetición léxica, se puede observar cómo el tercer objetivo específico corresponde al "para quê" de la investigación, aunque el objetivo general persigue otra finalidad que es "el uso de la lengua mixe" y no necesariamente "las funciones" de dicha lengua. Por ello, se puede notar que existe cierta indefinición en la dirección que se le quiere dar a este trabajo de investigación. Otro ejemplo similar es el siguiente:

b) Objetivo General:

Caracterizar las prácticas de escritura que se dan en el aula para marcar tendencias sobre las que cumplen el propósito de la producción de textos.

Objetivos específicos:

- Identificar y definir las características de las diferentes prácticas de escritura en el aula.

- Comparar diferentes prácticas de escritura para marcar tendencias sobre ellas.

- Describir las estrategias que se dan para la producción de textos. (MAGV-I2-F2)

En este caso, el segundo objetivo específico intenta responder de igual manera al para qué de la investigación mediante la estrategia de señalizaciones repetición léxica, es decir, que 
La textualidad académica de estudiantes de origen indígena en estudios de posgrado: el proceso de elaboración de tesis

el autor utiliza los mismos argumentos tanto en el objetivo general como en el específico cuando el autor menciona "para marcar tendencias...". Sin embargo, el verbo principal del objetivo específico difiere del general, ahora se enfoca a "comparar diferentes prácticas de escritura" lo cual rebasa el alcance del objetivo general porque implica desarrollar actividades para comparar diversas prácticas de escritura y no sólo caracterizarlas, con esto se muestra todavía cierta imprecisión en lo que pretende desarrollar el autor de esta investigación.

Un caso más de este tipo de objetivos es el siguiente:

c) Objetivo general:

Analizar el concepto de saberes comunitarios desde la investigación documental cualitativa para contribuir a su mejor concepción.

Objetivos específicos:

- Analizar el concepto de saberes comunitarios a partir de diferentes textos que abordan esta temática para conceptualizarla.

- Identificar los elementos que constituyen el concepto de "saberes comunitarios" para contribuir a su comprensión conceptual y caracterización.

- Indagar e interpretar el concepto de "saberes comunitarios" y como subyace en los documentos normativos y proyectos de la educación indígena en Oaxaca en la actualidad. (AGG-I5-F2)

En este ejemplo se puede notar claramente cómo el autor utiliza señalizaciones de repetición léxica y discursiva tanto en su objetivo general como en los específicos. Con esto, nos damos cuenta que dos de los objetivos específicos que él plantea son muy similares al general. Por ejemplo, el primer objetivo específico se plantea de manera muy similar que el general cuando el autor menciona "Analizar el concepto de saberes comunitarios", donde prácticamente utiliza los mismos vocablos en ambos tipos de objetivo. De igual forma el tercer objetivo específico se dice "Indagar e interpretar el concepto de "saberes comunitarios..." donde los verbos indagar e interpretar se encuentran implicados en el verbo analizar que es el que se utiliza tanto el objetivo general como en el primer objetivo específico. Entonces, ambos tipos de objetivos son muy similares en el sentido que persiguen, ya que el autor, aunque intenta utilizar vocablos distintos, su intención tanto en el objetivo general como en el específico mantienen la misma dirección, lo cual crea cierta confusión entre lo que se quiere lograr de manera general con la investigación, y los objetivos concretos para lograrlo.

Es así como se puede apreciar que los objetivos específicos, por un lado, mantienen una estructura que es verbo principal en infinitivo + sustantivo + complemento y se caracterizan por utilizar verbos similares a los utilizados en los objetivos generales que mantienen un 
sentido de indagación y comprensión de una problemática. Pero, por otro lado, algunos objetivos específicos se plantean como si fueran un objetivo general, por ejemplo cuando intentan responder al para qué de la investigación, esto crea confusión porque el objetivo principal tiene otra intención, considerando que responder al para qué implica que una vez desarrollada y terminada la investigación, ésta aporta algunos elementos que permiten responder en cierta medida a ese para qué y no necesariamente como una respuesta parcial dentro de la investigación como lo proyectan los autores en sus objetivos específicos. Es decir, el para qué de la investigación incluido en un objetivo específico puede causar confusión e indefinición en lo que cada autor persigue en su investigación, puesto que responder al para qué no es una meta a corto plazo.

También, se aprecia que hay autores que utilizan señalizaciones de repetición léxica y discursiva para plantear sus objetivos específicos, donde de alguna manera repiten literalmente o parafrasean su objetivo general. Nuevamente, esto indica que aún falta mayor precisión en los objetivos específicos y posiblemente en el general.

En suma, los objetivos planteados en esta segunda fase difieren de la anterior por diversas razones. Una tiene que ver con que en esta fase los objetivos se muestran más organizados, en objetivos generales y en específicos, y en la fase 1 se proyectaban muy dispersos e imprecisos. Otra característica en esta etapa es que se utilizan otro tipo de verbos cuyo sentido conduce a indagar, conocer y/o comprender una problemática o fenómeno, y ya no verbos que se mostraban muy ambiciosos e imprecisos en la fase anterior como desarrollar o contribuir, o en su caso, el uso de verbos muy abstractos como provocar, liberar, o formar. Un rasgo más encontrado en esta fase tiene que ver con la forma en que los autores formulan su objetivo general, además de utilizar verbos mucho más alcanzables, casi en todos los casos mencionan el "qué" y el "para quê" de su investigación, y en otros casos también incluyen el "cómo" desarrollarla. Con esto los objetivos generales planteados tienen mayor consistencia y precisión, lo cual le da mayor direccionalidad a la investigación y reduce la posibilidad de perder el rumbo de la misma, situación que difiere en gran medida de los objetivos en la fase inicial. Finalmente, los objetivos específicos mantienen cierta estructura y podría decirse que se relacionan con el objetivo general, sin embargo, no siempre sucede así, hay casos donde los 
La textualidad académica de estudiantes de origen indígena en estudios de posgrado: el proceso de elaboración de tesis

objetivos específicos no apoyan la intención plasmada en el objetivo general, sino por el contrario, crean cierta confusión y dispersión en los que se desea desarrollar.

Así, en términos generales, en esta segunda fase de este análisis longitudinal respecto a los objetivos que guían la investigación, es posible afirmar que se nota claramente un avance significativo en la forma en que se plantea la ruta que seguirá la investigación, donde éstos están mejor delimitados y formulados, de manera que el camino de la investigación está mejor trabajado. Pero, hay que tomar en cuenta que en la fase 1, los anteproyectos de investigación revisados fueron presentados cuando los autores aún eran aspirantes al programa de maestría, es decir que sus anteproyectos los construyeron desde su experiencia previa en la licenciatura. En la fase 2, los protocolos de investigación revisados se hicieron una vez que terminaron su "Seminario de tesis I", es decir, después del primer año de maestría, con lo cual se percibe que el programa de maestría en que estuvieron inmersos seguramente contribuyó en su formación como investigadores, lo cual se revela en la forma en que los autores formulan sus objetivos en esta etapa.

Esto nos puede dar una idea de cómo la inmersión a un programa, en este caso de posgrado, incide de alguna manera en cómo un problema práctico se va perfilando hacia un problema de investigación, es decir, como una situación problemática que el autor experimenta en su vida laboral y/o personal y que desea resolver, va convirtiéndose en un problema de investigación, es decir, un problema que "se origina en la mente [del investigador], debido a un conocimiento incompleto o una comprensión errónea... [es decir] aprendiendo más acerca de algo o comprendiéndolo mejor.”(Booth et al, 2008, p. 71), y no sólo pretender resolverlo. Así, en esta etapa 2, los objetivos muestran varios cambios que van afinando la consistencia de la investigación y el rumbo que ésta seguirá. Ahora, es necesario revisar los rasgos que los objetivos presentan en la fase final de este estudio correspondiente a la fase tres.

\subsubsection{Fase 3: Orientación contextual y concreción en los objetivos}

En esta fase, el objetivo general planteado por cada uno de los autores se caracteriza por estar redactado en prosa y se ubica en la introducción del documento en todos los casos; los objetivos específicos ya no se mencionan puesto que en esta etapa la investigación ya ha sido 
desarrollada y tanto el objetivo general como los específicos ya han funcionado como la guía para el desarrollo de la investigación. Cabe aclarar que ha transcurrido un poco más de un año desde la construcción de protocolo de investigación y los estudiantes acaban de terminar los cuatro semestres de su posgrado y están en la recta final de su tesis como documento recepcional de investigación. Es decir que durante este tiempo seguramente se hicieron modificaciones al objetivo propuesto en el protocolo de investigación presentado un año antes y posiblemente modificaron el rumbo de tomaría el estudio, lo cual se revisará en los siguientes ejes de análisis.

\section{a) La orientación contextual en los objetivos}

Una de las características que sobresale en los objetivos planteados en la fase 3 es que los autores delimitan su objetivo mediante el uso de orientaciones contextuales, donde sitúan el lugar, grado escolar o nivel educativo para ubicar en dónde se llevará a cabo la investigación, como se puede apreciar en los siguientes ejemplos:

a) El objetivo principal de este trabajo monográfico es mostrar los usos y funciones de la lengua ayuujk de algunas comunidades mixes ubicadas en la región alta. (NHG-I1-F3)

b) En el presente trabajo se analizará el uso y las funciones que tiene la lengua zapoteca en la comunidad de San Andrés Solaga y poblaciones aledañas, a través del contacto con otras lenguas, principalmente el español. (GMV-I7-F3)

En estos dos primeros casos los objetivos planteados presentan rasgos que tienen que ver con la ubicación donde se desarrolla la investigación mediante el uso de orientaciones contextuales. Es decir que en ambos ejemplos las autoras delimitan contextualmente el objetivo de su investigación mencionando que éstas se realizarán en una determinada comunidad o un grupo de ellas, cuando mencionan “a) comunidades mixes ubicadas en la región alta" y "b) la comunidad de San Andrés Solaga y poblaciones aledañas". En los dos casos, el objetivo se delimita contextualmente al ámbito comunitario, concretamente a un grupo de comunidades indígenas que cada autora menciona.

En los siguientes ejemplos la orientación contextual refiere al ámbito escolar como se aprecia en los siguientes casos

c) Así que este trabajo tiene como objetivo principal caracterizar y explicar las funciones de las preguntas que utiliza el docente en el proceso de enseñanza y aprendizaje en un grupo de $5^{\circ}$ y $6^{\circ}$ de Primaria de Educación Indígena. (FMM-I4-F3) 
La textualidad académica de estudiantes de origen indígena en estudios de posgrado: el proceso de elaboración de tesis

d) Este trabajo es un intento por analizar las interacciones comunicativas que suceden en un aula de segundo grado de educación primaria y de qué manera estas interacciones contribuyen en la enseñanza de la lengua escrita, sobre todo en el aspecto de la enseñanza de la producción de textos en español a alumnos del primer nivel de educación primaria indígena (AGG-I5-F3)

e) A partir de este panorama y enfatizando en las actividades de lectura que se realizan en la escuela, se pretende caracterizar las prácticas de lectura que se realizan en la materia de español recuperar los elementos que permitan conocer de manera detallada lo que ocurre en un grupo de quinto grado de la Escuela Primaria Venustiano Carranza, ubicada en la comunidad de San Pedro Juchatengo (HGL-I8-F3)

En el caso c) y d) la orientación contextual refiere al contex to escolar, específicamente a un grado o grados escolares en un sistema educativo particular, en este caso, la educación primaria indígena cuando los autores mencionan “c) un grupo de $5^{\circ}$ y $6^{o}$ de Primaria de Educación Indígena” y “d) un aula de segundo grado de educación primaria... alumnos del primer nivel de educación primaria indígena". En estos dos ejemplos se nota claramente cómo los autores mencionan tanto el grupo como el nivel educativo en que pretenden desarrollar su investigación. Por último, en el inciso e) cuando el autor menciona "un grupo de quinto grado de la Escuela Primaria Venustiano Carranza, ubicada en la comunidad de San Pedro Juchatengo", no sólo específica el grupo escolar, sino también la escuela y la comunidad donde ésta se encuentra, lo cual puede contribuir a que el autor tenga más elementos para orientar contextualmente su investigación.

Cabe aclarar que, en las fases anteriores, los objetivos generales usualmente no manifestaban esta característica, por el contrario, este aspecto contextual no se consideraba necesario para ubicarlo en el objetivo, con esto no intento decir que en los documentos anteriores revisados en la fase 1 y 2, no se dé una orientación contextual, porque sí se realiza, lo que noto es que tal orientación está ausente en los objetivos planteados, situación contraria a la fase 3 donde varios autores coinciden en la necesidad de ubicar contextualmente su objetivo como se vio en los ejemplos citados. Con esto, es posible apreciar que los objetivos mantienen mayor definición en la orientación contextual que cada uno de los autores expresa en sus objetivos. Sin embargo, es insuficiente basarse solo en una orientación de este tipo para tener elementos necesarios que muestren el rumbo que pretende seguir la investigación. Por ello, es necesario recurrir a otros aspectos que se manifiestan en los objetivos para revisar los cambios y/o avances que los autores han realizado en el planteamiento de sus objetivos en la idea de que éstos queden más delimitados. 


\section{b) Los objetivos: modificaciones en el contenido}

Los objetivos en esta fase final se caracterizan por ubicarse en la introducción o presentación del borrador de tesis en todos los casos, están escritos en forma de prosa y muestran mayor definición en cuanto a lo que se quiere lograr. De hecho, se observan algunos cambios que hacen que el objeto de estudio esté mejor definido, para ello, es necesario recuperar los objetivos generales de las fases anteriores, como se muestra a continuación:

FASE 1. Fortalecer la identidad cultural y lingüística de los mixes, mediante un modelo de lecto-escritura que respondan a sus necesidades y características concretas. (NHG-I1F1)

FASE 2: Explicar el uso de la lengua mixe, mediante la observación en un aula bilingüe de primer grado de primaria "José María Morelos y Pavón" para conocer sus funciones en la escolarización de los niños. (NHG-I1-F2)

FASE 3: El objetivo principal de este trabajo monográfico es mostrar los usos y funciones de la lengua ayuujk de algunas comunidades mixes ubicadas en la región alta. (NHG-I1-F3)

Como se puede notar, el objeto de estudio se va delimitando y precisando cada vez un poco más. En este primer caso a) la autora originalmente en la fase 1 parte de un objetivo muy amplio e impreciso como "Fortalecer la identidad cultural y lingüística mediante una propuesta metodológica..." que también es un tanto ambiciosa. Pero, en la fase 2, este objetivo se va concretando un poco más a "Explicar el uso de la lengua mixe", donde la delimitación se reduce al estudio de la lengua y ya no se incluye la identidad ni la cultura como en la fase 1. En la fase 3, este objetivo manifiesta mayor precisión porque el verbo principal se limita a "mostrar los usos y funciones de la lengua ayuujk", es decir, con el verbo "mostrar" delimita mucho más el alcance de su investigación porque es un verbo mucho más alcanzable a corto plazo y porque revela que la intención de la autora es expresar lo que sucede con una lengua indígena en un contexto definido. Al mismo tiempo, en este objetivo de la fase 3 revela la fusión del "qué" y el "para qué" presentados en el objetivo de la fase anterior, con esto la autora muestra los cambios hechos en esta fase final donde su objetivo presenta mayor precisión y dirección a su trabajo de investigación.

Otro caso similar es el siguiente: 
La textualidad académica de estudiantes de origen indígena en estudios de posgrado: el proceso de elaboración de tesis

FASE 1: Hacer una propuesta metodologica que incluya las competencias a desarrollar en i, ii y iii ciclo de primaria, en lenguas originarias. (zapoteco del valle con variantes) (FMM-I4-F1)

FASE 2. Identificar y describir las funciones de las preguntas que el docente utiliza como mediación en su discurso para mejorar la comunicación y el desarrollo cognitivo en un aula con diversidad étnica. (FMM-I4-F2)

FASE 3: Así que este trabajo tiene como objetivo principal caracterizar y explicar las funciones de las preguntas que utiliza el docente en el proceso de enseñanza y aprendizaje en un grupo de $5^{\circ}$ y $6^{\circ}$ de Primaria de Educación Indígena. (FMM-I4-F3)

En el caso b), el autor inicia con un objetivo mucho más abierto como "Hacer una propuesta metodológica", sobre todo porque abarca todo un nivel de educación como el nivel de primaria. Después se va delimitando un poco más a "Identificar y describir las funciones de las preguntas", no obstante, aun es un poco abierto e impreciso porque refiere al discurso del docente e involucra la comunicación y desarrollo cognitivo que también es bastante complejo de investigar para un investigador principiante. En la fase 3, este objetivo se define un poco más cuando el autor decide "caracterizar y explicar las funciones de las preguntas", específicamente porque este objetivo en esta fase refiere concretamente al "proceso de enseñanza aprendizaje" lo cual hace que esté mejor delimitado porque se reduce un solo aspecto como es el proceso de enseñanza aprendizaje y deja fuera otros aspectos como la comunicación o el desarrollo cognitivo. Con esto este autor va definiendo todavía más su objetivo, lo que le da una orientación más precisa en su investigación.

Un tercer ejemplo que refuerza este eje de análisis es el siguiente:

FASE 1: Formar niños productores de diferentes textos. (HGL-I8-F1)

FASE 2: Caracterizar la lectura en voz alta que se realizan en un aula de sexto grado de educación primaria, el cual permita apreciar los procesos, funciones y significados que se configuran en torno a esta práctica (HGL-I8-F2)

FASE 3: A partir de este panorama y enfatizando en las actividades de lectura que se realizan en la escuela, se pretende caracterizar las prácticas de lectura que se realizan en la materia de español recuperar los elementos que permitan conocer de manera detallada lo que ocurre en un grupo de quinto grado de la Escuela Primaria Venustiano Carranza, ubicada en la comunidad de San Pedro Juchatengo (HGL-I8-F3)

En la fase 1 el objetivo es nuevamente es muy abierto e impreciso porque "formar niños productores de diferentes textos" puede tomar un tiempo a largo plazo, además de que este objetivo requiere de mayor información, por ejemplo, el tipo de textos en que se desea formar a los alumnos. En la fase 2, el autor define mucho más su objetivo utilizando un verbo 
más concreto como "Caracterizar la lectura en voz alta", pero aún queda abierto porque la segunda parte todavía es imprecisa, ya que en el "para quê" incluye conceptos complejos como "procesos, funciones y significados" que posiblemente no se logren con sólo “caracterizar" el fenómeno. En la fase 3, este objetivo se concreta un poco más porque, aunque se mantiene el verbo principal, se define mejor el objeto de estudio "caracterizar las prácticas de escritura que se realizan en la materia de español" donde se precisa que sólo se abarcará una asignatura, y los conceptos complejos expuestos en el "para qué" de la fase anterior se sustituyen por "conocer" lo que ocurre en el grupo escolar mencionado. Esto hace que el objetivo este más delimitado y presente mayor consistencia en lo que el autor desea lograr.

Con estos tres ejemplos, es posible demostrar que los objetivos van manifestando cambios de manera favorable a lo largo de las tres fases analizadas. En la fase inicial, se nota una clara dispersión en el o los propósitos que cada uno de los autores persigue en su investigación, éstos se caracterizan por ser muy abiertos y mostrar vaguedad, lo cual hace incierto el rumbo que tomará el estudio que se plantea. Al mismo tiempo, estos objetivos tienen el rasgo de reflejar la solución de la problemática mediante el desarrollo de propuestas que en general escapan de las posibilidades de autor, esto refleja que se pretende lograr una solución práctica a un problema práctico (Booth et al, 2008).

No obstante, en la fase 2, los objetivos muestran cambios significativos porque se van perfilando hacia un problema de investigación que se refleja en la estructura que presentan, desde el tipo de verbos que utilizan que son más concretos y alcanzables que intenta conocer o comprender un fenómeno más que resolver una problemática, así como el hecho de incluir el $q u e ́$ se investiga, para qué se investiga y el cómo se pretende hacerlo. Con esto, los objetivos en esta fase intermedia empiezan a consolidarse como un problema de investigación.

Finalmente, en la fase 3, los objetivos manifiestan otros cambios como el hecho de incluir una orientación contextual de la investigación, característica que no se refleja en las etapas anteriores. De igual forma, en esta fase los objetivos presentan cambios de contenido, no solo en el tipo de verbo si no que se hacen cambios en los verbos en sí mismos, los autores toman decisiones en cuanto a cuál es la intención real de su investigación. También hacen modificaciones en el complemento de su objetivo, donde delimitan su estudio a un aspecto particular de la problemática y en un ámbito escolar específico. Con esto el objetivo queda 
La textualidad académica de estudiantes de origen indígena en estudios de posgrado: el proceso de elaboración de tesis

más delimitado y con mayor consistencia, lo cual reduce los riesgos de perderse en la investigación tanto para el autor del borrador de tesis que se presenta como posiblemente para el lector que lo revisa en esta última etapa.

\section{Conclusiones específicas}

En este segundo caso, referente a los objetivos de investigación presentados en cada etapa, se demuestra cómo los autores de los textos revisados establecen objetivos que se caracterizan por ser abiertos e imprecisos y que crean ambigüedad en el rumbo que sigue la investigación. No obstante, también se refleja un corrimiento metodológico donde los objetivos en la fase final van adquiriendo mayor solidez y precisión, lo cual repercute directamente tanto en el rumbo como en el alcance de la investigación de cada uno de los autores revisados.

Sin embargo, es importante aclarar que la intención de este análisis no es determinar si los objetivos estuvieron bien formulados o no, o si éstos son suficientes para el desarrollo de la investigación para garantizar el buen término de la misma, lo cual es tarea del director de tesis. Lo que se pretende demostrar es que los alumnos/autores de las investigaciones realizadas presentan cambios importantes en sus objetivos, lo cual les ayuda a delimitar su objeto de estudio y también le va dando mayor consistencia a lo que desean desarrollar o están desarrollando. Es decir, estos estudiantes demuestran que ellos van adquiriendo conocimientos tanto teóricos como metodológicos que los hacen tomar decisiones en cuanto a lo que quieren investigar y cómo desean hacerlo, no es cuestión de evaluar si tales decisiones son las más apropiadas o pertinentes, sino mostrar que ellos como sujetos y autores de su investigación ya no son los mismos en comparación a cuando ingresaron al programa de maestría. Posiblemente, la formación que hayan adquirido en dicho programa de posgrado, les haya dado elementos y herramientas para delimitar en un primer momento su objeto de estudio mediante el planteamiento de sus objetivos.

\subsection{Caso 3. Los conceptos técnicos en la investigación}


Los conceptos técnicos son otro componente fundamental e inherente a toda investigación, y éste es uno de los saberes que los autores de los productos escritos revisados tienen y que los van manifestando a lo largo del proceso de construcción de su proyecto de tesis. Por ello, a continuación, se presentan los rasgos que caracterizan la explicación de los conceptos técnicos que los autores mencionados desarrollan a lo largo de dicho proceso. Con esto, se pretende tener un panorama general de cómo los autores de los productos escritos revisados en las tres etapas desarrollan sus conceptos técnicos, y al mismo tiempo conocer su comprensión de lo que éstos son e implican en una investigación.

\subsubsection{Fase 1: Un uso insistente de citas textuales}

En esta fase, los productos escritos revisados se caracterizan por incluir un marco conceptual muy breve, entre dos y seis páginas aproximadamente, donde los autores presentan e intentan desarrollar conceptos técnicos que ellos consideran necesarios explicar en su anteproyecto de investigación como aspirantes al Programa de Maestría en Sociolingüística de la Educación Básica y Bilingüe en la UPN 201. De los nueve trabajos analizados, cuatro incluyen un apartado conceptual, al cual le denominan como "Marco teórico" o "Marco referencial", dos presentan conceptos técnicos dentro de un solo rubro que refiere al planteamiento de la problemática, otro lo incluye dentro de un apartado contextual, y dos trabajos más no incluyen ningún concepto técnico o alguna referencia bibliográfica, lo cual sugiere que los autores de estos dos últimos documentos únicamente recurren a su experiencia personal y laboral para presentar su anteproyecto de investigación, particularmente su problemática, como ya se explicó en el caso 1. Así, son siete los documentos revisados en esta fase inicial, en los cuales encuentro rasgos recurrentes que caracterizan la explicación de los conceptos técnicos utilizados y que presento a continuación.

\section{a) La orientación disciplinar: el punto de partida}

Uno de los aspectos que se notan en los textos analizados en esta fase, es que algunos de éstos presentan una orientación de tipo disciplinar donde los estudiantes-investigadores especifican la perspectiva teórica que asumen para explicar el o los conceptos técnicos que 
La textualidad académica de estudiantes de origen indígena en estudios de posgrado: el proceso de elaboración de tesis

consideran pertinentes, como se muestra en los siguientes ejemplos.

Desde el punto de vista psicológico este proyecto de trabajo toma en cuenta los diferentes procesos mentales de los alumnos, es decir los estadios por los cuales cruza, a través de los cuales van adquiriendo nuevos conocimientos y reconstruyendo esquemas y estructuras mentales, a lo que Montserrat Moreno dice al respecto: (MAGV-I2-F1-p.9)

En este ejemplo, se presenta claramente la orientación disciplinar que el investigador expone al inicio de su argumento cuando dice "Desde el punto de vista psicológico", perspectiva teórica que refuerza con expresiones como "procesos mentales" y "esquemas y estructuras mentales", las cuales orientan la explicación hacia una mirada más psicológica.

Otro ejemplo que presenta una orientación disciplinar es el siguiente caso, el cual se concreta en una perspectiva teórica como se muestra a continuación:

\begin{abstract}
En base al planteamiento y justificación que ya se hizo en los apartados anteriores, estoy convencido de que es necesario realizar este trabajo de investigación para plantear y argumentar teóricamente una nueva modalidad a la evaluación de la enseñanza aprendizaje, ya que como se puede apreciar, la evaluación como proceso continuo requiere de una atención y reorientación constante si se le quiere dar un enfoque formativo, como acertadamente lo menciona la antología de 10 preguntas sobre la evaluación y 10 ideas claves para responderlas; (GHV-I3-F1-p. 12)
\end{abstract}

En este caso se evidencia que el investigador sugiere partir de "un enfoque formativo" para desarrollar su explicación en torno al concepto técnico de "evaluación" que él plantea en este extracto. Cabe aclarar que en este eje de análisis solamente se expone la orientación disciplinar que los autores pretenden asumir para explicar los conceptos técnicos, más no se analiza si el desarrollo de la explicación es compatible con la orientación disciplinar. Un ejemplo más es el que se muestra a continuación.

\begin{abstract}
La escritura vista desde el enfoque comunicativo implica que el alumno pueda comunicarse mejor con la lengua ${ }^{3}$, para esto es fundamental que los chicos escriban en la escuela textos de verdad para destinatarios concretos y con propósitos definidos. Por eso antes de la producción de cualquier texto ya sea un cuento, una carta, una noticia, o un cartel; es necesario que los alumnos hayan tenido experiencias de lectura de este tipo de textos. Las experiencias de lectura que el niño haya tenido le servirán a este para tener elementos, como el conocimiento de la superestructura de los textos, que le permitirán más oportunidades al momento de escribir. Para concretar el propósito de formar a todos los alumnos como practicantes de la cultura escrita tomando como referencia Fundamental las prácticas sociales de lectura y escritura . (HGL-I8F1-p.3)
\end{abstract}

En este ejemplo, el investigador sugiere explicar "la escritura vista desde el enfoque 
comunicativo", dejando claro desde donde pretende desarrollar su explicación. Además, refuerza este argumento cuando al final de este párrafo hace alusión a las "prácticas sociales de lectura y escritura" lo cual deja entrever que el enfoque comunicativo, según el autor, posiblemente se vincula de alguna manera con las prácticas sociales de la lectura y escritura.

Así, es posible observar en estos ejemplos que los estudiantes-investigadores exhiben una orientación disciplinar que provee el escenario teórico desde donde se desarrollará la explicación de los conceptos técnicos propuestos, definiendo con precisión la orientación disciplinar que pretende seguir el investigador.

\section{b) La estructura de las explicaciones de conceptos técnicos}

Otra de las características principales y recurrentes encontradas en los productos escritos analizados fue la estructura que manifiestan los textos revisados al momento de explicar algunos conceptos técnicos. Cabe aclarar que esta estructura se reconoce en los extractos de argumentos que constituyen el apartado conceptual de donde se obtuvieron, es decir, no es una estructura de todo el apartado teórico, sino sólo de algunas partes de él que, para efectos de esta investigación, son necesarios analizar. A continuación, se ejemplifican algunos casos donde se presentan rasgos coincidentes respecto la forma de explicar conceptos técnicos.

\section{Caso 1}

En este primer caso, se aprecia una explicación breve de algunos conceptos técnicos que la investigadora intenta desarrollar, organizando su explicación de la siguiente manera.

\section{Fase de Inicio: apertura de la explicación}

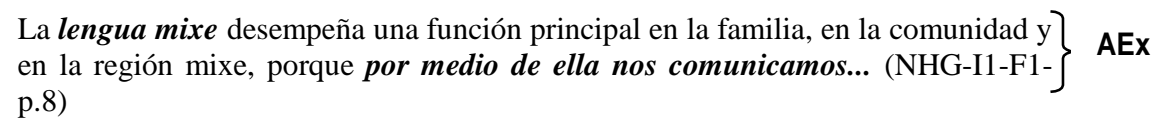

En este párrafo, se nota la apertura de la explicación (AEx) muy breve cuando el investigador alude a la "La lengua mixe" y a su función en "la familia, en la comunidad y en la región mixe", con lo cual se evidencia de manera general el tema que pretende desarrollar en su explicación, en este caso, respecto a la lengua mixe. 
La textualidad académica de estudiantes de origen indígena en estudios de posgrado: el proceso de elaboración de tesis

\section{Fase de desarrollo: Señalizaciones para vincular apertura y cita textual}

Este caso manifiesta la característica que el inicio de la explicación también corresponde a la apertura de una cita (AdC), como se muestra a continuación.

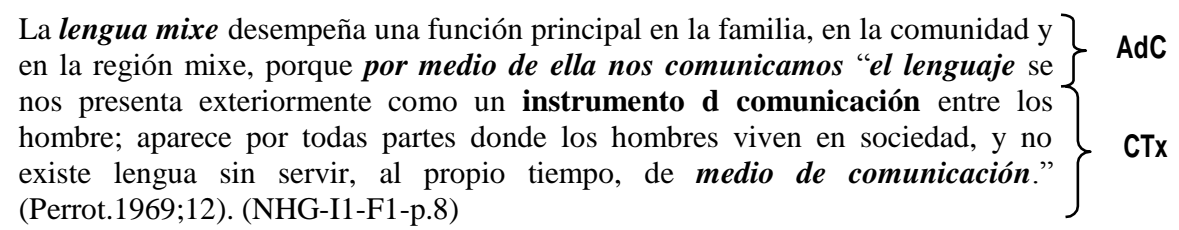

En este párrafo, cuando el investigador alude a la función de "La lengua mixe" inicia su explicación, pero a la vez introduce una cita textual (CTx) donde se define "el lenguaje" como primer concepto técnico en esta explicación. Así, el primer argumento que hace referencia a la función de la "lengua mixe..." corresponde a apertura de la cita (ApC) porque en ella el investigador anuncia la cita textual (CTx) que continúa, es decir, adelanta cierta información que también se menciona en la cita textual planteada. Por ejemplo, cuando la autora menciona que "por medio de ella nos comunicamos" refiriéndose a la "lengua mixe", manifiesta que dicha lengua funciona como un "medio de comunicación", idea que también se señala en la cita textual cuando el autor citado asevera que el "lenguaje es un instrumento de comunicación". Esto significa que la autora se vale de señalizaciones de repetición discursiva para intentar vincular su argumento con el de los autores citados, recuperando una de las ideas principales de la cita textual para plantear su argumento y asumiendo implícitamente una relación entre los conceptos "lengua mixe" y "lenguaje".

De aquí sigue otra apertura de una cita (ApC) seguida de otra cita textual, estructura que se repite dos veces, y donde se plantea un segundo concepto técnico que es "el aprendizaje" como se muestra a continuación.

Los niños mixes aprenden la lengua mixe, porque esto se enseña desde la casa, con la familia y con la comunidad, así el niño se va desarrollando socialmente, al $\}$ estar interactuando con los otros miembros de la sociedad "el aprendizaje surge directamente de las experiencias personales..., como aprendemos mas sobre nosotros mismos y llegamos a descubrir y reconstruir nuestra propia realidad". (Coll.1990, 103)

El aprendizaje se da en todo el proceso de la vida del ser humano, en la cual en un cierto contexto se apropia de conocimientos, habilidades y destrezas. "El\} aprendizaje es un proceso mediante el cual un sujeto adquiere destrezas o 
habilidades prácticas incorpora contenidos, y adopta nuevas estrategias de conocimientos “. (Sanchez.1998,116). (NHG-I1-F1-p.8)

En este extracto se observa claramente que la estructura presenta una apertura de la cita seguida de una cita textual en ambos párrafos, donde se pretende explicar otro concepto técnico que es "el aprendizaje", término que, al igual que el anterior, la autora intenta vincular con la lengua mixe, mediante el uso de señalizaciones de repetición léxica y discursiva expresados en la apertura de la cita (AdC). Por ejemplo, en el primer párrafo, la investigadora abre un argumento que alude a que "Los niños mixes aprenden la lengua mixe..." donde el término "aprender" se expresa en el concepto técnico de la cita textual (CTx) que es "El aprendizaje". De igual forma, esta característica se nota claramente en el párrafo que continúa, cuando en la apertura de cita (AdC), la investigadora adelanta algunos términos expresados en la cita textual (CTx), como "Aprendizaje", "proceso", “conocimientos, habilidades y destrezas", vocablos que están explícitamente en la cita textual. De esta manera, la autora nuevamente intenta vincular su argumento de la apertura con la cita textual.

Así, en estos ejemplos se observa claramente que, mediante la estrategia de señalizaciones de repetición léxica y discursiva, la investigadora intenta relacionar su argumento en la apertura de la cita con los conceptos técnicos que ella plantea, donde ambos conceptos se pretenden explicar a partir de argumentos de autores externos. No obstante, vemos que la forma en que la autora organiza su explicación se limita al planteamiento de citas textuales, asumiendo la relación que puede existir entre ambos conceptos técnicos y sus propios argumentos, porque una vez que introduce la cita de manera breve, inmediatamente después aparece la cita textual (CTx), esquema se nota en la estructura de este extracto que constituye la fase de desarrollo de su argumento.

\section{Fase de cierre: coda y contribuciones}

En esta fase de cierre de la explicación (CEx), la investigadora concreta su argumento y se apoya del uso de la coda para finalizar su argumento, en la cual también se observa una contribución a un conocimiento que la autora expresa en esta fase como se muestra a continuación.

todos estos aprendizajes que el niño y la niña mixe adquiere desde su entorno, $\underline{\text { es }}$ primordial recuperarla en el aula escolar. La lengua mixe que es uno de los 
La textualidad académica de estudiantes de origen indígena en estudios de posgrado: el proceso de elaboración de tesis

primeros aprendizajes por el niño y la niña introducirla en el salón de clases no
es un obstáculo sino al contrario lograremos construir un aprendizaje
significativo. (NHG-I1-F1-p.8)

Este cierre de la explicación (CEx) se identifica porque en él la investigadora recurre al uso de la coda para anunciar que su explicación ha finalizado respecto a "la lengua mixe" tema con el cual inicia su explicación. Este uso de la coda se evidencia cuando recurre a la expresión impersonal "es primordial recuperarla en el aula escolar...” expresión que alude a la lengua mixe y a la importancia y necesidad de incluirla en el entorno escolar, pero también es una forma de manifestar que se está concluyendo el argumento porque tiene un sentido de recomendación por parte de la autora, es decir que al momento de sugerir algo implica que ha terminado con el desarrollo de la explicación. Este cierre se refuerza con una contribución que la investigadora intenta hacer a un conocimiento, para esto ella utiliza una cláusula en futuro simple para mostrar su compromiso e interés de hacer algo por solucionar o mejorar tal situación problemática, lo cual se manifiesta en su argumento cuando ella dice "lograremos construir un aprendizaje significativo". Así, el cierre de la estructura identificada se compone del uso de la coda y de la contribución que a la investigadora le interesa realizar.

De esta forma, vemos en el análisis de este primer caso el intento de la autora por desarrollar una explicación muy breve en torno a la lengua mixe con lo cual recurre a la explicación de dos conceptos técnicos que son "el lenguaje” y "el aprendizaje”, quedando la estructura identificada de la siguiente manera:

\begin{tabular}{|l|l|l|}
\hline & Fase de Inicio & $\begin{array}{l}\text { Apertura de la explicación (AEx) } \\
\text { Apertura de la cita (AdC) }\end{array}$ \\
\cline { 2 - 3 } FASE 1. & Fase de Desarrollo & $\begin{array}{l}\text { Apertura de la cita (AdC) } \\
\text { Cita textual (CTx) } \\
\text { TÉCNICOS }\end{array}$ \\
& & $\begin{array}{l}\text { Apertura de la cita (AdC) } \\
\text { Cita Textual (CTx) } \\
\end{array}$ \\
& & Apertura de la cita (AdC) \\
& & Cita Textual (CTx) \\
\cline { 2 - 3 } & Fase de Cierre & Cierre de la explicación (CEx) \\
\hline
\end{tabular}

Esta explicación se caracteriza por una fase de inicio donde la investigadora abre su argumento y da pistas del tema a seguir en su explicación. Sin embargo, este inicio de la explicación funciona a la vez como una apertura de la cita que corresponde a la fase de desarrollo, etapa que se desarrolla básicamente por el uso de citas textuales, lo cual muestra que los autores citados tienen el rol principal. Finalmente, en el cierre se evidencia el uso de la 
coda, donde la investigadora anuncia el final de su explicación y se plantea una contribución al conocimiento del tema tratado mediante la idea de mejorar la situación problemática. Así, esta estructura se caracteriza por un uso insistente de citas textuales donde la voz de los autores externos juega el papel principal; quedando los argumentos de la autora subordinados y dependientes de las citas textuales planteadas.

\section{Caso 2}

El siguiente caso muestra una estructura y características similares al anterior.

\section{Fase de inicio: apertura de la explicación}

Desde el punto de vista psicológico este proyecto de trabajo toma en cuenta los diferentes procesos mentales de los alumnos, es decir los estadios por los cuales cruza, a través de los cuales van adquiriendo nuevos conocimientos y AEx reconstruyendo esquemas y estructuras mentales... (MAGV-I2-F1-p.9)

En esta apertura de la explicación (AEx), el investigador enuncia la orientación disciplinar que asume, en este caso refiere al "punto de vista psicológico", pero además plantea que su "proyecto de trabajo toma en cuenta los diferentes los procesos mentales", expresión con la que deja claro el tema que guiará su explicación, idea que refuerza cuando alude a "esquemas y estructuras mentales", con lo cual inicia su argumento.

\section{Fase de Desarrollo: argumentos divergentes}

Esta etapa muestra características similares al caso anterior, específicamente porque la apertura de la explicación también corresponde a una apertura de la cita (AdC) donde el estudiante investigador expone el concepto técnico a explicar que refiere a "los procesos mentales" y anuncia la cita textual (CTx) que sigue, mediante el uso de señalizaciones de repetición discursiva, como se evidencia en el siguiente extracto.

Desde el punto de vista psicológico este proyecto de trabajo toma en cuenta los diferentes procesos mentales de los alumnos, es decir los estadios por los cuales cruza, a través de los cuales van adquiriendo nuevos conocimientos y reconstruyendo esquemas y estructuras mentales, a lo que Montserrat AdC Moreno dice al respecto:

Es necesario conocer los procesos mentales propios de la inteligencia infantil y sus formas particulares de interpretar la realidad para no contrariar su evolución espontánea, si no potenciarla. (MontserratMoreno 1983, p.22) (MAGV-I2-F1-p.9) 
La textualidad académica de estudiantes de origen indígena en estudios de posgrado: el proceso de elaboración de tesis

En la apertura de la cita (AdC), el autor del texto alude a "los procesos mentales de los alumnos", y en la cita textual (CTx) que continúa se menciona los "procesos mentales propios de la inteligencia infantil", con lo cual el investigador intenta vincular su argumento de la apertura con la cita textual. De aquí, viene un párrafo donde el autor intenta plantear un argumento más personal pero también desvinculado del tema que trata.

Socialmente hablando la formación de hombres y mujeres requiere la definición de rasgos a alcanzar, concretándolos en una sociedad crítica que excluya la opresión; formando así ciudadanos analíticos, críticos, reflexivos, autónomos, que pueden ejercer su derecho a la participación y representatividad, pretendiendo así alcanzar una sociedad pluralista, tolerante y fundada en el reconocimiento de la otredad. (MAGV-I2-F1-p.9)

Como se puede observar en el argumento anterior el investigador parte de una postura "psicológica" para abrir su discusión, es decir, se centra en el aspecto cognitivo de los alumnos como él mismo manifiesta apoyado en la cita textual. Sin embargo, el argumento personal que plantea en este párrafo está desvinculado porque éste hace alusión, en varios momentos, a aspectos de la sociedad. Por ejemplo, cuando él menciona "Socialmente hablando." o "concretándonos en una sociedad crítica...", o "pretendiendo así alcanzar una sociedad pluralista", evidencia que su argumento gira en torno a aspectos sociales y no a cuestiones cognitivas como lo cita anteriormente. Después, continúa otra apertura de una cita (AdC) que conlleva otro concepto técnico, como se exhibe a continuación.

Por otro lado, el habito a la lectura y la producción de textos no es un proceso que se de de la noche a la mañana, para facilitar este proceso en los alumnos es necesaria la constante motivación para que sienta la necesidad de leer y escribir. Para ellos es necesario mostrarles las diferentes aplicaciones y utilidades de la lectura así como de sus textos producidos, como nos menciona Margarita Gómez Palacio: (p. 8)

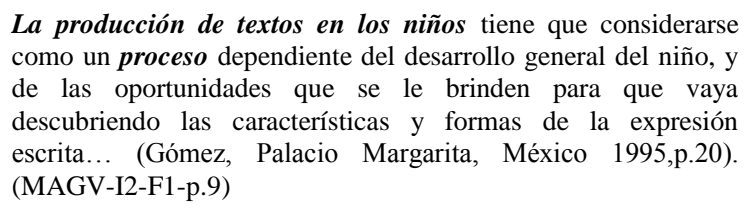
como un proceso dependiente del desarrollo general del niño, y de las oportunidades que se le brinden para que vaya descubriendo las características y formas de la expresión escrita... (Gómez, Palacio Margarita, México 1995,p.20). (MAGV-I2-F1-p.9)

AdC

CTx

Aquí vemos que en la apertura de la cita $(\mathrm{AdC})$, mediante un conector de transición "Por otro lado", el investigador introduce otro tema que refiere al "hábito a la lectura y la producción de textos", que retoma en la cita textual (CTx) cuando hace mención de la "producción de textos", y que intenta vincular mediante el uso de señalizaciones de repetición discursiva. Por ejemplo, cuando el autor refiere en la apertura de la cita a la "producción de 
textos" y al "proceso en los alumnos", esta idea se manifiesta igualmente en la cita textual cuando se alude a "La producción de textos en los niños... como un proceso" con lo cual el investigador relaciona su argumento en la apertura de la cita con la cita textual. No obstante, no se aprecian explicaciones que vinculen este concepto técnico con los argumentos anteriores.

\section{Fase de Cierre: el uso de la coda}

Para llegar a este objetivo se trabajará con las técnicas Freinet, además de otras mas que se presentan según PRONALES. Comenzaremos mencionando a las técnicas freinet para continuar con las estrategias de PRONALES. (MAGV-I2-F1-p.9)

El cierre de este argumento (CEx) se caracteriza por el uso de la coda donde el investigador anuncia de cierta forma el término de su explicación. En este caso el autor hace referencia a clausulas en futuro simple que indican lo que continua en otro apartado. Por ejemplo, cuando él dice "Para llegar a este objetivo se trabajará con las técnicas Freinet..." y "Comenzaremos mencionando las técnicas freinet para continuar con las estrategias de PRONALES”, está señalando que ya terminó su explicación respecto a los conceptos técnicos aludidos, porque está indicando lo que continua, en este caso este cierre es la apertura de otra explicación, donde, como él dice, mencionará las técnicas freinet y otras estrategias en otro apartado.

De esta manera, en este fragmento se identifica que la explicación gira en torno a dos conceptos técnicos que son "los procesos mentales" y "la producción de textos", los cuales el investigador intenta desarrollar apoyado en citas textuales, quedando la estructura de la siguiente manera.

\begin{tabular}{|l|l|l|}
\hline \multirow{4}{*}{$\begin{array}{l}\text { FASE 1. } \\
\text { CONCEPTOS }\end{array}$} & Fase de Inicio & $\begin{array}{l}\text { Apertura de la explicación (AEx) } \\
\text { Apertura de la cita (AdC) }\end{array}$ \\
\cline { 2 - 3 } TÉCNICOS & Fase de & Apertura de la cita (AdC) \\
& desarrollo & $\begin{array}{l}\text { Cita textual (CTx) } \\
\text { Argumento Personal (ArP) } \\
\end{array}$ \\
& & $\begin{array}{l}\text { Apertura de la cita (AdC) } \\
\text { Cita Textual (CTx) }\end{array}$ \\
\cline { 2 - 3 } & Fase de cierre & Cierre de la explicación (CEx) \\
\hline
\end{tabular}


La textualidad académica de estudiantes de origen indígena en estudios de posgrado: el proceso de elaboración de tesis

En la estructura identificada se muestra que ésta tiene una fase de inicio de la explicación, donde el investigador expresa brevemente, y a grandes rasgos, el tema a tratar en su explicación. Después, se nota una fase desarrollo donde se aprecia un uso insistente de citas textuales y un intento por parte del investigador para plantear un argumento más personal pero que está desvinculado del argumento inicial que él propone. Además, se observa que hace un cambio drástico de tema apoyado en un conector de transición "por otro lado" con el cual introduce un nuevo concepto técnico que, al menos explícitamente, no se relaciona con su argumento anterior, lo cual hace que esta fase presente implícitos tanto en la relación entre los dos conceptos técnicos que se plantean, así como en el intento del investigador por exponer una reflexión más propia. Finalmente, en el cierre, se caracteriza por el uso de cláusulas en futuro simple para indicar el final de su explicación, es decir, el recurre a la coda para cerrar su argumento que, a la vez, conecta con otra explicación. Así, la estructura identificada es bastante similar a la del primer ejemplo, pero para reforzar este eje de análisis de muestra un caso más que evidencia esta lógica de la explicación, como se presenta a continuación.

\section{Caso 3}

\section{Fase de inicio: una apertura personal}

Este caso comparte características similares a los casos anteriores, pero también exhibe rasgos particulares como una apertura personal de la explicación, es decir, se nota la presencia del investigador, como se muestra a continuación.

\footnotetext{
En este sentido, se hace necesario retomar nuestro compromiso como profesores investigadores a fin de conocer nuevas modalidades de trabajo e innovar nuestra practica laboral, así pues estoy seguro de que una evaluación diagnóstica aplicada_desde el inicio de una actividad o tema sería de gran utilidad para valorar el nivel de conocimiento de los alumnos y posteriormente retomarlo para ofrecer una enseñanza más adecuada en los nuevos contenidos haciendo más significativo su conocimiento. (GHV-I3-F1-p. 12)
}

AEx

Este primer párrafo corresponde a la apertura de la explicación (AEx) la cual muestra un rasgo más personal del investigador cuando el menciona que "se hace necesario retomar nuestro compromiso como profesores investigadores a fin de conocer nuevas modalidades de trabajo e innovar nuestra práctica laboral", argumento donde él plantea su compromiso por mejorar su práctica docente. Además, él se asume como un "profesor investigador”, con lo cual exhibe su voz, característica que se desarrollará más adelante. En este mismo párrafo, 
también se muestra el concepto técnico que pretende desarrollar en su explicación, en este caso es la "evaluación diagnóstica".

\section{Fase de desarrollo: Señalizaciones para vincular apertura y cita textual}

En esta apertura de la cita, hay una parte que corresponde a una apertura de la cita $(\mathrm{AdC})$, con la cual inicia la fase de desarrollo, como se muestra a continuación.


inicio de una actividad o tema sería de gran utilidad para valorar el nivel de conocimiento de los alumnos y posteriormente retomarlo para ofrecer una enseñanza más adecuada en los nuevos contenidos haciendo más significativo su conocimiento;

"La evaluación inicial o diagnostica se debe realizar al inicio del curso o de una sesión educativa con el fin de conocer los conocimientos previos que trae el alumno y así orientar la profundidad y forma de desarrollar los

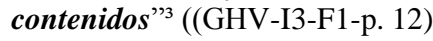

${ }^{3}$ VILLALOBOS Elvira M. "La naturaleza de la evaluación”, pag. 201 (Nota al pie de página en el documento original)

AdC

CTx

En el primer párrafo, se nota claramente que el investigador no sólo anuncia el concepto técnico a desarrollar en su explicación, sino también éste funciona como apertura de la cita (AdC) que continúa; es decir, el autor del texto anticipa información que se menciona en la cita textual mediante la estrategia de señalizaciones de repetición léxica y discursiva cuando en su argumento retoma las ideas centrales de la cita textual. Por ejemplo, cuando el investigador alude en la apertura de la cita $(\mathrm{AdC})$ a "la evaluación diagnóstica aplicada desde el inicio de una actividad o tema" es un argumento que está claramente en la cita textual (CTx), donde el autor citado menciona "La evaluación inicial o diagnostica se debe realizar al inicio del curso o de una sesión"; ambos argumentos están vinculados por el uso se repeticiones discursivas que evidencian la misma idea. Lo mismo ocurre cuando el autor del texto argumenta sobre la utilidad de "valorar el nivel de conocimientos de los alumnos... para ofrecer una enseñanza más adecuada en los nuevos contenidos" idea que también se menciona en la cita textual cuando el autor citado señala "conocer los conocimientos previos que trae el alumno y orientar... la forma de desarrollar los contenidos". Esto dos argumentos están conectados precisamente por las señalizaciones de repetición discursiva a las cuales el autor del texto recurre para plantear su argumento antes de la cita. Con esto, queda claro que el investigador anticipa el contenido que expone en la cita textual. De aquí, continúa otra apertura de la cita (AdC) seguida de otra cita textual (CTx), como se presenta a continuación. 
Para obtener resultados reales y verídicos en la evaluación será necesario tomar en cuenta muchos aspectos que demuestren los avances que cada alumno va presentando, tales como la participación del alumno en el aula, su cuaderno de trabajo, la observación del maestro (lista de cotejo), la escritura, el diario del alumno y del maestro, etc., para tomarlos como referencia de partida al abordar un nuevo tema y valorar los logros que se vayan alcanzando en base a los objetivos propuestos durante todo el proceso de su aprendizaje, de acuerdo con lo que se señala en 10 preguntas sobre la evaluación y 10 ideas claves para responderlas (p. 12-13)

\footnotetext{
"Se tiende a pensar que solo un examen tradicional pone de manifiesto qué es lo que el alumno sabe y cuales son sus errores y dificultades, cuando de hecho se pueden utilizar múltiples fuentes de información y aplicar instrumentos bien variados que se adapten a la diversidad de estilos motivacionales y de aprendizaje de los estudiantes... Los instrumentos de evaluación (cuestionarios de todo tipo, mapas conceptuales, diarios de clase, exposiciones verbales, investigaciones, observaciones, listas de cotejo,...) se deben escoger en función de los objetivos de la evaluación y el tipo de contenido que se va a evaluar"' (GHV-I3-F1-p. 13)

'ACTIVIDADES, INSTRUMENTOS Y TECNICAS DE EVALUACIÓN, en 10 preguntas sobre evaluación y 10 ideas clave para responderlas, pag. 103. (Nota al pie de página en el documento original)

El primer párrafo refiere a la apertura de la cita $(\mathrm{AdC})$ donde el investigador nuevamente anticipa información mencionada en la cita textual (CTx) que continua, recurriendo a la estrategia de señalizaciones de repetición léxica y discursiva. Por ejemplo, en la apertura de la cita (AdC) se hace mención a "aspectos que de muestren los avances..." idea que se nota en la cita textual (CTx) cuando el autor citado refiere a “instrumentos de evaluación”. De ambos argumentos, se desprende una lista de vocablos que se encuentran tanto en la apertura como en la cita textual. Así, cuando el investigador menciona en la apertura de la cita "cuaderno de trabajo, la observación del maestro (lista de cotejo), la escritura, el diario del alumno y del maestro", son vocablos que también se expresan en la cita textual cuando el autor citado refiere a "Los instrumentos de evaluación (cuestionarios de todo tipo, mapas conceptuales, diarios de clase, exposiciones verbales, investigaciones, observaciones, listas de cotejo,...)". De igual manera, la apertura hace alusión a los "objetivos propuestos" señalización que también se encuentra presente en la cita textual cuando el autor refiere a "los objetivos de la evaluación". Con esto se demuestra una vez más que la apertura de la cita incluye información de la cita textual, con lo cual el investigador vincula sus argumentos con el de las citas textuales. Aquí termina la fase de desarrollo de la explicación e inicia la fase de cierre.

\section{Fase de Cierre: La evaluación de la explicación}


Como ya se mencionó anteriormente, es necesario considerar la evaluación como un proceso continuo, ya que la evaluación no solo se limita al momento en el que se resuelve un examen o se evalúa a los alumnos, por el contrario, es un proceso constante que esta presente en todo momento, lo cual nos va proporcionando información sobre los avances en los conocimientos que los alumnos van adquiriendo, así como también nos indica si se están cumpliendo o no los objetivos propuestos y en que medida se están logrando.... (GHV-I3-F1-p. 13)

Este cierre de la explicación (CEx) se identifica claramente cuando el autor del texto expresa "Como ya se mencionó anteriormente", expresión con la cual indica claramente el cierre de su explicación donde concreta su argumento, pero también hace una evaluación del mismo, es decir, realiza una valoración de lo explicado, esto se refleja cuando menciona que "es necesario considerar la evaluación como un proceso continuo" argumento que el elabora a partir de su explicación, ya que esta idea no se encuentra de forma explícita en el desarrollo de su argumentación, sino que el autor la elabora a partir de dicha explicación. Además, en este cierre, el investigador concreta su explicación cuando recupera algunas de las ideas principales desarrolladas en los argumentos anteriores. Por ejemplo, cuando refiere a los "avances en los conocimientos que los alumnos van adquiriendo" y cuando hace mención a los "objetivos propuestos" son argumentos que se pueden ver claramente en varios momentos del desarrollo de su explicación. Con esto, queda claro que, en esta fase de cierre, el autor recupera argumentos anteriores de autores externos para cerrar el suyo.

Así, esta explicación se caracteriza por desarrollar el concepto técnico que refiere a "la evaluación diagnóstica", por mantener una estructura organizada con un inicio donde el investigador abre su explicación haciendo referencia a aspectos más personales como su compromiso por la mejora en su práctica docente, rasgo particular que presenta esta explicación. También, se identifica una etapa de desarrollo de la explicación donde el autor apoya sus argumentos mayormente en el planteamiento de citas textuales que evidencian el intento del investigador por explicar el concepto técnico aludido y por vincular sus argumentos y el de los autores citados. Finalmente, en la etapa de cierre, el investigador recupera ideas desarrolladas previamente y realiza una especie de evaluación de su explicación, quedando la estructura identificada de la siguiente manera: 
La textualidad académica de estudiantes de origen indígena en estudios de posgrado: el proceso de elaboración de tesis

\begin{tabular}{|c|c|c|}
\hline \multirow{3}{*}{$\begin{array}{l}\text { FASE } 1 . \\
\text { CONCEPTOS } \\
\text { TÉCNICOS }\end{array}$} & Fase de Inicio & Apertura de la explicación (AEx) \\
\hline & Fase de desarrollo & $\begin{array}{l}\text { Apertura de la cita (AdC) } \\
\text { Cita textual (CTx) } \\
\text { Apertura de la cita (AdC) } \\
\text { Cita Textual (CTx) }\end{array}$ \\
\hline & Fase de cierre & Cierre de la explicación (CEx) \\
\hline
\end{tabular}

De esta manera, la estructura que se identifica y que comparten los casos ejemplificados en este eje de análisis inicia con una "apertura de la explicación” muy breve que a la vez es la "apertura de una cita" donde el autor introduce de forma concisa una cita textual. Después sigue una "cita textual" donde el investigador se vale de los argumentos de otros autores para desarrollar su explicación del concepto o conceptos técnicos que plantea, estructura que se repite dos veces antes del "cierre del argumento" donde el autor recupera ideas y/o ideas desarrolladas previamente, y con los cuales termina su explicación y, en algunos casos, lo vincula con otra cita.

Entre otras características que comparten los ejemplos analizados, es que ellos intentan explicar, en un extracto corto, al menos dos conceptos técnicos que precisamente por la característica de ser explicaciones breves, los conceptos se presentan con mucha premura. Esto ocasiona una serie de implícitos que no dejan claro el argumento que los autores intentan desarrollar, específicamente, estos vacíos se encuentran entre la apertura de la cita y la cita textual puesto que el investigador asume la relación que existe entre ambas, ocasionando que la explicación quede fragmentada y/o incompleta. Otro aspecto que se notó en este eje de análisis, es la insistencia de recurrir a citas textuales para explicar, o al menos, definir en parte un concepto técnico provocando que la explicación se quede en el nivel de enunciar dichos conceptos, a veces sin relación entre ellos, lo cual genera desarticulación, puesto que se asume el hecho de que citar autores externos para explicar un concepto técnico es suficiente para desarrollar un argumento o discusión. Por tanto, las citas textuales que definen los conceptos técnicos mantienen un rol primordial en los extractos revisados.

Con estos ejemplos, se aprecia que la forma de vincular un argumento con una cita textual es mediante el uso de señalizaciones de repetición léxica y discursiva que les permite a los autores elaborar un argumento antes y/o después de la cita textual. Sin embargo, el hecho de recurrir esta estrategia de forma excesiva, limita a los autores de los productos escritos revisados en el sentido de que sus argumentos quedan subordinados a los argumentos de los 
autores citados, ya que dichos ejemplos evidencian la ausencia de un argumento propio por parte de los autores. Es decir, los autores se valen de términos e ideas de otros autores para intentar construir su propio argumento, pero aún con limitaciones porque desde la manera en que estructuran su explicación, nos damos cuenta que hay un uso excesivo de citas textuales. Por lo tanto, son los autores citados los que juegan el rol principal en el desarrollo del manuscrito.

\section{c) La voz de los autores en la apertura y cierre de la explicación}

Otro de los aspectos identificados en el desarrollo de la explicación de conceptos técnicos es el papel que juega la voz de los investigadores en los documentos revisados, donde se aprecia claramente que la voz de los autores investigados se explicita únicamente en la apertura de un argumento y/o en el cierre del mismo como se muestra a continuación.

\footnotetext{
La lengua mixe desempeña una función principal en la familia, en la comunidad y en la región mixe, porque por medio de ella nos comunicamos "el lenguaje se nos presenta exteriormente como un instrumento d comunicación entre los hombre; aparece por todas partes donde los hombres viven en sociedad, y no existe lengua sin servir, al propio tiempo, de medio de comunicación.”(Perrot.1969;12)

todos estos aprendizajes que el niño y la niña mixe adquiere desde su entorno, es primordial recuperarla en el aula escolar. La lengua mixe que es uno de los primeros aprendizajes por el niño y la niña introducirla en el salón de clases no es un obstáculo sino al contrario lograremos construir un aprendizaje significativo. (NHG-I1-F1, p.8)
}

En este primer ejemplo, es posible observar que la autora del texto manifiesta su voz en la apertura que ella hace de la cita textual que plantea. Cuando ella dice "por medio de ella nos comunicamos", hace referencia a la "lengua mixe", por ello queda claro que ella es hablante de la lengua mixe y que a través de ella se comunica, por tanto, es posible advertir que ella pertenece a esta cultura. En el párrafo que le sigue, su voz se evidencia en el siguiente argumento "lograremos construir un aprendizaje significativo" en donde su voz es impersonal porque utiliza el futuro simple en primera persona del plural para exponer la necesidad de atender una problemática y su compromiso por hacerlo. Con este ejemplo, vemos que la voz de la autora se reduce a abrir la cita textual y a cerrar un argumento. No obstante, no se observa su voz en el desarrollo del argumento. Esta misma forma de proyectar la voz del autor se nota en el siguiente ejemplo. 
La textualidad académica de estudiantes de origen indígena en estudios de posgrado: el proceso de elaboración de tesis

Desde el punto de vista psicológico este proyecto de trabajo toma en cuenta los diferentes procesos mentales de los alumnos, es decir los estadios por los cuales cruza, a través de los cuales van adquiriendo nuevos conocimientos y reconstruyendo esquemas y estructuras mentales...

Para llegar a este objetivo se trabajará con las técnicas Freinet, además de otras mas que se presentan según PRONALES. Comenzaremos mencionando a las técnicas freinet para continuar con las estrategias de PRONALES. (MAGV-I2-F1-p.9)

En este ejemplo, se observa también que en la apertura de la explicación correspondiente al primer párrafo evidencia la voz impersonal del investigador cuando refiere a al proyecto (de investigación) que él plantea desarrollar, así cuando él menciona "este proyecto de trabajo toma en cuenta los diferentes procesos mentales...", está mostrando su voz de forma impersonal para expresar la orientación temática de su explicación. El segundo párrafo corresponde a la fase de cierre donde mantiene esta característica de expresar su voz de forma esta impersonal. Por ejemplo, cuando el investigador argumenta que "se trabajará con las técnicas Freinet” está mostrando su voz respecto a lo que continúa en su explicación, idea que refuerza cuando dice "comenzaremos mencionando las técnicas freinet..." donde su voz está incluida en el pronombre personal "nosotros". Otro ejemplo que se nota claramente en las explicaciones mostrados en el eje de análisis anterior es el siguiente.

\footnotetext{
En este sentido, se hace necesario retomar nuestro compromiso como profesores investigadores a fin de conocer nuevas modalidades de trabajo e innovar nuestra practica laboral, así pues estoy seguro de que una evaluación diagnóstica aplicada desde el inicio de una actividad o tema sería de gran utilidad para valorar el nivel de conocimiento de los alumnos y posteriormente retomarlo para ofrecer una enseñanza más adecuada en los nuevos contenidos haciendo más significativo su conocimiento; (GHV-I3-F1-p. 12)
}

Como ya se mencionó anteriormente, es necesario considerar la evaluación como un proceso continuo, ya que la evaluación no solo se limita al momento en el que se resuelve un examen o se evalúa a los alumnos, por el contrario, es un proceso constante que esta presente en todo momento, lo cual nos va proporcionando información sobre los avances en los conocimientos que los alumnos van adquiriendo, así como también nos indica si se están cumpliendo o no los objetivos propuestos y en que medida se están logrando.... (GHV-I3-F1-p. 13)

En este tercer ejemplo, el autor muestra su voz impersonal en la apertura de su explicación igualmente implicada en el pronombre personal "nosotros" cuando expone que "se hace necesario retomar nuestro compromiso como profesores investigadores" donde él manifiesta tanto su compromiso laboral, así como su identidad como profesor e investigador, idea que refuerza cuando afirma "innovar nuestra práctica laboral" en la cual refiere a la mejora de su práctica docente. En su siguiente argumento que es "así pues estoy seguro de 
que..." esta vez el investigador recurre a la primera persona de singular para manifestar su seguridad por atender una situación de su práctica docente mediante la inclusión de una evaluación diagnóstica. Así, en la apertura de la explicación, se evidencia que la voz del autor exhibe su identidad como profesor e investigador y, a la vez, su compromiso por mejorar una situación problemática.

En el párrafo que continua correspondiente a la fase de cierre de la explicación, el investigador expresa su voz de forma impersonal refiriéndose a sus argumentos anteriores cuando dice "Como ya se mencionó anteriormente" con lo cual indica explícitamente el cierre de su argumento. Además, similar al caso anterior, la voz del autor en la fase de cierre queda inmersa en pronombre de objeto indirecto "nos", cuando él señala "lo cual nos va proporcionando información" o "nos indica si se están cumpliendo o no los objetivos...", es decir, la voz del investigador está nuevamente inmersa en un "nosotros".

Un último ejemplo respecto al voz de los autores es el que se presenta a continuación:

\begin{abstract}
A partir de una experiencia personal puedo decir que el alumno tiene mayor conocimiento e información acerca de un saber comunitario que el propio docente, porque cotidianamente esta inmerso en estas actividades en su comunidad. Por lo tanto considero que estos conocimientos pueden favorecer una amplia gama de contenidos que fortalezcan no solo la identidad cultural del niño que si no también el acceso a nuevos conocimiento a partir de lo propio.

Gashé menciona que "los conocimientos y prácticas culturales están socialmente situadas en las actividades cotidianas de los habitantes de las comunidades" Por lo tanto considero que es necesario enriquecer este tipo de prácticas o conocimientos, accediendo a nuevos contenidos o temas que bien pueden ayudar a propiciar una educación intercultural, encauzando a los docentes a ser investigadores de su propia practica diseñando propuestas pedagógicas que puedan fortalecer una educación Bilingüe Intercultural. (WEZ-I9-F1-p.5)
\end{abstract}

En el primer párrafo que abre la explicación, el autor recurre a su "experiencia personal" para emitir una afirmación, donde utiliza el presente simple en primera persona singular del verbo "poder", en esta afirmación se puede deducir que él es un profesor puesto que habla del alumno y del docente. Después, en las frases donde dice "Por lo tanto considero que estos conocimientos pueden favorecer...", su voz está expresando una opinión, específicamente cuando menciona "considero que". Aquí vemos que en la apertura de esta explicación el investigador expresa su voz de forma personal.

El siguiente párrafo corresponde a la fase de cierre donde nuevamente el investigador manifiesta su voz de forma personal para exponer una opinión respecto al tema que trata, 
La textualidad académica de estudiantes de origen indígena en estudios de posgrado: el proceso de elaboración de tesis

cuando el señala "Por lo tanto considero que es necesario enriquecer este tipo de prácticas..." utilizando la misma expresión que en la apertura, "considero que...", mostrando así su opinión e interés por hacer algo para mejorar alguna situación. Concretamente este ejemplo, la voz del investigador es personal, y revela primeramente su identidad como profesor, pero también su interés y necesidad por mejorar una situación.

Con estos ejemplos, se aprecia que la voz de los autores se caracteriza por ser principalmente impersonal, tanto en la apertura como en el cierre dela explicación, donde ellos plantean la necesidad de atender una problemática, concretamente en el cierre del mismo para proponer algunas posibilidades de mejora de una situación o problema a atender. Sin embargo, esto evidencia y refuerza el hecho de que en el desarrollo de la explicación la voz que prevalece es el de los autores externos mediante el uso de las citas textuales, lo cual significa que, en el desarrollo de los argumentos respecto a los conceptos técnicos, la voz de los investigadores queda subordinada a la voz de los autores citados, y limitada a la enunciación de un problema, lo cual se articula con el eje de análisis anterior donde se demuestra que la voz de los investigadores queda ausente, debido al uso insistente de citas textuales.

\subsubsection{Fase 2: Un intento de explicaciones más propias}

En esta fase en relación a las explicaciones de conceptos técnicos, los productos escritos revisados de los estudiantes-investigadores, se caracterizan a grandes rasgos por incluir un apartado conceptual, entre 3-16 páginas, que denominan "Conceptualización”, "Marco Teórico", "Marco Conceptual” o "Fundamentación Teórica", lo cual muestra que estos apartados no tienen un título. Además, en su mayoría, estos apartados no están organizados en subapartados, sino que es una sola discusión a lo largo de todo el apartado conceptual. De estos textos, se construyó el corpus de análisis donde se eligieron fragmentos que mostraran explicaciones respecto a, al menos, un concepto técnico. De este corpus de datos construido (ver anexos) se identificaron rasgos recurrentes que se exponen a continuación.

\section{a)La orientación disciplinar: un escenario abierto}


Uno de las primeras características que se notaron fue la orientación disciplinar que los autores manifiestan en sus manuscritos al inicio de su argumentación. Sin embargo, a diferencia de la fase anterior, los textos exhiben una imprecisión en torno a la perspectiva en la cual se posicionan los autores. Un primer ejemplo que manifiesta este rasgo es el siguiente:

\begin{abstract}
A continuación, recuperaré a unos especialistas que han abordado el estudio del lenguaje y sus funciones. El lenguaje lo poseen todos los seres humanos y por lenguaje entenderemos según López (1989) como: "el medio a través del cual se comunican y expresan significados" (p. 11). Es decir, que por medio del lenguaje el ser humano, interactúa, comunica y construye su realidad. (NHG-I1-F2-p.4)
\end{abstract}

En este ejemplo se aprecia claramente que la autora de este texto expresa de forma abierta e imprecisa la orientación que guía su explicación. Cuando ella menciona "recuperaré a unos especialistas que han abordado el estudio del lenguaje y sus funciones" indica que se referirá a algunos autores para explicar el concepto técnico que ella plantea. No obstante, aunque esta información da pistas al lector para seguir la explicación, también es imprecisa porque la investigadora utiliza el adjetivo indefinido "unos", el cual expone de manera incierta a los "especialistas" a los que recurrirá para desarrollar su explicación, con lo cual no queda clara la orientación hacia el campo disciplinar al cual se afilia la investigadora. Otro ejemplo similar es:

Para apoyarme en cuanto a comprenderemos como escritura primeramente me fundamentaré en algunos autores que han hecho investigación sobre este tema, tal es el caso de Liliana Tolchisky quien nos dice que la escritura: (MAGV-I2-F2-p.8)

En este caso el estudiante-investigador, refiriéndose, a la "escritura", menciona lo siguiente, "me fundamentaré en algunos autores que han hecho investigación sobre este tema", donde utiliza de igual forma el adjetivo indefinido "algunos" con lo cual deja abiertas varias posibilidades de autores y distintas investigaciones en torno al tema que él plantea, por lo que, al igual que el ejemplo anterior, la impresión en la orientación disciplinar queda indefinida. Un ejemplo más de este tipo de orientación es el que sigue a continuación.

\footnotetext{
Considerando los avances en las diversas investigaciones en torno a la cultura escrita, han surgido diversas concepciones sobre lo que se debe entender por leer, al igual que didácticas en torno a la enseñanza de estas actividades. En torno a la lectura, Cassany (2006:25) distingue tres concepciones de la comprensión lectora, según consideremos que sea el procedimiento para obtener el significado. No son tres formas de leer, sino tres representaciones sobre la lectura... (HGL-I8-F2-p.8)
}

Aquí se nota nuevamente que el investigador hace referencia a "los avances en las diversas investigaciones en torno a la cultura escrita" que es el concepto del cual "han 
La textualidad académica de estudiantes de origen indígena en estudios de posgrado: el proceso de elaboración de tesis

surgido diversas concepciones sobre lo que se debe entender por leer". Así, en este fragmento el investigador utiliza el adjetivo calificativo "diversas" que mantiene el sentido de indefinición cuando alude a "diversas investigaciones" y "diversas concepciones", con esto abre un abanico de posibilidades a tratar en su explicación, dejando muy abierto el campo disciplinar que oriente su explicación. Un último ejemplo con esta característica es el que sigue.

\begin{abstract}
Los estudios realizados en las diversas disciplinas, y mayormente en las ciencias sociales Giménez (2000) dicta que a finales de "los sesenta, la cuestión de identidad presenta un interés renovado, desde la cultura Americana que destaca al sujeto como actor social y la formación de su identidad a partir de la participación en un mundo social, y desde la tradición francesa vincula el estudio de la identidad con los movimientos sociales y las migraciones". (WEZ-I9-F2-p.7)
\end{abstract}

Al igual que los ejemplos anteriores, este estudiante investigador utiliza el mismo adjetivo calificativo cuando refiere a "diversas disciplinas" aunque lo enmarca en el campo de las ciencias sociales, pero aún es impreciso porque nuevamente se despliegan varias posibilidades disciplinarias para orientar la temática que propone el investigador.

Por tanto, en este eje de análisis se observa que la orientación disciplinar que presentan los productos escritos revisados se caracteriza por ser abierta e imprecisa, ya que los investigadores recurren a uso de adjetivos indefinidos y calificativos que mantiene el mismo sentido de imprecisión porque con estos recursos lingüísticos el escenario disciplinar queda abierto.

\title{
b) Estructura para explicar conceptos técnicos
}

La estructura para explicar conceptos técnicos es uno de los elementos que también se identifican claramente en los productos escritos revisados, la cual corresponde a extractos obtenidos del apartado conceptual el manuscrito correspondiente a la fase dos. En esta fase, dicha estructura evidencia una organización de inicio, desarrollo y cierre, pero también presenta características distintas a las encontradas en la fase uno, lo cual significa que los autores de dichos textos manifiestan modificaciones en la forma de organizar sus argumentos respecto a los conceptos técnicos, como se muestra en los siguientes casos.

\section{Caso 1}




\title{
I. Fase de inicio: apertura de la explicación
}

La explicación de este caso se caracteriza por iniciar con una apertura donde el investigador expone el concepto técnico a desarrollar, en este caso refiere a la escritura, como se muestra en el siguiente fragmento.

\begin{abstract}
En la actualidad la forma de concebir a la escritura ha cambiado, esto se debe en gran medida a que ha sido estudiada por algunas disciplinas que han apoyado a conceptualizarla de otra manera y como consecuencia tendríamos que abordarla de forma diferente a lo que se hacía anteriormente, así por ejemplo una forma de definir la escritura es la que nos ofrece Margarita Gómez Palacios al decir; (MAGV-I2-F2-p. 9)
\end{abstract}

\section{AEx}

En esta apertura de la explicación (AEx), cuando el investigador alude a "algunas disciplinas que han apoyado a conceptualizarla de otra manera" refiriéndose al concepto técnico "escritura", expresa primeramente una orientación disciplinar abierta por las características explicadas en el eje de análisis anterior. Además, se observa que el autor del texto propone una explicación contrastiva, es decir, desarrollar una explicación diferente de la escritura, lo cual se evidencia en las expresiones que él menciona, por ejemplo, "la escritura ha cambiado", "conceptualizarla de otra manera" y "abordarla de forma diferente a lo que se hacía anteriormente". Con estas frases se exhibe que el investigador pretende desarrollar su explicación haciendo un contraste con un argumento contrario "a lo que se hacía anteriormente" como él mismo lo expresa; no obstante, en este extracto, no señala qué es lo que se solía hacer anteriormente respecto al tema que plantea.

\section{Fase de desarrollo: Explicaciones propias del investigador}

La fase de desarrollo en esta etapa del análisis longitudinal tiene una característica similar a la fase anterior respecto a que la apertura de la explicación (AEx) funciona también como una apertura de una cita (AdC), como se evidencia en seguida:

En la actualidad la forma de concebir a la escritura ha cambiado, esto se debe en gran medida a que ha sido estudiada por algunas disciplinas que han apoyado a conceptualizarla de otra manera y como consecuencia tendríamos que abordarla de forma diferente a lo que se hacía anteriormente, así por ejemplo una forma de definir la escritura es la que nos ofrece Margarita Gómez Palacios al decir; (MAGV-I2-F2-p. 9) 
La textualidad académica de estudiantes de origen indígena en estudios de posgrado: el proceso de elaboración de tesis

Este primer párrafo funciona como una apertura de la cita (AdC) porque en él, el autor del texto señala que su explicación expresará una concepción diferente respecto al tema que plantea, ejemplificando su argumento con una cita textual. Concretamente, cuando él menciona que "por ejemplo una forma de definir la escritura es la que nos ofrece Margarita Gómez Palacios al decir:", está introduciendo su discusión e intentando respaldarlo recurriendo a una cita textual donde se define el concepto de "escritura" como se muestra a continuación.

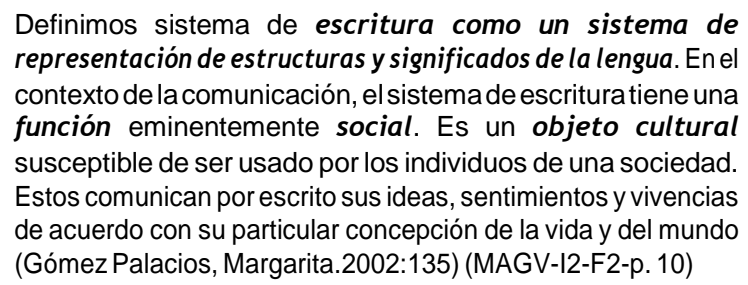

En esta cita, se define el concepto técnico referido que es la "escritura como un sistema de representación de estructuras y significados de la lengua", idea que el investigador recupera para explicar la cita textual (CTx) que él plantea; así, una vez introducida la cita textual, el autor hace una explicación de dicha cita $(\operatorname{ExdC})$ :

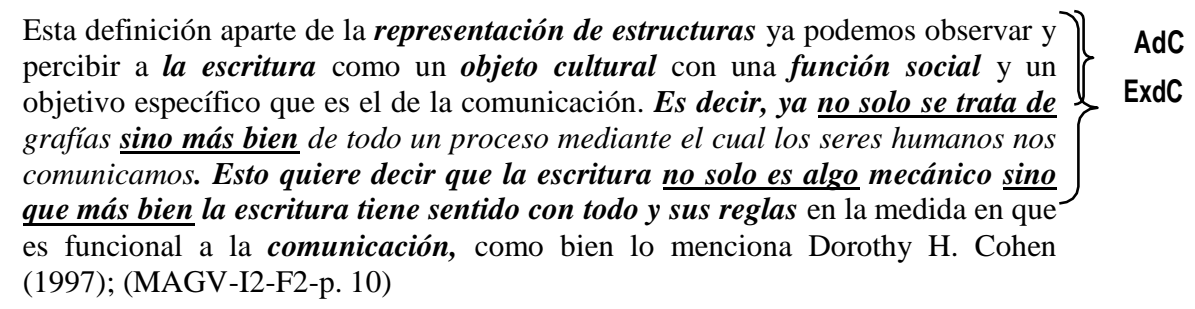

En esta explicación de la cita, el investigador alude a la idea expresada en la cita textual mediante la estrategia de señalizaciones de repetición léxica y discursiva; por ejemplo, cuando refiere a "representación de estructuras", "objeto cultural" y "función social", son expresiones que también se encuentran en la cita textual aludida con las que desarrolla la explicación de la cita textual. No obstante, el argumento del investigador no se queda en este nivel de recuperar términos incluidos en la cita textual, sino que él recurre a otros elementos discursivos como los conectores "Es decir" y "Esto quiere decir" para explicar en otras palabras la cita planteada. Además, cuando él utiliza expresiones como "ya no solo se trata de... sino más bien" y "no solo es algo... sino que más bien”, está mostrando pistas de que su 
explicación implica un contraste de argumentos respecto al concepto técnico que desarrolla que es "la escritura". De esta manera, el autor del texto, explica la cita textual previa, proporcionando argumentos que refuerzan su argumento inicial. Sin embargo, la parte final de esta explicación, corresponde también a una apertura de la cita (AdC), donde el investigador adelanta información que se menciona también en la cita textual. Así, la apertura de la cita (AdC) inicia cuando él dice que "la escritura tiene sentido con todo y sus reglas en la medida en que es funcional a la comunicación, como bien lo menciona Dorothy H. Cohen (1997)”, argumento que se evidencia en la cita textual que le sigue.

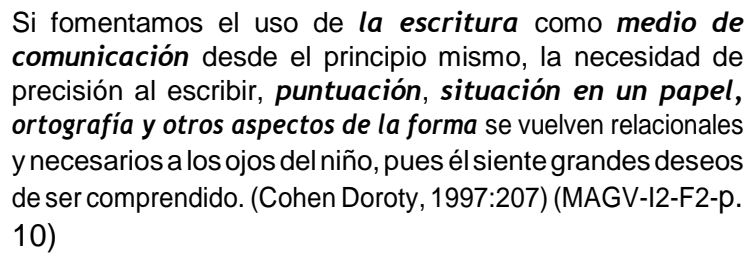

Específicamente, vemos que cuando el autor alude a la expresión "reglas" se puede advertir que este término abarca "la puntuación, la ortografía y otros aspectos de la forma" que se menciona en la cita textual. Lo mismo ocurre cuando él menciona "que es funcional a la comunicación", expresión que también se evidencia en la cita textual cuando la autora citada refiere la escritura como "medio de comunicación”. Así, se nota el vínculo entre la apertura de la cita (AdC) y la cita textual (CTx) que el investigador intenta exponer. De aquí, viene un párrafo que identifico como elaboración de un argumento (ElbAr) porque éste intenta ser un argumento más personal que el investigador construye:

\begin{abstract}
Tanto Margarita Gómez Palacios como Doroty Cohen nos muestran la escritura como un sistema de estructuras y reglas pero además como una forma de comunicación, lo cual indica que necesariamente tiene que existir un emisor que es el que escribe y un receptor que es a quien va dirigido el mensaje, es decir leemos porque alguien escribió y escribimos para que alguien los lea (incluso uno mismo), es un acto mutuo que se da en base a la necesidad de comunicación entre los seres humanos, es un sistema en el cual se le da significado a nuestras ideas mediante la lengua escrita. Esta interrelación que se da entre lector y autor convierte la escritura en un todo un proceso en el cual los seres humanos a través de la producción de un texto escrito manifestamos nuestra actividad lingüística. (MAGV-I2-F2-p. 10)
\end{abstract}

ElbAr

Esta elaboración del argumento (ElbAr) significa que el autor del texto revisado desarrolla un argumento más personal, es decir, se manifiesta su intento por elaborar una reflexión propia, lo cual se evidencia en dos puntos. Primero, cuando el investigador hace referencia a las dos autoras citadas anteriormente señalando que "Tanto Margarita Gómez. Palacios como Doroty Cohen nos muestran la escritura como un sistema de estructuras y 
La textualidad académica de estudiantes de origen indígena en estudios de posgrado: el proceso de elaboración de tesis

reglas pero además como una forma de comunicación" con lo cual alude al planteamiento de las autoras citadas recurriendo a la estrategia de señalizaciones de repetición léxica y discursiva; por ejemplo, cuando el autor refiere a las expresiones "sistema de estructuras", "reglas" y "forma de comunicación" son vocablos mencionados previamente en esta fase. Segundo, el investigador elabora su argumento porque agrega expresiones que se vinculan con el concepto técnico pero que no están explícitamente mencionados en el desarrollo del argumento; por ejemplo, vocablos como "emisor", "receptor" y "mensaje". Además, esta reflexión más personal se refuerza cuando el autor explicita su voz de manera impersonal, por ejemplo, cuando conjuga los verbos en primera persona del plural "leemos", "escribimos" o "manifestamos" para dejar claro que él es parte de ese "nosotros" que escribe.

\section{Fase de cierre: coda y evaluación}

Finalmente, esta estructura muestra un cierre de la explicación (CEx) desarrollado en este extracto elegido, donde el autor concluye su argumento como se evidencia en el siguiente extracto.

Según lo anterior estaríamos diciendo entonces que el acto de escribir es una forma o una de las representaciones del lenguaje el cual siempre tiene un propósito que es el de comunicar o mostrar algo. Ahora bien considero desde mi punto de vista que dependiendo del propósito o intención que se tenga al escribir será la motivación que tengamos al hacerlo, es decir existen diversas prácticas de escritura pero no todas cumplen la misma función ni el mismo propósito. (MAGV-I2-F2-pp. 10-11)

En esta última parte de la explicación, el investigador recurre al uso de la coda para anunciar el término de su explicación, lo cual se evidencia cuando el autor del texto menciona "Según lo anterior estaríamos diciendo entonces que..." porque esta expresión manifiesta que su argumento refiere a ideas desarrolladas anteriormente, y concretamente cuando dice “estaríamos diciendo entonces que...”, significa que hará referencia a la conclusión a la cual llega después de su explicación. Dicho cierre lo hace mediante la estrategia de señalización discursiva, donde recupera las ideas principales del desarrollo de su argumento, específicamente cuando afirma que "el acto de escribir es una forma o una de las representaciones del lenguaje el cual siempre tiene un propósito que es el de comunicar o mostrar algo" enfatizando la escritura como una representación del lenguaje y como medio de comunicación, como se mencionó en la etapa de desarrollo. También, en este cierre, el 
investigador evalúa su argumento porque emite una apreciación global de los argumentos; por ejemplo, cuando expresa una opinión personal "“Ahora bien considero desde mi punto de vista $q u$ e” está dando una valoración personal de los argumentos desarrollados respecto al concepto técnico desarrollado que es la escritura.

De esta manera, esta explicación gira en torno al concepto técnico que es "la escritura" el cual el autor desarrolla en este fragmento, quedando la estructura identificada de la siguiente manera:

\begin{tabular}{|l|l|l|}
\hline \multirow{3}{*}{$\begin{array}{l}\text { FASE 2. } \\
\text { CONCEPTOS }\end{array}$} & Fase de Inicio & Apertura de la explicación (AEx) \\
\cline { 2 - 3 } TÉCNICOS & Fase de desarrollo & Apertura de la cita (AdC) \\
& & Cita textual (CTx) \\
& & Explicación de la Cita (ExdC) \\
& & Apertura de la cita (AdC) \\
& & Cita Textual (CTx) \\
& & Elaboración del Argumento \\
\cline { 2 - 3 } & Fase de cierre & (ElbAr) \\
\hline
\end{tabular}

En esta estructura, se aprecia que la explicación inicia con una apertura de la explicación donde el investigador expone una orientación disciplinar abierta, pero este inicio también corresponde a la apertura de una cita con lo cual empieza el desarrollo de la explicación, característica similar a la Fase 1 de este análisis longitudinal. En la fase de desarrollo, se observa que el investigador se apoya en citas textuales, pero también se nota que aparece una explicación de una cita textual (ExdC), rasgo que no se precia en la fase anterior. También, se percibe el intento del investigador por construir argumentos más personales mediante la elaboración de un argumento (ElbAr) más propio. Finalmente, el cierre de la explicación tiene la particularidad de que el investigador recurre al uso de la coda donde anticipa el término de su explicación y donde realiza una evaluación mostrando su apreciación respecto a sus argumentos desarrollados.

Así, se concluye que en el caso 1 se presentan cambios en la forma de desarrollar la explicación de un concepto técnico que en este caso es la escritura. Primero, se observa claramente que la explicación gira en torno a un solo concepto técnico, lo cual delimita mejor el objeto de estudio que el autor del texto pretende desarrollar. Segundo, se aprecia la explicación de las citas textuales que también va acompañada de un argumento más elaborado 
La textualidad académica de estudiantes de origen indígena en estudios de posgrado: el proceso de elaboración de tesis

por parte del autor para apoyar su explicación tanto de la cita textual como de los argumentos desarrollados para explicar el concepto técnico. Finalmente, una característica no menos importante es la valoración y evaluación que el investigador expresa en la fase de cierre de su explicación.

\title{
Caso 2
}

Un segundo caso que muestra características similares, se presenta a continuación.

\section{Fase de inicio: referencia a argumentos anteriores}

\begin{abstract}
En ese sentido como ya lo mencione en el apartado anterior, la evaluación educativahoy en día es un tema que induce a la reflexión de la práctica docente, ya que cada profesor le ha otorgado diferentes funciones dentro de su labor, pues algunos la han tomado como un requisito meramente administrativo... otros la consideran para determinar quiénes son los alumnos que deben aprobar o reprobar ya sea el bimestre o el ciclo escolar, algunos más la aplican simplemente para medir el logro de aprendizaje de sus alumnos....El avance en las investigaciones referentes a este tema ha ido construyendo poco a poco nuevas formas de conceptualizar a la evaluación, tal como lo afirma ROSALES C. (2000); (GHVI3-F2-pp. 3-4)
\end{abstract}

En esta fase de inicio de la explicación, el investigador abre su explicación (AEx) haciendo referencia a discusiones anteriores, cuando él dice "como ya lo mencione en el apartado anterior, la evaluación..." está aludiendo a argumentos previos, haciendo énfasis en el concepto técnico a desarrollar que es "la evaluación” y en torno al cual gira la apertura de su explicación. También se aprecia una orientación disciplinar abierta donde el investigador refiere a "investigaciones referentes a este tema" como se explicó en el eje de análisis anterior.

\section{Fase de desarrollo: explicaciones más propias del investigador}

Aquí vemos que parte de la apertura de la explicación corresponde a la apertura de una cita (AdC) como se exhibe en seguida.

\footnotetext{
El avance en las investigaciones referentes a este tema ha ido construyendo poco a poco nuevas formas de conceptualizar a la evaluación, tal como lo afirma ROSALES C. (2000);
}

AdC

En esta apertura de la cita (AdC) se observa claramente que el investigador anuncia la "conceptualización" de su concepto técnico "la evaluación", apoyado en una cita textual, cuando refiere a "nuevas formas de conceptualizar a la evaluación". De esta apertura de la cita, continúa la cita textual: 
Paulatinamente se va introduciendo en el ámbito del objeto de evaluación al profesor, la metodología, los recursos y la propia institución escolar. Es posible observar cómo a su vez, dentro de cada uno de los componentes citados, se produce de manera progresiva un enriquecimiento de carácter interno, en cuanto a la consideración de nuevas dimensiones del objeto que se evalúa (30). (GHV-I3-F2-p. 4)

En esta cita textual, se aprecia el concepto técnico introducido que es la "evaluación" y algunos términos que el investigador recupera en una explicación de la cita $(\mathrm{ExdC})$ que el desarrolla, como se muestra a continuación.

\footnotetext{
De acuerdo al planteamiento anterior, la evaluación no debe minimizarse solamente en la idea de medir el conocimiento del alumno, es decir, no se debe centrar solo en el estudiante y en sus conocimientos adquiridos, pues el docente, los objetivos de la enseñanza, el método, en fin, todo el contexto deben ser tomados en cuenta para tratar de alcanzar el verdadero objetivo de la evaluación, la cual deberá ser sin duda la de mejorar las prácticas de la enseñanza y de aprendizaje en términos generales, como acertadamente lo menciona San Marti, N. (2007); "La finalidad principal de la evaluación es la regulación, tanto de las dificultades y los errores del alumnado, como del proceso de enseñanza"(29) (GHV-I3-F2-p. 4)

\section{ExdC \\ $\mathrm{AdC}$ \\ CTx}

La explicación de la cita (ExdC) inicia cuando investigador expresa "De acuerdo al planteamiento anterior" lo que significa que se referirá a la cita textual previa, recurriendo a la estrategia de señalizaciones de repetición léxica y discursiva para recuperar algunos términos mencionados en la cita textual. Por ejemplo, cuando en su explicación señala los términos "el docente", "el método" y "todo el contexto", son vocablos que se reflejan en la cita textual previa en la cual se alude al "profesor", a "la metodología", a "los recursos" y "la propia institución", que son señalizaciones de repetición discursiva con las que el investigador vincula la cita textual (CTx) con la explicación de la misma (ExdC). Con esto se advierte que el autor se apoya en ideas y términos expuestos en la cita textual para poder explicarla.

Además de la explicación de la cita, en este mismo párrafo, también se percibe la apertura de otra cita (AdC) seguida de la cita textual, cuyo vínculo nuevamente se apoya en señalizaciones léxicas y discursivas. Por ejemplo, cuando el investigador refiere al "objetivo de la evaluación" en la apertura la cita (AdC), esta expresión también se señala en la cita textual (CTx) cuando se menciona "la finalidad... de la evaluación", donde ambas expresiones tienen el mismo significado. De aquí, continúa nuevamente una breve explicación de la cita anterior (ExdC), seguida de una elaboración del argumento (ElbAr) como se muestra a continuación. 
La textualidad académica de estudiantes de origen indígena en estudios de posgrado: el proceso de elaboración de tesis

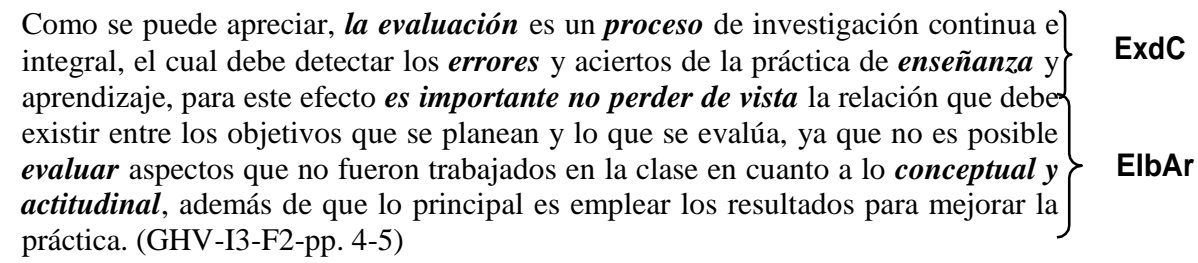

Esta breve explicación de la cita $($ ExdC), se construye a partir de recuperar términos expresados en la cita textual previa (CTx), tales como "proceso", "errores" y "enseñanza" que se encuentran explícitamente en la cita textual anterior "(San Marti, N. 2007)". Después, continua una parte que denomino una elaboración del argumento (ElbAr) porque en ella, el autor pretende exponer una reflexión más personal respecto al tema que trata, lo cual se evidencia en dos aspectos. El primero es porque expone una opinión (impersonal) cuando recurre a expresiones impersonales como "es importante no perder de vista..." con lo cual está haciendo una sugerencia, y "no es posible evaluar..." para expresar su apreciación respecto al tema abordado. Segundo, el autor expresa ideas que no se habían mencionado anteriormente en el desarrollo de su explicación, como "lo conceptual y actitudinal", términos que se mencionan por única vez en el extracto analizado, aunque no se descarta que se hayan mencionado en algún momento del apartado conceptual. De esta manera, se ejemplifica el intento del autor por desarrollar un argumento propio. Posterior a esta elaboración del argumento, continúa el cierre de la explicación.

\section{Fase de cierre: coda y evaluación}

Este cierre se caracteriza por presentar el uso de la coda y de una evaluación que el investigador realiza del desarrollo de su explicación, como se presenta a continuación.

\footnotetext{
En congruencia con lo anterior puedo afirmar que a pesar de que tradicionalmente la evaluación se ha enfocado mayormente a los aprendizajes de los alumnos, ignorando la evaluación al docente, a los contenidos, a la metodología, a la enseñanza, etc., una evaluación integral debe considerar los diferentes factores que intervienen en todo el proceso de la enseñanza y aprendizaje para lograr su verdadero objetivo, la cual deberá ser siempre la de mejorar toda la práctica de enseñanza y de aprendizaje. No obstante existen diferentes tipos de evaluación que se pueden aplicar según el interés que se persiga, de lo cual me encargaré de desarrollar a continuación. (GHV-I3-F2-p. 5)
}

CEx

En esta última parte de la explicación (CEx), el investigador hace uso de la coda para advertir el final de su explicación, cuando él menciona "En congruencia con lo anterior puedo 
afirmar que..." está indicando que su argumento se vincula con lo desarrollado anteriormente, orientando su discurso hacia una conclusión respecto al concepto técnico desarrollado. La coda también se evidencia cuando el investigador plantea en la última parte de este cierre, otro tema que refiere a los "tipos de evaluación", tema que abordará en un apartado posterior cuando él dice "de lo cual me encargaré de desarrollar a continuación". Con estas expresiones, el investigador deja claro que su explicación ha terminado. En la parte central de este cierre se observa también que el investigador se apoya en señalizaciones de repetición léxica para concretar su argumento en esta fase. Por ejemplo, cuando menciona los términos “docente", "metodología", "proceso de enseñanza" y "objetivo", refiere a vocablos que se utilizaron en distintos momentos de la explicación, y que el autor recupera para cerrar su argumento. Finalmente, se aprecia que el investigador realiza una evaluación de su argumento cuando menciona que "una evaluación integral debe considerar los diferentes factores", expresión con la cual el autor del texto plantea su apreciación respecto a la explicación desarrollada, es, decir, él hace una valoración general de sus argumentos.

De esta manera, este segundo caso de este eje de análisis evidencia una explicación en torno a un concepto técnico que es "la evaluación", con una estructura similar al caso anterior, quedando de la siguiente manera.

\begin{tabular}{|l|l|l|}
\hline \multirow{3}{*}{$\begin{array}{l}\text { FASE 2. } \\
\text { CONCEPTOS }\end{array}$} & Fase de Inicio & Apertura de la explicación (AEx) \\
\cline { 2 - 3 } TÉCNICOS & Fase de desarrollo & Apertura de la cita (AdC) \\
& & Cita textual (CTx) \\
& & Explicación de la Cita (ExdC) \\
& & Apertura de la cita (AdC) \\
& & Cita Textual (CTx) \\
\cline { 2 - 3 } & Fase de cierre & Elaboración del Argumento (ElbAr) \\
\hline
\end{tabular}

Esta estructura se caracteriza por un inicio de la explicación donde el investigador presenta argumentos referidos a discusiones anteriores para construir la apertura de la explicación, con lo cual ya no se queda únicamente en el nivel de la apertura de la cita. En la fase de desarrollo, se observan explicaciones de las citas textuales planteadas y algunos argumentos más elaborados donde el autor intenta plantear reflexiones más personales. En la fase de cierre se aprecia que el investigador recurre al uso de la coda para evidenciar el final de su explicación, asimismo, el autor expresa una evaluación global de sus argumentos, con lo 
La textualidad académica de estudiantes de origen indígena en estudios de posgrado: el proceso de elaboración de tesis

cual cierra su explicación. Así, el análisis de ese caso muestra intentos del autor por trascender de la enunciación de las citas textuales a reflexiones y argumentos más propios.

\section{Caso 3}

Un ejemplo más en este eje de análisis es el que se analiza a continuación, el cual exhibe características similares a los ejemplos analizados anteriormente, pero también se evidencian rasgos particulares. Por ejemplo, este caso se caracteriza por incluir explicaciones internas en la fase de desarrollo, es decir, son explicaciones más pequeñas que también muestran una estructura de inicio, desarrollo y cierre, como se presenta a continuación.

\section{Fase de inicio: Abstract (resumen) de la explicación}



Este argumento inicia con una apertura de la explicación (AEx) cuando el investigador menciona alude a "Considerando los avances en las diversas investigaciones en torno a la cultura escrita, han surgido diversas concepciones sobre lo que se debe entender por leer", ," con lo cual expone una orientación disciplinar abierta, específicamente cuando refiere a “diversas investigaciones" y "diversas concepciones", rasgó que se analizó en el eje de análisis anterior. Además en esta entrada, el autor explicita el concepto técnico a desarrollar en su explicación que en este caso es "la lectura". Para esto, el investigador se apoya en una cita textual (CTx) donde se alude a "tres concepciones de la comprensión lectora", en torno a las cuales gira su explicación. De esta apertura, se aprecia el desarrollo de la explicación, el cual empieza con una elaboración de un argumento del investigador, como se muestra en el siguiente párrafo.

\footnotetext{
Estas formas de mirar la lectura conllevan también determinadas prácticas lectoras, las cuales condicionan al lector en cuanto al uso que pueda realizar de la ElbAr información o interpretación de determinado texto, por ello diferenciar estas concepciones nos ayudará a entender y tener mayor claridad sobre el tema. (HGLI8-F2-p.7)
}

Denomino este fragmento como una elaboración del argumento (ElbAr), porque en él, el investigador intenta construir un argumento más propio, lo cual se evidencia cuando el 
autor afirma que "Estas formas de mirar la lectura conllevan también determinadas prácticas lectoras", con lo cual expresa una característica relacionada con el concepto técnico que plantea cuando menciona "prácticas lectoras" concepto que él explica en este párrafo. Además, este argumento refuerza la necesidad de su explicación respecto a las "concepciones de la lectura” cuando él afirma “... por ello diferenciar estas concepciones nos ayudará a entender y tener mayor claridad sobre el tema", argumento con el cual abre la discusión que se muestra a continuación en la etapa de desarrollo.

\section{Fase de desarrollo: explicaciones internas}



La fase de desarrollo de la explicación inicia con la explicación de la primera de las tres concepciones sobre la lectura, propuestas en la fase de inicio. En esta primera parte del desarrollo, se observa una apertura de la explicación interna (AExI), donde el investigador indica una orientación disciplinar específica desde donde explica "una de las concepciones... en torno a la lectura", la cual refiere a la "concepción Lingüística". No obstante, esta apertura también funciona como una apertura de la cita (AdC) porque en ella se alude a dicha “concepción" que se explica en la cita textual (CTx) en la cual se apoya el investigador para desarrollar su argumento, característica particular de este caso.

De esta cita textual, continúa una explicación de esa cita (ExdC), donde el investigador recurre a señalizaciones de repetición léxica y discursiva para vincular sus argumentos, como se aprecia en el siguiente párrafo.

Desde esta concepción podemos entender que el lector es un sujeto pasivo, no )] intervine de manera activa en la construcción de significados, también es posible afirmar que los conocimientos previos del lector no afectan a la forma en cómo se $\}$ CExI estructura el significado en la mente del lector; que mediante la decodificación correcta del código escrito se adquiere el significado existente en el texto. De ahí que las actividades comunes en las aulas correspondientes en ésta concepción, con frecuencia es la decodificación del código escrito en voz alta, la repetición y memorización de determinados textos, o parte de ellos. (HGL-I8-F2-pp.7-8) 
La textualidad académica de estudiantes de origen indígena en estudios de posgrado: el proceso de elaboración de tesis

En esta explicación de la cita (Exdc), el investigador refiere a términos mencionados en la cita textual (CTx) para enlazar su explicación con la cita aludida, cuando él refiere principalmente a los vocablos "lector" y "significado", vemos que estos términos son muy recurrentes tanto en la cita como en la explicación de la misma. De esta parte, se observa un breve cierre de la explicación interna (CExI) donde el investigador concreta su argumento haciendo alusión a la concepción de lectura referida y mencionando algunos aspectos relacionados con dicha concepción. Esto se evidencia cuando dice "De ahí que las actividades comunes... en ésta concepción... es la decodificación del código escrito en voz alta, la repetición y memorización de determinado textos...", frase con la cual finaliza su explicación interna respecto a la primera concepción de la lectura.

De esta explicación, el investigador continúa con la explicación de la "segunda concepción" que exhibe la misma lógica que el extracto anterior.

La segunda concepción sobre la lectura representa cierta oposición en torno a la AExI primera sobre todo en el papel que desempeña el lector en el proceso de lectura. AdC Desde la perspectiva psicolingüística: (HGL-I8-F2-p.8)

Como es posible ver, el investigador alude a la "segunda concepción sobre la lectura representa cierta oposición" con lo cual abre su explicación interna (AExI) aclarando que esta concepción mantiene "cierta oposición”, es decir, el autor del texto manifiesta un contraste entre su explicación previa y ésta. En esta apertura también se especifica la orientación disciplinar que guía esta explicación interna cuando el autor del texto menciona "Desde la perspectiva psicolingüística", lo cual es también es un rasgo que indica que esta apertura de la explicación interna (AExI) igualmente funciona como una apertura de la cita (AdC) porque en ella se señala la perspectiva que orienta el argumento de la cita textual (CTx) como se muestra a continuación.

Leer no solo exige conocer las unidades y las reglas combinatorias del idioma. También requiere desarrollar las habilidades cognitivas implicadas en el acto de comprender: aportar conocimiento previo, hacer inferencias, formular hipótesis y saberlas verificar 0 reformular, etc. (Cassany, 2006:25) (HGL-18-F2-p.8) 
Esta cita textual se vincula con el argumento anterior porque en ella se hace referencia a "las habilidades cognitivas en el acto de comprender" argumento que se relaciona con aspectos "psicolingüísticos". Se nota también en esta explicación que el autor expone un argumento de contraste para vincular sus argumentos, concretamente cuando hace referencia a “cierta oposición” en la apertura de esta explicación interna. Para esto, el investigador elabora un argumento (ElbAr) apoyando se en una cita textual (CTx) como se indica en seguida.

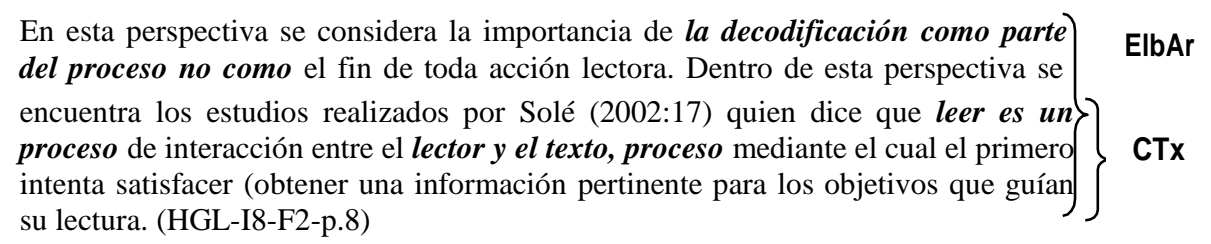

En esta elaboración del argumento (ElbAr), se aprecia que el investigador recupera un vocablo enunciado en la primera explicación interna de esta fase, éste es "la decodificación" término al que recurre para elaborar un argumento de contraste que se evidencia cuando menciona que "la decodificación como parte del proceso no como el fin de toda acción lectora", para marcar la diferencia entre ambas perspectivas respecto al concepto técnico que es "la lectura", esto se exhibe específicamente cuando alude al término "no como...". Como se puede observar, esta elaboración del argumento se apoya en una cita textual en la cual el autor citado utiliza el vocablo "proceso", término al que recurre el investigador desde el inicio de su explicación interna para vincular sus argumentos y las citas textuales. De aquí se aprecia un cierre de la segunda explicación interna donde el autor del texto se apoya en señalizaciones de repetición léxica para finalizar su argumento como se muestra a continuación.

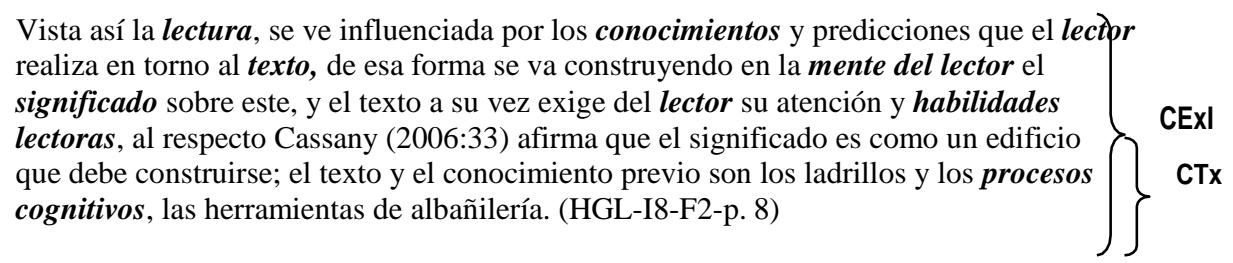

En este cierre de la segunda explicación interna (CExI), el investigador retoma las ideas principales desarrolladas previamente y se apoya en la estrategia de señalizaciones de repetición léxica y discursiva para concluir su argumento. Por ejemplo cuando recupera los vocablos "conocimientos", "lector", "mente del lector", "significado", "texto" y "habilidades lectoras", son términos que ya se han mencionado previamente y que se vinculan con la 
La textualidad académica de estudiantes de origen indígena en estudios de posgrado: el proceso de elaboración de tesis

"perspectiva psicolingüística". En este cierre, el investigador también se apoya en una cita textual donde el autor citado alude a "procesos cognitivos", con lo cual se finaliza la explicación respecto a la "segunda concepción sobre la lectura".

De esta parte continua "la tercera perspectiva en torno a la lectura"; no obstante, por la amplitud de esta explicación interna, he decidido únicamente analizar las primeras dos porque valoro que es suficiente para mostrar la lógica en que este investigador desarrolla su explicación. Por tanto, en la siguiente fase de cierre, únicamente expongo la manera en que el autor del texto culmina su explicación respecto a las tres concepciones aludidas.

\section{Fase de cierre: la coda}

\section{A partir de estos tres enfoques de la lectura Frank Serafini (2003 en Cassany 2006:79) los clasifica de la siguiente manera: la modernista (modernist), la \\ CEx} transaccional (transactional) y la crítica (critical). (HGL-I8-F2-p.10)

En esta etapa de cierre de la explicación (CEx) el investigador concreta su argumento mediante el uso de la coda con la cual evidencia que su explicación ha finalizado, cuando él menciona "A partir de estos tres enfoques de la lectura" está aclarando que ya ha terminado de explicar cada uno de dichos enfoques. Además, él se apoya en un autor externo para referir a una clasificación respecto al concepto técnico "la lectura". Con esto, el investigador cierra su explicación de las tres concepciones aludidas, pero también este cierre es una forma de vincular su explicación con argumentos posteriores que corresponden a otras explicaciones, en este caso, con la explicación de la clasificación con la que cierra su argumento previo.

Como se puede apreciar, esta explicación gira en torno al concepto técnico que es "la lectura" y donde se identifica una estructura que presenta características propias, quedando de la siguiente manera:






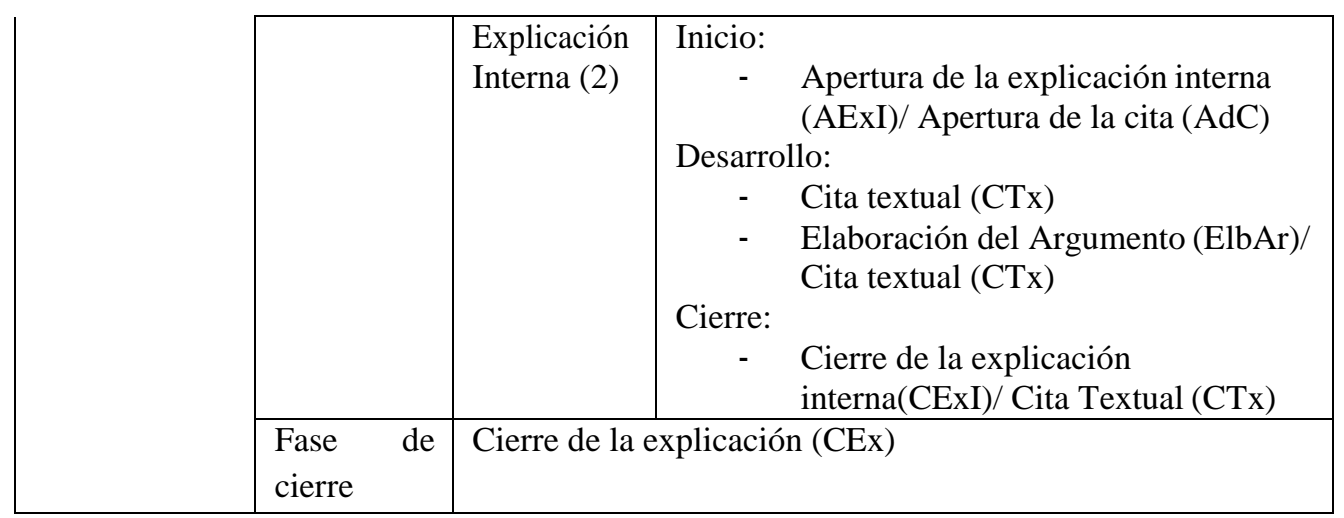

En este cuadro se aprecia claramente que esta explicación evidencia una organización más elaborada de los argumentos, porque ésta integra explicaciones breves internas. Así, en la fase de inicio de la explicación se plantea una orientación disciplinar, en principio abierta, pero que se va concretando durante el transcurso de la explicación. La fase de desarrollo se caracteriza, principalmente, por incluir explicaciones internas breves que a la vez muestran una estructura similar a los casos analizados anteriormente, como lo es un inicio, un desarrollo y un cierre de la explicación interna. No obstante, en esta fase se aprecian rasgos compartidos con los casos anteriores donde el investigador plantea argumentos más propios, es decir, trata de añadir información adicional y personal mediante explicaciones de la cita y elaboraciones de su argumento. Finalmente, en la etapa de cierre se hace uso de la coda para mostrar el desenlace de la explicación que a la vez es una apertura para explicaciones posteriores.

De esta manera, se concluye que en esta fase dos en este análisis longitudinal respecto a la estructura para explicar conceptos técnicos, los casos analizados presentan cambios importantes en relación a la fase uno. Una de las primeras características de las explicaciones analizadas es que éstas son más extensas en cuanto a la longitud de la explicación, lo cual repercute en la extensión del análisis realizado. Otro rasgo es que las explicaciones estudiadas giran en torno a un solo concepto, y ya no en dos o más como se evidenció en la fase uno. Otra particularidad refiere a presencia de explicaciones de las citas textuales, es decir, los argumentos de los autores citados se explican, no sólo se enuncian. Además, se aprecian argumentos más elaborados por parte de los investigadores donde intentan plantear argumentos más personales. Otra cualidad de esta fase, es que las explicaciones expresan un ciclo más completo de articulación textual entre cada una de las partes, por ejemplo, se nota con mayor claridad una apertura de la explicación que ya no se reduce una apertura de la cita 
La textualidad académica de estudiantes de origen indígena en estudios de posgrado: el proceso de elaboración de tesis

como se observó en la fase uno. Finalmente, este conjunto de particularidades que caracterizan la estructura de las explicaciones en esta fase, manifiesta una explicación mejor construida por parte del investigador, reduciendo los implícitos que pueden ocasionar ambigüedad en sus argumentos, sobre todo, el reducir el planteamiento de las citas textuales y agregar elaboraciones más propias, abre posibilidades para que el autor del texto explicite su voz en el transcurso de su explicación.

\title{
c) La voz de los autores en el transcurso de la explicación
}

Otra de las características que presentan las explicaciones respecto a los conceptos técnicos en esta segunda fase del análisis longitudinal, es la voz de los autores de los manuscritos, donde se aprecia claramente su intento por explicitar su voz en distintos momentos del transcurso de la explicación.

\section{El inicio de la explicación}

Uno de los primeros momentos en se presenta la voz de los de forma explícita es en la fase de inicio de la explicación como se muestra en el siguiente extracto.

\begin{abstract}
En la actualidad la forma de concebir a la escritura ha cambiado, esto se debe en gran medida a que ha sido estudiada por algunas disciplinas que han apoyado a conceptualizarla de otra manera y como consecuencia tendríamos que abordarla de forma diferente a lo que se hacía anteriormente, así por ejemplo una forma de definir la escritura es la que nos ofrece Margarita Gómez Palacios al decir; (MAGV-I2-F2-p. 9)
\end{abstract}

AEx

En este párrafo se observa que el investigador manifiesta su voz de manera impersonal porque su voz queda inmersa en la primera persona del plural "nosotros". Así, su voz se aprecia en la apertura de su explicación respecto al abordaje del concepto técnico que plantea, que en este caso refiere a "la escritura", lo cual se evidencia cuando menciona "tendríamos que abordarla de forma diferente". Asimismo, el autor expresa su voz impersonal para introducir una cita textual cuando dice "una forma de definir la escritura es la que nos ofrece Margarita Gómez Palacios". De esta manera, este autor proyecta su voz de forma impersonal en el momento inicial de la explicación.

Éste es otro ejemplo donde el investigador, de igual forma expresa su voz en la apertura de su explicación, pero lo hace de forma personal como se muestra a continuación. 
En ese sentido como ya lo mencione en el apartado anterior, la evaluación educativa hoy en día es un tema que induce a la reflexión de la práctica docente, ya que cada profesor le ha otorgado diferentes funciones dentro de su labor, pues algunos la han tomado como un requisito meramente administrativo... otros la consideran para determinar quiénes son los alumnos que deben aprobar o reprobar ya sea el bimestre o el ciclo escolar, algunos más la aplican simplemente para medir el logro de aprendizaje de sus alumnos... (GHV-I3-F2-pp. 3-4)

Aquí vemos claramente que la voz del autor se nota cuando conjuga el verbo en la primera persona del singular "yo" para referir a argumentos previos para iniciar su explicación, cuando dice "como ya lo mencione en el apartado anterior", manifiesta su voz de forma personal. Un ejemplo más de esta manera de expresar la voz del autor es el que sigue:

Estas formas de mirar la lectura conllevan también determinadas prácticas lectoras, las cuales condicionan al lector en cuanto al uso que pueda realizar de la información o interpretación de determinado texto, por ello diferenciar estas concepciones nos ayudará a entender y tener mayor claridad sobre el tema.

AEx ElbA (HGL-I8-F2-p.7)

En este último ejemplo el autor, exhibe su voz cuando hace referencia a la utilidad de diferenciar ciertas concepciones respecto al concepto técnico que pretende explicar que es "la lectura", esto se muestra cuando el investigador menciona "diferenciar estas concepciones nos ayudará a entender y tener mayor claridad sobre el tema”, expresión donde el autor utiliza el objeto indirecto "nos" donde él refleja su voz en un "nosotros", por tanto, la voz que refleja es impersonal. De esta forma, se observa claramente cómo la voz de los autores se aparece en el inicio de la explicación, ya sea de forma impersonal o personal, pero se nota la presencia de los autores en la fase de inicio de la explicación, característica similar a la fase anterior.

\section{El desarrollo de la explicación: las elaboraciones del investigador}

Una característica de particular de esta fase en este eje de análisis, es que la voz de los investigadores también se proyecta en las explicaciones que ellos hacen de las citas que plantean y en la elaboración de argumentos más propios que intentan desarrollar.

Tanto Margarita Gómez Palacios como Doroty Cohen nos muestran la escritura como un sistema de estructuras y reglas pero además como una forma de comunicación, lo cual indica que necesariamente tiene que existir un emisor que es el que escribe y un receptor que es a quien va dirigido el mensaje, es decir leemos porque alguien escribió y escribimos para que alguien los lea (incluso uno mismo), es un acto mutuo que se da en base a la necesidad de comunicación entre los seres humanos, es un sistema en el cual se le da significado a nuestras ideas mediante la lengua escrita. Esta interrelación que se da entre lector y autor convierte la escritura en un todo un proceso en el cual los seres humanos a través 
La textualidad académica de estudiantes de origen indígena en estudios de posgrado: el proceso de elaboración de tesis

de la producción de un texto escrito manifestamos nuestra actividad lingüística. (MAGV-I2-F2-p. 10)

Así, este primer ejemplo corresponde a una elaboración de un argumento donde el autor expresa su voz para desarrollar un argumento en torno al concepto técnico que trata, en este caso es "la escritura". La voz que manifiesta el autor es de manera impersonal porque recurre a la primera persona del plural donde su voz queda inmersa. Por ejemplo, cuando menciona en un principio "nos muestran la escritura", es un primer momento donde hace referencia a un "nosotros" mediante el uso del objeto indirecto "nos". Igualmente, cuando el autor menciona "leemos porque alguien escribió y escribimos para que alguien los lea (incluso uno mismo)", recurre a su persona reflejada en el sujeto "nosotros" para conjugar el verbo "escribir" para desarrollar su argumento. También, cuando alude a "nuestras ideas" hace uso de un adjetivo demostrativo, reflejando su voz nuevamente en un "nosotros". Finalmente, en su último argumento "manifestamos nuestra actividad" el investigador recurre al pronombre de la primera persona del plural "nosotros" para conjugar el verbo manifestar y también utiliza el adjetivo demostrativo "nuestra" con lo cual termina la elaboración de su argumento en la fase de desarrollo.

Otro ejemplo de esta fase, es el siguiente.

Como se puede apreciar, la evaluación es un proceso de investigación continua e
integral, el cual debe detectar los errores y aciertos de la práctica de enseñanza y y
aprendizaje, para este efecto es importante no perder de vista la relación que debe
existir entre los objetivos que se planean y lo que se evalúa, ya que no es posible
$\begin{aligned} & \text { evaluar aspectos que no fueron trabajados en la clase en cuanto a lo conceptual y } \\ & \text { actitudinal, además de que lo principal es emplear los resultados para mejorar la }\end{aligned}$
práctica. (GHV-I3-F2-pp. 4-5)

Este fragmento corresponde en parte a una explicación de una cita y también a una elaboración del argumento que realiza el investigador, donde la voz que manifiesta es de manera impersonal porque recurre a expresiones impersonales para indicar su opinión respecto al tema que trata. Por ejemplo, cuando el autor menciona "es importante no perder de vista...", "no es posible evaluar..." y "lo principal es emplear los resultados..." el investigador está dando su apreciación e incluso en la última frase, expresa una sugerencia. Por tanto, es posible advertir que la voz de este autor es impersonal y que le ayuda para construir un argumento más propio. 
Un último ejemplo de esta fase se presenta a continuación.

Desde esta concepción podemos entender que el lector es un sujeto pasivo, no intervine de manera activa en la construcción de significados, también es posible afirmar que los conocimientos previos del lector no afectan a la forma en cómo se estructura el significado en la mente del lector; que mediante la decodificación correcta del código escrito se adquiere el significado existente en el texto. (HGL-

ExdC I8-F2-pp.7-8)

En este párrafo que corresponde a la explicación de una cita, la voz del investigador se manifiesta nuevamente de forma impersonal porque, al igual que los ejemplos anteriores, utiliza el pronombre de la primera persona del plural para conjugar el verbo "poder" cuando menciona "podemos entender...". También se observa la voz del autor cuando recurre a una expresión impersonal "es posible afirmar que" con la cual expone su apreciación en torno a concepto que explica.

Así, esta fase de desarrollo se caracteriza por reflejar la voz del autor de texto de manera impersonal, ya sea recurriendo a la primera persona del plural o a expresiones impersonales conjugadas en la tercera persona del singular para expresar su opinión o valoración respecto al tema que trata.

\section{El cierre de la explicación}

La voz de los autores también se refleja en el cierre de la explicación manteniendo la misma lógica de los ejemplos anteriores como se exhibe a continuación.

\footnotetext{
Según lo anterior estaríamos diciendo entonces que el acto de escribir es una forma o una de las representaciones del lenguaje el cual siempre tiene un propósito que es el de comunicar o mostrar algo. Ahora bien considero desde mi punto de vista que dependiendo del propósito o intención que se tenga al escribir será la motivación que tengamos al hacerlo, es decir existen diversas prácticas de escritura pero no todas cumplen la misma función ni el mismo propósito. (MAGV-I2-F2-pp. 10-11)
}

En este primer ejemplo, se observa que el investigador explicita su voz de forma impersonal conjugando los verbos "estar" y "tener" en la primera persona del plural cuando menciona "estaríamos diciendo entonces que..." y "tengamos al hacerlo...". También, el autor manifiesta su voz de forma impersonal cuando conjuga el verbo "tener" en la tercera persona del singular "se tenga", con lo cual el autor se implica en el argumento de cierre de la explicación. Asimismo, el investigador muestra una voz más personal cuando conjuga el verbo considerar en la primera persona del singular "yo" cuando dice "considero desde mi 
La textualidad académica de estudiantes de origen indígena en estudios de posgrado: el proceso de elaboración de tesis

punto de vista que..." expresión que enfatiza claramente la opinión del investigador respecto al tema que aborda. Entonces, en este fragmento del cierre se evidencia tanto una voz impersonal como personal del investigador.

El segundo ejemplo que se presenta a continuación, muestra la voz del autor del texto de forma personal.

\begin{abstract}
En congruencia con lo anterior puedo afirmar que a pesar de que tradicionalmente la evaluación se ha enfocado mayormente a los aprendizajes de los alumnos, ignorando la evaluación al docente, a los contenidos, a la metodología, a la enseñanza, etc., una evaluación integral debe considerar los diferentes factores que intervienen en todo el proceso de la enseñanza y aprendizaje para lograr su verdadero objetivo, la cual deberá ser siempre la de mejorar toda la práctica de enseñanza y de aprendizaje. No obstante existen diferentes tipos de evaluación que se pueden aplicar según el interés que se persiga, de lo cual me encargaré de desarrollar a continuación. (GHV-I3-F2p.5)
\end{abstract}

CEx

En este ejemplo la voz del investigador es personal porque recurre a la primera persona del singular "yo" para conjugar los verbos tanto al inicio de su argumento como al final del mismo, lo cual se refleja cuando menciona "puedo afirmar que..." para empezar su argumento en esta etapa de cierre; y cuando dice "me encargaré de..." para vincular su argumento con otro apartado. Así, el investigador expresa su voz explícitamente de manera personal.

Un último ejemplo que refuerza este análisis es el siguiente, donde el autor del texto enuncia su voz de forma impersonal.

Vista así la lectura, se ve influenciada por los conocimientos y predicciones que el lector realiza en torno al texto, de esa forma se va construyendo en la mente del lector el significado sobre este, y el texto a su vez exige del lector su atención y habilidades lectoras... (HGL-I8-F2-p. 8)

Aquí, se observa nuevamente la voz del autor de forma impersonal, pero con la característica de se recurre a la voz pasiva del verbo "ver" para iniciar su argumento, cuando menciona "Vista así la lectura", con lo cual hace referencia a una discusión previa sobre el concepto que desarrolla en su explicación que es "la lectura".

En esta fase dos, se aprecia, con el análisis de los ejemplos citados, que la voz de los autores del texto tiene una presencia mayor que en la fase anterior. Primero, la voz de los 
investigadores se presenta generalmente de forma impersonal en los tres momentos de la explicación, en el inicio, desarrollo y cierre. En el inicio es donde el autor expone el tema a tratar en el desarrollo de la explicación. En el desarrollo es la fase donde los autores plantean explicaciones de las citas y elaboraciones de sus argumentos más propios en los cuales la voz de los autores tiene mayor presencia. Finalmente, en el cierre también se aprecia la voz de los autores para concretar sus argumentos. Esta forma en que los autores reflejan su voz indica que éstos tienen un papel más significativo en el transcurso de la explicación, en comparación a la fase anterior, porque se notan los esfuerzos de los investigadores por plantear argumentos más personales, con lo cual se evidencia que las citas textuales planteadas mantienen una función más de apoyo que de argumento principal como se evidenció en primera fase.

\subsubsection{Fase 3: Citas parafraseadas y elaboraciones propias del investigador}

En esta fase, los productos escritos que se revisaron se caracterizan por integrar un apartado conceptual más amplio que en las etapas anteriores, entre 25 y 30 páginas aproximadamente, el cual conforman un capítulo del último trabajo revisado. Estos capítulos conceptuales se caracterizan por mostrar un título tanto en el capítulo como en los apartados y sub-apartados que contiene cada uno de ellos. Las explicaciones identificadas giran en torno a diversos conceptos técnicos que el investigador considera necesarios abordar, por ello, dichas explicaciones son más amplias y abarcativas, por lo que se decidió únicamente recuperar un sub-apartado donde el investigador desarrollara una explicación de algún concepto técnico. De esta manera, se analizan extractos más amplios, puesto que las explicaciones también son más extensas, de donde surgen los siguientes ejes de análisis.

\section{a) La orientación disciplinar: una perspectiva concreta}

Entre los rasgos que presentan las explicaciones de los conceptos técnicos, se encuentra la orientación disciplinar a la que cada uno de los investigadores se afilia para desarrollar su planteamiento teórico, como se ejemplifica a continuación.

\footnotetext{
$\mathrm{Al}$ remitirme a las raíces etimológicas de la palabra interacción, es posible mencionar que esta proviene de dos vocablos latinos, inter que significa entre y acción que denomina a la operación realizada entre dos o más agentes, es decir acción entre dos o más agentes, en este caso y para mis propósitos me referiré a la acción entre dos o más individuos, la cual puede ser verbal o no verbal. Pero el término interacción en la actualidad supone algo más que la acción entre dos individuos pues esta acción trae
} 
La textualidad académica de estudiantes de origen indígena en estudios de posgrado: el proceso de elaboración de tesis

consigo diversas consecuencias y formas de analizarse mismas que se abordan desde un enfoque sociolingüistico. (MAGV-I2-F3-p.8)

En este primer ejemplo, vemos claramente que el investigador especifica en su explicación el concepto técnico que trata que es la "interacción” el cual introduce partiendo de las raíces etimológicas, pero también especifica la disciplina que orienta su discusión cuando alude al "enfoque sociolingüístico" para abordar el tema que plantea. Cuando él menciona que "el término interacción... supone algo más" está sugiriendo que este "algo más" va más allá de lo que se plantea en las raíces etimológicas, y que lo pretende explicar desde un enfoque concreto. De esta manera, el autor del texto guía con mayor precisión el desarrollo de su explicación.

En este eje, analizo dos ejemplos más donde se evidencia la orientación disciplinar que asumen los autores en su discusión conceptual. Pero antes, vale la pena aclarar que ambos ejemplos no se encuentran en la explicación elegida, puesto que, considerando que los apartados conceptuales son más extensos, los autores especifican su orientación disciplinar en otros momentos de su argumentación, y no exactamente en la explicación seleccionada, es decir, los dos ejemplos que se analizan pertenecen a explicaciones más globales donde se ubica el sub-apartado elegido para analizar la explicación. Así, el ejemplo con esta característica es el siguiente.

\footnotetext{
Dado lo anterior, me parece importante señalar brevemente que la evaluación escolar en términos generales puede ser observada desde dos grandes perspectivas: cuantitativo y cualitativo ya que como se mencionó en los párrafos anteriores, cada una de estas perspectivas plantea diferentes enfoques._En ese entendido, es necesario tener en cuenta que el tipo de evaluación que el docente aplique en su práctica ha de obedecer a la perspectiva que tenga acerca de la misma. (GHV-I3-F3-pp.13-14)
}

En este ejemplo, el autor expresa el tema que aborda en su explicación que es "la evaluación escolar", a partir de "dos... perspectivas: cuantitativo y cualitativo", característica que difiere en parte del ejemplo anterior porque en este caso se especifican "dos perspectivas" para abordar el tema en cuestión; y en el anterior, se presenta solo un enfoque disciplinario. No obstante, en ambos casos se presentan filiaciones disciplinarias más específicas.

Un ejemplo más de la orientación disciplinar en las explicaciones analizadas es el que sigue:

En este sentido el concepto de los actos de habla sustenta la parte central de esta investigación, ya que se enfoca básicamente al análisis exhaustivo de los usos del lenguaje en situaciones reales de la clase, por lo tanto se considera de forma 
específica la teoría de los actos de habla o actos lingüísticos que plantean Searle (1999) y Austin (1996) para mostrar cómo inciden éstos en los procesos de interacción verbal y en los procesos de enseñanza y aprendizaje dentro del aula. (RRG-I6-F3-pp.10-11)

En este ejemplo, el investigador indica claramente el concepto central de su explicación cuando mencionan que "el concepto de los actos de habla sustenta la parte central de esta investigación", por lo que no hay duda del tema en torno al cual gira su discusión teórica. Asimismo, en este extracto se aprecia la filiación disciplinar que adopta cuando refiere a que "considera de forma específica la teoría de los actos de habla..." con lo cual evidencia la orientación disciplinar que guía el desarrollo de sus explicaciones.

De esta manera, la orientación disciplinar que exhiben los ejemplos analizados en esta fase se caracteriza por ser más concreta, debido a que los investigadores especifican con mayor precisión su filiación disciplinar porque enuncian claramente cuál es la disciplina o la teoría en la que sustentan sus explicaciones respecto a los conceptos técnicos que desarrollan.

Así, en este estudio longitudinal respecto a la orientación disciplinar, se aprecian los siguientes rasgos. En la fase uno se nota que los autores expresan una orientación disciplinar que ellos determinan antes de su formación en la maestría, en el cual se observa un punto de partida. No obstante, en la fase dos se aprecia claramente que los investigadores presentan imprecisión en su filiación disciplinar porque aluden a "investigaciones" pero no especifican a cuál exactamente refieren, por ello, en esta fase la orientación disciplinar queda abierta. Por último, en la fase tres se observa con mayor especificidad la orientación disciplinar que adoptan los investigadores porque plantean claramente la disciplina o teoría que guía su explicación. De esta manera, se pueden advertir los cambios que manifiestan cada una de las fases en torno a este eje de análisis, lo cual muestra en parte el entendimiento que los autores tienen respecto a orientación disciplinar que implican las explicaciones de los conceptos técnicos que integran un apartado conceptual de una tesis de grado.

\section{b) La estructura de las explicaciones en torno a los conceptos técnicos}

En esta fase tres se observan explicaciones más amplias a las fases anteriores, por lo que las explicaciones elegidas en esta etapa corresponden a explicaciones más concretas que pertenecen a explicaciones más globales, en las cuales se identifica una estructura más 
La textualidad académica de estudiantes de origen indígena en estudios de posgrado: el proceso de elaboración de tesis

elaborada pero que comparte rasgos con la estructura de las explicaciones en las fases previas, como lo es un inicio, un desarrollo y un cierre, como se muestran a continuación.

\section{Caso 1}

\section{I) Fase de inicio: una apertura más elaborada}

Por la amplitud de las explicaciones de los conceptos técnicos desarrollados en este primer caso es un apartado que corresponde al capítulo conceptual, por lo que el fragmento que se analiza es solo una parte de esa explicación más global. La explicación que se expone refiere al concepto técnico "interacción comunicativa" que el investigador intenta definir en su explicación, como él mismo lo plantea:

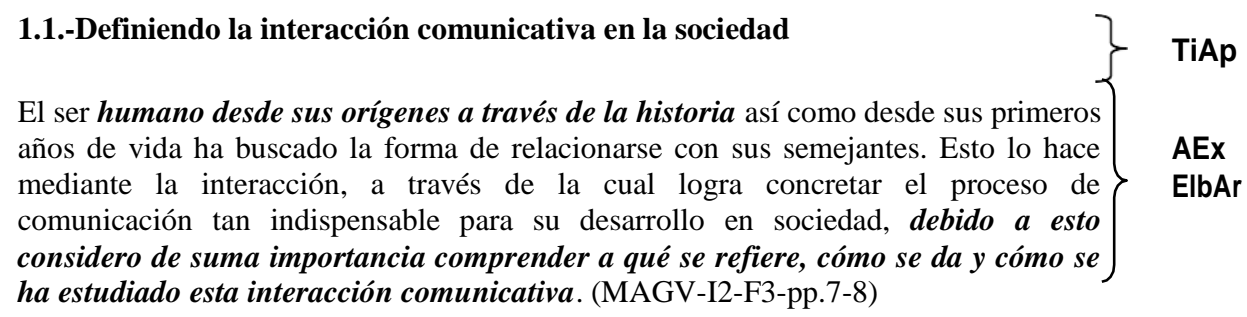

En este extracto, se aprecia claramente que el apartado tiene un título del apartado (TiAp) que muestra a grandes rasgos el concepto técnico "interacción comunicativa" a desarrollar en esta explicación, característica que no se nota claramente en las fases anteriores.

Se identifica también que este primer párrafo corresponde a la "apertura de la explicación" (AEx) porque, valiéndose de un argumento que refiere a la "historia del ser humano", el investigador "considera de suma importancia comprender a qué se refiere, cómo se da y cómo se ha estudiado la interacción comunicativa", con lo cual el investigador evidencia el rumbo que tomará su explicación porque especifica lo que quiere comprender respecto al concepto técnico que plantea, en este caso sobre la "interacción comunicativa". Esta apertura continúa en el siguiente párrafo donde el autor elabora un argumento más propio.

Al remitirme a las raíces etimológicas de la palabra interacción, es posible mencionar que esta proviene de dos vocablos latinos, inter que significa entre y acción que denomina a la operación realizada entre dos o más agentes, es decir acción entre dos o más agentes, en este caso y para mis propósitos me referiré a la acción entre dos o más individuos, la cual puede ser verbal o no verbal. Pero el término interacción en AEx la actualidad supone algo más que la acción entre dos individuos pues esta acción 
trae consigo diversas consecuencias y formas de analizarse mismas que se abordan desde un enfoque sociolingüístico. (MAGV-I2-F3-p.8)

Esta segunda parte de la apertura de la explicación se identifica a partir de que el investigador empieza a definir el concepto técnico (ElbAr), para lo cual recurre a "las raíces etimológicas" del término "interacción" como se observa en este párrafo, aunque no se especifica de dónde se obtuvo esa información. Además, esta elaboración del argumento se caracteriza por el vínculo que hace el investigador entre los argumentos de su explicación y el objetivo que desea lograr con ella, cuando él dice "en este caso y para mis propósitos me referiré $a$ " está especificando el rumbo que tomará su explicación. Esta idea se refuerza cuando el autor del texto alude a que la "interacción... supone algo más..." y que "trae consigo diversas consecuencias" donde se muestra su intención por desarrollar otros aspectos del concepto técnico planteado desde una perspectiva específica, en este caso "un enfoque sociolingüístico". Con esto queda claro que el investigador inicia su explicación y delimita la mirada desde la cual se posicionará para explicar el concepto de "Interacción comunicativa", dando paso a la fase de desarrollo de la explicación, como se muestra a continuación.

\section{I) Fase de desarrollo: presencia de citas parafraseadas}

Esta fase de desarrollo inicia con la apertura de una cita (ApC), como se puede ver en el siguiente párrafo.

La interacción es un fenómeno que se presenta en toda sociedad en general. Es más, es la base para que una sociedad pueda existir como tal. Puedo decir entonces, que sin interacción no existiera sociedad, pues desde el mismo momento en el que los seres humanos comenzaron a interactuar entre ellos se fueron formando las primeras ApC sociedades, muchas de las cuales se conservan actualmente. (MAGV-I2-F3-p.8)

En este argumento, el investigador abre un argumento construido a partir de términos e ideas que se plantean en la cita que expone posteriormente. Por ejemplo, los términos "interacción”, "sociedad”, "seres humanos", y la idea de reciprocidad cuando él dice que "sin interacción no existiera sociedad" son argumentos que se expresan en la cita donde el estudiante investigador parafrasea a otros autores como se nota en el siguiente extracto.

En este sentido de la importancia de la interacción para la sociedad, Regina Jiménez. y Georgina Paulín (1985) argumentan que una sociedad existe y se mantiene en la medida en la que se establece y posibilita un proceso de contactos humanos continuos y recíprocos, proceso al cual le denominan interacción social. Dicho de 
La textualidad académica de estudiantes de origen indígena en estudios de posgrado: el proceso de elaboración de tesis

otra manera, la interacción es un proceso mediante el cual los seres humanos entran en contacto de forma activa, pues al ser recíproca, la presencia de un agente influye en el otro, además de que la continuidad de estos contactos es lo que mantiene a la sociedad, resultando ser el vehículo más importante que ésta utiliza para transmitir sus conocimientos. (MAGV-I2-F3-p.8)

$\operatorname{ExCPr}$

En este ejemplo, se aprecia que el investigador parafrasea a otros autores (CPr) para desarrollar su explicación, donde primeramente se hacen visibles las expresiones del argumento anterior; por ejemplo, "interacción", "sociedad", "contactos humanos... recíprocos", con lo cual se puede afirmar que el investigador vincula ambos argumentos mediante la estrategia de señalizaciones de repetición léxica y discursiva. Le sigue a la cita parafraseada $(\mathrm{CPr})$ la explicación de la misma $(\mathrm{ExCPr})$ donde el autor utiliza una expresión impersonal para explicar de otra manera el argumento de los autores citados. Cuando el investigador dice "Dicho de otra manera, la interacción es un proceso..." sugiere que recurrirá a otros elementos discursivos para consolidar su explicación, sin embargo, se aprecia que en la explicación de la cita $(\mathrm{ExCPr})$ recurre nuevamente a señalizaciones de repetición léxica y discursiva, utilizando los términos expresados en la cita que él parafrasea, tales como "seres humanos", "recíproco", "continuidad" y "contacto". Después de esta explicación, continua otra cita parafraseada.

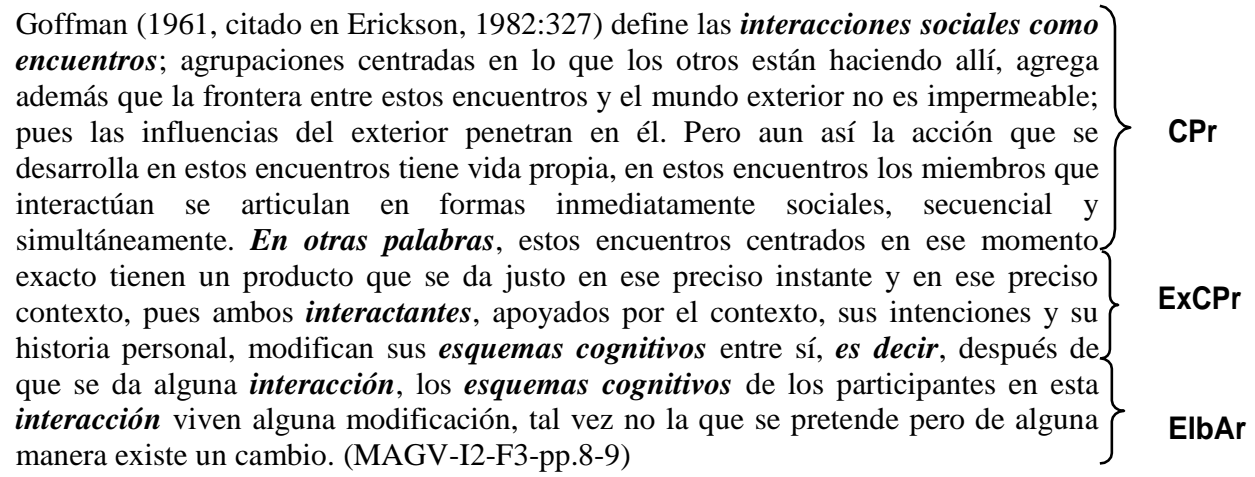

Podemos observar en este ejemplo que el parafraseo de otra cita (CPr) plantea la definición de "interacciones sociales" término que combina argumentos anteriores como "interacción" y "sociedad". Después, el investigador explica la cita parafraseada (ExCPr) cuando dice "En otras palabras, estos encuentros.", lo cual sugiere que agregará otros elementos para desarrollar su argumento y vincularlo con el posterior. Además, la explicación de la cita se ve apoyada en con una elaboración del argumento (ElbAr) cuando menciona "es decir..." lo que evidencia el respaldo de la explicación de la cita donde vemos que el 
investigador introduce en su argumento un nuevo elemento que refiere a "esquemas cognitivos" que retoma más adelante. De aquí continua una apertura de la cita.

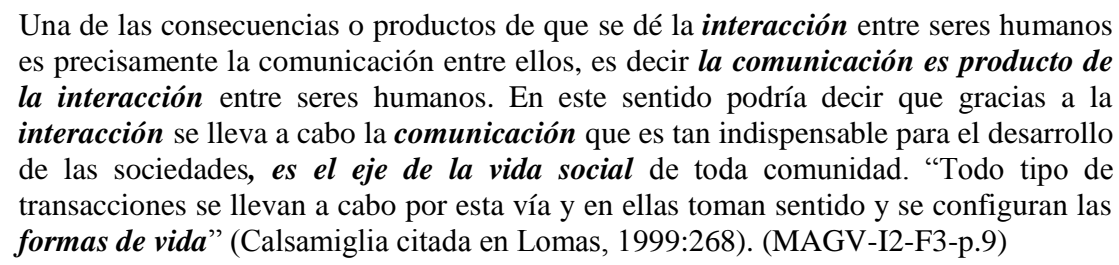

En esta apertura de la cita (ApC), se observa que el investigador introduce otro concepto que es "la comunicación" el cual intenta relacionar con el concepto técnico "interacción" cuando afirma que "la comunicación es producto de la interacción" y que "gracias a la interacción se lleva a cabo la comunicación... es el eje de la vida social", argumento que se apoya en una cita textual (CTx) donde retoma una expresión mencionada en su argumento previo "vida social" y una expresión mencionada en la cita textual "formas de vida" con lo cual intenta vincular su argumento de forma explícita. De ahí continua el siguiente argumento.

En una interacción participan dos o más agentes, los cuales tienen una intención y ambos saben de la existencia del otro, es decir, es una acción recíproca. El resultado

ElbAr de esta acción recíproca, de acuerdo a la intención, es la modificación del estado cognitivo de los interlocutores, en todo caso el de comunicar algo. (MAGV-I2-F3-p.9)

En este ejemplo, el investigador elabora su argumento (ElbAr) a partir de ideas desarrolladas anteriormente porque claramente se nota que retoma expresiones ya mencionadas como "acción recíproca", "modificación del estado cognitivo", y "comunicar", lo cual evidencia el intento del autor por hacer una elaboración más propia de sus argumentos anteriores. Esto también se muestra en el siguiente extracto.

Pero para que se den estos encuentros de la forma en que lo afirma Goffman, y que se llegue a dar la comunicación, es necesario que los interactantes compartan $\}$ ElbAr algunos rasgos comunes, tal y como lo argumenta Gumperz (1982), cuando nos menciona que interactuar también implica compartir algunos niveles gramaticales $y\}$ $\mathrm{CPr}$ normas sociales, es decir tener un lenguaje en común. (MAGV-I2-F3-p.9)

En este párrafo vemos que le investigador elabora de forma breve su argumento (ElbAr) donde no sólo recupera conceptos mencionados previamente, como "encuentros" y “comunicación”, sino también retoma a uno de los autores citados, "Goffman” en quien se apoya para sustentar su argumento. Además, recurre a otro autor "Gumperz (1982)" a quien parafrasea (CPr) para reforzar su idea anterior, concretamente su argumento respecto a "compartir rasgos comunes", lo cual se expresa en el cita que el parafrasea "compartir 
La textualidad académica de estudiantes de origen indígena en estudios de posgrado: el proceso de elaboración de tesis

algunos niveles..., tener un lenguaje común”. Con esto, el investigador va relacionando sus ideas con los argumentos de otros autores con lo cual va finalizando esta etapa del desarrollo de la explicación para pasar al cierre de la misma.

\section{II) Fase de cierre: La evaluación y conclusión de la explicación}

Creo importante recalcar en este momento que el término interacción comunicativa no sólo se refiere al acto de usar el lenguaje oral para expresarse, sino que es más amplio, pues abarca otras formas de acción extralingüísticas como la mímica, la gesticulación, movimientos corporales y de posición con respecto al otro interlocutor, entre otras. Además interactuar comunicativamente implica tener un discurso, dos o más individuos, la intención de hacerlo y un contexto. Es decir, el lenguaje oral forma parte de la interacción mas no es por si solo interacción comunicativa. Más aun, tanto el lenguaje oral como las acciones extralingüísticas forman parte de lo que se denomina interacción comunicativa. (MAGV-I2-F3-pp.9-10)

CEx

En este último párrafo el investigador cierra su explicación (CEx) aludiendo principalmente a su argumento de la cita previa respecto al "lenguaje" para concretar su argumento respecto a concepto de "interacción comunicativa", donde resaltan dos aspectos fundamentales. Uno tiene que ver con una evaluación que el investigador hace de su explicación cuando él menciona "Creo importante recalcar en este momento que el término interacción comunicativa no solo se refiere a.... sino que es más amplio", expresión donde el autor del texto realiza una valoración de su argumento, específicamente cuando señala "creo importante recalcar..." y mediante las conjunciones "no sólo... sino que...", haciendo referencia al concepto de "interacción comunicativa", el investigador está manifestando su apreciación respecto al alcance que implica el concepto que explica. Otra característica de este cierre, es una conclusión que plantea el investigador respecto al tema que trata cuando dice "Más aun, tanto el lenguaje oral como las acciones extralingüísticas forman parte de lo que se denomina interacción comunicativa”, expresión donde la conclusión se exhibe cuando el autor del texto conecta dos elementos mediante el uso de "tanto... como" para construir su frase, con lo cual expresa una noción de igualdad entre ambos elementos que son "el lenguaje oral" y las "acciones extralingüísticas" para concluir su argumento respecto a la "interacción comunicativa" como él mismo lo expresa en este cierre de la explicación.

De esta manera, vemos que en el caso analizado corresponde sólo a una parte de la explicación global que el investigador desarrolla en su apartado conceptual, lo cual indica que la explicación analizada no es un concepto técnico sino de una parte de él, es decir de una 
explicación interna a la que el investigador le da un título donde explica parte del concepto técnico que es la "interacción comunicativa", cuya estructura queda de la siguiente manera:

\begin{tabular}{|l|l|l|}
\hline & Fase de Inicio & $\begin{array}{l}\text { Título del Apartado (TiAp) } \\
\text { Apertura de la explicación (AEx) } \\
\text { Elaboración del Argumento (ElbAr) }\end{array}$ \\
\cline { 2 - 3 } & Fase de desarrollo & $\begin{array}{l}\text { Apertura de la cita (AdC) } \\
\text { Cita Parafraseada (CPr) }\end{array}$ \\
FASE 3. & & Explicación de la Cita Parafraseada (ExCPr) \\
CONCEPTOS & & Cita Parafraseada (CPr) \\
TÉCNICOS & & Explicación de la Cita Parafraseada (ExCPr) \\
& & Apertura de la cita (AdC) \\
& & Cita Textual (CTx) \\
& & Elaboración del Argumento (ElbAr) \\
& & Elaboración del Argumento (ElbAr) \\
& & Cita Parafraseada (CPr) \\
\hline & Fase de cierre & Cierre de la explicación (CEx) \\
\cline { 2 - 3 } & &
\end{tabular}

En el inicio, el investigador abre su argumento enfatizando la importancia de comprender el concepto que el plantea, se aprecia también una elaboración de un argumento más personal donde clarifica su orientación disciplinar. En la fase de desarrollo el investigador recurre a otros conceptos como "sociedad", "interacciones sociales", “comunicación", "lenguaje”, en los cuales se apoya para explicar el concepto de "interacción comunicativa". En esta fase también se observa la presencia notable tanto de citas parafraseas, es decir ya no textuales, como una explicación de ellas. Asimismo, se observan elaboraciones de argumentos que el autor intenta desarrollar de forma más personal. Finalmente, en la fase de cierre, el autor concreta su argumento respecto al concepto técnico aludido, mediante la evaluación de su explicación y la conclusión a la que llega. Con esto, es posible afirmar que la explicación desarrollada en este caso mantiene una estructura más definida, donde el parafraseo de las citas, las explicaciones de las mismas, y las elaboraciones de algunos argumentos, caracterizan principalmente la explicación del concepto técnico analizado. Esta lógica de plantear la explicación se evidencia también en el siguiente caso.

\section{Caso 2}

El apartado que se presenta a continuación, corresponde a una parte del capítulo conceptual que, por cuestiones de amplitud, solamente se recuperó una parte de él. Sin embargo, este extracto es suficiente para mostrar la estructura de los argumentos del 
La textualidad académica de estudiantes de origen indígena en estudios de posgrado: el proceso de elaboración de tesis

investigador respecto a los conceptos técnicos que él desarrolla en su explicación, como se muestra a continuación.

\section{Fase de inicio: una apertura más elaborada}

1.1 La interacción social vs la interacción verbal en el contexto escolar

Primeramente considero importante precisar que la interacción social, se entiende como el proceso comunicativo que se establece entre personas en torno a cierto tema, en una situación dada y en un ámbito socio-cultural determinado, en donde se necesita por lo menos de un hablante y un oyente o un auditorio, y en otros casos esta interacción se establece entre un hablante y varios oyentes al mismo tiempo, de tal modo que los interlocutores puedan mantener un evento de habla ${ }^{24}$ con ciertas intenciones y con ciertos propósitos sociales. En este sentido este tipo de interacción se considera "social" porque se trata de una práctica comunicativa necesaria en cualquier sociedad. (RRG-I6-F3-p.11)
TiAp

AEx

ElbAr

Como se puede notar en esta fase de inicio, el apartado, al igual que el caso anterior, tiene un título que exhibe los conceptos técnicos que el investigador desea abordar, en este caso, se refiere a "La interacción social" y a la "interacción verbal en el contexto escolar". Para esto, se observa que el autor del texto inicia su explicación (AEx) mediante la elaboración de un argumento (ElbAr) donde define uno de los conceptos que él propone desarrollar, cuando menciona "considero importante precisar que la interacción social, se entiende como..." está expresando su entendimiento respeto a dicho término. También se aprecia que la elaboración de su argumento se apoya en otro concepto que es "un evento de habla" el cual se define mediante una nota al pie de página. Así, el investigador abre su explicación con una elaboración de un argumento para definir el concepto que plantea inicialmente. Después de esta apertura continúa la fase de desarrollo de la explicación.

\section{Fase de desarrollo: argumentos de contraste}

De la misma manera Cazden (1991) señala que las escuelas son uno de los contextos o ambientes humanos más concurridos, por lo que las clases se asemejan a los contextos comunicativos e interactivos que se presentan en los restaurantes, en los autobuses, en el metro, mismos que se caracterizan por ser lugares en donde son normales las $\mathrm{CPr}$ conversaciones independientes, espontáneas, libres, comunes y simultáneas, solo que en la escuela esta interacción verbal es diferente, ya que una persona, el maestro, mantiene el control de todo lo que se habla en el transcurso "oficial" de la clase y en estos casos los actos de habla regularmente se enfocan a contenidos programáticos, por lo que el lenguaje empleado es más formal en contenido y en forma a diferencia
de otros contextos y situaciones comunicativas que se mencionan anteriormente (los restaurantes o en los autobuses). (RRG-I6-F3-pp.11-12)

\footnotetext{
24 Según Hymes (citado en Pilleux, 2001) Un evento de habla, es la actividad comunicativa o aspectos de la misma que está regido por reglas o normas para el uso lingüístico, por ejemplo, una conversación, una discusión o un dialogo...
} 
Esta fase de desarrollo (FDes) inicia con el argumento de un autor externo, el cual el investigador parafrasea (CPr), y vincula con su argumento anterior, cuando dice "De la misma manera Cazden (1991) señala que", está indicando que el argumento del autor citado se relaciona con el argumento que él plantea en la fase de inicio de la explicación. De esta cita parafraseada (CPr), se observa un argumento que contrasta con el concepto anterior cuando investigador menciona "solo que en la escuela esta interacción verbal es diferente", es decir que esta frase es un elemento discursivo que el autor de texto utiliza para expresar el contraste entre los dos términos que se evidencian en el título de su apartado. Este contraste se refuerza cuando él afirma "por lo que el lenguaje empleado es más formal en contenido y en forma a diferencia de otros contextos y situaciones comunicativas que se mencionan anteriormente". En ambas expresiones se exhiben términos como "solo que...", “...es diferente" y " diferencia de..." los cuales dejan claro que el investigador está haciendo una comparación de dos planteamientos y su intento por elaborar un argumento (ElbAr) propio. Con esto, el autor va organizando y vinculando sus argumentos, característica que también se presenta en el siguiente párrafo.

\begin{tabular}{|c|}
\hline $\left.\begin{array}{l}\text { Por su parte Gumperz (1998) menciona que en los actos comunicativos, existen } \\
\text { indicaciones e interpretaciones que los participantes reconocen a partir de una } \\
\text { interacción social cotidiana, la cual se establece como secuencias más amplias de } \\
\text { conversación, y los ámbitos y dominios sociales pueden ser variados al igual que las } \\
\text { necesidades comunicativas o los temas a tratar entre los actores de un grupo social. } \\
\text { Mientras que en el contexto escolar la interacción verbal ya está preestablecida, así } \\
\text { mismo se crean y se señalizan los esquemas interactivos que sirven como marcos para } \\
\text { estas interpretaciones y significaciones de los actos lingüísticos que se generan en este } \\
\text { contexto institucionalizado, prueba de esto son los actos de habla que se establecen } \\
\text { dentro del aula, en donde la interacción está pautada por las normas de la institución } \\
\text { escolar. (RRG-I6-F3-p.12) }\end{array}\right\}$ \\
\hline
\end{tabular}

Aquí nuevamente el investigador se apoya en un autor externo a quien parafrasea para definir el concepto de "actos comunicativos", pero que a la vez contrasta con el concepto de "interacción verbal", lo cual se manifiesta cuando realiza una comparación apoyado en un conector de contraste y dice "Mientras que en el contexto escolar la interacción verbal ya está preestablecida". Con esta expresión, el investigador elabora un argumento (ElbAr) más personal y mantiene la lógica de comparación entre los dos conceptos técnicos que plantea al inicio de su explicación.

La fase de desarrollo continúa en el siguiente fragmento donde el investigador recurre a otro autor externo. 
La textualidad académica de estudiantes de origen indígena en estudios de posgrado: el proceso de elaboración de tesis

Para complementar esta idea también se retoma lo que plantea Hymes cuando argumenta que la interacción comunicativa se basa en la competencia sociolingüística de los hablantes en donde los usos de la lengua y el habla están pautados y normados por reglas de interacción social de un grupo, una institución, una comunidad o una sociedad en particular (Hymes, 1971 citado en Maqueo, 2010). De tal forma que cuando se trata de un contexto como el aula, la interacción verbal no es igual que la que se da en otros contextos, ya que la escuela condiciona las formas de hablar y los interactuantes se sujetan consciente o inconscientemente a estas reglas de interacción. Esto significa que la interacción en los contextos sociales es más libre, común y espontánea, o por lo menos las reglas son más flexibles y convencionales para los interlocutores a diferencia de las normas que rigen la interacción en una institución como la escuela. (RRG-I6-F3-p.12)

CTx

ElbAr

En este párrafo se aprecia que el investigador intenta reforzar su argumento anterior mediante el planteamiento de una cita textual (CTx), cuando él menciona que "Para complementar esta idea también se retoma lo que plantea Hymes cuando argumenta que la interacción comunicativa...”. De la cita textual, se nota que el investigador elabora un argumento donde, basado en la cita textual, una vez más hace una comparación respecto al concepto técnico que está explicando, en este caso es la “interacción verbal”, lo cual se manifiesta en su argumento "De tal forma que cuando se trata de un contexto como el aula, la interacción verbal no es igual que la que se da en otros contextos", recurriendo a expresiones como "De tal forma que" y "no es igual que..." que le dan el sentido de contraste a su argumento. Con este queda claro que el autor del texto desarrolla su explicación contrastando argumentos, lo cual es compatible con lo que el plantea al inicio de su explicación. Con esto culmina fase de desarrollo y continúa la fase de cierre.

\title{
III. Fase de cierre: coda y el contraste en los argumentos
}

\begin{abstract}
Por lo tanto la interacción verbal que se establece entre el profesor y los alumnos durante una clase, sobre todo la que se lleva a cabo al realizar las actividades didácticas, está enmarcada y condicionada por las normas institucionales del aula. Por eso los actos de habla del profesor y los alumnos en una clase, reflejan el papel que juega la institucionalidad de la escuela en un proceso de interacción verbal. Situación que no se da en una interacción comunicativa en un contexto social, ya que en éste existe más libertad de los actores para establecer ciertos actos de habla, sin que exista un rol dominante del hablante o sin que haya un tema ya definido desde donde centrar la interacción verbal. (RRG-I6-F3-p.13)
\end{abstract}

CEx

Finalmente, encontramos el cierre de la explicación (CEx) donde se observa la presencia de una "coda" es decir, cláusulas que anuncian el cierre de la explicación; por ejemplo, la frase "Por lo tanto la interacción verbal que se establece durante la clase..." indica que el investigador está terminando con su explicación, específicamente cuando refiere al conector "por tanto". También se observa que el autor cierra su argumento respecto al 
contraste que hace entre los dos conceptos técnicos cuando afirma "Situación que no se da en una interacción comunicativa en un contexto social" porque cuando dice concretamente "Situación que no se da..." está contrastando los argumentos respecto a los conceptos técnicos planteados desde el título de este apartado. Con esto queda claro que el investigador introduce clausulas finales que cierran la explicación, es decir una coda y expresiones de contraste con lo cual finaliza su explicación.

De esta manera, este caso se caracteriza por plantear el contraste entre dos conceptos técnicos que son "interacción social" e "interacción verbal" que se desarrolla a lo largo de la explicación, la cual está organizada en una fase de inicio, de desarrollo y de cierre.

\begin{tabular}{|l|l|l|}
\hline \multirow{4}{*}{$\begin{array}{l}\text { FASE 3. } \\
\text { CONCEPTOS } \\
\text { TÉCNICOS }\end{array}$} & Fase de Inicio & $\begin{array}{l}\text { Título del Apartado (TiAp) } \\
\text { Apertura de la explicación (AEx) } \\
\text { Elaboración del Argumento (ElbAr) }\end{array}$ \\
\cline { 2 - 3 } & Fase de desarrollo & $\begin{array}{l}\text { Cita Parafraseada (CPr) } \\
\text { Elaboración del Argumento (ElbAr) } \\
\text { Cita Parafraseada (CPr) } \\
\text { Elaboración del Argumento (ElbAr) } \\
\text { Cita Textual (CTx) } \\
\text { Elaboración del Argumento (ElbAr) }\end{array}$ \\
\hline & & Cierre de la explicación (CEx) \\
\cline { 2 - 3 } & Fase de cierre & \\
\hline
\end{tabular}

Esta estructura identificada evidencia características textuales donde destaca una fase de inicio más amplia que incluye un apartado titulado, así como una elaboración de un argumento por parte del investigador. En la fase de desarrollo, se observan sobre todo la presencia de citas que el autor del texto parafrasea, además de presentar elaboraciones de argumentos donde el investigador contrasta los conceptos que el plantea en el título de este apartado, lo cual evidencia la intención del autor por plantear argumentos más propios en el desarrollo de su explicación. En la fase de cierre, se observa que el uso de la coda y un argumento de contraste donde el investigador concreta su argumento. Al igual que el caso anterior, éste se caracteriza por presentar una estructura más elaborada, por expresar citas parafraseadas y argumentos más elaborados por parte del investigador, lo cual muestra cambios importantes a las fases ateriores.

\section{Caso 3}


La textualidad académica de estudiantes de origen indígena en estudios de posgrado: el proceso de elaboración de tesis

Similar a los casos anteriores, el apartado analizado pertenece a un apartado mayor que a su vez forma aparte del apartado principal que corresponde al capítulo conceptual. Por ello, por cuestiones de amplitud en las explicaciones solamente se eligió un sub-apartado para realizar el análisis, no obstante, éste es suficiente para identificar la estructura de la explicación que se plantea, la cual comparte algunas características similares al caso anterior como se puede observar a continuación.

\section{Fase de inicio: un resumen (abstract) de la explicación}

a) La evaluación inicial

En el marco de las observaciones anteriores, es conveniente mencionar que la evaluación inicial se refiere a la que practican los docentes al iniciar un nuevo proceso de enseñanza y aprendizaje, la cual también es definida como evaluación diagnóstica. Este tipo de evaluación trata principalmente de recuperar y analizar la situación de cada estudiante, en cuanto a lo que saben o recuerdan del tema de estudio para tomar conciencia (tanto alumnos como docentes) de la situación de partida. (GHV-I3-F3-p.23)

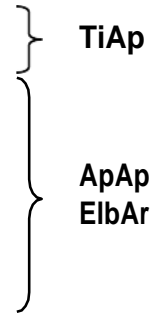

Primeramente, se percibe claramente que el apartado tiene un título el cual presenta el concepto técnico que el investigador desarrolla en su explicación, en este caso es "La evaluación inicial". La explicación inicia con una apertura del apartado (ApAp) que a la vez es una elaboración del argumento (ElbAr) donde el investigador, en un primer momento, vincula su apartado con discusiones previas cuando hace referencia a "observaciones anteriores". De ahí, el autor del texto elabora un argumento (ElbAr) para empezar a explicar el concepto técnico que plantea cuando dice "la evaluación inicial se refiere a...". Para esto él recupera, mediante la estrategia de señalización de repetición léxica y discursiva, algunas expresiones e ideas desarrolladas a lo largo de su explicación, por ejemplo cuando hace referencia a "iniciar un nuevo proceso de enseñanza y aprendizaje", "evaluación diagnóstica", "situación de cada estudiante" y "tomar conciencia", son expresiones que se mencionan en párrafos posteriores como se podrá notar más adelante.

\section{Fase de desarrollo: señalizaciones para vincular los argumentos}

De esta apertura del apartado, sigue la fase de desarrollo de la explicación la cual inicia con una apertura de la cita (Apc) donde el investigador plantea una idea con la cual relaciona su argumento con una cita textual como se observa en el siguiente extracto. 
Entendida así, la evaluación inicial pasa a ser un instrumento clave para conocer la situación de partida de los alumnos. Sin embargo, se debe aclarar que su objetivo no es evaluar -en el sentido de calificar- sino más bien diagnosticar el conocimiento que tienen los alumnos. (GHV-I3-F3-p.23)

En este ejemplo, el autor del texto hace alusión a la idea de "conocer la situación de partida de los alumnos", argumento que también se plantea en el cita textual (CTx) que continúa.

Siguiendo este razonamiento, Barberá define a la evaluación inicial de la siguiente manera;

La evaluación inicial supone determinar la situación de los alumnos antes de iniciar
un proceso de enseñanza y aprendizaje. Con ello se pretende adecuar la planificación
del profesor a las necesidades y características de sus discípulos. Pero conviene que,
además de ser explicita para el profesor, también lo sea para cada alumno y para el
conjunto del grupo clase. (GHV-I3-F3-p. 23)

En síntesis, la evaluación inicial aporta:

a) Al profesor: una expresión preliminar de sus alumnos, y datos relevantes para la CTx organización de su planteamiento didáctico.

b) A cada alumno: conciencia de lo que conoce en relación con un tema, posibles dificultades o grado de dominio de un procedimiento particular.

c) $\mathrm{Al}$ conjunto de los alumnos como grupo clase: la oportunidad de contrastar el nivel de conocimiento personal, las dificultades particulares o los usos idiosincrásicos de ciertos procedimientos con los conocimientos, las dificultades y los modos de uso de los demás compañeros, lo que amplía su perspectiva particular y moviliza sus esquemas de conocimiento (Barberá G. 1999: 93). (GHV-I3-F3-p. 23-24)

Esta cita textual (CTx) que el investigador expone, conlleva señalizaciones discursivas que se plantearon anteriormente en la apertura de la cita como "situación de cada estudiante", “iniciar un nuevo proceso de enseñanza y aprendizaje" y "tomar conciencia”, expresiones a las cuales también se hace alusión en la cita textual como "situación de los alumnos", "iniciar un proceso de enseñanza y aprendizaje" y "conciencia de lo que se conoce". Con estas señalizaciones de repetición léxica y discursiva en las que el investigador se apoya, está vinculando su argumento inicial con los posteriores. Esto se evidencia también en la explicación de la cita $(\mathrm{ExC})$ que sigue.

Es importante mencionar que para la evaluación con enfoque formativo, es indispensable la evaluación en la fase inicial del proceso educativo, ya que esta es la que permitirá al docente obtener el conocimiento previo que es preciso poseer de los alumnos antes de iniciar una nueva etapa de conocimiento para poder adecuar la enseñanza a sus ExC condiciones de aprendizaje y optimizar la construcción de las nuevas actividades escolares, cumpliendo así con una de las funciones principales que se le ha asignado a este tipo de evaluación que es la regulación. (GHV-I3-F3-p. 24)

En este párrafo, el investigador explica la cita (Exc) anterior, en un primer momento, enmarcando su argumento desde "un enfoque formativo", con lo cual orienta su argumento para enfatizar la idea de "obtener el conocimiento previo... de los alumnos". Para apoyar su discusión, el autor también recupera en su explicación, una idea mencionada en la cita textual 
La textualidad académica de estudiantes de origen indígena en estudios de posgrado: el proceso de elaboración de tesis

(CTx) que es "adecuar la enseñanza a sus condiciones de aprendizaje”. De esta manera, el investigador va relacionando sus argumentos con los argumentos de otros autores. Enseguida aparece la apertura de otra cita textual en esta fase de desarrollo.

Cabe mencionar que algunos aspectos que se pueden diagnosticar en esta fase evaluativa pueden ser -aparte de las ideas previas que posee el alumno en relación con el tema que se va a tratar- las actitudes hacia dicha temática y el dominio de los procedimientos que van a ser necesarios para su desarrollo.

$\mathrm{Al}$ respecto, cabe retomar las aportaciones que hace Sanmartí al menciona que;

Los aspectos que hay que diagnosticar en una evaluación inicial pueden ser muy
variados [...] Esta expresión hace referencia al conjunto de actitudes, conductas,
representaciones y maneras espontaneas de razonar propias de cada alumno en cada
momento de su desarrollo que conforman la estructura en la que se inserta y organiza el

Como se puede apreciar en la apertura de la cita (Apc) se retoman nuevamente ideas mencionadas en la cita textual (CTx). Por ejemplo, el investigador abre la cita haciendo referencia a "aspectos que se pueden diagnosticar", idea que menciona literalmente el autor de la cita textual cuando dice "aspectos que hay que diagnosticar" como se aprecia en el extracto anterior. De la misma manera, se observa que en la apertura al igual que en la cita textual, se alude a las "actitudes... de cada alumno... para su desarrollo". En este ejemplo, otra vez, vemos cómo el investigador vincula sus argumentos recurriendo a la estrategia de señalizaciones de repetición léxica y discursiva. Después de la cita textual, continúa la elaboración de un argumento (ElbAr) pero que pertenece a la fase de cierre porque en él se concreta el argumento de la explicación.

\title{
III. Fase de cierre: evaluación y contribución
}

Este cierre de la explicación presenta la particularidad de que incluye a la vez una elaboración de un argumento (ElbAr) como se muestra en el siguiente párrafo.

\begin{abstract}
Queda claro que sin una evaluación inicial, no es posible obtener el conocimiento previo de los estudiantes que se hace necesario para poder adecuar la nueva enseñanza a sus condiciones de aprendizaje. De esta manera se establece entonces que la preocupación del profesor es que el alumno logre establecer conexiones entre lo que sabe, lo que ha vivido, lo que entiende y el nuevo material de aprendizaje que le presenta en la clase. (GHV-I3-F3-p. 24)
\end{abstract}

CEx ElbAr

Este extracto muestra, primeramente, una evaluación que el investigador hace en torno al tema que trata, cuando menciona "Queda claro que sin una evaluación inicial, no es posible obtener..." y "De esta manera se establece entonces que la preocupación ..." son frase que señalando una valoración por aparte del investigador respeto al concepto técnico que 
es la "evaluación inicial. Cuando se recurre a expresiones como "queda claro que", "no es posible" y "se establece entonces que" significa que el investigador va evaluando sus argumentos respecto al tema tratado. Esta evaluación que el investigador construye, es también una elaboración del argumento, porque en él, el autor está manifestando una apreciación con la cual va cerrando su explicación. El siguiente párrafo corresponde a la segunda parte del cierre.

Por otro lado, esta evaluación también servirá de referente en el momento de valorar el final de un proceso educativo o de comprobar en qué medida los resultados han sido satisfactorios, ya que de esta manera será posible equiparar los conocimientos CEx iniciales con los adquiridos al final de un determinado periodo. (GHV-I3-F3-p.25)

Por último, aparece otra parte del cierre de la explicación (CEx) donde el investigador plantea una conclusión que a la vez incluye una contribución a un campo de conocimiento. Cuando el autor alude a que "esta evaluación también servirá de referente..." y "de esta manera será posible..." recurre al uso de expresiones que conllevan verbos conjugados en futuro simple como "servirá" y "serâ", lo cual es un indicador de la contribución que pretende hacer con su explicación en torno a la "evaluación inicial" y contribuir a este campo de conocimiento. De esta forma, este cierre se caracteriza por integrar una elaboración de un argumento y una evaluación de la explicación.

En este caso, la estructura identificada queda de la siguiente manera:

\begin{tabular}{|l|l|l|}
\hline & Fase de Inicio & $\begin{array}{l}\text { Título del Apartado (TiAp) } \\
\text { Apertura de la explicación (AEx) } \\
\text { Elaboración del Argumento (ElbAr) }\end{array}$ \\
\cline { 3 - 3 } $\begin{array}{l}\text { FASE 3. } \\
\text { CONCEPTOS } \\
\text { TÉCNICOS }\end{array}$ & $\begin{array}{l}\text { Fase } \\
\text { desarrollo }\end{array}$ & $\begin{array}{l}\text { Apertura de la cita (ApC) } \\
\text { Cita Textual (CTx) } \\
\text { Explicación de la cita (ExC) } \\
\text { Apertura de la cita (ApC) } \\
\end{array}$ \\
& & Cita Textual (CTx) \\
\cline { 2 - 3 } & Fase de cierre & Cierre de la explicación (CEx) \\
& & Elaboración del Argumento (ElbAr) \\
\hline
\end{tabular}

La estructura identificada de este caso analizado se presenta también de una forma más organizada porque se evidencia claramente el inicio, el desarrollo y el cierre de la explicación. La fase de inicio es bastante similar a los dos casos anteriores porque se identifica claramente el título del apartado, la apertura de la explicación que se caracteriza por incluir una 
La textualidad académica de estudiantes de origen indígena en estudios de posgrado: el proceso de elaboración de tesis

elaboración del argumento construida por el investigador. La fase de desarrollo difiere un poco en este caso porque aquí se presentan citas textuales y una explicación de una de las citas, no obstante, el investigador vincula unos argumentos con otros mediante la estrategia de señalización léxica y discursiva con la que va conectando un argumento con otro, incluyendo los argumentos de otros autores expuestos en las citas textuales en las que se apoya. La fase de cierre, también manifiesta un cambio, porque en ella se incluye una elaboración de un argumento, donde el autor evalúa su argumento y plantea unas contribuciones. Así, es posible advertir que esta estructura manifiesta una organización más elaborada donde el autor del texto intenta exponer argumentos más propios.

Es así como se evidencia en los tres casos analizados la forma en que los investigadores organizan su explicación respeto a los conceptos técnicos que consideran necesarios para el desarrollo del tema que cada uno trata. Uno de esos rasgos es que los fragmentos analizados pertenecen a explicaciones más globales dentro de un apartado conceptual mucho más amplio, es decir, de un capítulo teórico de hasta 30 páginas, por lo que los extractos analizados, son tan solo una parte pequeña de toda una explicación global. Esto significa que los autores de los textos analizados desarrollan explicaciones mucho más densas en relación a las fases anteriores. Otra característica importante de la estructura de las explicaciones es más elaborada, primero porque desde la fase de inicio se identifica que el apartado analizado está titulado, además la apertura de la explicación no solo anuncia el concepto técnico a explicar, sino también muestra una elaboración de un argumento del investigador. La fase de desarrollo se caracteriza por el parafraseo de citas, las explicaciones de éstas y de argumentos elaborados por el investigador. Finalmente, la fase de cierre muestra el uso de la coda, la evaluación y algunas contribuciones que hace el investigador en torno al concepto técnico que explica. Así es posible afirmar que esta fase de caracteriza por presentar una estructura mejor construida que implica principalmente la elaboración de argumentos más personales y reflexivos por parte del investigador.

\section{C) La voz de los autores}

Este eje de análisis se caracteriza por presentar rasgos similares a la fase dos en el sentido de que la voz de los autores se logra apreciar a lo largo de la explicación. No obstante, 
en esta fase tres se perciben particularidades concretas que distinguen a esta fase, como se analiza a continuación.

\title{
I. Fase de inicio. La voz para presentar el tema
}

Una de características que comparte esta fase con la anterior, es que la voz de los autores se identifica de forma explícita en la apertura de la explicación para presentar el tema y/o concepto técnico de su argumentación. Así, este primer ejemplo evidencia dicha cualidad.

El ser humano desde sus orígenes a través de la historia así como desde sus primeros años de vida ha buscado la forma de relacionarse con sus semejantes. Esto lo hace mediante la interacción, a través de la cual logra concretar el proceso de comunicación tan indispensable para su desarrollo en sociedad, debido a esto considero de suma importancia comprender a qué se refiere, cómo se da y cómo ElbAr se ha estudiado esta interacción comunicativa. (MAGV-I2-F3-pp.7-8)

En este primer ejemplo, se observa inicialmente la elaboración de un argumento que el autor construye para abrir su explicación, donde se distingue claramente la voz explícita del autor cuando menciona que "considero de suma importancia comprender... esta interacción comunicativa" expresión donde recurre a la primera persona del singular "yo" para exponer la intención de su explicación cuando alude a "considero de suma importancia", haciendo referencia al concepto técnico que desarrolla que es "la interacción comunicativa". De esta forma, este ejemplo muestra visiblemente la voz del autor para presentar su temática a abordar. Otro ejemplo similar es el que sigue:

\begin{abstract}
Primeramente considero importante precisar que la interacción social, se entiende como el proceso comunicativo que se establece entre personas en torno a cierto tema, en una situación dada y en un ámbito socio-cultural determinado, en donde se necesita por lo menos de un hablante y un oyente o un auditorio, y en otros casos esta interacción se establece entre un hablante y varios oyentes al mismo tiempo, de tal modo que los interlocutores puedan mantener un evento de habla $^{25}$ con ciertas intenciones y con ciertos propósitos sociales. En este sentido este tipo de interacción se considera "social" porque se trata de una práctica comunicativa necesaria en cualquier sociedad. (RRG-I6-F3-p.11)
\end{abstract}

AEx

ElbAr

En este ejemplo se nota nuevamente que el investigador presenta el tema en torno al cual gira su explicación cuando menciona "considero importante precisar que la interacción social, se entiende como...", donde recurre a la primera persona del singular "yo" para conjugar el verbo “considerar" manifestando no sólo "la importancia de entender" el

\footnotetext{
25 Según Hymes (citado en Pilleux, 2001) Un evento de habla, es la actividad comunicativa o aspectos de la misma que está regido por reglas o normas para el uso lingüístico, por ejemplo, una conversación, una discusión o un dialogo...
} 
La textualidad académica de estudiantes de origen indígena en estudios de posgrado: el proceso de elaboración de tesis

concepto que plantea que es "la interacción social”, sino también haciendo una elaboración de un argumento donde él explica "como se entiende" el concepto técnico que menciona. Así, este ejemplo refleja otra vez la característica de esta fase de inicio de la explicación para presentar el tema a desarrollar pero también la elaboración de un argumento por parte del autor del texto. Un ejemplo más con rasgos a los anteriores es el siguiente.

\footnotetext{
En el marco de las observaciones anteriores, es conveniente mencionar que la evaluación inicial se refiere a la que practican los docentes al iniciar un nuevo proceso de enseñanza y aprendizaje, la cual también es definida como evaluación diagnóstica. Este tipo de evaluación trata principalmente de recuperar y analizar la situación de cada estudiante, en cuanto a lo que saben o recuerdan del tema de estudio para tomar conciencia (tanto alumnos como docentes) de la situación de partida. (GHV-I3-F3-p.23)
}

\section{ApAp \\ ElbAr}

En este último ejemplo de la fase de inicio de la explicación, la voz del autor se presenta de forma particular, él recurre a una expresión impersonal para presentar el concepto técnico que aborda cuando menciona "es conveniente mencionar que la evaluación inicial se refiere a..." donde utiliza precisamente una expresión en tercera persona del singular "es conveniente mencionar" haciendo referencia al concepto técnico que desea explicar que es "la evaluación inicial", y el cual define cuando dice "se refiere a", con lo que se percibe la elaboración de un argumento que él construye para definir dicho concepto técnico. De esta manera, este ejemplo se identifica la voz impersonal del autor para anunciar el concepto que explica y un argumento que él expone para definirlo.

Es así como los ejemplos citados manifiestan la voz de los autores tanto de forma personal recurriendo a la primera persona del singular "yo" como de forma impersonal apoyados en la tercera persona del singular, con el fin de empezar con su explicación. Además, la voz de los autores está en el marco de la elaboración de un argumento para presentar el concepto técnico que desarrollan. Esto significa que la voz del autor se manifiesta de forma explícita en los argumentos, pero también ésta se ve apoyada por el contexto argumentativo que los investigadores elaboran para iniciar su explicación.

\section{Fase de desarrollo: voces combinadas de un autor externo y del investigador}

En el desarrollo de la explicación también se aprecia la voz de los autores, pero se manifiestan algunas características particulares como la presencia de la voz de los autores 
citados en los argumentos elaborados por el investigador. El primer ejemplo evidencia este rasgo.

\begin{tabular}{|c|}
\hline $\begin{array}{l}\text { Goffman (1961, citado en Erickson, 1982:327) define las interacciones sociales como } \\
\text { encuentros; agrupaciones centradas en lo que los otros están haciendo allí, agrega } \\
\text { además que la frontera entre estos encuentros y el mundo exterior no es impermeable; } \\
\text { pues las influencias del exterior penetran en él. Pero aun así la acción que se } \\
\text { desarrolla en estos encuentros tiene vida propia, en estos encuentros los miembros } \\
\text { que interactúan se articulan en formas inmediatamente sociales, secuencial y } \\
\text { simultáneamente. En otras palabras, estos encuentros centrados en ese momento } \\
\text { exacto tienen un producto que se da justo en ese preciso instante y en ese preciso } \\
\text { contexto, pues ambos interactantes, apoyados por el contexto, sus intenciones y su } \\
\text { historia personal, modifican sus esquemas cognitivos entre sí, es decir, después de que } \\
\text { se da alguna interacción, los esquemas cognitivos de los participantes en esta } \\
\text { interacción viven alguna modificación, tal vez no la que se pretende pero de alguna } \\
\text { manera existe un cambio. (MAGV-I2-F3-pp.8-9) }\end{array}$ \\
\hline
\end{tabular}

Este primer ejemplo inicia con el argumento de un autor externo "Goffman" al cual el investigador parafrasea para definir el concepto técnico que plantea que son las "interacciones sociales". Después de esta cita, el autor realiza una explicación de la cita parafraseada cuando menciona "En otras palabras" con la cual proporciona otros argumentos para respaldar los argumentos planteados en la cita, donde se logra apreciar la voz impersonal del investigador, ya que cuando dice "en otras palabras" se refiere a "sus palabras" con las cuales explica dicha cita. La voz del autor también se logra percibir cuando hace una elaboración de un argumento para apoyar tanto la cita como la explicación de la misma, cuando dice "es decir", expresión con la cual el investigador introduce otro argumento que él elabora para reforzar los anteriores.

Además, el investigador va hilando sus planteamientos con los de la cita planteada haciendo referencia a términos como "interacción" y "encuentros" que se observan tanto en la cita como en el argumento del investigador para desarrollar su explicación. De esta forma, se aprecia que la voz del investigador es impersonal recurriendo a expresiones más generales para desarrollar sus argumentos. Asimismo, se nota que la voz impersonal del investigador tiene como base el argumento del autor citado del cual parte para elaborar el suyo, con lo cual es posible advertir en este ejemplo que tanto la voz del investigador como el autor externo se combinan para desarrollar la explicación.

Otro ejemplo con rasgos parecidos es el siguiente.

De la misma manera Cazden (1991) señala que las escuelas son uno de los contextos o ambientes humanos más concurridos, por lo que las clases se asemejan a los contextos comunicativos e interactivos que se presentan en los restaurantes, en los autobuses, en el metro, mismos que se caracterizan por ser lugares en donde son 
La textualidad académica de estudiantes de origen indígena en estudios de posgrado: el proceso de elaboración de tesis

\begin{abstract}
normales las conversaciones independientes, espontáneas, libres, comunes y simultáneas, solo que en la escuela esta interacción verbal es diferente, ya que una persona, el maestro, mantiene el control de todo lo que se habla en el transcurso "oficial" de la clase y en estos casos los actos de habla regularmente se enfocan a contenidos programáticos, por lo que el lenguaje empleado es más formal en contenido y en forma a diferencia de otros contextos y situaciones comunicativas que se mencionan anteriormente (los restaurantes o en los autobuses). (RRG-I6-F3pp.11-12)
\end{abstract}

ElbAr

Este segundo ejemplo refleja la misma lógica que el anterior, el investigador inicia su argumento apoyándose en una cita de un autor externo al cual parafrasea "Cazden (1991)" y a quien recurre para respaldar su argumento respecto al tema que trata. De ahí, el investigador recurre a expresiones para indicar una comparación cuando menciona "solo que en la escuela esta interacción verbal es diferente, ya que...", y utilizando los vocablos "solo que" y "es diferente" para hacer una comparación en torno a la "interacción verbal" a partir del argumento que se plantea en la cita previa. Después, el investigador refuerza su argumento con otro argumento contrastivo cuando señala "por lo que el lenguaje empleado es más formal en contenido y en forma a diferencia de...", recurriendo a expresiones como "Por lo que" y "a diferencia de" que muestran la comparación que el investigador hace respecto al "lenguaje". En este fragmento también se aprecia que el investigador va enlazando su argumento con el de la cita cuando refiere concretamente a los términos "escuela" "contextos" y al adjetivo "comunicativos(as)". Entonces, éste es un ejemplo más donde se manifiesta la voz impersonal del investigador porque recurre a expresiones contrastivas, en este caso, para comparar un argumento con otro, partiendo inicialmente del argumento planteado en la cita que él parafrasea. Así, la voz del investigador se presenta teniendo como referencia la voz de un autor externo, por tanto, ambas voces tienen presencia. Un ejemplo más con esta cualidad se expone a continuación.

Siguiendo este razonamiento, Barberá define a la evaluación inicial de la siguiente) manera;

La evaluación inicial supone determinar la situación de los alumnos antes de iniciar un proceso de enseñanza y aprendizaje. Con ello se pretende adecuar la planificación del profesor a las necesidades y características de sus discípulos. Pero conviene que, además de ser explicita para el profesor, también lo sea para cada alumno y para el conjunto del grupo clase... (Barberá G. 1999: 93) (GHV-I3-F3-p. 23)

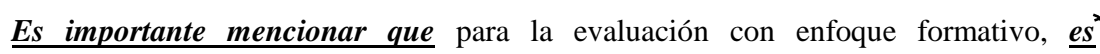
indispensable la evaluación en la fase inicial del proceso educativo, ya que esta es la que permitirá al docente obtener el conocimiento previo que es preciso poseer de los alumnos antes de iniciar una nueva etapa de conocimiento para poder adecuar la enseñanza a sus condiciones de aprendizaje y optimizar la construcción de las ExC nuevas actividades escolares, cumpliendo así con una de las funciones principales que se le ha asignado a este tipo de evaluación que es la regulación. (GHV-I3-F3-p. 24) 
Este último ejemplo exhibe propiedades similares porque el autor del texto inicia su argumento planteando el argumento de un autor externo “(Barberá G. 1999:93)” mediante una cita textual donde alude al concepto técnico a desarrollar en su explicación que es "La evaluación inicial”. Después, el autor hace una explicación de la cita donde se nota su voz impersonal porque recurre precisamente al uso de expresiones impersonales conjugadas en la tercera persona del singular cuando menciona "Es importante mencionar que", "es indispensable" y "es preciso poseer" con las cuales expone la relevancia de su argumento. No obstante, éste se apoya cuando el investigador recupera en su explicación algunas expresiones señaladas en la cita que plantea. Por ejemplo, cuando refiere a "situación de los alumnos antes de iniciar un proceso de enseñanza y aprendizaje” y "adecuar la planificación del profesor a las necesidades y características de sus discípulos", señalizaciones a las que el investigador alude en su explicación cuando hace mención a "obtener conocimiento previo... de los alumnos" y "adecuar la enseñanza a sus condiciones de aprendizaje”, estrategia con la cual va hilando sus argumentos con los de la cita textual.

De esta manera, se observa en la explicación de la cita, la voz impersonal del investigador mediante el uso de expresiones impersonales para aludir al argumento en la cita textual, es decir, la explicación que plantea el investigador tiene como punto de partida la cita textual, por ello, en este fragmento resaltan tanto su voz como la del autor citado.

Así, en esta fase de desarrollo se identifica la voz impersonal del investigador porque, en los tres ejemplos, hacen uso de expresiones generales e impersonales, ya sea para hacer una paráfrasis o plantear una cita textual de un argumento de autores externos. Esta voz impersonal que se identifica tiene como punto de partida precisamente al argumento de los autores externos, del cual parten para desarrollar sus explicaciones o elaboraciones argumentativas. Entonces, en esta fase de la explicación, la presencia de citas parafraseadas y textuales implica la combinación de la voz impersonal tanto de los investigadores como de los autores citados en los cuales se basan para desarrollar sus argumentos.

\section{Fase de cierre:}

En esta fase de cierre de la explicación, la voz de los autores se manifiesta para concretar el argumento de sus explicaciones, mediante el uso, sobre todo, de expresiones impersonales como se explica a continuación. 
La textualidad académica de estudiantes de origen indígena en estudios de posgrado: el proceso de elaboración de tesis

Creo importante recalcar en este momento que el término interacción comunicativa no sólo se refiere al acto de usar el lenguaje oral para expresarse, sino que es más amplio, pues abarca otras formas de acción extralingüísticas como la mímica, la gesticulación, movimientos corporales y de posición con respecto al otro interlocutor, entre otras. Además interactuar comunicativamente implica tener un discurso, dos o más individuos, la intención de hacerlo y un contexto. $\underline{E} \boldsymbol{s}$ decir, el lenguaje oral forma parte de la interacción mas no es por si solo interacción comunicativa. Más aun, tanto el lenguaje oral como las acciones extralingüísticas forman parte de lo que se denomina interacción comunicativa. (MAGV-I2-F3-pp.9-10)

CEx

En este primer ejemplo, es donde se nota la voz personal explícita del autor cuando menciona "Creo importante recalcar" para hacer referencia al concepto técnico que explica que es "interacción comunicativa". También, este autor utiliza expresiones impersonales como "Es decir" o "Más aún" para desarrollar su argumento donde se refleja su voz, sobre todo cuando plantea expresiones donde conecta sus argumentos mediante vocablos como "no solo se refiere al... sino que..." о "tanto... como" para definir el concepto técnico que desarrolla. Otro ejemplo en esta fase es el que sigue.

Por lo tanto la interacción verbal que se establece entre el profesor y los alumnos durante una clase, sobre todo la que se lleva a cabo al realizar las actividades didácticas, está enmarcada y condicionada por las normas institucionales del aula. $\underline{\boldsymbol{P o r}}$ $\underline{\boldsymbol{e s} \boldsymbol{O}}$ los actos de habla del profesor y los alumnos en una clase, reflejan el papel que juega la institucionalidad de la escuela en un proceso de interacción verbal. Situación que no se da en una interacción comunicativa en un contexto social, ya que en éste CEx existe más libertad de los actores para establecer ciertos actos de habla, sin que exista un rol dominante del hablante o sin que haya un tema ya definido desde donde centrar la interacción verbal. (RRG-I6-F3-p.13)

En este segundo ejemplo se aprecia la voz impersonal del autor cuando hace uso de conectores para hilar su argumento cuando menciona "Por lo tanto" y "por eso" para concluir su explicación. También, se nota la voz impersonal del investigador cuando realiza una comparación entre sus argumentos recurriendo a la expresión "Situación que no se da en..." con lo cual muestra su voz precisamente cuando compara un argumento con otro en el cierre de su explicación. Un último ejemplo similar es el que se presenta a continuación.

Queda claro que sin una evaluación inicial, no es posible obtener el conocimiento previo de los estudiantes que se hace necesario para poder adecuar la nueva enseñanza a sus condiciones de aprendizaje. De esta manera se establece entonces que la preocupación del profesor es que el alumno logre establecer conexiones entre lo que sabe, lo que ha vivido, lo que entiende y el nuevo material de aprendizaje que le presenta en la clase. (GHV-I3-F3-p. 24)

CEx

ElbAr

Este ejemplo evidencia nuevamente expresiones impersonales y conectores que muestran la voz impersonal del investigador. Primero, cuando el autor menciona "Queda claro que..." está reflejando su entendimiento respecto al concepto técnico que plantea en su 
explicación que es la "evaluación inicial”. Después utiliza otra expresión impersonal negativa cuando dice "no es posible obtener..." expresión en la tercera persona del singular que muestra su apreciación respecto al argumento que menciona. Finalmente recurre a dos conectores y una expresión impersonal para concluir su argumento cuando señala " $D e$ esta manera se establece entonces". Así la voz de este autor se manifiesta de forma impersonal cuando recurre tanto a expresiones impersonales como a conectores que le ayudan conectar sus ideas y a finalizar su explicación.

Entonces, este eje de análisis se caracteriza principalmente por mostrar la voz de los autores de forma impersonal en los tres momentos de su explicación. En la fase uno es donde se nota tanto la voz personal e implícita como la voz impersonal de los autores para presentar el concepto técnico que abordan en su explicación. En la fase de desarrollo es donde se manifiesta la voz impersonal pero también implícita de los autores, lo cual se debe a que el argumento que ellos desarrollan se basan en los argumentos de los autores externos que ellos citan o parafrasean, a partir de los cuales explican la cita o elaboran un argumento, es decir que los argumentos de los investigadores se construyen con el apoyo de los autores citados, por lo que se aprecia un combinación de voces, tanto de los autores externos como de los investigadores, cuya voz es impersonal porque recurren a expresiones impersonales, pero es también implícita porque ésta se deduce a partir de los argumentos que construyen así como de la manera de plantearlo. Finalmente, en la fase tres de la explicación se percibe la voz personal e impersonal de los autores porque utilizan la primera y la tercera persona del singular para cerrar su explicación. Así, vemos en esta fase que la voz del investigador sigue teniendo presencia en el desarrollo de su explicación, intentando plantear argumentos más personales al momento de explicar las citas o construyendo argumentos más elaborados. No obstante, la voz del investigador se ve acompañada de la voz de autores externos, lo cual indica cierta interdependencia en ambos tipos de argumentos.

\section{Conclusiones específicas}

En este estudio longitudinal de las explicaciones de los conceptos técnicos, que involucra las tres fases de los productos escritos revisados, de estudiantes del Programa de Maestría en Sociolingüística de la Educación Básica y Bilingüe en la UPN 201, se observan 
La textualidad académica de estudiantes de origen indígena en estudios de posgrado: el proceso de elaboración de tesis

características que van cambiando de una fase a otra. Primeramente, en la fase 1 que corresponde al anteproyecto de investigación que presentan los entonces aspirantes a dicho programa de posgrado, se observa que los apartados conceptuales a los cuales denominan "Marco Teórico" o "Marco Referencial”, son muy breves, desde dos hasta seis páginas, donde se explican al menos dos conceptos técnicos. En la fase dos, se revisan los protocolos de investigación que los estudiantes construyen al finalizar el primer año de formación en el programa aludido. En esta etapa, se aprecian apartados conceptuales más extensos, entre 3 y 16 páginas, denominados “Conceptualización”, Marco Teórico" o "Fundamentación Teórica”, los cuales reflejan una discusión continua a lo largo del apartado conceptual.

En suma, en la fase tres se revisan borradores de tesis construidos al finalizar el proceso de formación al programa de maestría referido. Así, los extractos revisados pertenecen a apartados todavía más extensos, de hecho, son capítulos entre 25 y 30 páginas, los cuales se caracterizan por tener un título, al igual que los sub-apartados que integran cada uno de ellos. Estos rasgos caracterizan de forma general los manuscritos elegidos, donde la extensión del apartado conceptual, así como la denominación que cada investigar le asigna, van presentando modificaciones a lo largo de este estudio longitudinal respecto a los conceptos técnicos.

En cuanto a la orientación disciplinar, en la primera fase se advierte que ésta presenta un escenario teórico definido del cual parten los investigadores para desarrollar su investigación antes de su ingreso al programa de posgrado. Cabe aclarar que la intención de este estudio no es mostrar si esta orientación disciplinar efectivamente guía la explicación o no, puesto que no se trata de evaluar los textos revisados, sino caracterizarlos. En la fase dos, se observa que la orientación disciplinar es abierta e imprecisa, lo cual se evidencia en los adjetivos indefinidos y calificativos a los que recurre el investigador para aludir a "diversas" orientaciones teóricas. En la fase tres, el escenario es mucho más concreto porque los investigadores especifican con mucha más definición la disciplina a la cual se afilian para desarrollar su explicación. Así, es posible afirmar que los estudiantes investigadores inician con una orientación definida; después, al parecer, se pierden en la concreción de su filiación disciplinaria, posiblemente se deba a su inserción en el programa referido donde experimentan un proceso de socialización disciplinaria, es decir, se vinculan con distintas teorías lo cual puede causar cierta dispersión. 
Finalmente, en la fase tres se aprecia una orientación disciplinar concreta, lo cual posiblemente se deba un mayor involucramiento con los campos disciplinares donde logran identificarse con alguno en particular. Por tanto, esto muestra la comprensión que los autores respecto a la apropiación de una disciplina que necesariamente implica el desarrollo de explicaciones de los conceptos técnicos que integran un apartado conceptual de una tesis de grado.

Respecto a la estructura de la explicación, también se perciben cambios importantes a lo largo del análisis longitudinal, por ejemplo, que las explicaciones están estructuradas en una fase inicio, una de desarrollo y una de cierre, donde se identifican rasgos particulares en cada etapa. En la fase uno, la estructura presenta la explicación de al menos dos conceptos técnicos, donde la apertura de la explicación se reduce a la apertura de una cita textual. En el desarrollo se nota el uso excesivo de citas textuales donde simplemente se enuncian los conceptos técnicos, lo cual crea desarticulación e implícitos entre los argumentos, puesto que se asume el hecho de que citar autores externos para explicar un concepto técnico es suficiente para desarrollar un argumento o discusión. Por tanto, las citas textuales que definen los conceptos técnicos mantienen un rol primordial en los extractos revisados.

En la fase dos se aprecia que las explicaciones son más extensas pero que gira en torno a un solo concepto técnico, donde se identifican explicaciones de las citas textuales que se plantean, es decir, las citas ya no sólo se enuncian como en la fase uno. También, se observa la presencia de elaboraciones de argumentos que los autores construyen, lo cual le da un toque más propio a sus argumentos. Otro rasgo de esta fase es que las explicaciones expresan un ciclo más completo de articulación textual entre cada una de las partes, por ejemplo, se nota con mayor claridad una apertura de la explicación que ya no se reduce una apertura de la cita como se observó en la fase uno. Por tanto, esta fase presenta cambios novedosos haciendo que la explicación esté mejor construida y, sobre todo, porque se refleja la presencia del autor en el texto.

En la fase tres del estudio longitudinal, la estructura nuevamente presenta modificaciones, considerando que los apartados conceptuales en esta etapa conforman todo un capítulo, de donde se obtienen los fragmentos analizados, lo que implica que los autores desarrollen explicaciones mucho más densas en relación a las fases anteriores. Por ello, se 
La textualidad académica de estudiantes de origen indígena en estudios de posgrado: el proceso de elaboración de tesis

identifican explicaciones más elaboradas, iniciando desde el título del sub-apartado analizado, el cual expresa claramente el concepto técnico a desarrollar en la explicación. La fase de inicio de la explicación en esta etapa manifiesta una apertura de la explicación donde no sólo se expone el concepto técnico a explicar, sino también se muestra una elaboración de un argumento del investigador. La fase de desarrollo se caracteriza por el parafraseo de citas, las explicaciones de éstas y de argumentos elaborados por el investigador. Finalmente, la fase de cierre muestra el uso de la coda, la evaluación y algunas contribuciones que hace el investigador en torno al concepto técnico que explica. Así es posible afirmar que esta fase de caracteriza por presentar una estructura mejor construida que implica principalmente la elaboración de argumentos más personales y reflexivos por parte del investigador.

En relación a la voz de los autores al momento de explicar conceptos técnicos igualmente se identifican variaciones novedosas entre una fase $\mathrm{u}$ otra en este análisis longitudinal. En la fase uno se observa principalmente que la voz de los autores se caracteriza por ser impersonal por la voz del investigador está inmersa en la primera persona del plural "nosotros" y en expresiones impersonales conjugadas en la tercera persona del singular. Además, la voz únicamente se aprecia para iniciar la explicación aludiendo de manera imprecisa el tema a tratar, y en el cierre de la misma para plantear la necesidad de atender una problemática. En el desarrollo se observa que la voz que prevalece es la de los autores externos mediante el uso insistente de citas textuales, por lo que la voz de los investigadores queda subordinada a la voz de los autores citados, y limitada a la enunciación de un problema.

En esta fase dos, se aprecia que la voz de los autores del texto tiene una presencia mayor que en la fase anterior, manteniendo el rasgo de presentarse generalmente de forma impersonal en los tres momentos de la explicación, en el inicio, desarrollo y cierre. Particularmente, en la fase de desarrollo donde se identifican explicaciones de la citas y elaboraciones de los argumentos, es donde a observa la voz de los autores, ya que éste es el espacio donde ellos intentan construir argumentos que reflejen su entendimiento de lo que están explicando. Por tanto, en esta fase la voz de los investigadores juega un papel más relevante que en la fase anterior.

Finalmente, en la fase tres, la voz de los autores se manifiesta casi en todos los casos de forma impersonal en los tres momentos de su explicación. Sobre todo, en el desarrollo de la 
explicación es donde se identifica los esfuerzos de los investigadores por construir argumentos más personales. En esta parte de la explicación es donde se observan varias citas que el autor del texto parafrasea, a partir de las cuales el investigador elabora sus argumentos, haciendo que la voz de investigador se combine con la voz de los autores externos citados. De esta forma, se aprecia que la voz del investigador sigue teniendo presencia en esta fase pero ésta se ve acompañada de la voz de autores externos, lo cual indica cierta interdependencia en ambos tipos de argumentos.

De este análisis longitudinal en torno a las explicaciones de los conceptos técnicos es posible concluir primeramente que en las tres fases del proceso de textualización que los estudiantes-investigadores siguen para construir su tesis de grado, se manifiestan cambios importantes tanto su filiación disciplinar, en la forma de cómo organizar su explicación y en la voz que reflejan los autores en sus manuscritos. En la primera fase, se muestra con el análisis realizado que los anteproyectos expresan una filiación disciplinar específica, no obstante, ésta se contradice de cierta forma con la estructura ya que la manera de organizar los argumentos exhibe el uso excesivo de citas textuales que no permiten que la explicación fluya y por tanto, la orientación disciplinar se pierde, al igual que la voz de los investigadores porque la presencia un tanto obsesiva de las citas textuales.

En la fase dos se nota un cambio puesto que la orientación disciplinar es dispersa, lo cual puede ser por los procesos de socialización disciplinar que van experimentando los estudiantes-investigadores en el primer año de su inmersión en el programa de posgrado, donde dicha inmersión les provee un panorama más amplio de disciplinas teóricas en las cuales ellos se dispersan en un primer acercamiento. No obstante, la estructura de la explicación se observan una organización más clara, lo cual también refleja las habilidades textuales que los alumnos van adquiriendo. Esto se relaciona con la voz de los autores porque al momento de organizar su explicación de manera más elaborada, se nota la presencia de argumentos más propios del autor.

Finalmente, en la fase tres los cambios se notan claramente en la filiación disciplinar que adoptan cada uno de los autores, lo cual repercute en la estructura de su explicación porque la organización de los argumentos es más elaborada y dirigida, es decir, las tres fases de la explicación evidencian una estructura más compleja por los esfuerzos de los 
La textualidad académica de estudiantes de origen indígena en estudios de posgrado: el proceso de elaboración de tesis

investigadores por construir argumentos más elaborados, pero también más organizados, lo cual hace que la lectura fluya. Esto se vincula con la voz de los autores que se combinan con los autores citados, con lo cual se puede advertir que teniendo una orientación disciplinar definida repercute en una estructura más compleja donde la voz de los autores se construye a partir de los argumentos de los autores externos. Con esto se presenta un panorama general de cómo los autores desarrollan sus explicaciones en torno a los conceptos técnicos que son fundamentales en el proceso de construcción de una tesis de grado. 


\section{CONCLUSIONES}

Las conclusiones a las que arriba esta investigación, se organizan en conclusiones teóricas, metodológicas, en los resultados que permiten tener una mirada más global de la investigación y, por último, las conclusiones generales que surgen de este estudio y que intentan llegar a reflexiones más abstractas que muestren los aportes de la investigación.

\section{Teóricas}

Uno de los aspectos medulares en esta investigación es la perspectiva teórica a la cual me afilié para poder desarrollar este estudio. Este acercamiento disciplinar fue con el campo de la escritura académica, particularmente con el tema de la textualidad académica como una forma de comunicación escrita, donde se encuentra la tesis como uno de los textos académicos más complejos y exigentes en el ámbito universitario. Para esto, fue necesario recurrir a diversas fuentes que dieran cuenta de este fenómeno tan cotidiano en el ámbito universitario, pero tan poco problematizado. En esta búsqueda encontré diversas perspectivas que contribuyeron no sólo a complejizar teóricamente este fenómeno de la escritura académica sino también a orientar tanto el proceso metodológico como de análisis en esta investigación.

Los aportes de Lea y Street (1998) ha sido de fundamentales para complejizar la escritura académica en el nivel superior, ya que ellos identifican tres paradigmas que coexisten en el ámbito universitario y permiten cuestionar las prácticas textuales que se realizan cotidianamente en el ámbito escolar, donde el lenguaje académico, particularmente, el escrito, cobra mayor relvancia. Éstos son, el paradigma de habilidades de estudio, de socialización académica y el de literacidad académica como práctica social. Desde esta perspectiva, se ubica el lenguaje académico que implica distintos alcances cognitivos que dependiendo del contexto en que se encuentren las diversas prácticas textuales (Cummins, 2002). No obstante, escribir académicamente no solo exige cuestiones cognitivas, sino también involucra procesos formativos vinculados con procesos de socialización disciplinaria y de profesionalización (Muñoz, 2013) que se encuentran enmarcados y delimitados por la cultura académica que es la que regula los usos y costumbres institucionales. 
La textualidad académica de estudiantes de origen indígena en estudios de posgrado: el proceso de elaboración de tesis

En este escenario complejo y de tensión se encuentra la tesis como uno de los textos más complejos inserto en una cultura académica que norma gran parte de las formas en que se concibe y se lleva a la práctica, donde el proceso de elaboración de una tesis implica necesariamente transitar dichos procesos formativos para tener acceso a la cultura académica, así como el uso de un lenguaje académico mucho más técnico como una exigencia más de dicha cultura académica. Estas discusiones teóricas abordadas contribuyen a mirar y actuar de una manera más crítica y reflexiva los procesos de enseñanza y aprendizaje, revisión y evaluación de las diversas prácticas textuales que día a día enfrentan los estudiantes en el nivel superior. También, permiten plantear que las distintas prácticas del lenguaje académico es una práctica social académica que combina cierta estabilidad por parte de la cultura académica que establece las reglas de juego, pero también cierta flexibilidad porque crea posibilidades para resinificar, reestructurar, reorganizar e incluso modificar las dichas prácticas Así, tanto la mirada desde el paradigma de socialización académica como el de literacidad académica enriquecen una visión que es necesaria para observar las prácticas textuales académicas y considerar al lenguaje académico como una práctica social académica.

Esta mirada más crítica es la que orienta tanto la ruta metodológica a seguir, así como el análisis posterior para comprender las implicaciones de lenguaje académico en el proceso de elaboración de un proyecto de investigación como lo es la tesis, concretamente en el nivel de posgrado.

\section{Metodológicas}

Uno de logros metodológicos fue ubicar a las explicaciones como unidades compuestas de análisis, desde la perspectiva de Maturana (1989), como la plataforma con la cual trabajar con los materiales recabados, de donde surgió un corpus de datos que contempló las tres fases de análisis para el desarrollo de un estudio longitudinal. Esto exigió el diseño de un modelo de análisis interpretativo, lo cual fue todo un reto porque me di cuenta que no hay muchas opciones para analizar textos desde una mirada más integral para conocer la lógica de la explicación que manifestaban los materiales. Sin embargo, los aportes de Street (2009) y Labov (2013) fueron fundamentales para construir un modelo de análisis que destacara elementos para identificar componentes esenciales de la actividad conceptual en las 
explicaciones construidas por los estudiantes investigados, es decir, con una mirada totalmente interpretativa e inductiva.

Durante este proceso, un apoyo metodológico necesario fue el análisis cualitativo de contenido, el cual me permitió no solo mirar el contenido manifiesto de los textos, sino también el contenido latente de los mismos (Mayring 2000). La conjunción de estas dos decisiones metodológicas fue la base para explorar la lógica de las explicaciones que desarrollan los estudiantes en su manuscrito para comunicar un conocimiento nuevo, lo cual permitió conocer la racionalidad de las explicaciones de los estudiantes investigadores.

Entonces, analizar la lógica de la explicación apoyada en el análisis cualitativo de contenido, permitió hacer una exploración más de fondo del corpus recabado y construir un modelo de análisis que me acercara lo más posible a analizar aspectos significativos de la explicación que tienen que ver con cuestiones cognitivas, pero también con procesos de socialización disciplinaria. Con este recorrido metodológico, se logra articular los tres elementos indispensables de toda investigación que son: conceptualización, elicitación e interpretación, con el fin de conocer y comprender el proceso la textualización de los estudiantes de posgrado.

Cabe mencionar que, durante este proceso metodológico, como investigadora, experimenté una transición de pasar de una mirada que se quedaba en la superficie del texto donde miraba cuestiones léxicas y morfológicas, a una forma más relacionada con la lógica conceptual de cómo los sujetos investigados desarrollan sus explicaciones en torno a un conocimiento nuevo. Esto tiene que ver con que en el ámbito académico superior también se manifiestan estas miradas que hasta cierto punto se han naturalizado, ya que cuando se evalúa un texto, generalmente se queda en un nivel de las características superficiales del texto que involucran aspectos ortográficos, morfológicos, de puntuación, e incluso de caligrafía. De hecho, en mi experiencia en el desarrollo de esta investigación me enfrenté a esta forma de mirar textos académicos, ya que inicialmente, mis intentos metodológicos también se quedaban en este nivel. Por ello, decidir la metodología más adecuada para el análisis textual que trascendiera esta perspectiva fue todo un reto, considerando que mi propósito en esta investigación no es calificar los performances textuales, sino tener una visión diagnóstica 
La textualidad académica de estudiantes de origen indígena en estudios de posgrado: el proceso de elaboración de tesis

general del estado en que se encuentra esta práctica de la escritura académica en el proceso de construcción de una tesis de grado.

\section{Resultados de la investigación}

El análisis desarrollado de manera longitudinal se conforma por el análisis de tres casos en tres etapas del proceso de elaboración de una tesis, concretamente de la lógica de la explicación en torno al planteamiento de una problemática que manifiestan los manuscritos de los estudiantes investigados. El primer caso corresponde al problema de investigación, el segundo, a los objetivos de la investigación que se plantean los estudiantes, y el tercero a los conceptos técnicos desarrollados en apartados conceptuales.

En el primer caso, correspondiente al planteamiento de un problema, se pudo observar que en la primera fase, se evidencia que el problema refiere a un problema netamente práctico porque parte directamente de la experiencia personal y/o laboral del investigador y también porque, mediante señalizaciones de repetición léxica y discursiva, se muestra con claridad que la intención de los investigadores es darle solución a su problema identificado, con lo cual es más que evidente que el problema se encuentra en el nivel empírico. En la fase 2, se notan algunas modificaciones en el planteamiento del problema, se observa todavía que el problema surge de la experiencia del investigador, pero ahora los autores recurren al apoyo de otros autores mediante citas textuales o indirectas de fuentes bibliográficas que refuerzan sus argumentos para establecer una problemática y darle mayor solidez apoyado en los argumentos de autores externos, lo cual son indicios de que el problema práctico inicial se perfila hacia un problema de investigación que busca el entendimiento de un fenómeno identificado en un contexto específico. Finalmente, en la última fase, se aprecia que, aunque el problema parte de la experiencia del autor, éste trasciende a un nivel más de comprensión, es decir, los autores identifican una situación en su ámbito personal o laboral que intentan conocer y/o explicar, y ya no con la intención de darle una solución.

Por tanto, en las tres fases, los autores parten de su experiencia para plantear la problemática, sin embargo, en la fase tres es diferente porque ésta va orientada hacia un tema de investigación, más allá de un problema que requiere solución, un fenómeno que desean investigar. Es así como en este caso se revela que el problema que se plantea, parte de la 
experiencia vivida del investigador pero que trasciende al hecho de comprender un fenómeno, con lo cual el problema inicial se convierte en un problema de investigación. Esto evidencia una transición que los estudiantes experimentaron en su proceso formativo, ya que el estudio muestra no sólo la forma en cómo los autores van planteando su problemática sino también reflejan su comprensión en cuanto a lo que es e implica un problema de investigación que tiene que ver directamente con la formación disciplinaria que han recibido a lo largo del programa de maestría en el que estuvieron inmersos por dos años.

En el caso dos, respecto a los objetivos de la investigación, el análisis realizado demuestra que los objetivos manifiestan cambios en cada una de las fases. En la fase inicial, se nota una clara dispersión en el o los propósitos que cada uno de los autores persigue en su investigación, éstos se caracterizan por ser muy abiertos y mostrar vaguedad, lo cual hace incierto el rumbo que tomará el estudio que se plantea. Al mismo tiempo, estos objetivos tienen el rasgo de reflejar la solución de la problemática mediante el desarrollo de propuestas que en general escapan de las posibilidades de autor, esto refleja que se pretende lograr una solución práctica a un problema práctico. En la fase 2, los objetivos muestran cambios significativos porque se van perfilando hacia un problema de investigación que se refleja en la estructura que presentan, desde el tipo de verbos que utilizan que son más concretos y alcanzables que intenta conocer o comprender un fenómeno más que resolver una problemática, así como el hecho de incluir el qué se investiga, para qué se investiga y el cómo se pretende hacerlo. Con esto, los objetivos en esta fase intermedia empiezan a consolidarse como un problema de investigación.

En la fase 3, los objetivos manifiestan otros cambios como el hecho de incluir una orientación contextual de la investigación, característica que no se refleja en las etapas anteriores. De igual forma, en esta fase los objetivos presentan cambios de contenido, no solo en el tipo de verbo si no que se hacen cambios en los verbos en sí mismos, los autores toman decisiones en cuanto a cuál es la intención real de su investigación. También hacen modificaciones en el complemento de su objetivo, donde delimitan su estudio a un aspecto particular de la problemática y en un ámbito escolar específico. Con esto el objetivo queda más delimitado y con mayor consistencia, lo cual reduce los riesgos de perderse en la investigación tanto para el autor del borrador de tesis que se presenta como posiblemente para 
La textualidad académica de estudiantes de origen indígena en estudios de posgrado: el proceso de elaboración de tesis

el lector que lo revisa en esta última etapa.

Lo anterior evidencia que los estudiantes investigadores demuestran que ellos van adquiriendo conocimientos tanto teóricos como metodológicos que los hacen tomar decisiones en cuanto a lo que quieren investigar y cómo desean hacerlo, no se trata de evaluar si tales decisiones son las más apropiadas o pertinentes, sino mostrar que ellos como sujetos y autores de su investigación ya han adquirido habilidades textuales que, claramente se nota que no manifestaban antes de ingresar al programa de maestría. Por tanto, se aprecia claramente la formación académica que han adquirido en dicho programa de posgrado, la cual les ha dado elementos y herramientas para delimitar en un primer momento su objeto de estudio mediante el planteamiento de sus objetivos de su investigación.

En el caso tres, correspondiente a los conceptos técnicos en este estudio longitudinal, se observan características que van cambiando de una fase a otra. Particularmente, en este caso se identifican tres aspectos fundamentales de las explicaciones de los conceptos técnicos. El primero refiere a la orientación disciplinar, donde los estudiantes investigadores inician con una orientación definida; después, al parecer, se pierden en la concreción de su filiación disciplinaria, posiblemente se deba a su inserción en el programa referido donde experimentan un proceso de socialización disciplinaria, es decir, se vinculan con distintas teorías lo cual puede causar cierta dispersión. No obstante, en la fase tres se aprecia una orientación disciplinar concreta, lo cual posiblemente se vincula con un mayor involucramiento con los campos disciplinares donde logran identificarse con alguno en particular. Por tanto, esto muestra la comprensión de los autores respecto a la apropiación de una disciplina que necesariamente implica el desarrollo de explicaciones de los conceptos técnicos que integran un apartado conceptual de una tesis de grado.

Un segundo aspecto de las explicaciones de los conceptos técnicos es la estructura de la explicación, también se perciben cambios importantes a lo largo del análisis longitudinal. Uno de ellos es que en términos generales presentan una estructura de inicio, desarrollo y cierre, sin embargo, en la fase uno, esta estructura no está totalmente definida porque la explicación que involucra al menos dos conceptos técnicos, se reduce prácticamente al planteamiento de cita textuales, las cuales mantienen el rol principal de la explicación. En la 
fase las explicaciones presentan un ciclo más completo de articulación entre los componentes de la explicación, ya que se presentan explicaciones de las citas textuales que se plantean, lo cual hace que la explicación esté mejor construida y, sobre todo, se refleje en parte la presencia del autor en el texto. En la fase tres, se aprecia con mayor nitidez una estructura de inicio, desarrollo y cierre, considerando que las explicaciones en esta fase corresponden a apartados conceptuales que conforman todo un capítulo, lo que implica que los autores desarrollen explicaciones mucho más densas. Así es posible afirmar que la estructura de la explicación va cambiando a lo largo del análisis longitudinal, de va de una estructura imprecisa a otra mejor construida que implica principalmente la elaboración de argumentos más personales y reflexivos por parte del investigador.

En relación a la voz de los autores, en la fase uno, la voz que prevalece en la explicación es la de los autores externos mediante el uso insistente de citas textuales. La voz del estudiante investigador únicamente se aprecia de manera imprecisa en la fase de inicio y en el cierre de la explicación, lo que evidencia que la voz de los investigadores queda subordinada a la voz de los autores citados, y limitada a la enunciación de un problema. En la fase dos, la voz de los autores del texto tiene una presencia mayor, precisamente donde se identifican explicaciones de la citas y elaboraciones de los argumentos, ya que éste es el espacio donde ellos intentan construir argumentos que reflejen su entendimiento de lo que están explicando. Por tanto, en esta fase la voz de los investigadores juega un papel más relevante. Finalmente, en la fase tres, la voz de los autores se evidencia en el desarrollo de la explicación donde intenta construir argumentos más personales, así como en el parafraseo de citas, a partir de las cuales el investigador elabora sus argumentos. De esta forma, la voz del investigador sigue teniendo presencia en esta fase, pero ésta se ve acompañada de la voz de autores externos, lo cual indica cierta interdependencia en ambos tipos de argumentos.

De este análisis longitudinal en torno a las explicaciones de los conceptos técnicos es posible concluir primeramente que en las tres fases del proceso de textualización que los estudiantes-investigadores siguen para construir su tesis de grado, se manifiestan cambios importantes tanto su filiación disciplinar, en la forma de cómo organizar su explicación y en la voz que reflejan los autores en sus manuscritos. También se aprecia claramente la articulación que hay entre cada uno de los aspectos identificados y cómo un aspecto afecta a otro, es decir, 
la filiación disciplinar evidencia el acercamiento de los estudiantes investigadores con las diversas disciplinas que van conociendo e identificando en su formación académica. Esto se relaciona con la estructura que manifiestan las explicaciones más definidas, ya que se nota el entendimiento que los estudiantes tienen respecto a la lógica de las explicaciones, pero también se vincula con el aspecto de nombrar a otros autores para desarrollar sus propios argumentos, lo cual hace que su voz no sea únicamente suya, sino que ésta se complementa con la de los autores citados. Entonces, estos tres elementos identificados se conjugan para conocer la racionalidad de la explicación, esto es, los estudiantes investigadores se esfuerzan claramente en apropiarse cada vez más de un lenguaje académico cada vez más técnico, pero también, todavía dependiente en parte de la voz de otros autores.

\section{Generales}

Por tanto, mediante el desarrollo del análisis longitudinal en cada una de las tres fases y en cada uno de los casos, planteamiento del problema, los objetivos de la investigación y los conceptos técnicos, arribo a las siguientes conclusiones:

Primeramente, este estudio evidencia la formación endeble con la que llegan los estudiantes al programa de Maestría en Sociolingüística de la Educación Básica y Bilingüe de la UPN, unidad 201, respecto a las habilidades textuales que conllevan las prácticas académicas en el nivel superior. Particularmente, de las implicaciones que involucra la elaboración de una tesis, lo que refleja el desconocimiento de lo que es y el trabajo que conlleva la construcción de una tesis de grado en el ámbito académico. Esto muestra la problemática en la formación académica previa del magisterio oaxaqueño, puesto que esta investigación evidencia la poca atención que se le ha dado a los procesos formativos de estos profesores, particularmente al desarrollo de habilidades textuales como lo es la elaboración de textos académicos, donde el dominio del lenguaje académico se da por adquirido. Esto también evidencia la ausencia de una interlocución cercana con los expertos, lo cual es indispensable para cualquier investigador, no sólo en el proceso de investigación, sino también en el proceso de textualización para comunicar los resultados de la misma.

No obstante, otra conclusión relevante a la que llego, refiere a que el análisis realizado en cada una de las fases, demuestra claramente el proceso de socialización disciplinaria por la 
que han pasado los estudiantes investigadores en dicho programa de posgrado. Es decir, el hecho de iniciar con un problema práctico y llegar a un problema de investigación; de partir de objetivos muy abiertos y ambiguos y arribar a objetivos más concretos, así como empezar a explicar varios conceptos técnicos en un apartado breve y llegar a explicaciones más amplias y organizadas, muestra los procesos formativos y cognitivos de transformación que los estudiantes fueron experimentando.

Este proceso de socialización disciplinaria implicó una incorporación a un nuevo campo de conocimiento, a una nueva cultura académica, en donde cada estudiante inició un proceso de aprendizaje de conocimientos racionales y científicos que involucran las distintas disciplinas del saber y desde donde se pueden estudiar, explicar e interpretar diversos tipos de fenómenos que contribuyan al entendimiento de las realidades sociales. Así, con este estudio, se demuestra que estos estudiantes investigadores aprendieron y se familiarizaron con conocimientos particulares y especializados propios del campo disciplinar al que se afilian en sus investigaciones como parte de su formación académica y profesional.

Lo anterior también se evidencia en la afinación de un lenguaje cada vez más técnico, y cada vez cognitivamente más exigente, considerando que la elaboración de un texto académico como una tesis, implica el manejo de distintas formas de expresión escrita para comunicar un conocimiento nuevo, donde los conceptos técnicos propios de la disciplina juegan un papel fundamental. Por tanto, el proceso de socialización disciplinaria que experimentaron los sujetos investigados demuestra la transición tanto académica como intelectual de su nivel formativo previo al nivel de posgrado, lo cual implicó el conocimiento de lo que es un problema de investigación y cómo se plantea en un documento académico como lo es la tesis.

Una tercera conclusión refiere a que el proceso de socialización disciplinaria que experimentaron los estudiantes investigadores no se realiza en solitario, en necesario un proceso de acompañamiento por parte de expertos. Por ello, se puede afirmar que los estudiantes insertos en el Programa de Maestría en Sociolingüística de la Educación Básica y Bilingüe, mantuvieron un acompañamiento e interlocución muy cercanos por parte del equipo de asesores de dicho programa de posgrado durante el proceso de investigación y textualización que involucra la tesis como documento recepcional de titulación. En otras 
La textualidad académica de estudiantes de origen indígena en estudios de posgrado: el proceso de elaboración de tesis

palabras, el hecho de que los estudiantes mostraran diversos cambios significativos en su proceso formativo y que lograran cerrar su investigación con un borrador de tesis, evidentemente tiene que ver con todo el trabajo académico que se organiza y se desarrolla en este programa de posgrado, lo cual fortalece la formación académica y profesional de los maestrantes.

Una conclusión más a partir de los resultados de esta investigación, es que en el ámbito educativo superior los tres paradigmas mantienen una relación acumulativa y no fragmentada. Esto es, los tres paradigmas se complementan unos a otros; el primero respecto a las habilidades de estudios son parte importante del desarrollo textual para cualquier persona tanto en ámbitos académicos como fuera de ellos. Sin embargo, no es suficiente tener esta destreza, es importante y necesario también tener conocimientos y habilidades en torno al paradigma de socialización académica, es decir, conocer cómo funciona la escritura en espacios académicos para poder insertarnos en ellos. Pero, también es preciso tomar en cuenta al sujeto que escribe, cuáles son sus referentes sociolingüísticos y socioculturales para poder partir de ello, proponiendo otros referentes, donde el contexto académico universitario es fundamental, mirada que se plantea en el tercer paradigma. Por ello, es posible afirmar que, en el escenario de la educación superior, el lenguaje académico no sólo se queda en el nivel cognitivo, sino que es una práctica social académica, que implica el despliegue de destrezas comunicativas pertenecientes a las propuestas en los tres paradigmas mencionados, de ahí su carácter acumulativo en la educación superior.

Una última conclusión de la investigación realizada tiene que ver con los elementos que ésta aporta para mostrar que la comunicación escrita no es genérica ni plena. Que cada forma de comunicación, cada texto, cada contexto y cada autor poseen características particulares que le dan sentido a lo que intenta comunicar. Entonces, la textualidad académica no se puede generalizar, ni asumir que las habilidades textuales adquiridas en los procesos formativos, son suficientes e iguales en todos los estudiantes, o fácil de aplicar automáticamente en todos los contextos y/o tipos de textos. Es decir, cada texto tiene propiedades, alcances y exigencias específicas enmarcadas dentro de un contexto determinado. En este caso, la tesis requiere de habilidades textuales y alcances cognitivos específicos que no todos los estudiantes dominan al mismo nivel. Hay estudiantes que enfrentan más dificultades 
que otros al momento de desarrollar un proyecto de investigación y elaborar una tesis, aun cuando ya hayan tenido contacto y experiencia con otros textos académicos. Esto es porque una tesis es uno de los textos académicos más complejos, puesto que exige un dominio del lenguaje académico cognitivamente más exigente y mucho más abstracto, que no todos logran alcanzar. Pero también tiene que ver con la experiencia que los estudiantes de posgrado hayan tenido o no respecto a la construcción de una tesis. De ahí la necesidad de crear espacios y procesos de acompañamiento e interlocución que ayuden a comprender con mayor agudeza las implicaciones de la escritura académica en el nivel superior.

Por ello, los resultados de esta investigación cuestionan la idea implícita, en la educación superior, de que todos los estudiantes ya poseen las habilidades textuales para elaborar textos académicos, cuando la realidad nos muestra la gran dificultad que es para los estudiantes escribir académicamente. Entonces, el gran reto, no solo para este programa de posgrado, sino para todos los espacios formativos de educación superior, es encontrar las posibilidades de armonizar lo más posible lo que el alumno sabe o no de la escritura académica y de las prácticas textuales se exigen en el ámbito universitario.

Estas conclusiones son la base para plantear algunos aportes de esta investigación. Una de las contribuciones de este estudio son las discusiones teóricas presentadas, puesto que éstas me han permitido comprender que en las diversas prácticas de la cultura académica subyacen paradigmas que pueden explicar los fenómenos que vivimos cotidianamente en el quehacer universitario, concretamente respecto a la escritura académica. Además, los referentes teóricos planteados me proporcionaron una mirada mucho más compleja de la escritura académica y las prácticas textuales en el nivel superior. Pero, sobre todo, la teoría contribuyó en mi persona para entrenar mi mirada y ver de otra manera las producciones de los estudiantes investigadores, lo cual puede ayudar a otras investigaciones a desarrollar planteamientos que aporten a las discusiones sobre el tema de la escritura y textualidad académica en el nivel superior.

Otro aporte de la investigación está en el plano metodológico, ya que combinar la complejidad a conlleva una explicación científica y revisar de forma cualitativa el contenido latente de las producciones escritas, dio pie al diseño de un modelo de análisis novedoso que 
La textualidad académica de estudiantes de origen indígena en estudios de posgrado: el proceso de elaboración de tesis

permite mirar rasgos más ocultos en los textos analizados e ir un poco más allá de elementos que se encuentran en la parte formal del texto.

Una contribución más de este estudio, de mucha importancia tanto para el programa de posgrado donde se hizo la investigación, así como para los actores involucrados en el ámbito académico, es que esta investigación da cuenta del proceso de textualización que llevan los estudiantes para elaborar su tesis de grado, lo cual nos provee un panorama general de las prácticas textuales que desarrollan en sus procesos formativos. Esto es de gran relevancia porque tanto a los profesores como a los estudiantes en el nivel universitario nos permite conocer, por un lado, cómo escriben los alumnos, con qué habilidades textuales llegan, qué saben o no de los textos académicos; y, por otro lado, también revela la distancia que hay respecto a las exigencias académicas e instituciones donde ambos estamos inmersos. Por ello, este estudio es una posibilidad para reflexionar sobre el fenómeno de la escritura académica, repensar nuestras prácticas textuales y las que les exigimos a los estudiantes, pero también, puede ayudar a tomar decisiones y reflexionar sobre nuestro papel como educadores en el nivel superior. 


\section{REFERENCIAS BIBLIOGRÁFICAS}

Andréu J. (2000). Las técnicas de análisis de contenido: una revision actualizada. Fundación Centro Estudios Andaluces, Universidad de Granada, v. 10, no. 2, pp. 1-34. Disponible en: http://public.centrodeestudiosandaluces.es/pdfs/S200103.pdf

Argudín, Y. \& Luna M. (2005). Aprende a pensar escribiendo bien. Desarrollo de habilidades para escribir. México: Trillas.

Bajtin, M. (1982). Estética de la creación verbal. México: Siglo XXI Editores (8 Ed.en Español; Original en Ruso, 1979).

Barton, D. \& Hamilton, M. Literacy practices. En Barton D., Hamilton M. \& Ivanic R. (Eds.), Situated literacies. Reading and writing in contex. New York. Routledge, pp. 7-15.

Bazerman, C. (1988). Shaping Written Knowledge. The genre and activity of the experimental article in science. USA: The University of Wisconsin Press.

Blommaert, J. \& Jie D. (2010). Ethnographic Fieldwork: A beginner's guide. Bristol: Multilingual Matters.

Booth et al (2008). Cómo convertirse en un hábil investigador. México: Gedisa.

Bogdan, R. \& Biklen S. (2007) Qualitative Research for Education: An Introduction to Theories and Methods. Boston: Allyn and Bacon

Brice Heath, S. (1983). Ways with words: language, life, and work in communities and classrooms. New York: Cambridge University Press.

Brice Heath, S. \& Street B. (2008). Ethnography: Approaches to language and literacy. New York: Teachers College Press.

Cabrera, A. \& Pelayo, N. (2002). Lenguaje y Comunicación. Venezuela: Los libros de El Nacional. 
La textualidad académica de estudiantes de origen indígena en estudios de posgrado: el proceso de elaboración de tesis

Cáceres P. (2003). Análisis cualitativo de contenido: una alternativa metodológica alcanzable. En Psicoperspectivas, revista de la escuela de psicología, facultad de filosofía y educación. Pontificia Universidad Católica de Valparaíso. Vol. II, pp. 53-82.

Calsamiglia, H. (1997). Singularidades de la elaboración textual: aspectos de enunciación escrita. En Lomas C. \& Osoro A. (Comps), El enfoque comunicativo de la enseñanza de lengua. España: Paidos, pp. 181-197.

Camps, A. \& Castelló, M. (2013). La escritura académica en la universidad. En Revista de Docencia Universitaria, Enero-Abril, 11 (1), 17-36.

Carlino, P. (2003). La experiencia de escribir una tesis: contextos que la vuelven más difícil. Trabajo presentado en el II Congreso Internacional Cátedra UNESCO Lectura y Escritura. Pontificia Universidad Católica de Valparaíso, 5-9 de mayo. Disponible en línea en formato PDF.

(2004). El proceso de la escritura académica: cuatro dificultades de la enseñanza universitaria. En Educare, Julio-Agosto, 8: 026, 321-327.

(2005). Escribir, leer y aprender en la universidad. Una introducción a la alfabetización académica. México: Fondo de Cultura Económica.

Castelló, C., \& Iñesta, A. (2012). Texts as artifacts-in activity: Developing authorial identity and academic voice in writing academic research papers. En M. Castelló \& C. Donahue (Eds.), University writing: Selves and texts in academic societies. Bingley, UK: Emerald Group Publishing Limited, pp. 179-200

Cassany D., Luna M. \& Sanz, G. (2007). Enseñar Lengua. México: GRAÓ.

Cummins, J. (2002). Lenguaje, poder y pedagogía. Madrid: Ediciones Morata.

Gee, P. (2010). A situated -sociocultural approach to literacy and technology. En E. A. Baker, The new literacies. Multiple Perspectives on research and practice. USA: The Guilford Press, pp. 165-193. 
Hermerschmidt, M. (1999). Foregrounding background in academic learning. En Jones C., Turner J., \& Street B. (Eds.), Students writing in the university, cultural and epistemological issues. USA: John Benjamins Publishing Company, pp. 5-16.

Hernández Álvarez, R. (2013). Análisis de la escritura en estudiantes universitarios. Tesis para obtener el grado de Maestro en Sociolingüística de la Educación Básica y Bilingüe. UPN, 201.

Hernández Ramírez, K. (2015). Las prácticas de escritura en la universidad: el reporte de lectura un ejemplo de géneros textuales académicos. Tesis para obtener el grado de Maestra en Sociolingüística de la Educación Básica y Bilingüe. UPN, 201.

Hernández Rodríguez. (2013). Panorama sobre literacidad y escritura académica en la educación superior. En Muñoz H. (Ed.), Textualidad y lengua extranjera en el desarrollo académico de estudiantes bilingües en la educación superior. México: UAM-I-CONACYT, pp. 5-13.

Labov W. (2013). The language of Life and Death. The transformation of experience in oral narrative. United Kingdom: Cambridge University Press.

Lea, M. (1999). Academic literacies and learning in higher education. Constructing knowledge throug texts and experience. En Jones C., Turner J., \& Street B. (Eds.), Students writing in the university. Cultural and epistemological issues. USA: John Benjamins Publishing Company, pp. 103-124.

Lea, M. \& Street, B. (1998). Student writing in higher education: An academic literacies approach. En Studies in Higher Education, 23: 2, 157-172.

Maturana H. (1989). Todo lo dice un observador. En Thompson W. I. (Ed.), GAIA Implicaciones de la nueva biología. Barcelona: Kairós, pp. 63-79.

Mayring, P. (2000) Qualitative content analysis. Forum qualitative social research, 1(2). Disponible en línea: http://qualitativeresearch.net/fqs/fqs-e/2-00inhalt-e.htm. Recuperado el 30 de junio de 2017.

Miller, C. (2005). Genre as Social Action. En Aviva Freedman and Peter Medway (Eds), Genre and the New Rhetoric. London: Taylor \& Francis Publishers. pp. 20-36. 
La textualidad académica de estudiantes de origen indígena en estudios de posgrado: el proceso de elaboración de tesis

Muñoz, H. (2013). Presentación. En Muñoz H. (Ed.), Textualidad y lengua extranjera en el desarrollo académico de estudiantes bilingües en la educación superior. México: UAM-I-CONACYT, pp. 5-13.

Parra Mosquera, C. (2013). Lectura, escritura y cultura académica en la universidad. Avances de investigación. Disponible en: ww.faceducacion.org/redlecturas4/?q= book/export/html/45

Porta L. \& Silva M. (2003). La investigación cualitativa: El análisis de contenido en la investigación educativa. En Investigación Cualitativa \& Nvivo, octubre 2003. http://www.investigacioncualitativa.es/Paginas/Articulos/investigacioncualitativa/Port aSilva.pdf.

Schlieben-Lange, B. (1997). Iniciación a la Sociolingüística. España: Gredos

Street, B. (1993). Cross cultural approaches to literacy. New York: Cambridge University Press.

Street, B. (2003). "What's "new" in New Literacy Studies? Critical approaches to literacy in theory and practice". Current issues in comparative education, Teachers College. Columbia University. Vol. 5 (2).

(2010). 'Academic Literacies approaches to Genre'? RBLA, Belo Horizonte, v. 10, n. 2, 347-361.

(2009). "Hidden" Features of Academic Paper Writing. Working Papers in Educational Linguistics, 24/1:1-17.

Titira, M. (2013). La escritura en las redes sociales. Disponible en Formato PDF: www.usfq.edu.ec/.../para_el.../pea_008_0010.pdf

Tolchinsky, L. (2000). Distintas perspectivas acerca del objeto y propósito del trabajo y la reflexión metalinguiística en la escritura académica. En Milian M y Camps A. (Comps), EL papel de la actividad metalingüística en el aprendizaje de la escritura. Buenos Aires: Homo Sapiens Ediciones, pp. 39-65. 


\section{ANEXOS \\ CORPUS DE DATOS: LA PROBLEMÁTICA DE INVESTIGACIÓN}

FASE 1: ANTERPOYECTO DE INVESTIGACIÓN (ASPIRANTES AL PROGRAMA DE MAESTRÍA (noviembre-diciembre 2011)

\begin{tabular}{|c|c|c|c|}
\hline NHG-I1-F1 & Explicaciones de/sobre... & Apartado & Primeras observaciones analíticas \\
\hline $\begin{array}{l}\text { La } \\
\text { problemática }\end{array}$ & $\begin{array}{l}\text { La realidad que se vive como docente es extremadamente preocupante, porque no se } \\
\text { cuenta con suficientes armas para proponer propuestas innovadoras que impacten en el } \\
\text { medio social en donde se presta el servicio educativo. } \\
\text { En donde las comunidades cuentan con su propia cultura y lengua. Y por lo consiguiente } \\
\text { no ha sido recuperada por los educadores originarios. Por no contar con una metodología } \\
\text { adecuada al medio social en que se desarrolla la practica docente. (p.3) } \\
\text { Las comunidades originarias Mixes, se localizan en los lugares más alejados de la sierra } \\
\text { norte de Oaxaca, donde por décadas han estado en extrema pobreza y solitarias, donde los } \\
\text { grupos radicales y los partidos políticos, se acuerdan de ellos cuando es cambio de } \\
\text { gobierno... } \\
\text { Para la élite los mixes somos un obstáculo para el avance social, económico, etc. A nivel } \\
\text { nacional. Por ello, la política educativa es, integrar a los mixes a la vida de ellos... } \\
\ldots \\
\text { En los mixes, se ha valorado toda esta riqueza cultural pero, como contrarestar el modelo } \\
\text { educativo que propone el estado, tenemos en las manos el nuevo plan y programas } 2009 \text {, } \\
\text { donde nos marca todo lo que vamos a abordar cada grupo de alumnos en educación } \\
\text { primaria, donde a los mixes nos imponen contenidos y temas que no son adecuados a } \\
\text { nuestra cultura, a nuestro medio social y es más no contamos con una metodología para la } \\
\text { enseñanza de la lecto-escritura mixe. } \\
\text { Los alumnos de nivel primaria no cuentan con libros y materiales escritos en mixe, por } \\
\text { ello, la enseñanza en los primeros años en la escuela primaria es en la segunda lengua. } \\
\text { La preocupación ha sido muy grande, por lo que se considera que es momento de iniciar } \\
\text { con este trabajo, proponer una metodología para la enseñanza de la lengua mixe en el aula. } \\
\text { Pero como, si no contamos con un especialista mixe, el problema con que nos enfrentamos } \\
\text { como maestros de grupo es; como enseñar a leer y escribir en mixe a los alumnos de } \\
\text { primer año. (p. 4). } \\
\text { docente se le dé la oportunidad de profesionalizarse. Con el fin de que se cuente con más } \\
\text { instrumentos y fundamentación en proponer metodologías adecuadas. }\end{array}$ & $\begin{array}{l}\text { Planteamiento } \\
\text { del problema }\end{array}$ & \\
\hline
\end{tabular}




\begin{tabular}{|c|c|c|c|}
\hline MAGV-I2-F1 & Explicaciones de/sobre... & Apartado & Primeras observaciones analíticas \\
\hline $\begin{array}{l}\text { La } \\
\text { problemática }\end{array}$ & 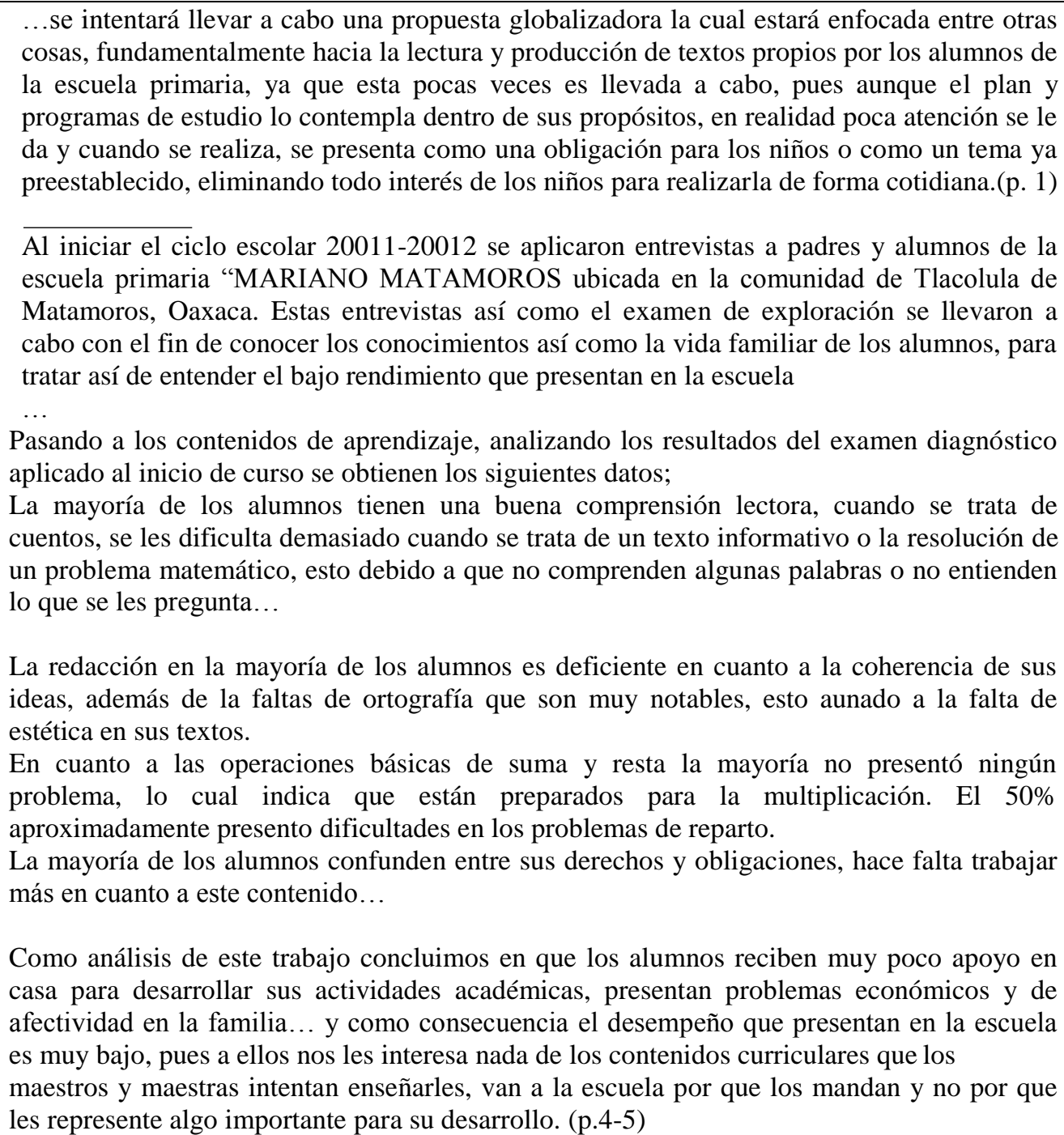 & $\begin{array}{l}\text { Planteamiento } \\
\text { del problema }\end{array}$ & \\
\hline
\end{tabular}




\begin{tabular}{|c|c|c|c|}
\hline RRG-I6-F1 & Explicaciones de/sobre... & Apartado & Primeras observaciones analíticas \\
\hline $\begin{array}{l}\text { La } \\
\text { problemática }\end{array}$ & $\begin{array}{l}\text { A lo largo de la educación primaria no se logra el desarrollo de un bilingüismo coordinado } \\
\text { en la mayoría de los alumnos y persiste el dominio de una lengua sobre la otra, ya que lo } \\
\text { docentes no hemos podido implementar estrategias que permitan usar la lengua zapoteca } \\
\text { como objeto de estudio y como medio de comunicación de acuerdo a los enfoques de la } \\
\text { educación bilingüe e intercultural, solo se realizan algunas actividades para justificar el uso } \\
\text { de la lengua indígena dentro del aula como asignatura... (p. 1) } \\
\ldots \\
\text { Ante esta situación no se ha logrado el desarrollo de un bilingüismo coordinado en los } \\
\text { alumnos y persiste el predominio de una lengua sobre la otra, dentro del aula por la forma } \\
\text { de trabajo de los docentes se usa más el español que el zapoteco, mientras que fuera del aula } \\
\text { los alumnos emplean más la lengua indígena para comunicarse, provocando de tal manera } \\
\text { algunos problemas de comunicación tanto en una lengua como en la otra, específicamente } \\
\text { en la expresión oral y escrita de los alumnos, ya que existe una gran diferencia entre la } \\
\text { estructura de la lengua zapoteca y el español, por lo que los alumnos muestran confusión en } \\
\text { diferentes circunstancias y esto se debe a que los docentes no hemos sabido trabajar con } \\
\text { alumnos en un contexto bilingüe e intercultural. (p.2) } \\
\text {.. } \\
\text { Por otra parte puedo mencionar que por lo general los docentes empleamos el español como } \\
\text { lengua de instrucción, aún cuando los docentes somos hablantes de la lengua indígena de } \\
\text { los alumnos y los alumnos presentan un mayor dominio de la lengua indígena, solo en un } \\
\text { porcentaje mínimo se emplea la lengua indígena de acuerdo a las características lingüísticas } \\
\text { de los alumnos o por necesidades de evaluar la lengua indígena como asignatura de } \\
\text { educación primaria.... hasta la actualidad no se ha concretado un proyecto de desarrollo de } \\
\text { la lengua indígena con el reconocimiento, respaldo y financiamiento del IEEPO, la DGEI o } \\
\text { la DEI. Esta situación de alguna manera ha limitado el desarrollo de nuestra lengua } \\
\text { indígena, por esta misma razón no se ha logrado un bilingüismo coordinado en los alumnos. } \\
\text { (pp. 3-4) }\end{array}$ & Justificación & \\
\hline
\end{tabular}


FASE 2.- PROTOCOLO DE INVESTIGACIÓN (Producto Final del Seminario de Tesis I, junio, 2013)

\begin{tabular}{|c|c|c|c|}
\hline NHG-I1-F2 & Explicaciones de/sobre... & Apartado & Primeras observaciones analíticas \\
\hline $\begin{array}{l}\text { La } \\
\text { problemática }\end{array}$ & 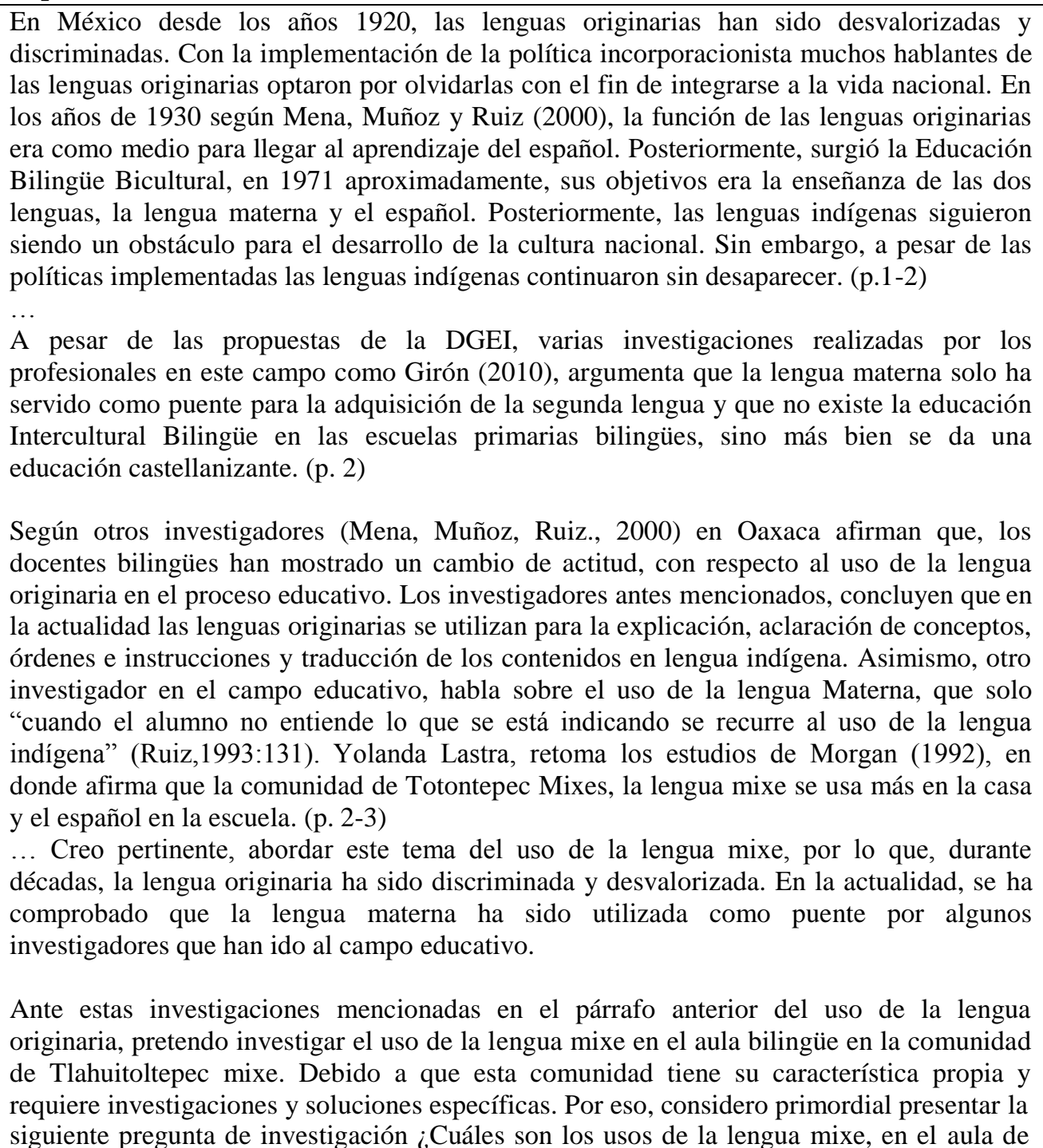 & $\begin{array}{l}\text { Planteamiento del } \\
\text { problema }\end{array}$ & \\
\hline
\end{tabular}




\begin{tabular}{|c|c|c|c|}
\hline & primer grado de la escuela primaria bilingüe "José María Morelos y Pavón? & & \\
\hline MAGV-I2-F2 & Explicaciones de/sobre... & Apartado & Primeras observaciones analíticas \\
\hline $\begin{array}{l}\text { La } \\
\text { problemática }\end{array}$ & $\begin{array}{l}\text { Este proyecto nace primeramente como una necesidad personal al darme cuenta de que en } \\
\text { el momento en el que me encontraba con una hoja en blanco, para mí era y es muy difícil } \\
\text { poder expresar mis ideas. Simplemente mi expresión escrita era muy limitada en } \\
\text { comparación con las ideas que deseaba plasmar, además las veces en que se elaboraba una } \\
\text { redacción era para cumplir con algún trabajo y no para plasmar textos de mi interés. } \\
\text { En mi práctica docente he encontrado en mis alumnos grandes dificultades para escribir } \\
\text { algún texto propio, pues aunque estén en los grados más avanzados y aparentemente sepan } \\
\text { leer y escribir en la escuela, esto se les dificulta en su vida cotidiana, así por ejemplo es } \\
\text { muy común escuchar a algún maestro decir que sus alumnos ya leen y escriben bien, pero } \\
\text { esto solo aplica para algunas actividades escolares, es decir escriben para la escuela no para } \\
\text { comunicarse a través del texto. Estas son solo algunas de las razones por las cuales } \\
\text { pretendo trabajar la escritura enfocada hacia la producción de textos pues aunque ya } \\
\text { muchos autores hayan abordado el tema, (Emilia Ferreiro, Margarita Gómez Palacios, } \\
\text { Alicia Palacios, C. Freinet, Dorothy H. Cohen, Ana Teberosky, entre otros), además de } \\
\text { proponer diversas estrategias se sigue observando la misma problemática en los alumnos. } \\
\text { (p.2) } \\
\text { Se hace verdaderamente importante la realización de este proyecto, primeramente para } \\
\text { conocer cómo se está trabajando la escritura en las aulas de clase, tratar de vislumbrar } \\
\text { porque no se ha avanzado o en qué medida se han dado avances en esta problemática, para } \\
\text { que en un futuro podamos ofrecer posibles estrategias. (p. 3) } \\
\text { En algunos casos enfrentarse con la escritura en la escuela no representa ningún conflicto } \\
\text { para el alumno y se involucra inmediatamente en este proceso, pero en algunos otros casos } \\
\text { este proceso les representa verdaderamente una problemática, puesto que dominar la } \\
\text { escritura con sus reglas gramaticales y signos sin la comprensión de las mismas es algo que } \\
\text { requiere un mayor esfuerzo, si es que se parten de ellas... En este caso nos encontramos } \\
\text { ante dos posiciones con respecto a la enseñanza de la lecto-escritura en las escuelas. Una } \\
\text { que parte de la idea de que el alumno se le tiene que enseñar a escribir y a leer empezando }\end{array}$ & $\begin{array}{l}\text { Planteamiento del } \\
\text { problema }\end{array}$ & \\
\hline
\end{tabular}




\begin{tabular}{|c|c|c|c|}
\hline & $\begin{array}{l}\text { por el abecedario y las reglas gramaticales, ortográficas y de puntuación (Método } \\
\text { Alfabético o Deletreo, Método Fonético, Método silábico, entre otros). Por el otro lado } \\
\text { están las propuestas que parten del texto completo, tomando en cuenta las inquietudes y } \\
\text { necesidades del alumno, así como el significado del texto, las reglas gramaticales, } \\
\text { ortográficas y de puntuación y el nombre de las letras se van adquiriendo durante el proceso } \\
\text { (Método Global, Pronalees). El hecho de trabajar bajo alguna de estas dos posturas } \\
\text { considero que traerá consecuencias sobre la forma en la que el alumno considerara a la } \\
\text { escritura en los grados posteriores. (pp. 4-5) }\end{array}$ & & \\
\hline FMM-I4-F2 & Explicaciones de/sobre... & Apartado & Primeras observaciones analíticas \\
\hline $\begin{array}{l}\text { La } \\
\text { problemática }\end{array}$ & $\begin{array}{l}\text { Una de las características de las escuelas actuales es sin duda, que en ella albergan } \\
\text { alumnos con diferencias culturales. Alumnos que proceden de diferentes etnias, } \\
\text { costumbre, religión, ideología, estilos de habla, capacidades distintas, en fin, una } \\
\text { mezcla y relación entre diversos que convierten el espacio escolar en un lugar de encuentro } \\
\text { como diría Pablo Latapí. Gran parte de esta aglomeración humana obedece a fenómenos } \\
\text { sociales, económicos, políticos, conflictos o a intereses propio de las familias que optan por } \\
\text { emigrar hacia las ciudades o áreas conurbadas a las ciudades en busca de mejores } \\
\text { oportunidades de vida. (p. 1) } \\
\text {.. } \\
\text { La diversidad étnica en las escuelas son culturas o alumnos invisibles como lo afirma } \\
\text { Philips (1972) porque la escuela como institución no reconoce ni fomenta una educación } \\
\text { multicultural que aspire a considerar la diversidad cultural e individual de los alumnos. Aún } \\
\text { la escuela pertenezca al nivel de Educación Indígena, poco se ha hecho por atender las } \\
\text { características culturales de los niños. La situación escolar es compleja ante este panorama } \\
\text { de la diversidad. En las escuelas Bilingües (al igual que en la primaria general) trabajan } \\
\text { docentes que no hablan una lengua indígena o bien son hablantes de otra lengua, por lo que } \\
\text { la lengua de enseñanza impartida o el medio de comunicación entre el maestro y sus } \\
\text { alumnos es el castellano. Aun existiendo el reconocimiento oficial en los documentos solo } \\
\text { queda en políticas educativas, como lo es el documento lineamientos generales para la } \\
\text { educación intercultural bilingüe para las niñas y los niños indígenas como lo muestra en el } \\
\text { lineamiento } 5 \text {, que a la letra dice: } \\
\text { Se entenderá por educación intercultural aquella que reconozca y atienda a la } \\
\text { diversidad cultural y lingüística; promueva el respecto a las diferencias; } \\
\text { procure la formación de la unidad nacional, a partir de favorecer el } \\
\text { fortalecimiento de la identidad local regionaly nacional, así comoeldesarrollo } \\
\text { deactitudesyprácticasqueatiendanalabúsquedadelibertadyjusticiapara } \\
\text { todos (SEP-DGEl. 199:11) }\end{array}$ & $\begin{array}{l}\text { Planteamiento del } \\
\text { problema }\end{array}$ & \\
\hline
\end{tabular}




\begin{tabular}{|l|l|l|l|}
\hline $\begin{array}{l}\text { Tal situación no solo se presenta en el sistema de educación indígena, las escuelas actuales } \\
\text { de todos los niveles presentan estas características de diversidad, solo que pasan } \\
\text { desapercibidas tanto para los docentes como por las autoridades educativa. (p. 2) }\end{array}$ & & \\
\hline & & & \\
\hline
\end{tabular}

\begin{tabular}{|c|c|c|c|}
\hline HGL-I8-F2 & Explicaciones de/sobre... & Apartado & Primeras observaciones analíticas \\
\hline $\begin{array}{l}\text { La } \\
\text { problemática }\end{array}$ & $\begin{array}{l}\text { La lectura y la escritura se convierten así en las herramientas que los alumnos tendrán que } \\
\text { desarrollar a lo largo de la educación primaria y después de ella, puesto que día con día en } \\
\text { diferentes situaciones hacemos uso de la lectura y la escritura, con este fin en la escuela se } \\
\text { realizan una serie de actividades orientadas a desarrollar estas habilidades. Para ello se } \\
\text { consultan diversos textos para buscar información sobre un tema determinado, elaborar un } \\
\text { cartel, una carta, leer un libro, escribir un recado o un anuncio, que si bien algunas } \\
\text { actividades se ponen en duda sobre su pertinencia como contestar preguntas o un } \\
\text { cuestionario hecho por el maestro, son actividades que día a día se realizan en la escuela. (p. } \\
\text { 2-3) } \\
\text { Sin embargo, es muy común escuchar en las reuniones de consejo técnico escolar a } \\
\text { docentes de educación primaria, que laboran en contextos rurales o urbanos, hacer mención } \\
\text { de dificultades que tienen sus alumnos para comprender textos a la hora de leer. Estas } \\
\text { dificultades pueden ser de diferentes tipos, hay maestros que dicen que sus alumnos a la } \\
\text { hora de leer no tienen fluidez en su lectura, que deletrean silaba por silaba; en otros casos, } \\
\text { hay niños que mantienen una fluidez constante en la lectura, pero les cuesta trabajo expresar } \\
\text { algunas ideas sobre el texto leído. En algunos contextos rurales las dificultades pueden } \\
\text { resultar mayores, ya que los niños suelen manejar palabras y significados diferentes los } \\
\text { representados en los textos y libros que se leen en la escuela. } \\
\text { Esta situación lleva a los docentes a proponer ciertas actividades que pueden enmendar los } \\
\text { rezagos de la lectura, pero cuyos resultados no parecen ser alentadores, como menciona } \\
\text { Ramírez Leyva (2010:10) en algunos estudios encuentran deficiencias en las habilidades de } \\
\text { lectura y escritura aproximadamente en el } 60 \% \text { de jóvenes que cursan el tercer año de }\end{array}$ & $\begin{array}{l}\text { Planteamiento del } \\
\text { problema }\end{array}$ & \\
\hline
\end{tabular}




\begin{tabular}{|l|l|l|l|}
\hline educación básica. & & & \\
& & & \\
\hline
\end{tabular}

\section{FASE 3.- PLANTEAMIENTO DE LA PROBLEMÁTICA (noviembre -diciembre 2014)}

\begin{tabular}{|c|c|c|c|}
\hline MAGV-I2-F3 & Explicaciones de/sobre... & Apartado & Primeras observaciones analíticas \\
\hline $\begin{array}{l}\text { La } \\
\text { problemática }\end{array}$ & $\begin{array}{l}\text { El interés sobre el tema nace primeramente como una problemática personal al darme } \\
\text { cuenta de mi ineficiencia al intentar interactuar comunicativamente tanto en mi proceso } \\
\text { formativo como en el ámbito laboral e incluso en algunos otros contextos sociales, esta } \\
\text { misma problemática pude observarla en la mayoría de alumnos con los que he trabajado, se } \\
\text { incrementa al ser ésta una de las problemáticas actuales de la educación y se reafirma al } \\
\text { videograbar una clase de segundo grado de primaria formal. En esta videograbación pude } \\
\text { detectar un dato problemático en cuanto a la interacción comunicativa desarrollada entre la } \\
\text { maestra y los alumnos pues me percaté de que en las interacciones comunicativas } \\
\text { desarrolladas en la clase se presentaban ciertos fenómenos interesantes de investigar como } \\
\text { lo es el hecho de que la que más participa en estas interacciones es la maestra de grupo } \\
\text { utilizando a los alumnos solo para completar el discurso iniciado por ella. Este fenómeno } \\
\text { trae consigo diversas consecuencias y da origen a otros fenómenos más que influyen } \\
\text { directamente en el proceso enseñanza-aprendizaje. Se torna realmente interesante investigar } \\
\text { la influencia de este tipo de interacción comunicativa en el proceso de enseñanza- }\end{array}$ & Introducción & \\
\hline
\end{tabular}




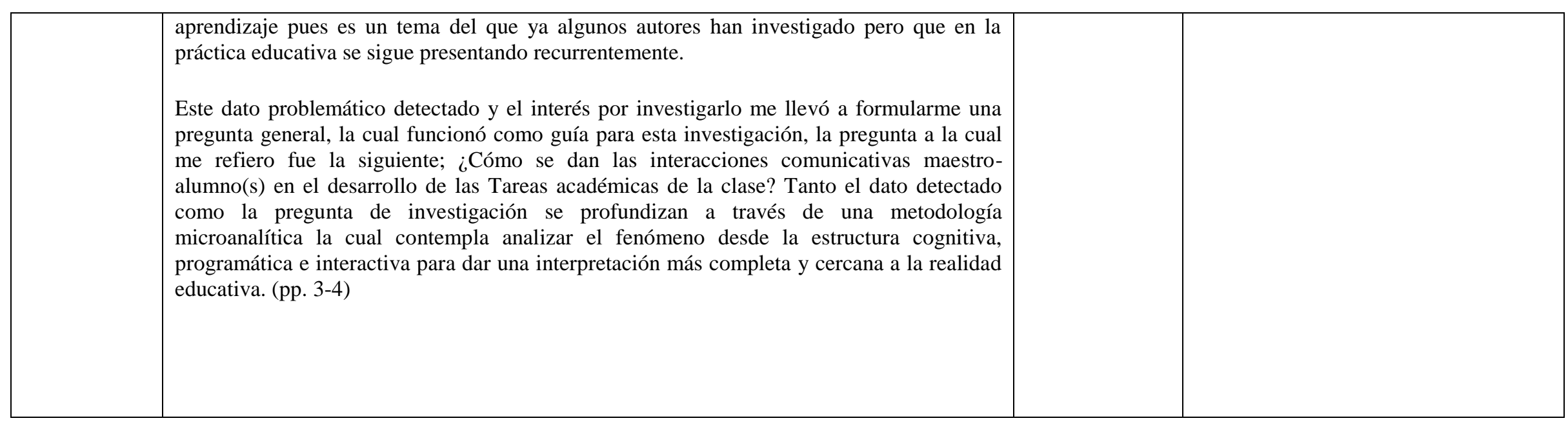

\begin{tabular}{|c|c|c|c|}
\hline FMM-I4-F3 & Explicaciones de/sobre... & Apartado & Primeras observaciones analíticas \\
\hline $\begin{array}{l}\text { La } \\
\text { problemática }\end{array}$ & $\begin{array}{l}\text { Estas prácticas de hacer preguntas aún prevalecen en la actualidad en los centros } \\
\text { escolares o más bien siguen siendo una de las formas de la enseñanza escolar, como } \\
\text { docente frente a grupo se recurre al uso de las preguntas con diferentes intenciones. Tal vez, } \\
\text { como alumno se considere solo como una evaluación del conocimiento para aprobar, pero } \\
\text { como docente quizás tenga otras implicaciones desde la lógica del proceso de la enseñanza } \\
\text { y el aprendizaje escolar. Por ello, en esta etapa como docente investigador nace mi } \\
\text { inquietud de saber lo que implican las preguntas del decente en el contexto de las tareas } \\
\text { académicas para la enseñanza y aprendizaje en un aula de Educación Primaria indígena. } \\
\text { Saber lo que implica el uso frecuente de las preguntas en el proceso de la enseñanza y } \\
\text { aprendizaje escolar, me remite a plantear la siguiente pregunta de investigación: ¿Cuáles } \\
\text { son las funciones pedagógicas y qué otras funciones realizan las preguntas que el docente } \\
\text { utiliza con sus alumnos para la enseñanza en el desarrollo de las tareas académicas en un } \\
\text { aula de } 5^{\circ} \text { y } 6^{\circ} \text { grado de Primaria Indígena? La interrogante planteada es la que guía esta } \\
\text { investigación y a la cual se dará respuesta y explicación con argumentación teórico y }\end{array}$ & Introducción & \\
\hline
\end{tabular}




\begin{tabular}{|l|l|l|l|}
\hline $\begin{array}{l}\text { empírico a través de un proceso de análisis de los datos desde la metodología del } \\
\text { microanálisis. (pp. 3-4) }\end{array}$ & & \\
\hline
\end{tabular}

\begin{tabular}{|l|l|l|l|}
\hline AGG-I5-F3 & Explicaciones de/sobre... & Apartado & Primeras observaciones analíticas \\
\hline $\begin{array}{l}\text { La } \\
\text { problemática }\end{array}$ & $\begin{array}{c}\text { Cotidianamente los docentes de educación primaria se enfrentan a retos muy } \\
\text { variados en el aula de clases cuando intentan realizar el proceso de enseñanza aprendizaje, } \\
\text { sobre todo en el aspecto de la comunicación de los contenidos escolares a los alumnos. La } \\
\text { comunicación es un elemento fundamental entre el docente y los alumnos porque a través } \\
\text { de ella se busca lograr propósitos e intenciones no solo establecidos desde un currículo, una } \\
\text { institucionalidad, un contexto social y cultural que determinan la clase sino como tarea del } \\
\text { mismo docente como agente con una responsabilidad de formar a individuos sociales. }\end{array}$ & Introducción & \\
& $\begin{array}{l}\text { En el contexto del aula la comunicación que se presenta en las interacciones no } \\
\text { son iguales a las conversaciones que se dan en otros espacios como el patio del recreo, en }\end{array}$ & & \\
\hline
\end{tabular}




\begin{tabular}{|l|l|l|}
\hline $\begin{array}{l}\text { la calle o un dialogo con el medico en un consultorio, etc. esto que se manifiesta en el salón } \\
\text { de clases nos hace entender que los diálogos en la enseñanza son tipos particulares de } \\
\text { acontecimientos comunicativos para propósitos instruccionales como lo argumentan } \\
\text { Fernández y Melero (1997). (p. 3) }\end{array}$ & $\begin{array}{l}\text { Todo lo anterior me llevo a tomar la decisión de hacer este trabajo de investigación } \\
\text { que surge a partir de la observación de una clase de lenguaje que hice durante el trabajo de } \\
\text { campo en una escuela primaria indígena, donde pude observar que la comunicación que se } \\
\text { estableció entre el maestro y los alumnos no tuvo los efectos planteados por el docente } \\
\text { antes de la clase, situación me hizo reflexionar y cuestionar sobre qué elementos } \\
\text { comunicativos no se retomaron durante las interacciones del maestro - alumnos y qué } \\
\text { influyó para que el objetivo de la escritura de un texto escrito como la carta no pudiera } \\
\text { cumplirse tal y como se propuso el docente antes de la clase. }\end{array}$ \\
$\begin{array}{l}\text { Mi interés por el estudio sobre la comunicación en el aula se cristalizó en mi } \\
\text { objeto de investigación que denomino "las interacciones comunicativas entre docente- } \\
\text { alumnos en segundo grado de educación primaria indígena" porque considero necesario } \\
\text { conocer las formas y los estilos de comunicación que se manifiestan en el aula de clases. } \\
\text { Puesto que las aulas son espacios donde el lenguaje y la comunicación son una herramienta } \\
\text { primordial para cumplir con los propósitos pedagógicos del proceso enseñanza - } \\
\text { aprendizaje, en este caso para la enseñanza de la lengua escrita. (p. 5) }\end{array}$ & \\
\hline
\end{tabular}

\section{HGL-I9-F3}

La
problemática

\section{Explicaciones de/sobre...}

Un aspecto trascendental en la educación primaria es lograr que en la enseñanza de la lectura y escritura se obtengan resultados satisfactorios. Como es el caso del primer grado de educación primaria, en donde los alumnos se involucran en el uso constante la lengua escrita, en el que a partir de una serie de interacciones los niños van aprendiendo a leer y escribir de manera convencional. (p. 4)

A partir de lo comentado hasta ahora, podríamos considerar que al desarrollarse en la escuela una serie de actividades de lectura y escritura éstas deben de reflejarse en las competencias de los alumnos para involucrarse en diferentes situaciones comunicativas que involucren situaciones de lectura y escritura.

Sin embargo, en mi experiencia como docente frente a grupo me he percatado de que al inicio de cada ciclo escolar se manifiesta en las la reuniones de consejo técnico escolar un

\begin{tabular}{|l|l|}
\hline Apartado & Primeras observaciones analíticas \\
\hline Introducción & \\
& \\
& \\
\hline
\end{tabular}




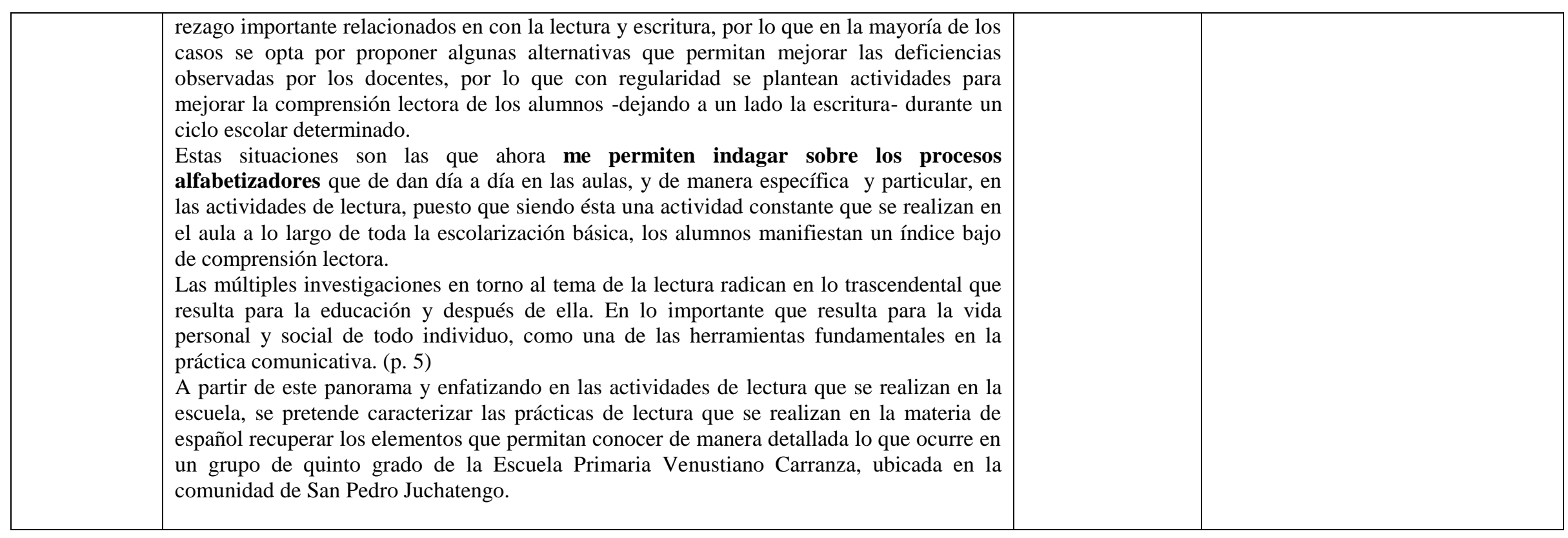

CORPUS DE DATOS: LOS OBJETIVOS DE LA INVESTIGACIÓN FASE 1: Anteproyecto de investigación (aspirantes al programa de maestría, noviembre-diciembre 2011)

\begin{tabular}{|ll|l|l|}
\hline NHG-I1-F1 & Explicaciones de/sobre... & Apartado & Primeras observaciones analíticas \\
\hline
\end{tabular}




\begin{tabular}{|c|c|c|}
\hline $\begin{array}{l}\text { Objetivos de } \\
\text { la } \\
\text { investigación }\end{array}$ & $\begin{array}{l}\text { 1.-Mostrar las contradicciones del conocimiento comunitario y escolar } \\
\text { 2.-Fortalecer la identidad cultural y lingüística de los mixes, mediante un modelo de lecto- } \\
\text { escritura que respondan a sus necesidades y características concretas. } \\
\text { Objetivo Específico: } \\
\text { 1.-Identificar la función de la lengua materna en la familia y la comunidad. } \\
\text { 2.-Describir y analizar la adquisición y apropiación de la lengua mixe antes de ingresar en } \\
\text { la escuela. } \\
\text { 3.- Caracterizar los diferentes tipos de actitudes y comportamientos que adquiere el niño y } \\
\text { la niña mixe frente a la escuela a partir de sus conocimientos comunitarios como la lengua. } \\
\text { 4.-valorar la lengua materna de los alumnos y alumnas } \\
\text { 5.- proponer una metodología para la enseñanza de la lecto-escritura mixe. (p.6-7) }\end{array}$ & $\begin{array}{l}\text { Objetivo } \\
\text { General }\end{array}$ \\
\hline
\end{tabular}

\begin{tabular}{|c|c|c|c|}
\hline MAGV-I2-F1 & Explicaciones de/sobre... & Apartado & Primeras observaciones analíticas \\
\hline $\begin{array}{l}\text { Objetivos de } \\
\text { la } \\
\text { investigación }\end{array}$ & $\begin{array}{l}\text {... es aquí donde se orienta a los alumnos para que construyan su propio aprendizaje } \\
\text { evitando la mera repetición de los libros, maestros que tomen en cuenta las inquietudes e } \\
\text { intereses de sus alumnos para abordar los contenidos... (p. } 7 \text { ) } \\
\text { - Provocar en los alumnos apasionamiento por la lectura y la producción de textos } \\
\text { por gusto, a su vez lectores y en un futuro autores. } \\
\text { - Apoyar a los alumnos a desarrollar su habilidad para producir textos a través de } \\
\text { las técnicas Freinet. } \\
\text { - Liberar a los alumnos de la opresión, capaces de expresarse libremente sin miedo } \\
\text { a la equivocación o a la diferencia. } \\
\text { - Partir de la lectura y producción de textos para abordar los contenidos } \\
\text { curriculares, construyendo de forma conjunta una atmosfera y un ambiente más } \\
\text { agradable e interesante para los alumnos. } \\
\text { Lograr que la educación de los alumnos no dependa solamente del maestro si no incluir en } \\
\text { ella: padres de familia-alumno-maestro-contexto. }\end{array}$ & Objetivos & \\
\hline
\end{tabular}




\begin{tabular}{|c|c|c|}
\hline $\begin{array}{l}\text { Objetivos de } \\
\text { la } \\
\text { investigación }\end{array}$ & $\begin{array}{l}\text { Objetivo General: } \\
\quad>\text { Considerar como docente, la importancia de utilizar diferentes medios de } \\
\quad \text { evaluación adecuados para cada momento del proceso de enseñanza-aprendizaje } \\
\text { para poder identificar el nivel real del aprovechamiento de alumnos y a partir de } \\
\text { los resultados obtenidos tomar decisiones de mejora. } \\
\text { Objetivos específicos: } \\
\checkmark \text { Considerar la evaluación como un proceso constante en el aula. } \\
\checkmark \quad \text { Considerar diversos aspectos en la valoración del logro académico de mis alumnos } \\
\text { Vincular los objetivos de enseñanza con los resultados obtenidos de la evaluación final y } \\
\text { tomar decisiones de mejora. (p.11) }\end{array}$ & Objetivos \\
\hline
\end{tabular}

\begin{tabular}{|c|c|c|c|}
\hline FMM-I4-F1 & Explicaciones de/sobre... & Apartado & Primeras observaciones analíticas \\
\hline $\begin{array}{l}\text { Objetivos de } \\
\text { la } \\
\text { investigación }\end{array}$ & $\begin{array}{l}\text {... para este estudio en la maestría me propongo como etapas a alcanzar, en conocer, } \\
\text { entender y comprender a los alumnos con los que me relaciono como maestro, saber hacer } \\
\text { un diagnostico lingüístico que permita tener una visión clara de lo que quiero hacer y lograr } \\
\text { con los alumnos e impulsar talleres lingüístico con los profesores que se enfrentan ante las } \\
\text { mismas condiciones. Por todo esto para mi estudio en la maestría planteo los siguientes: } \\
\text { OBJETIVOS } \\
\text { - Hacer una propuesta metodologica que incluya las competencias a desarrollar en i, } \\
\text { ii y iii ciclo de primaria, en lenguas originarias. (zapoteco del valle con variantes) } \\
\text { - Definir el perfil lingüístico de egreso de los alumnos a la concluir la educación } \\
\text { primaria. } \\
\text { Preservación de lenguas originarias que identifica a los niños de las diferentes cultural } \\
\text { existentes. (p.15 }\end{array}$ & Objetivos & \\
\hline
\end{tabular}

\begin{tabular}{|l|l|l|l|}
\hline \multicolumn{1}{|c|}{ AGG-I5-F1 } & Applicaciones de/sobre... & Apartado & Primeras observaciones analíticas \\
\hline $\begin{array}{l}\text { Objetivos de } \\
\text { la } \\
\text { investigación }\end{array}$ & $\begin{array}{l}\text { por ello me interesa mucho adquirir conocimientos teóricos metodológicos que me permitan } \\
\text { realizar un análisis de mi lengua originaria desde los principios de la lingǘstica descriptiva, } \\
\text { esto con el fin de tener bases que me permita socializar los conocimientos con los } \\
\text { compañeros docentes en servicio a través de la implementación de talleres escolares y, por } \\
\text { otro lado, tener los elementos lingǘsticos que permitan ejercer la docencia desde un } \\
\text { enfoque interculturalidad que actualmente está en boga. (pp. 5-6, apartado de planteamiento } \\
\text { del problema) } \\
\text { Objetivos: }\end{array}$ & $\begin{array}{l}\text { Obtener conocimientos teóricos-metodológicos para realizar un análisis profundo } \\
\text { de la lengua didzaa en general y la variante de san Baltazar Guelavila. } \\
\text { Lograr la elaboración de un documento que permita a los docentes y personas } \\
\text { originarias interesadas en adquirir elementos para establecer el uso oral y escrito }\end{array}$ & \\
\hline
\end{tabular}




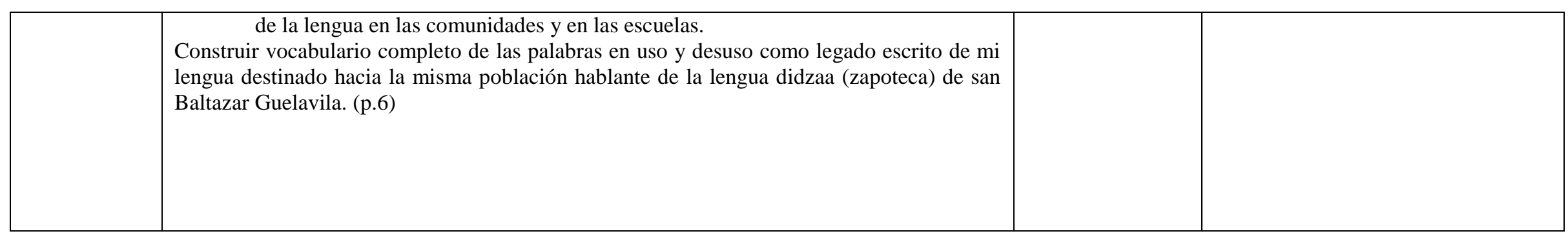

\begin{tabular}{|c|c|c|c|}
\hline RRG-I6-F1 & Explicaciones de/sobre... & Apartado & Primeras observaciones analíticas \\
\hline $\begin{array}{l}\text { Objetivos de } \\
\text { la } \\
\text { investigación }\end{array}$ & 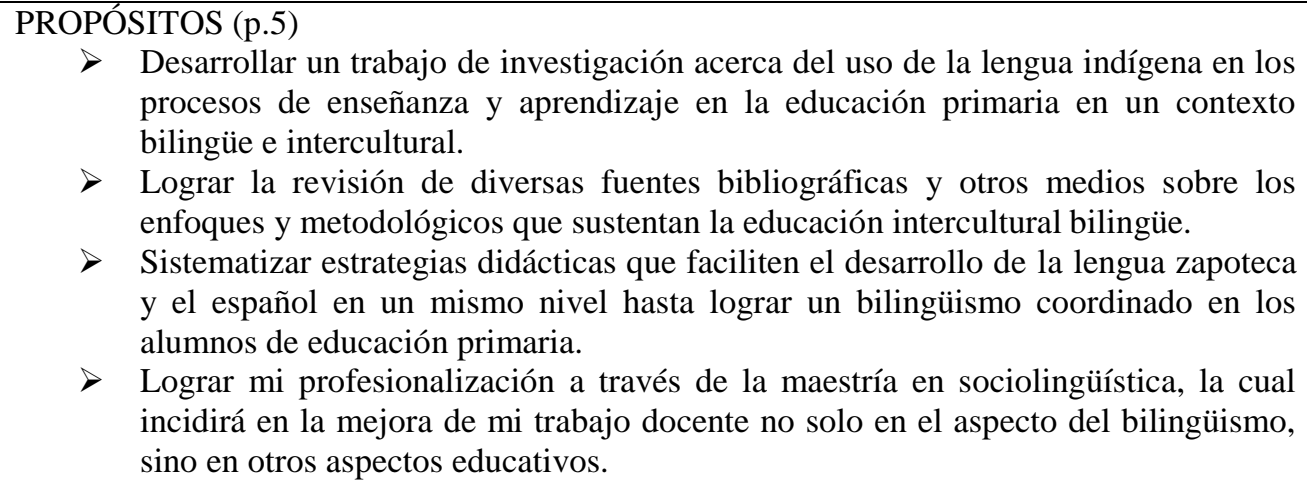 & Propósitos & \\
\hline
\end{tabular}

\begin{tabular}{|l|l|l|l|}
\hline GMV-I7-F1 & Explicaciones de/sobre... & Apartado & Primeras observaciones analíticas \\
\hline $\begin{array}{l}\text { Objetivos de } \\
\text { la } \\
\text { investigación }\end{array}$ & $\begin{array}{l}\text { Objetivo General } \\
\text { Objetivos específicos }\end{array}$ & \\
$\checkmark \quad \begin{array}{l}\text { Conocer las repercusiones que trae consigo una mala relación entre docente y sus } \\
\text { alumnos en el aula de clases. }\end{array}$ & & \\
& $\checkmark \begin{array}{l}\text { Describir las diversas formas que existen para mantener la disciplina en el aula } \\
\text { escolar }\end{array}$ & \\
& $\begin{array}{l}\text { Analizar las propuestas de diversos autores para mantener una óptima relación } \\
\text { interpersonal en el aula. (p. 9) }\end{array}$ & & \\
& & \\
\end{tabular}




\begin{tabular}{|c|c|c|c|}
\hline HGL-I8-F1 & Explicaciones de/sobre... & Apartado & Primeras observaciones analíticas \\
\hline $\begin{array}{l}\text { Objetivos de } \\
\text { la } \\
\text { investigación }\end{array}$ & 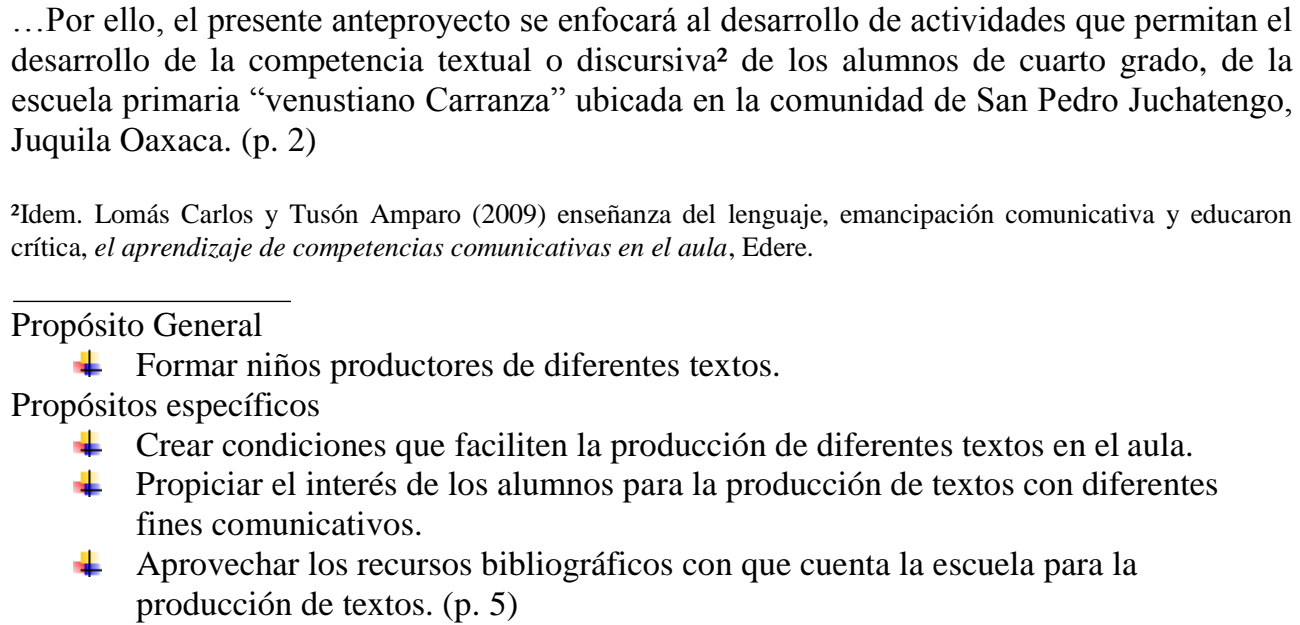 & Propósitos & \\
\hline
\end{tabular}

\begin{tabular}{|l|l|l|l|}
\hline \multicolumn{1}{|c|}{ WEZ-I9-F1 } & Explicaciones de/sobre... & Apartado & Primeras observaciones analíticas \\
\hline $\begin{array}{l}\text { Objetivos de } \\
\text { la } \\
\text { investigación }\end{array}$ & $\begin{array}{l}\text { Objetivos Generales. (p.10) } \\
\text { Diseñar una propuesta curricular para el medio indígena en el nivel de educación } \\
\text { primaria, a partir de los elementos culturales, para propiciar la interculturalidad en } \\
\text { las aulas. }\end{array}$ & Objetivos \\
& $\begin{array}{l}\text { Contribuir al mejoramiento del sistema educativo indígena, a partir de una } \\
\text { propuesta curricular destinada a los pueblos originarios. }\end{array}$ & \\
& $\begin{array}{l}\text { Objetivos espećficos. } \\
\text { Mediante la investigación -acción, recopilar la información y el análisis necesario } \\
\text { para el diseño de una propuesta curricular para propiciar la interculturalidad en las } \\
\text { escuelas de educación primaria indígena. }\end{array}$ & \\
& $\begin{array}{l}\text { Con los elementos teóricos metodológicos y prácticos, fortalecer la práctica Docente } \\
\text { Bilingüe Intercultural. (p.10) }\end{array}$ & \\
\end{tabular}

FASE 2.- PROTOCOLO DE INVESTIGACIÓN (Producto Final del Seminario de Tesis I, junio, 2013) 


\begin{tabular}{|c|c|c|c|}
\hline NHG-I1-F2 & Explicaciones de/sobre... & Apartado & Primeras observaciones analíticas \\
\hline $\begin{array}{l}\text { Objetivos de } \\
\text { la } \\
\text { investigación }\end{array}$ & $\begin{array}{l}\text { Tema: La lengua Mixe en el aula de primer grado en la Escuela Primaria Bilingüe "José María } \\
\text { Morelos y Pavón" de Nejapa, Tlahuitoltepec Mixe. } \\
\text { Objetivo General: Explicar el uso de la lengua mixe, mediante la observación en un aula bilingüe de } \\
\text { primer grado de primaria "José María Morelos y Pavón" para conocer sus funciones en la } \\
\text { escolarización de los niños. } \\
\text { Objetivos Específicos: } \\
\text { Describir el uso de la lengua mixe en el aula bilingüe. } \\
\text { Caracterizar el uso de la lengua mixe en el aula bilingüe. } \\
\text { Explicar las funciones que cumple la lengua mixe en el aula bilingüe. } \\
\text { Objeto de análisis: Los usos de la lengua mixe en el aula. }\end{array}$ & & \\
\hline
\end{tabular}

\begin{tabular}{|c|c|c|c|}
\hline MAGV-I2-F2 & Explicaciones de/sobre... & Apartado & Primeras observaciones analíticas \\
\hline $\begin{array}{l}\text { Objetivos de } \\
\text { la } \\
\text { investigación }\end{array}$ & $\begin{array}{l}\text { TEMA: Las prácticas de escritura enfocadas hacia la producción de textos en el quinto grado de la } \\
\text { escuela primaria mariano matamoros. } \\
\text { OBJETO DE ESTUDIO: Las prácticas de escritura } \\
\text { PREGUNA GENERAL: } \\
\text { ¿Qué prácticas se dan en el aula y de estas cuales están enfocadas hacia la producción de textos? } \\
\text { PREGUNTAS ESPECÍFICAS: } \\
\quad \text { ¿Qué funciones y usos desempeñan las prácticas de escritura en el aula? } \\
\quad \text { ¿Qué estrategias se siguen en el aula para la producción de textos? } \\
\text { OBJETIVO GENERAL: } \\
\text { Caracterizar las prácticas de escritura que se dan en el aula para marcar tendencias sobre las que } \\
\text { cumplen el propósito de la producción de textos. } \\
\text { ESPECÍFICOS: } \\
\text { Identificar y definir las características de las diferentes prácticas de escritura en el aula. } \\
\text { Comparar diferentes prácticas de escritura para marcar tendencias sobre ellas. } \\
\text { Describir las estrategias que se dan para la producción de textos. (p.1) }\end{array}$ & & \\
\hline GHV-I3-F2 & Explicaciones de/sobre... & Apartado & Primeras observaciones analíticas \\
\hline
\end{tabular}




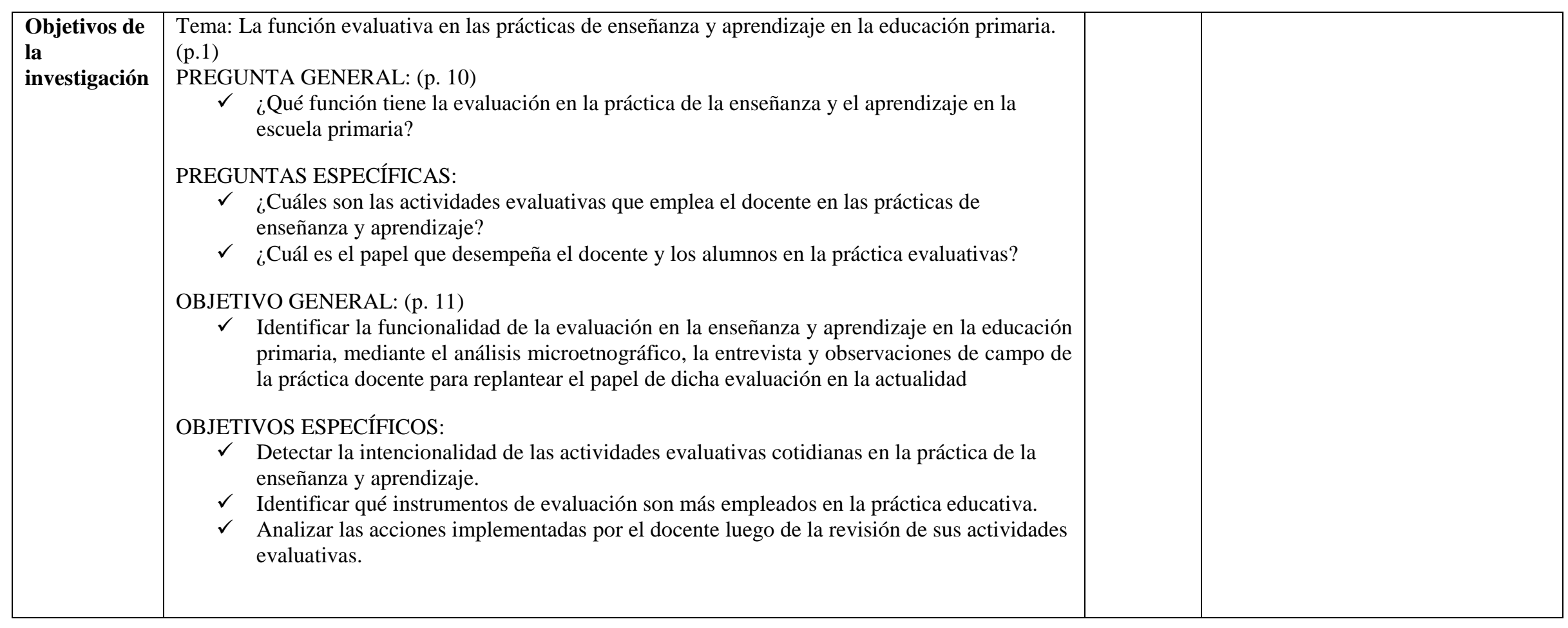

\begin{tabular}{|l|l|l|l|}
\hline FMM-I4-F2 & Explicaciones de/sobre... & Apartado & Primeras observaciones analíticas \\
\hline $\begin{array}{l}\text { Objetivos de } \\
\text { la } \\
\text { investigación }\end{array}$ & $\begin{array}{l}\text { Pregunta general. } \\
\text { ¿Qué funciones tienen las preguntas que utiliza el docente en su discurso para la mediación }\end{array}$ & & \\
& $\begin{array}{l}\text { comunicativa con sus alumnos en un aula con diversidad étnica? } \\
\text { Preguntas secundarias: }\end{array}$ & & \\
& - ¿Qué intención tienen las preguntas que el docente plantea a sus alumnos en el salón de clases? \\
& - Las preguntas planteadas, icorresponden a intereses del maestro, de los alumnos o de contenido? \\
& - ¿Las preguntas del docente promueven el desarrollo cognitivo de los alumnos? (p.4) & & \\
& $\begin{array}{l}\text { Objetivo General: Identificar y describir las funciones de las preguntas que el docente utiliza como } \\
\text { mediación en su discurso para mejorar la comunicación y el desarrollo cognitivo en un aula con } \\
\text { diversidad étnica. } \\
\text { Objetivos espećficos: } \\
\text { - Describir las preguntas según su función en el discurso del docente en un aula con diversidad }\end{array}$ & & \\
& & \\
\hline
\end{tabular}




\begin{tabular}{|l|l|l|}
\hline & $\begin{array}{l}\text { étnica. } \\
\text { - Clasificar las preguntas como discurso de tipo proléptico y de contingente utilizadas por el } \\
\text { docente en un aula con diversidad étnica. } \\
\text { - Caracterizar las preguntas que promueven el desarrollo cognitivo en los alumnos. } \\
\begin{array}{l}\text { Tema de Estudio: } \\
\text { Las preguntas del docente en la clase: apoyo u obstáculo para la comunicación y desarrollo } \\
\text { cognitivo en el aula con diversidad étnica. (p.5) }\end{array}\end{array}$ & \\
\hline
\end{tabular}

\begin{tabular}{|c|c|c|c|}
\hline AGG-I5-F2 & Explicaciones de/sobre... & Apartado & Primeras observaciones analíticas \\
\hline $\begin{array}{l}\text { Objetivos de } \\
\text { la } \\
\text { investigación }\end{array}$ & $\begin{array}{l}\text { Nombre del tema de investigación: } \\
\text { "Saberes comunitarios: un análisis conceptual desde la normatividad de la educación indígena en } \\
\text { Oaxaca" (título en mayúsculas) } \\
\text { Objetivo general: } \\
\text { Analizar el concepto de saberes comunitarios desde la investigación documental cualitativa para } \\
\text { contribuir a su mejor concepción. } \\
\text { Objetivos específicos: } \\
\text { 1.- Analizar el concepto de saberes comunitarios a partir de diferentes textos que abordan esta } \\
\text { temática para conceptualizarla. } \\
\text { 2.- Identificar los elementos que constituyen el concepto de "saberes comunitarios" para contribuir } \\
\text { a su comprensión conceptual y caracterización. } \\
\text { 4.- Indagar e interpretar el concepto de "saberes comunitarios" y como subyace en los documentos } \\
\text { normativos y proyectos de la educación indígena en Oaxaca en la actualidad. } \\
\text { Planteamiento de la investigación } \\
\text { ¿Cuál es la conceptualización del término saberes comunitarios desde la normatividad, los } \\
\text { elementos que la caracterizan y como subyace en los documentos normativos y proyectos de la } \\
\text { educación indígena en Oaxaca en la actualidad? } \\
\text { Objeto de estudio: } \\
\text { Análisis conceptual del término "saberes comunitarios" desde la normatividad de la Educación } \\
\text { Indígena en Oaxaca en la época actual. (p.2) }\end{array}$ & & \\
\hline
\end{tabular}




\begin{tabular}{|c|c|c|c|}
\hline RRG-I6-F2 & Explicaciones de/sobre... & Apartado & Primeras observaciones analíticas \\
\hline $\begin{array}{l}\text { Objetivos de } \\
\text { la } \\
\text { investigación }\end{array}$ & $\begin{array}{l}\text { TEMA: Las interacciones comunicativas entre alumnos en un grupo del primer ciclo }\left(1^{\circ} \text { y } 2^{\circ} \text { grado) }\right. \\
\text { de primaria indígena en un contexto multicultural. } \\
\text {... para ello es necesario plantearse las siguientes preguntas: (p.3) } \\
\text { a) General: } \\
\text { aCómo se establecen las interacciones comunicativas entre alumnos durante las tareas } \\
\text { b) Específicas: } \\
\text { ¿Enicas en un grupo de } 1^{\circ} \text { y } 2^{\circ} \text { grado de primaria en un contexto multicultural? } \\
\text { comunicativas? } \\
\text { Ante este escenario investigativo me planteo los siguientes objetivos y proposiciones: } \\
\text { General alumnos interactúan? } \\
\text { Identificar y analizar los procesos de interacciones comunicativas que se establecen entre } \\
\text { los alumnos de un grupo de } 1^{\circ} \text { y } 2^{\circ} \text { grado de primaria indígena en un contexto multicultural } \\
\text { a través de una investigación microetnográfica. } \\
\text { Específicos: } \\
\text { Describir los tipos de interacciones comunicativas entre alumnos presentes dentro del aula. } \\
\text { Caracterizar las interacciones comunicativas que establecen los alumnos en trabajos } \\
\text { colectivos o colaborativos. } \\
\text { Proposiciones: } \\
\text { Las interacciones comunicativas entre los propios alumnos dentro del aula y a partir de } \\
\text { las tareas académicas surge de manera más natural y espontánea, sin la intervención del } \\
\text { docente. } \\
\text { Las interacciones comunicativas entre alumnos en un contexto multicultural se ve } \\
\text { regulada por la estructura social y cultural tanto de la escuela como del docente. (p. } 7 \text { ) }\end{array}$ & & \\
\hline GMV-I7-F2 & Explicaciones de/sobre... & Apartado & Primeras observaciones analíticas \\
\hline $\begin{array}{l}\text { Objetivos de } \\
\text { la } \\
\text { investigación }\end{array}$ & $\begin{array}{l}\text { Tema de Investigación: Los roles de los alumnos en el aula en los procesos de interacción social. } \\
\text { Pregunta de Investigación: } \\
\text { ¿Cuáles son los roles que asume el alumno (a) en los procesos de interacción social que se dan en el } \\
\text { aula? } \\
\text { Objetivo General: } \\
\text { Caracterizar los roles que sume el alumno en los procesos de interacción social que dan en el aula a } \\
\text { través de la observación. } \\
\text { Proposición }\end{array}$ & & \\
\hline
\end{tabular}


Los alumnos y alumnas asumen diversos roles en el aula en los procesos de interacción social de acuerdo a la situación, contexto o actividad que se desarrolle.

\begin{tabular}{|c|c|c|c|}
\hline HGL-I8-F2 & Explicaciones de/sobre... & Apartado & Primeras observaciones analíticas \\
\hline $\begin{array}{l}\text { Objetivos de } \\
\text { la } \\
\text { investigación }\end{array}$ & $\begin{array}{l}\text { "la lectura en voz alta: una práctica cotidiana en las aulas de educación primaria" } \\
\text { Por consiguiente es necesario partir de las siguientes preguntas en torno a la actividad de leer, } \\
\text { preguntas que guiaran la presente investigación: } \\
\text { ¿Cuándo y cómo se llevan a cabo la lectura en voz alta? } \\
\text { ¿Qué funciones desempeña la lectura en el aula? } \\
\text { ¿Qué tipo de textos se leen? } \\
\text { ¿Qué papel desempeñan los alumnos y el docente en el desarrollo de esta actividad? } \\
\text { ¿Qué disposiciones y significados que se generan y/o refuerzan con estas prácticas? (p. 4-5) } \\
\text { Objetivo General } \\
\text { "Caracterizar la lectura en voz alta que se realizan en un aula de sexto grado de educación primaria, } \\
\text { el cual permita apreciar los procesos, funciones y significados que se configuran en torno a esta } \\
\text { práctica". } \\
\text { Objetivos Específicos } \\
\quad \text { Explicitar las funciones y procesos que se desarrollan en las prácticas de lectura en un aula } \\
\text { de sexto grado de la escuela primaria "Venustiano Carranza" perteneciente a la zona } \\
\text { escolar 033. } \\
\text { Configurar los significados que se generar en los niños y el maestro en torno a las prácticas } \\
\text { de lectura en voz alta. }\end{array}$ & & \\
\hline
\end{tabular}


FASE 3.- OBJETIVOS DE LA INVESTIGACIÓN (noviembre -diciembre 2014)

\begin{tabular}{|l|l|l|l|}
\hline NHG-I1-F3 & Explicaciones de/sobre... & Apartado & Primeras observaciones analíticas \\
\hline $\begin{array}{l}\text { Objetivos de } \\
\text { la } \\
\text { investigación }\end{array}$ & $\begin{array}{l}\text {...en este trabajo descriptivo-narrativo, muestro la situación actual de la lengua ayuujk, porque no } \\
\text { existe una descripción sociolingǘstica reciente del mixe. } \\
\text { El objetivo principal de este trabajo monográfico es mostrar los usos y funciones de la lengua } \\
\text { ayuujk de algunas comunidades mixes ubicadas en la región alta. (p.4) }\end{array}$ & & \\
& $\begin{array}{l}\text { Este trabajo es una investigación etnográfica, con un enfoque cualitativo cuya característica es la de } \\
\text { una monografía, en la cual se describe el uso de la lengua mixe en comunidades de la parte alta... } \\
\text { Para dar cuenta de la situación actual del mixe se utilizó las tipologías de situaciones comunicativas } \\
\text { y el microanálisis de situaciones comunicativas como herramientas etnográficas. De ahí que, la } \\
\text { metodología que se siguió fue la observación y la grabación del uso de la lengua en diversos } \\
\text { dominios (Fishman, 1979)... (p.5) }\end{array}$ & & \\
\hline
\end{tabular}

\section{FMM-I4-F3 $\quad$ Explicaciones de/sobre...}

Objetivos de $\quad$ Así que este trabajo tiene como objetivo principal caracterizar y explicar las funciones de las la preguntas que utiliza el docente en el proceso de enseñanza y aprendizaje en un grupo de $5^{\circ}$ y $6^{\circ}$ de investigación Primaria de Educación Indígena. Así mismo, la investigación iniciada en la línea de lenguaje del programa de Maestría en Sociolingüística de la Educación Básica y Bilingüe, permite poner en práctica los aportes teóricos y metodológicos adquiridos.

Por ello, planteo como proposiciones de este trabajo que:

a) Las preguntas que utiliza el docente sirven como instrumento para proporcionar información que contienen los libros de texto o currículo oficial.

b) Las preguntas planteadas por el docente le permite obtener información contextual de los alumnos así como de los conocimientos que tienen sobre el tema de estudio en el aula.

c) Las preguntas planteadas por el docente en la clase promueven la participación de los alumnos en el desarrollo del tema. (p. 4-5) 


\begin{tabular}{|c|c|c|c|}
\hline AGG-I5-F3 & Explicaciones de/sobre... & Apartado & Primeras observaciones analíticas \\
\hline $\begin{array}{l}\text { Objetivos de } \\
\text { la } \\
\text { investigación }\end{array}$ & $\begin{array}{l}\text { Mi interés por el estudio sobre la comunicación en el aula se cristalizó en mi objeto de } \\
\text { investigación que denomino "las interacciones comunicativas entre docente-alumnos en } \\
\text { segundo grado de educación primaria indígena" porque considero necesario conocer las formas } \\
\text { y los estilos de comunicación que se manifiestan en el aula de clases. Puesto que las aulas son } \\
\text { espacios donde el lenguaje y la comunicación son una herramienta primordial para cumplir con los } \\
\text { propósitos pedagógicos del proceso enseñanza - aprendizaje, en este caso para la enseñanza de la } \\
\text { lengua escrita. (p.5) } \\
\text { Este trabajo es un intento por analizar las interacciones comunicativas que suceden en un aula de } \\
\text { segundo grado de educación primaria y de qué manera estas interacciones contribuyen en la } \\
\text { enseñanza de la lengua escrita, sobre todo en el aspecto de la enseñanza de la producción de textos } \\
\text { en español a alumnos del primer nivel de educación primaria indígena. (p.7) }\end{array}$ & & \\
\hline
\end{tabular}

\begin{tabular}{|c|c|c|c|}
\hline GMV-I7-F3 & Explicaciones de/sobre... & Apartado & Primeras observaciones analíticas \\
\hline $\begin{array}{l}\text { Objetivos de } \\
\text { la } \\
\text { investigación }\end{array}$ & $\begin{array}{l}\text { La situación de convivencia de dos lenguas en el seno de una comunidad, indudablemente nos } \\
\text { ofrece un panorama de reparto de funciones entre cada una de estas lenguas. En el presente trabajo } \\
\text { se analizará el uso y las funciones que tiene la lengua zapoteca en la comunidad de San Andrés } \\
\text { Solaga y poblaciones aledañas, a través del contacto con otras lenguas, principalmente el español. } \\
\text { (p.1) }\end{array}$ & & \\
\hline
\end{tabular}

\begin{tabular}{|c|c|c|c|}
\hline HGL-I8-F3 & Explicaciones de/sobre... & Apartado & Primeras observaciones analíticas \\
\hline $\begin{array}{l}\text { Objetivos de } \\
\text { la } \\
\text { investigación }\end{array}$ & $\begin{array}{l}\text { Estas situaciones son las que ahora me permiten indagar sobre los procesos alfabetizadores que de } \\
\text { dan día a día en las aulas, y de manera específica y particular, en las actividades de lectura, puesto } \\
\text { que siendo ésta una actividad constante que se realizan en el aula a lo largo de toda la } \\
\text { escolarización básica, los alumnos manifiestan un índice bajo de comprensión lectora. (p.5) } \\
\text { A partir de este panorama y enfatizando en las actividades de lectura que se realizan en la escuela, } \\
\text { se pretende caracterizar las prácticas de lectura que se realizan en la materia de español recuperar } \\
\text { los elementos que permitan conocer de manera detallada lo que ocurre en un grupo de quinto grado } \\
\text { de la Escuela Primaria Venustiano Carranza, ubicada en la comunidad de San Pedro Juchatengo. (6) } \\
\text { A partir de lo anterior se plantea como objetivo general "Caracterizar las prácticas de lectura que } \\
\text { se realizan en un aula de quinto grado de educación primaria en la clase de español, en el que se } \\
\text { pueden identificar diferentes aspectos que influyen en el desarrollo de esta actividad". } \\
\text { Objetivos específicos: } \\
\quad \text { Describir las actividades de lectura que se realizan en la clase de español. } \\
\quad \text { Identificar cuáles son los elementos que condicionan las prácticas de lectura } \\
\text { coordinadas por el docente en el aula. (6) }\end{array}$ & & \\
\hline
\end{tabular}




\section{CORPUS DE DATOS: CONCEPTOS TÉCNICOS}

FASE 1: ANTERPOYECTO DE INVESTIGACIÓN (aspirantes al programa de maestría, noviembre-diciembre 2011)

\begin{tabular}{|c|c|c|}
\hline NHG-I1-F1 & Explicaciones de/sobre... (Apartado: Marco teórico) & Primeras observaciones analíticas \\
\hline $\begin{array}{l}\text { Conceptos } \\
\text { técnicos }\end{array}$ & 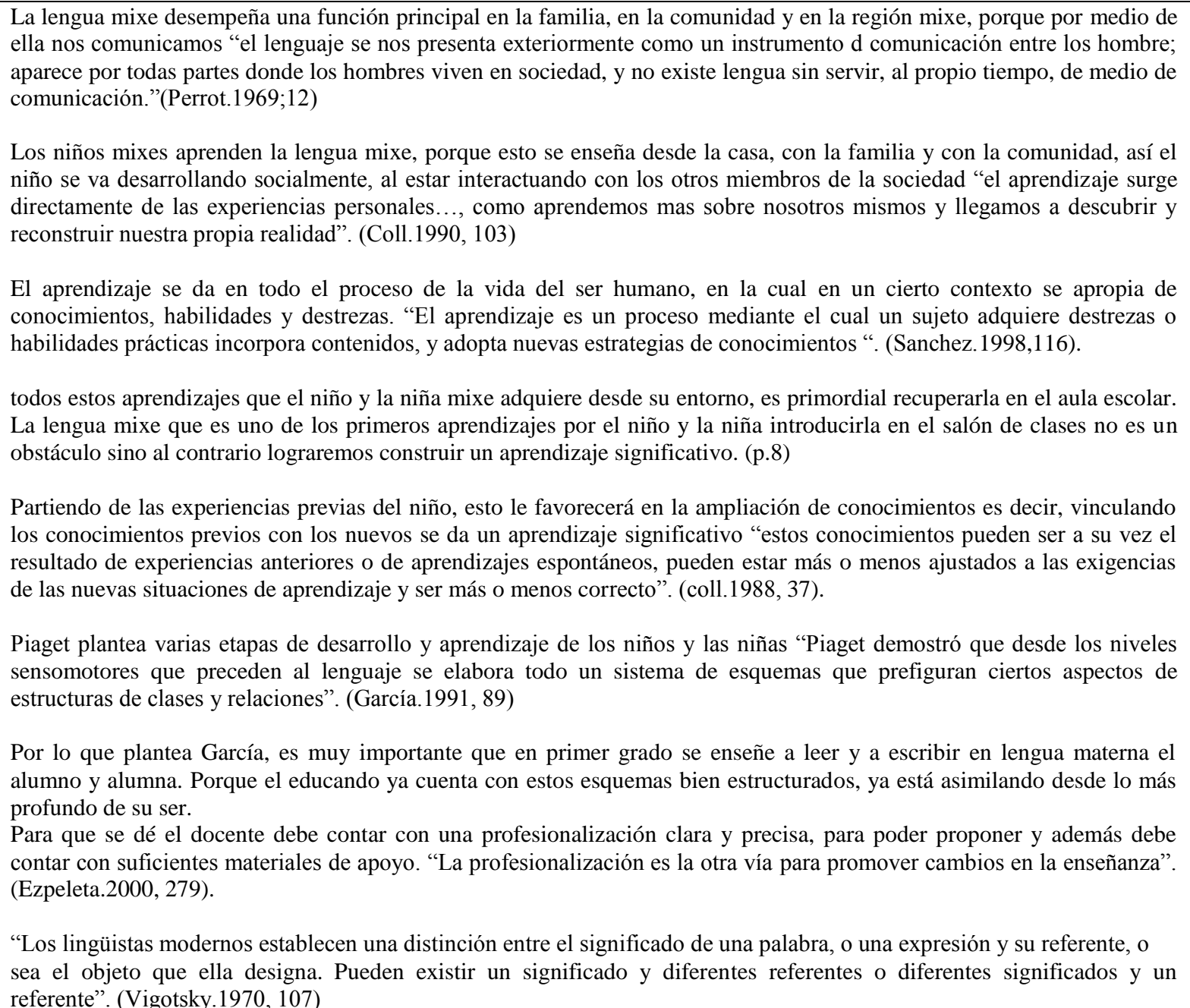 & \\
\hline
\end{tabular}




\begin{tabular}{|c|c|c|}
\hline \multicolumn{2}{|c|}{ MAGV I2-F1 Explicaciones de/sobre... (Apartado: Marco referencial) } & Primeras observaciones analíticas \\
\hline $\begin{array}{l}\text { Conceptos } \\
\text { técnicos }\end{array}$ & 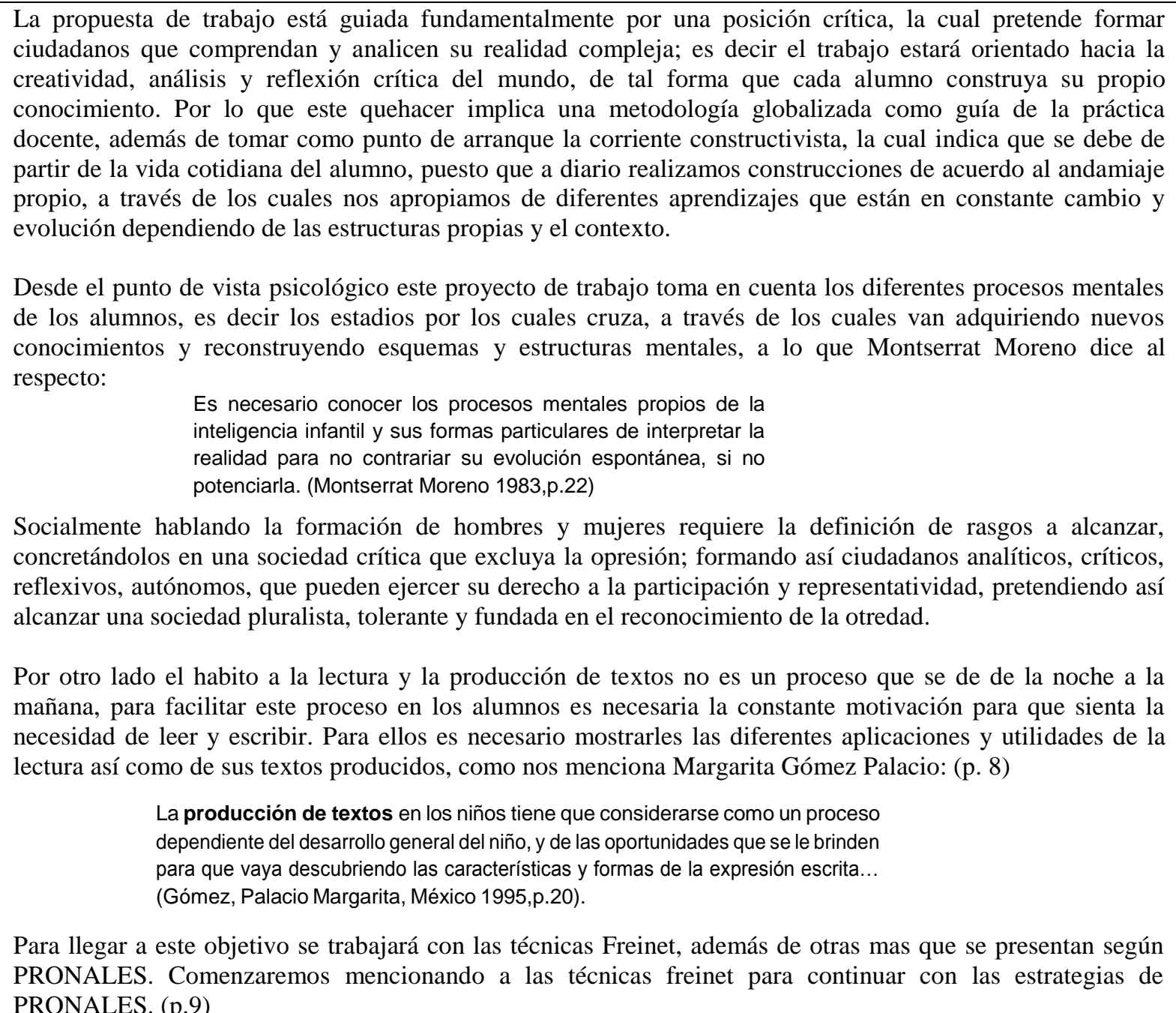 & \\
\hline
\end{tabular}




\begin{tabular}{|c|c|c|}
\hline GHV-I3-F & Explicaciones de/sobre... (Apartado: Marco teórico) & Primeras observaciones analíticas \\
\hline $\begin{array}{l}\text { Conceptos } \\
\text { técnicos }\end{array}$ & 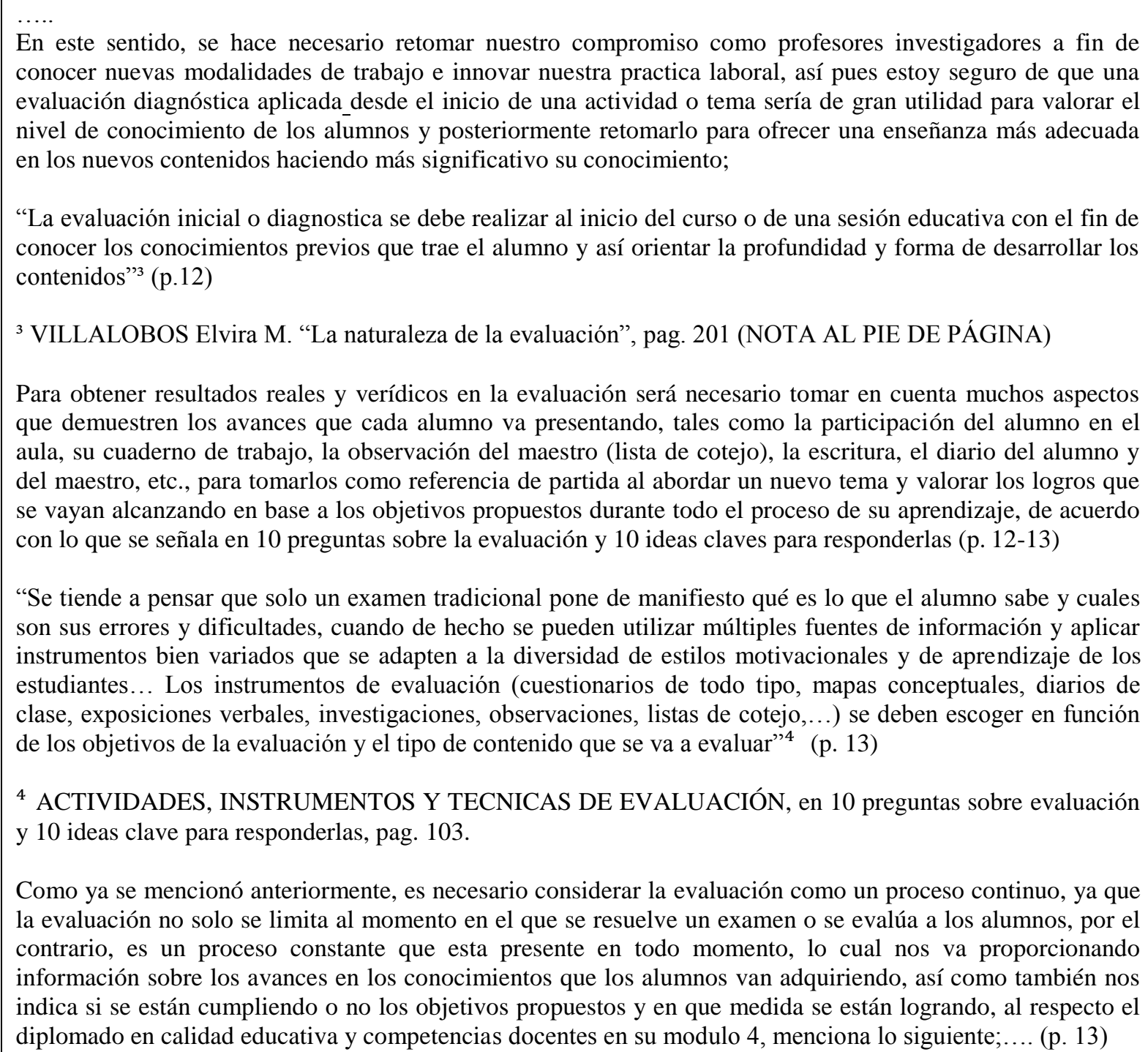 & \\
\hline
\end{tabular}




\begin{tabular}{|c|c|c|}
\hline HGL-I8-F1 & Explicaciones de/sobre... & Primeras observaciones analíticas \\
\hline $\begin{array}{l}\text { Conceptos } \\
\text { técnicos }\end{array}$ & $\begin{array}{l}\text { Aunque actualmente nos parece obvio que escribir va más allá de poner letras en una hoja de papel, no } \\
\text { siempre ha sido así, muestra de ello es que muchas de las prácticas para aprender a escribir en la escuela se } \\
\text { reducen aun a la enseñanza caligráfica y gramatical, las tareas escolares en las producciones hechas por los } \\
\text { estudiantes pierden sentido al solo usarse para la corrección ortográfica, al verse como una objeto acabado y } \\
\text { no considerarlo como parte de un proceso comunicativo en construcción. } \\
\text { La escritura vista desde el enfoque comunicativo implica que el alumno pueda comunicarse mejor con la } \\
\text { lengua }{ }^{3} \text {, para esto es fundamental que los chicos escriban en la escuela textos de verdad para destinatarios } \\
\text { concretos y con propósitos definidos }{ }^{4} \text {. Por eso antes de la producción de cualquier texto ya sea un cuento, una } \\
\text { carta, una noticia, o un cartel; es necesario que los alumnos hayan tenido experiencias de lectura de este tipo } \\
\text { de textos. Las experiencias de lectura que el niño haya tenido le servirán a este para tener elementos, como el } \\
\text { conocimiento de la superestructura de los textos, que le permitirán más oportunidades al momento de escribir. } \\
\text { Para concretar el propósito de formar a todos los alumnos como practicantes de la cultura escrita tomando } \\
\text { como referencia Fundamental las prácticas sociales de lectura y escritura }{ }^{5} \text {. (p.3) } \\
{ }^{3} \text { Cassany, D., Luna, M. y Sanz, G. enseñar lengua, 2da, ed, Grao, } 1997 \text {. } \\
{ }^{4} \text { Lerner, D. "lengua" en los quehaceres del escritor, Argentina: documentos curriculares de la municipalidad } \\
\text { de Buenos Aires } \\
{ }^{5} \text { Lerner, D, leer y escribir en la escuela: lo real, lo posible y lo necesario. SEP/FCE, 2004. } \\
\text { Saber construir un discurso coherente y adecuado forma parte de la competencia discursiva o textual, es decir } \\
\text { de los conocimientos y las habilidades que se precisan para poder construir diferentes tipos de discurso con } \\
\text { cohesión y con coherencia }{ }^{6} \text {... Para cumplir este precepto, y lograr la producción adecuada de textos es } \\
\text { necesario considera los siguientes procesos: (p. } 3-4) \\
{ }^{6} \text { Lomas, C. Cómo enseñar a hacer cosas con las palabras. Teoría y práctica de la educación lingüística, } 2 \\
\text { vols., Paidos, Barcelona, } 1999 \text {. }\end{array}$ & \\
\hline
\end{tabular}


FASE 2.- CONCEPTOS TÉCNICOS (PROTOCOLO DE INVESTIGACIÓN -Producto Final del Seminario de Tesis I, junio, 2013)

\begin{tabular}{|c|c|c|}
\hline NHG I1-F2 & Explicaciones de/sobre... Conceptos técnicos (apartado: Conceptualización) & Primeras observaciones analíticas \\
\hline $\begin{array}{l}\text { Conceptos } \\
\text { técnicos: } \\
\text { Lenguaje } \\
\text { Funciones del } \\
\text { lenguaje }\end{array}$ &  & \\
\hline
\end{tabular}


que es heredado de generación en generación" (Saussure, 2007:230). Cassany (1994) agrega que "la lengua como una forma de acción o de actividad que se realiza con alguna finalidad concreta. La lengua es un instrumento múltiple, un instrumento que sirve para conseguir mil y unas cosas: encargar una comida, poner gasolina, manifestar agradecimiento, quejarse, protestar, saludar, pedir información y darla, etc. “(p. 84)

La investigadora Schlieben-Lange (1997) agrega que, "Cuando el hablar tiene por finalidad ante todo el constatar o garantizar el funcionamiento y continuidad de la comunicación (por decirlo en términos específicos, cuando se refiere al canal, la lengua cumple entonces una función fática. Si es la propia lengua ( o en términos de la teoría de la información: el código) la que se convierte en objeto de comunicación, aparece así la función metalingüística." (p. 22). Gleich (2003) habla sobre las funciones del lenguaje en los procesos de enseñanza aprendizaje. En el cual identifica tres funciones del lenguaje en la enseñanza-aprendizaje "proceso y marco del desarrollo integral del sujeto (discurso pedagógico); desde su participación en las actividades referidas al desarrollo instructivo de los alumnos (discurso didáctico); y también en cuanto a espacio comunicacional en el que a través del cual los diversos interactuantes entran en contacto personal mutuo (discurso relacional). (p. 108)

Otros autores favorecen el uso de las lenguas indígenas como Díaz (1998) Afirma que "promover el uso de las lenguas indígenas y no solamente para preservarlas para el uso vernáculo al cual han sido relegadas, las lenguas indígenas deben ser, tanto materia de enseñanza como medio de instrucción" (p. 144). También afirma Muñoz (1998) que "construir una nueva escuela, basada en un modelo académico que implica colocar a la lengua y cultura indígena como recurso y objeto a la vez de la educación intercultural bilingüe (p. 84)

López afirma que las "Habilidades lingüísticas: se conoce con este nombre a cada uno de los aspectos que comprende el uso de la lengua: escuchar, hablar, leer y escribir. Las habilidades lingüísticas son clasificadas en orales (escuchar y hablar) y escritas (leer y escribir). 


\begin{tabular}{|c|c|c|}
\hline \multicolumn{2}{|c|}{ MAGV I2-F2 Explicaciones de/sobre... Conceptos técnicos (apartado: Marco Teórico) } & Primeras observaciones analíticas \\
\hline $\begin{array}{l}\text { Conceptos } \\
\text { técnicos: } \\
\text { Escritura }\end{array}$ & 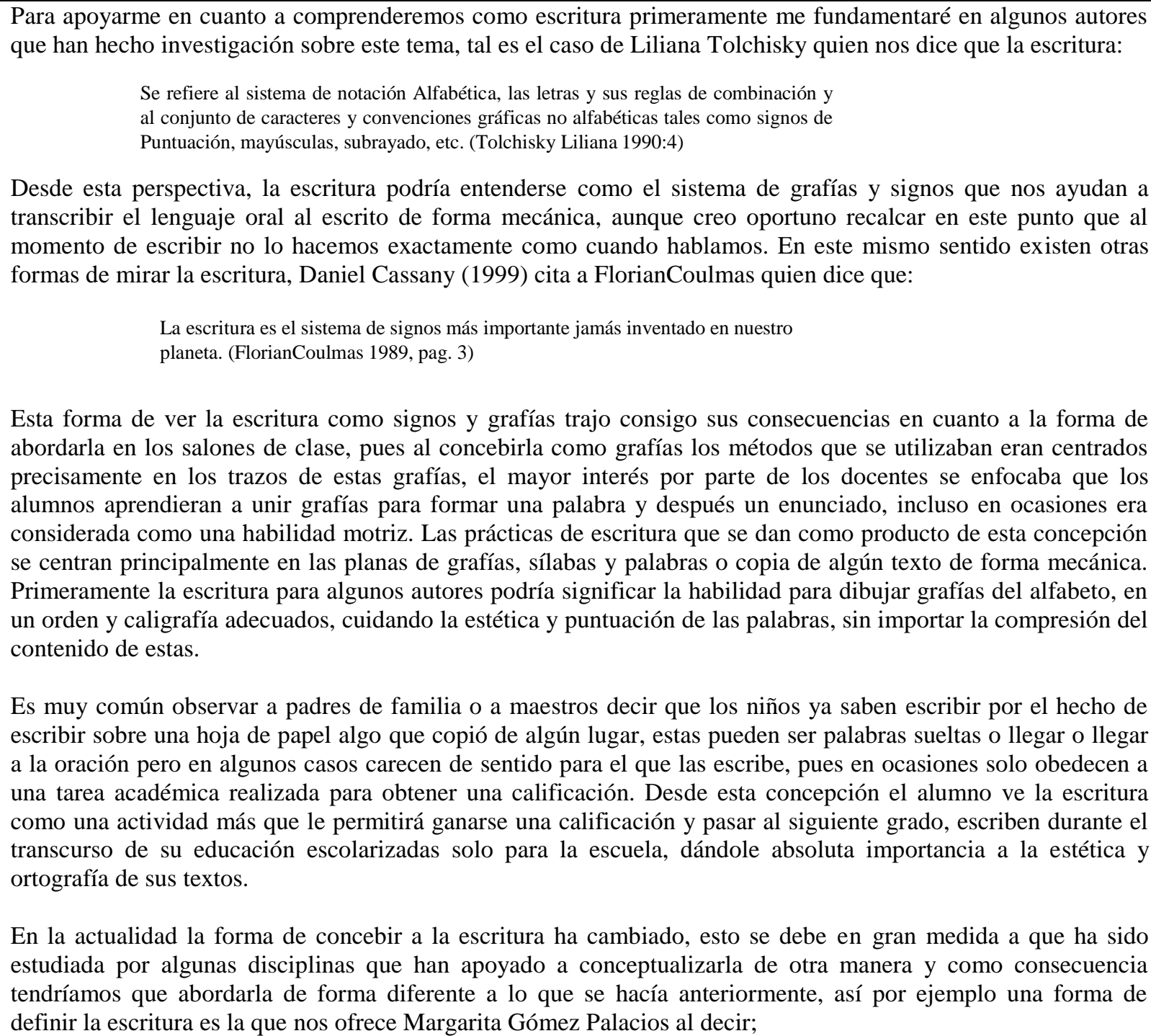 & \\
\hline
\end{tabular}




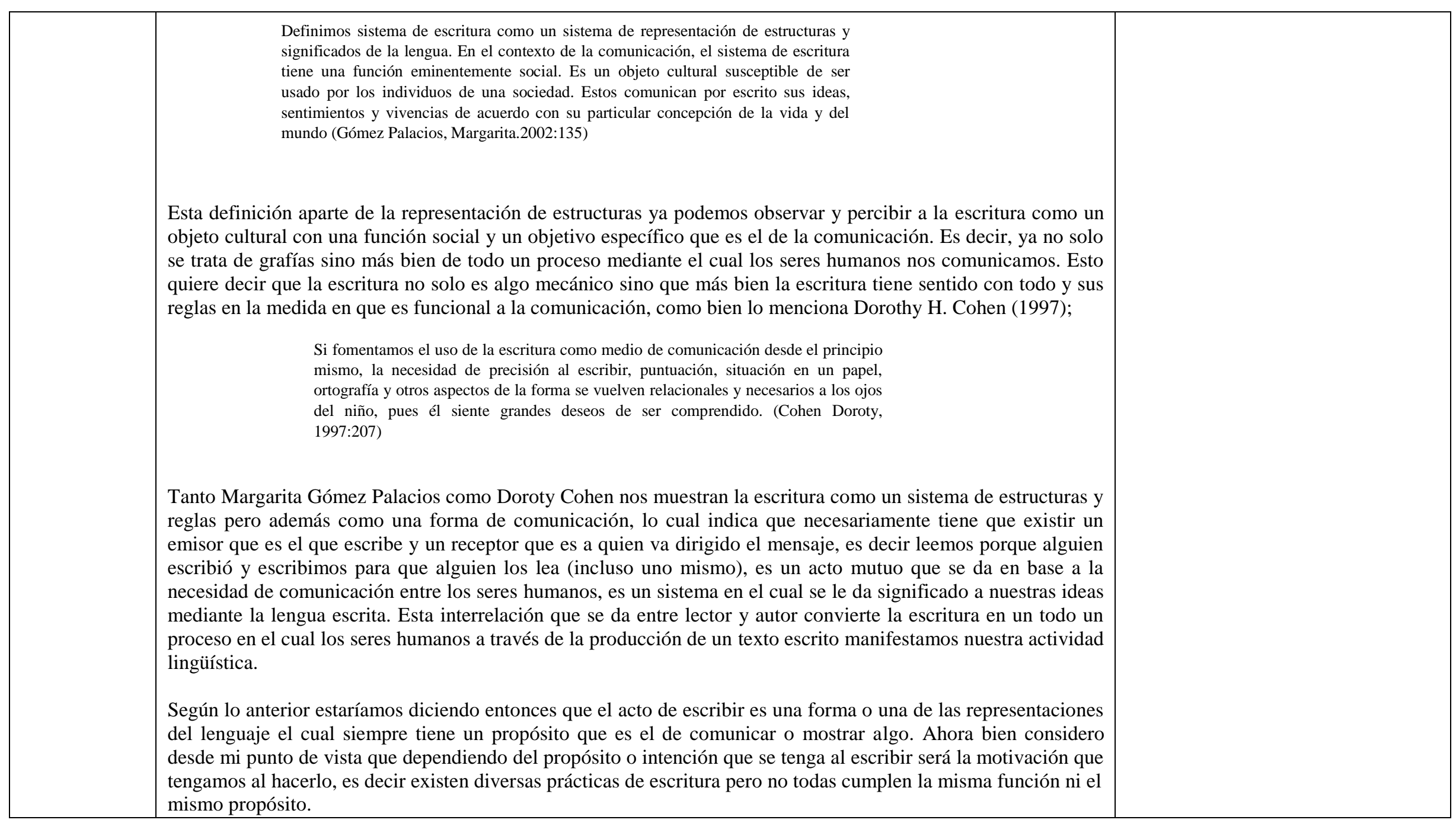




\begin{tabular}{|c|c|c|}
\hline GHV-I3-F2 & Explicaciones de/sobre... Conceptos técnicos (apartado: Marco Conceptual) & Primeras observaciones analíticas \\
\hline $\begin{array}{l}\text { Conceptos } \\
\text { técnicos: } \\
\text { Evaluación }\end{array}$ & 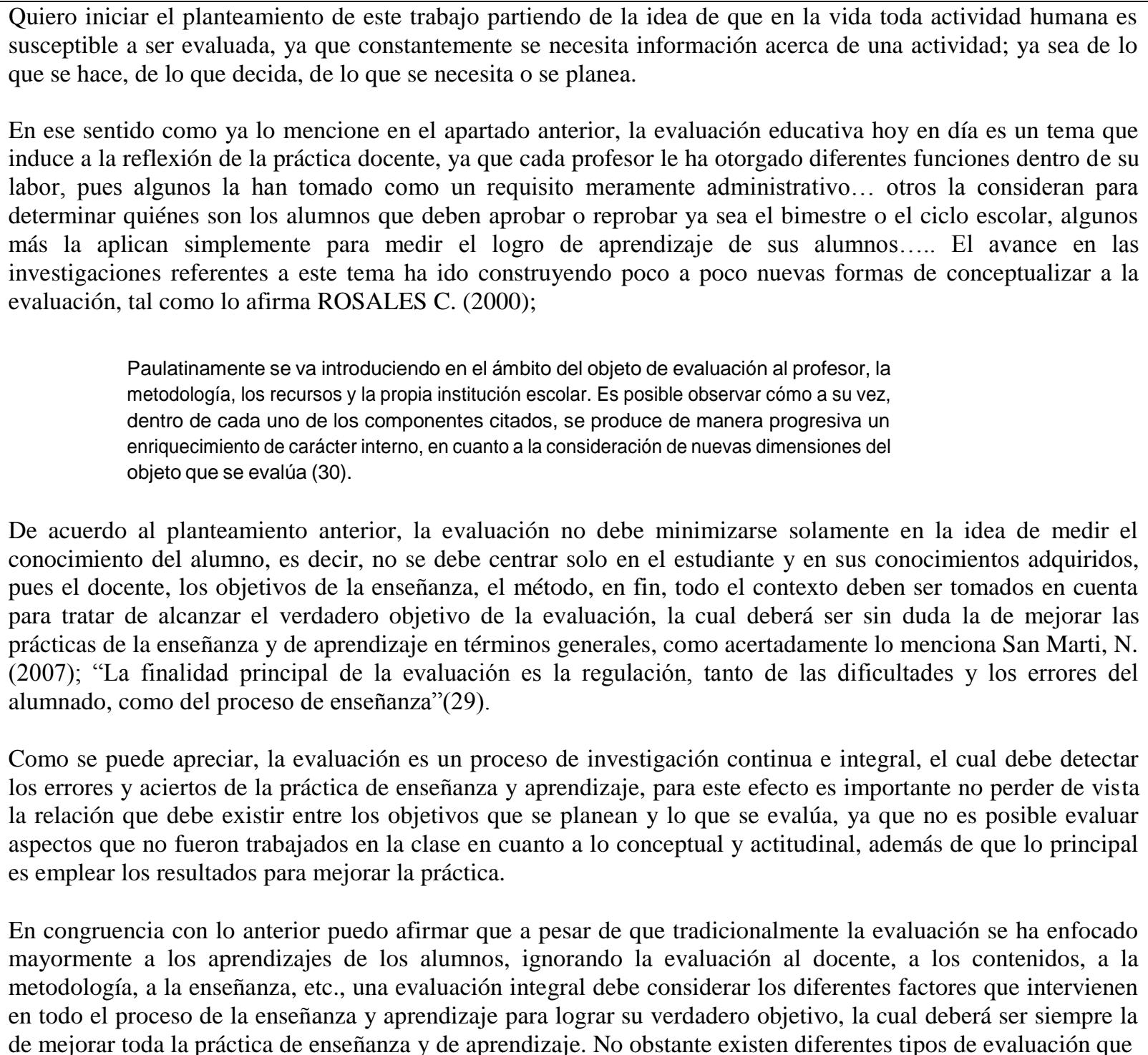 & \\
\hline
\end{tabular}




\begin{tabular}{|l|l|l|}
\hline se pueden aplicar según el interés que se persiga, de lo cual me encargaré de desarrollar a continuación. \\
$\begin{array}{l}\text { I.II ALGUNOS TIPOS DE EVALUACIÓN (Subtítulo) } \\
\text { Dados los razonamientos que se han venido haciendo en los párrafos anteriores se puede dimensionar lo } \\
\text { importante y lo amplio del tema, en ese sentido queda claro que la evaluación es una actividad inherente a la } \\
\text { enseñanza y aprendizaje, pues como lo menciona Rueda Beltran y Diaz Barriga, "un proceso de evaluación no } \\
\text { puede ser un hecho aislado, debe formar parte de un proyecto integral que tenga que ver con un modelo } \\
\text { educativo y con los procesos que dan forma a una institución educativa: planificación, diseño, operación, etc.: en } \\
\text { otras palabras, es parte del currículo" (Rueda Beltran M. y Diaz Barriga F.,2000:104). }\end{array}$ & $\begin{array}{l}\text { Desde esta lógica es necesario tener en cuenta que el tipo de evaluación que el docente aplique en su práctica } \\
\text { deberá ser acorde al tipo de enseñanza que él emplea en todo el proceso de enseñanza. }\end{array}$ & \\
\hline
\end{tabular}

\begin{tabular}{|c|c|c|}
\hline \multirow{3}{*}{$\begin{array}{l}\text { HGL-I8-F2 } \\
\text { Conceptos } \\
\text { técnicos: }\end{array}$} & Explicaciones de/sobre... Conceptos técnicos (apartado: Fundamentación teórica) & Primeras observaciones analíticas \\
\hline & $\begin{array}{l}\text { Considerando los avances en las diversas investigaciones en torno a la cultura escrita, han surgido diversas } \\
\text { concepciones sobre lo que se debe entender por leer, al igual que didácticas en torno a la enseñanza de estas } \\
\text { actividades. En torno a la lectura, Cassany (2006:25) distingue tres concepciones de la comprensión lectora, } \\
\text { según consideremos que sea el procedimiento para obtener el significado. No son tres formas de leer, sino tres } \\
\text { representaciones sobre la lectura. } \\
\text { Estas formas de mirar la lectura conllevan también determinadas prácticas lectoras, las cuales condicionan al } \\
\text { lector en cuanto al uso que pueda realizar de la información o interpretación de determinado texto, por ello } \\
\text { diferenciar estas concepciones nos ayudará a entender y tener mayor claridad sobre el tema. } \\
\text { Una de las concepciones que más ha influido en la mirada de los docentes en torno a la lectura y que en la } \\
\text { actualidad ha perdido vigencia en la concepción Lingüística, en esta concepción, Cassany dice: } \\
\text { el contenido del texto surge de la suma del significado, de todos sus vocablos y } \\
\text { oraciones. Así el significado es único, estable, objetivo e independiente de los } \\
\text { lectores y de las condiciones de lectura. Diferentes lectores deberían obtener } \\
\text { el mismo significado. (Cassany, 2006:25) }\end{array}$ & \\
\hline & $\begin{array}{l}\text { Desde esta concepción podemos entender que el lector es un sujeto pasivo, no intervine de manera activa en la } \\
\text { construcción de significados, también es posible afirmar que los conocimientos previos del lector no afectan a la } \\
\text { forma en cómo se estructura el significado en la mente del lector; que mediante la decodificación correcta del }\end{array}$ & \\
\hline
\end{tabular}


código escrito se adquiere el significado existente en el texto. De ahí que las actividades comunes en las aulas correspondientes en ésta concepción, con frecuencia es la decodificación del código escrito en voz alta, la repetición y memorización de determinados textos, o parte de ellos. (p. 7-8)

La segunda concepción sobre la lectura representa cierta oposición en torno a la primera sobre todo en el papel que desempeña el lector en el proceso de lectura. Desde la perspectiva psicolingüística:

Leer no solo exige conocer las unidades y las reglas combinatorias del idioma.

También requiere desarrollar las habilidades cognitivas implicadas en el acto de

comprender: aportar conocimiento previo, hacer inferencias, formular hipótesis

y saberlas verificar o reformular, etc. (Cassany, 2006:25)

En esta perspectiva se considera la importancia de la decodificación como parte del proceso no como el fin de toda acción lectora. Dentro de esta perspectiva se encuentra los estudios realizados por Solé (2002:17) quien dice que leer es un proceso de interacción entre el lector y el texto, proceso mediante el cual el primero intenta satisfacer (obtener una información pertinente para los objetivos que guían su lectura.

Vista así la lectura, se ve influenciada por los conocimientos y predicciones que el lector realiza en torno al texto, de esa forma se va construyendo en la mente del lector el significado sobre este, y el texto a su vez exige del lector su atención y habilidades lectoras, al respecto Cassany (2006:33) afirma que el significado es como un edificio que debe construirse; el texto y el conocimiento previo son los ladrillos y los procesos cognitivos, las herramientas de albañilería. (p. 8) 
que son las prácticas y pautas que adquieren desde el seno familiar basada en los diversos contextos socioculturales de cada individuo, para el caso de la socialización secundaria se adquiere desde las instituciones o contextos que el individuo interactúe, deonde “...Es cualquier proceso posterior que introduce al individuo ya socializado a nuevos sectores del mundo objetivo de la sociedad". Berger y Luckman 1971. (En Fernández 2003:211. Dubar (2000) enriquece esta aportación teórica al decir que: (viene una cita textual larga) (p. 7) 


\section{FASE 3: CONCEPTOS TÉCNICOS (Borradores finales, octubre-diciembre 2014)}

\begin{tabular}{|c|c|c|}
\hline MAGV I2-1 & plicaciones de/sobre... Conceptos técnicos (Versión primera lectoría - 16DIC2014) & Primeras observaciones analíticas \\
\hline $\begin{array}{l}\text { Conceptos } \\
\text { técnicos: }\end{array}$ & 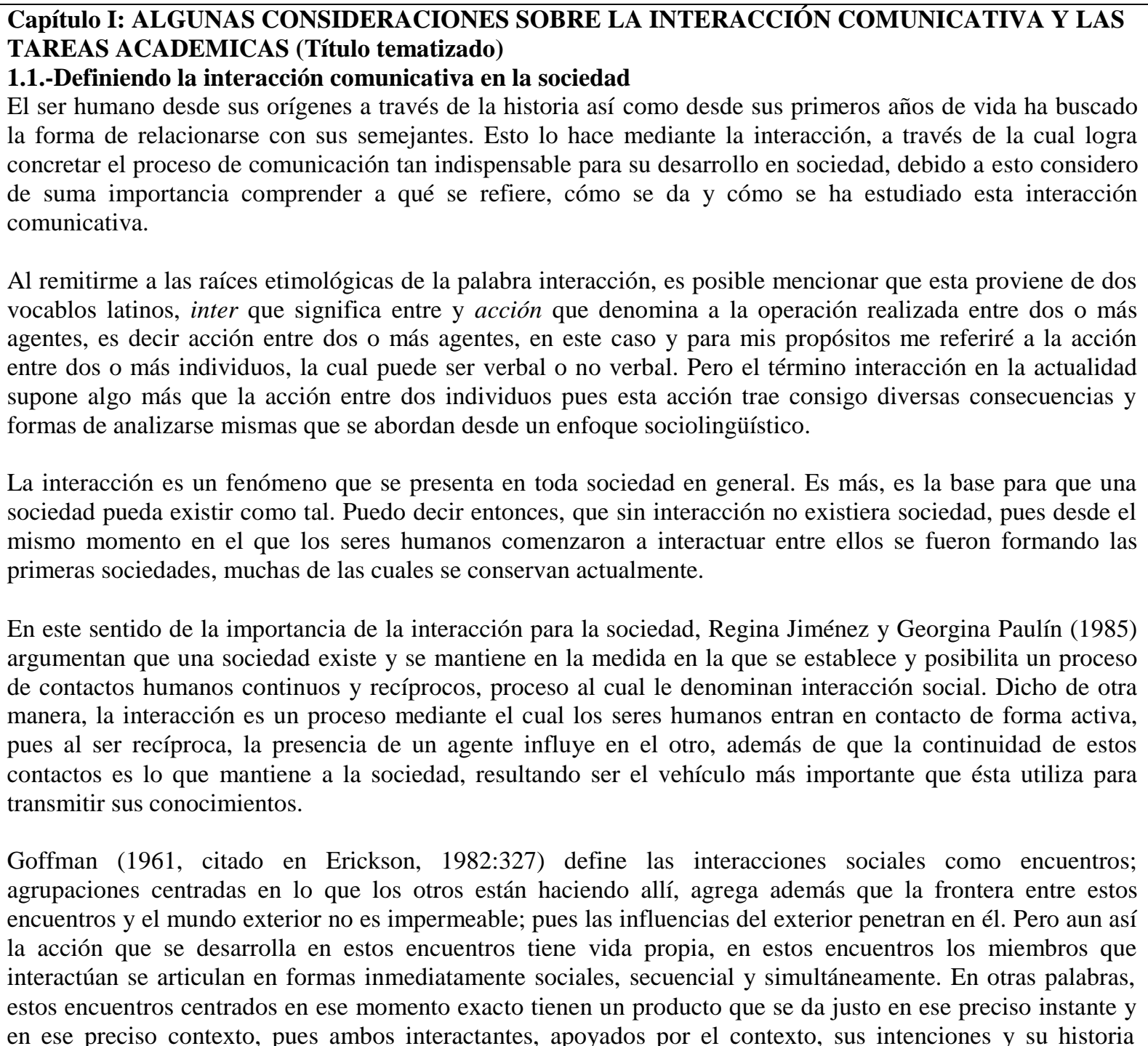 & \\
\hline
\end{tabular}


personal, modifican sus esquemas cognitivos entre sí, es decir, después de que se da alguna interacción, los esquemas cognitivos de los participantes en esta interacción viven alguna modificación, tal vez no la que se pretende pero de alguna manera existe un cambio.

Una de las consecuencias o productos de que se dé la interacción entre seres humanos es precisamente la comunicación entre ellos, es decir la comunicación es producto de la interacción entre seres humanos. En este sentido podría decir que gracias a la interacción se lleva a cabo la comunicación que es tan indispensable para el desarrollo de las sociedades, es el eje de la vida social de toda comunidad. "Todo tipo de transacciones se llevan a cabo por esta vía y en ellas toman sentido y se configuran las formas de vida" (Calsamiglia citada en Lomas, 1999:268)

En una interacción participan dos o más agentes, los cuales tienen una intención y ambos saben de la existencia del otro, es decir, es una acción recíproca. El resultado de esta acción recíproca, de acuerdo a la intención, es la modificación del estado cognitivo de los interlocutores, en todo caso el de comunicar algo.

Pero para que se den estos encuentros de la forma en que lo afirma Goffman, y que se llegue a dar la comunicación, es necesario que los interactantes compartan algunos rasgos comunes, tal y como lo argumenta Gumperz (1982), cuando nos menciona que interactuar también implica compartir algunos niveles gramaticales y normas sociales, es decir tener un lenguaje en común.

Creo importante recalcar en este momento que el término interacción comunicativa no sólo se refiere al acto de usar el lenguaje oral para expresarse, sino que es más amplio, pues abarca otras formas de acción extralingüísticas como la mímica, la gesticulación, movimientos corporales y de posición con respecto al otro interlocutor, entre otras. Además interactuar comunicativamente implica tener un discurso, dos o más individuos, la intención de hacerlo y un contexto. Es decir, el lenguaje oral forma parte de la interacción mas no es por si solo interacción comunicativa. Más aun, tanto el lenguaje oral como las acciones extralingüísticas forman parte de lo que se denomina interacción comunicativa. (pp. 7-10) 


\begin{tabular}{|c|c|c|}
\hline GHV-I3-F3 & Explicaciones de/sobre... Conceptos técnicos (Versión para lectoría - 5DIC2014) & Primeras observaciones analíticas \\
\hline $\begin{array}{l}\text { Conceptos } \\
\text { técnicos: }\end{array}$ & 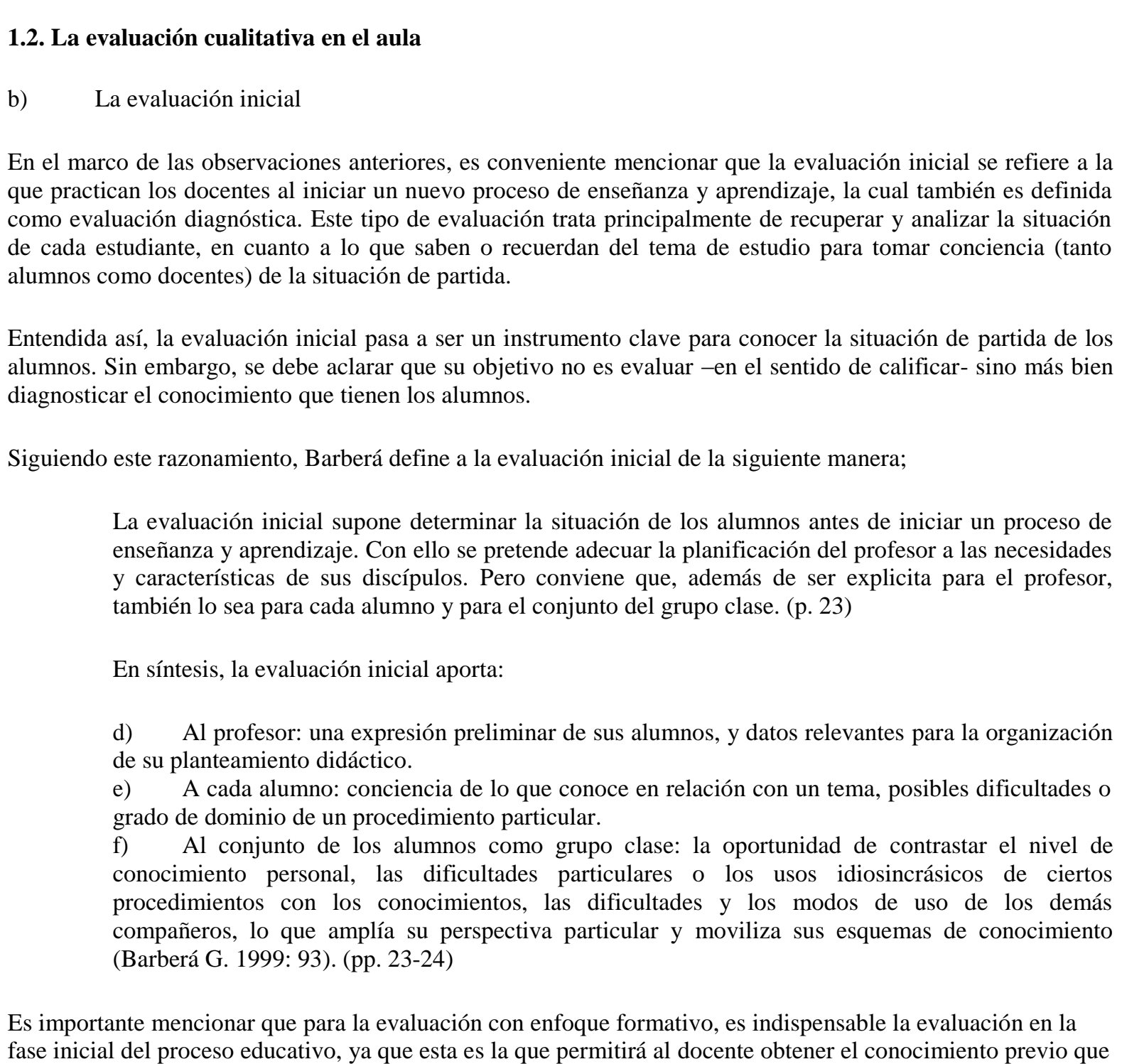 & \\
\hline
\end{tabular}


es preciso poseer de los alumnos antes de iniciar una nueva etapa de conocimiento para poder adecuar la enseñanza a sus condiciones de aprendizaje y optimizar la construcción de las nuevas actividades escolares, cumpliendo así con una de las funciones principales que se le ha asignado a este tipo de evaluación que es la regulación.

Cabe mencionar que algunos aspectos que se pueden diagnosticar en esta fase evaluativa pueden ser -aparte de las ideas previas que posee el alumno en relación con el tema que se va a tratar- las actitudes hacia dicha temática y el dominio de los procedimientos que van a ser necesarios para su desarrollo.

Al respecto, cabe retomar las aportaciones que hace Sanmartí al menciona que;

Los aspectos que hay que diagnosticar en una evaluación inicial pueden ser muy variados [...] Esta expresión hace referencia al conjunto de actitudes, conductas, representaciones y maneras espontaneas de razonar propias de cada alumno en cada momento de su desarrollo que conforman la estructura en la que se inserta y organiza el nuevo conocimiento que va adquiriendo (Sanmartí, 2008: $33)$.

Queda claro que sin una evaluación inicial, no es posible obtener el conocimiento previo de los estudiantes que se hace necesario para poder adecuar la nueva enseñanza a sus condiciones de aprendizaje. De esta manera se establece entonces que la preocupación del profesor es que el alumno logre establecer conexiones entre lo que sabe, lo que ha vivido, lo que entiende y el nuevo material de aprendizaje que le presenta en la clase. (p. 24)

Por otro lado, esta evaluación también servirá de referente en el momento de valorar el final de un proceso educativo o de comprobar en qué medida los resultados han sido satisfactorios, ya que de esta manera será posible equiparar los conocimientos iniciales con los adquiridos al final de un determinado periodo. (p. 25) 


\begin{tabular}{|c|c|c|}
\hline RRG-I6-F3 & Explicaciones de/sobre... Conceptos técnicos (Versión para lectoría 12NOV2014) & Primeras observaciones analíticas \\
\hline $\begin{array}{l}\text { Conceptos } \\
\text { técnicos: }\end{array}$ &  & \\
\hline
\end{tabular}

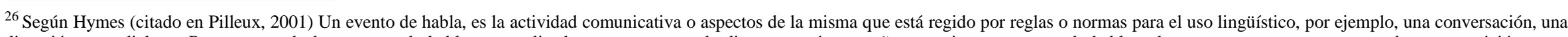

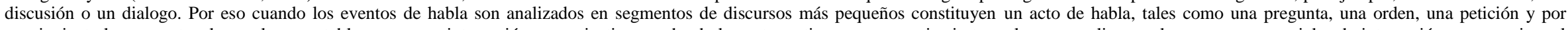

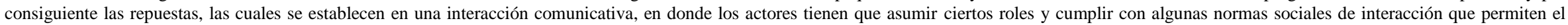

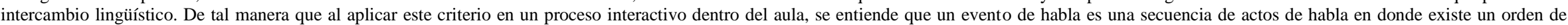



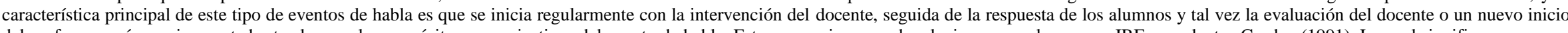

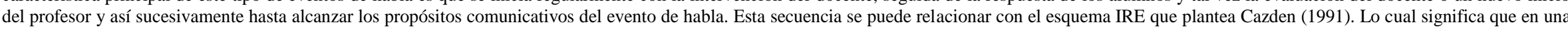
clase surgen muchos eventos de habla, por lo que en esta investigación se priorizan los actos de habla como la unidad mínima de análisis. 
comunicativa se basa en la competencia sociolingüística de los hablantes en donde los usos de la lengua y el habla están pautados y normados por reglas de interacción social de un grupo, una institución, una comunidad o una sociedad en particular (Hymes, 1971 citado en Maqueo, 2010). De tal forma que cuando se trata de un contexto como el aula, la interacción verbal no es igual que la que se da en otros contextos, ya que la escuela condiciona las formas de hablar y los interactuantes se sujetan consciente o inconscientemente a estas reglas de interacción. Esto significa que la interacción en los contextos sociales es más libre, común y espontánea, o por lo menos las reglas son más flexibles y convencionales para los interlocutores a diferencia de las normas que rigen la interacción en una institución como la escuela.

Por lo tanto la interacción verbal que se establece entre el profesor y los alumnos durante una clase, sobre todo la que se lleva a cabo al realizar las actividades didácticas, está enmarcada y condicionada por las normas institucionales del aula. Por eso los actos de habla del profesor y los alumnos en una clase, reflejan el papel que juega la institucionalidad de la escuela en un proceso de interacción verbal. Situación que no se da en una interacción comunicativa en un contexto social, ya que en éste existe más libertad de los actores para establecer ciertos actos de habla, sin que exista un rol dominante del hablante o sin que haya un tema ya definido desde donde centrar la interacción verbal. (pp. 11-13) 
Verónica Martínez Santiago

\section{ati}

ACTA DE DISERTACIÓN PÚBLICA

UNIVERSIDAD AUTONOMA METROPOLITANA

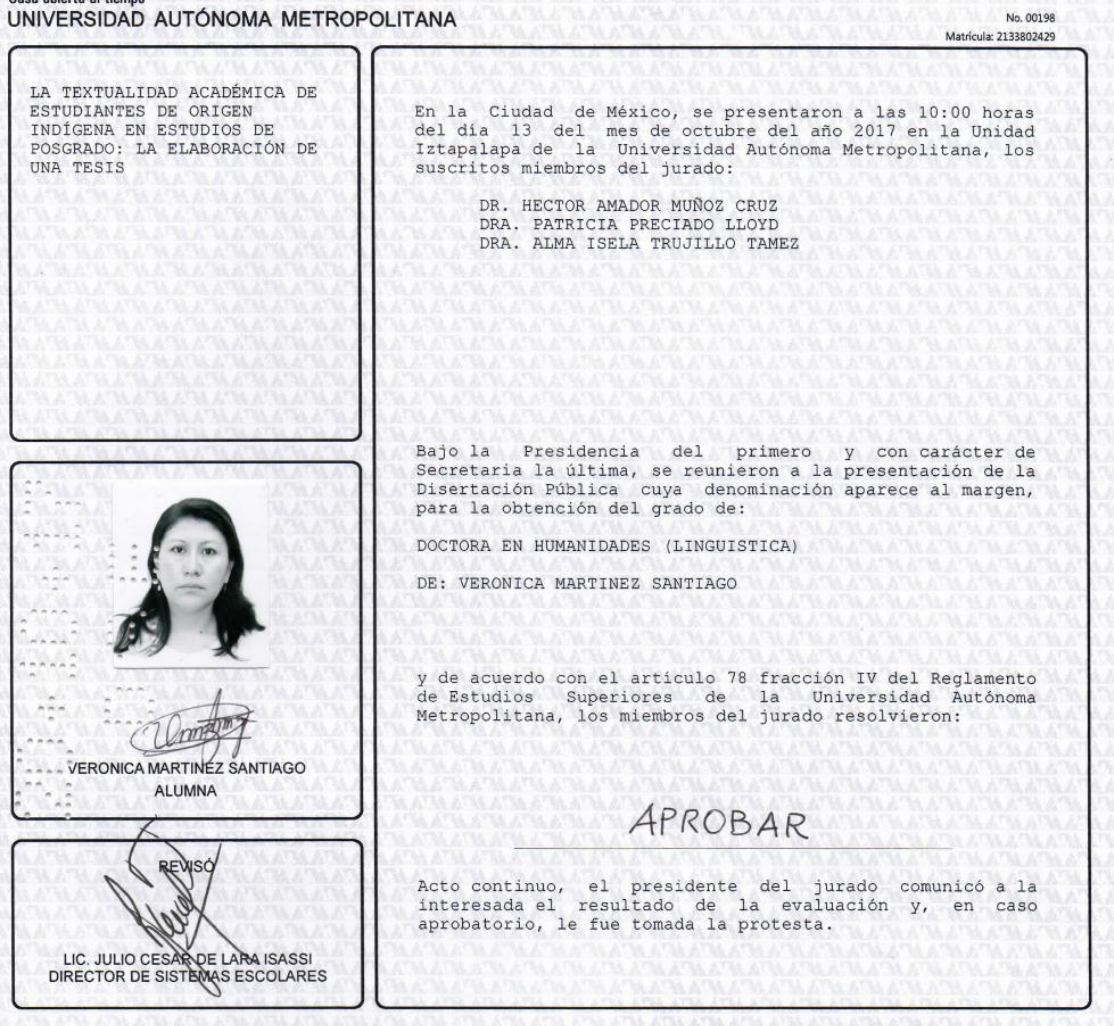

DIRECTORA DE LA DIIIIION DE CSH l P

heávef Kowiero
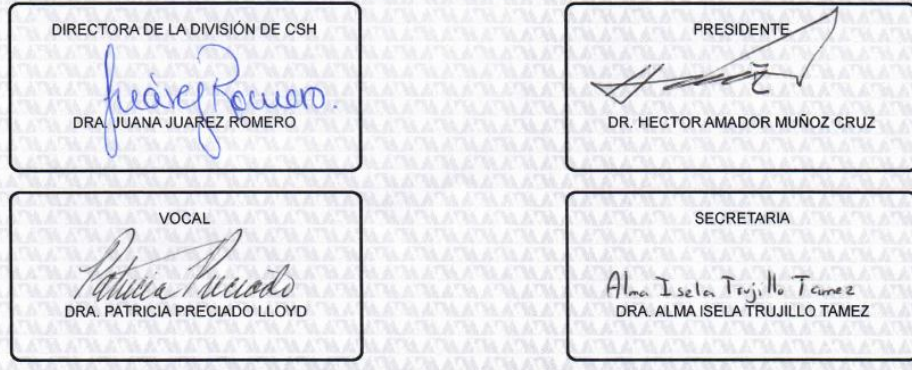

SECRETARIA

Alma I sela Truj il. Tames DRA. ALMA ISELA TRUJILLO TAMEZ 